\title{
UNIVERSIDADE DE SÃO PAULO ESCOLA DE ENFERMAGEM
}

CHRISTIANE BORGES DO NASCIMENTO CHOFAKIAN

CONTRACEPTIVE DISCONTINUATION AND ITS RELATION TO EMERGENCY CONTRACEPTION USE AMONG UNDERGRADUATE WOMEN 



\title{
CHRISTIANE BORGES DO NASCIMENTO CHOFAKIAN
}

\author{
CONTRACEPTIVE DISCONTINUATION AND ITS \\ RELATION TO EMERGENCY CONTRACEPTION USE \\ AMONG UNDERGRADUATE WOMEN
}

Tese apresentada ao Programa de Pós-Graduação em Enfermagem da Escola de Enfermagem da Universidade de São Paulo para obtenção do título de Doutor em Ciências.

Área de concentração: Cuidados em Saúde

Orientadora:

Profa. Dra. Ana Luiza Vilela Borges

Supervisora do doutorado sanduíche:

Prof ${ }^{a}$. Dra . Caroline Moreau

São Paulo 
AUTORIZO A REPRODUÇÃO E DIVULGAÇÃO TOTAL OU PARCIAL DESTE TRABALHO, POR QUALQUER MEIO CONVENCIONAL OU ELETRÔNICO, PARA FINS DE ESTUDO E PESQUISA, DESDE QUE CITADA A FONTE.

Assinatura:

Data:

l

Catalogação na Publicação (CIP)

Biblioteca "Wanda de Aguiar Horta"

Escola de Enfermagem da Universidade de São Paulo

Chofakian, Christiane Borges do Nascimento

Contraceptive discontinuation and its relation to emergency contraception use among undergraduate women / Christiane Borges do Nascimento Chofakian. - São Paulo, 2017.

277 p.

Tese (Doutorado) - Escola de Enfermagem da Universidade de São Paulo.

Orientadora: Prof $^{\mathrm{a}} \mathrm{Dr}^{\mathrm{a}}$ Ana Luiza Vilela Borges

Área de concentração: Cuidados em saúde

1. Contraception 2. Contraceptive discontinuation

3. Undergraduate students 4. Emergency contraception

5. Sexual and Reproductive Health

I. Título. 
Nome: Christiane Borges do Nascimento Chofakian

Título: Contraceptive discontinuation and its relation to emergency contraception use among undergraduate women

Tese apresentada ao Programa de Pós-Graduação em Enfermagem da Escola de Enfermagem da Universidade de São Paulo para obtenção do título de Doutor em Ciências.

Aprovado em:

\section{BANCA EXAMINADORA}

Prof. ${ }^{a}$ Dr. ${ }^{a}$ Ana Luiza Vilela Borges Instituição:

Julgamento:

Assinatura:

Prof. Dr. Instituição:

Julgamento: Assinatura:

Prof. Dr. Instituição:

Julgamento: Assinatura:

Prof. Dr. Instituição: Julgamento: Assinatura:

Prof. Dr. Instituição: Julgamento: Assinatura: 



\section{DEDICATION}

To my dear husband Carlos José Chofakian, who has been a constant source of steadfast support. For your unconditional love, company, patience and encouragment, which were essential to the progress and finalization of this thesis. Always present in my life, specially in the moments when I most needed it. Your

prayers and dedicated love enabled me to remain committed throughout my academic journey. I am truly thankful for having you in my life.

To my beloved family, who have always loved me unconditionally and whose good examples of determination and perseverance have taught me to work hard for the things that I aspire to achieve. 



\section{ACKNOWLEDGMENTS}

A dissertation is not the outcome of the struggles of one person. Many people contributed to its development. At the moment, I take the opportunity to acknowledge those who have made some impact on my doctoral journey and achievement.

Firstly, I would like to thank to the One who makes all things possible, and for enabling me to complete this thesis, Jesus Christ - to him I give all glory, honor and praise. I now understand the depth of this journey.

I must thank my husband, Carlos José Chofakian, who supported me through the entire doctoral process, since my master degree. He has always been my truly love and my best friend, always offering me your "shoulder", holding me in the most difficult times, being my safe harbor, and never let me give up even when I thought I should. He always provided me encouragement, was patient, and always got me to laugh even when it was a most difficult time. My true love, you are undoubtedly the best gift that God gave me. Thank you so much for sharing in my struggles and successes each day - you got me through this. I will always love you in all my lifes.

I am sincerely thankful to my advisor, my inspiration, teacher and mentor, Profa. Ana Luiza Vilela Borges. My understanding of sexual and reproductive health has broadened because of you. You always emphasized the value of hard work and dedication to academic excellence. Regardless of the challenges I faced during graduate school you were always available to offer good advices, inspiration and constructive criticism over the past six years, all of which permitted me to persist focused as a student. It is impossible to repay you for all you have done for me. For me your wisdom transcends the academic teachings, for me you represent the balance between personal and professional life, and you have all my respect for it. More than my supervisor, I consider you as a great friend that I intend to take for the rest of my life, outside the academic walls.

I would also like to sincerely thank to Profa. Caroline Moreau. I believe that you never imagined that there was someone in Brazil who always read your papers. Meeting 
you and having the opportunity to work with you in Baltimore was something I never imagined in my life. It was, without a doubt, one of the greatest professional experiences that I had in my life. You showed me a world that I never imagined existed. You represent to me a strong woman, clever, with a lot of energy and determination in what you do. I will never forget your support, for exposing me to cutting edge techniques in statistics, and I will always be grateful for it. I hope one day transmit all the knowledge learned from you, and give someone the same opportunity you gave me one day. You have a friend who really admires you in Brazil.

I extend my appreciation to Profa. Elizabeth Fujimori for the inspiration and unlimited encouragement. You have been following my academic journey and my growth for some years, and I am privileged to share this entire process with you. Thank you for sharing your teachings, for your friendship, for listening me in many times, for all invaluable support, help, and advice throughout the entire process of researching.

I would like to truly thank to my father Sergio and my mother Cecilia Maria even though she is no longer among us, for teaching me that anything is impossible and giving me the confidence to believe it. You have been a tower of strength and words cannot fully express my gratitude. There are no words to express my love for you. To Tatiana and Simone, thank you for always encouraging me and being the best sisters I could ever ask for. Even though we were miles apart, you always accompanying me on this journey and always supported me. I truly love you both.

I would like to thank to my husband's family, specially to my in-laws Ana Maria e Karekin, and to my sister-in-law's Renata and Ana Vitória, who always believed in me, for supporting me in all moments, for your assistance and encouragement. Thank you very much for your generosity, commitment, understanding, care and support that you gave me through this path.

I am also grateful to all my friends for their interest and insights on my dissertation. Special thanks go to the NEPESC Group, my friends at School of Nursing, and the friends that I made at Johns Hopkins University, for all support in particular and different moments in my life. I would particularly like to thank Osmara, Karina, Ana 
Paula, Áurea, Luciana, Claudia, Clariana, Natália, Patrícia, all of you inspired me, your support helped propel me to the finish line.

Finally, I particularly wish to thank the 1,679 young women who participated in my study and so openly and shared their lives with me. This study would not have been possible without their willingness to participate. 



\section{EPIGRAPH}

"We are shaped by our thoughts; we become what we think. When the mind is pure, joy follows like a shadow that never leave".

(Buddha) 

Chofakian CBN. Contraceptive discontinuation and its relation to emergency contraception use among undergraduate women [thesis]. São Paulo: Escola de Enfermagem, Universidade de São Paulo; 2017.

\begin{abstract}
Introduction: Contraceptive use dynamics is relevant to undergraduate students as they present high educational and professional aspirations, which affects reproductive intention. Also, they are mostly single, so they alternate the contraception according to their relationships. In that case, emergency contraception is an option, mainly in situations of discontinuation. However, little is known about discontinuation and its relation to the use of emergency contraception in Brazil. Objective: To analyze the frequency and correlates of contraceptive discontinuation within 12-months; to assess emergency contraception use after discontinuation, and evaluate dicontinuation after emergency contraception use. Methods: We conducted a 12-month retrospective cohort study on a sample of undergraduate women at University of São Paulo, Brazil. Students were selected by simple random sampling without replacement $(n=1,679)$. Data were collected online using a self-administered questionnaire. In Stata 14.2, we used multinomial and multivariate logistic regression, and generalized estimating equation to analyze the data. Results: First, we observed that women with casual relationships, lower socioeconomic status, enrolled in Human and Health Sciences programs, with less years of sexual experience, with multiple sexual partners in lifetime, and who use less effective method were more likely to discontinuation one or several times. Second, pill and condom users who had casual relationships, with lower socioeconomic status, and who had previous pregnancy were more likely to discontinue and to abandon or switch to a less effective method. Third, a significant proportion of women did not use emergency contraception after discontinuing or abandoning contraception. Fourth, emergency contraception was mostly used after inconsistent use of contraception. Fifth, women who used contraception prior to emergency contraception use, had no religion, were in stable relationships, and had only one sexual partner were more likely to use contraception after emergency contraception. Sixth, women with stable relationships, from lower socioeconomic status, enrolled in Human Sciences programs, and who had one sexual partner were more likely to switch to a less effective method after emergency contraception use. Lastly, few women presented gaps in contraception within 30days after emergency contraception use. Conclusions: Discontinuation does differ by type of method. Emergency contraception is underutilized after discontinuation. Partnership has an important influence on contraceptive use dynamics. Also, educational background, socioeconomic status, and number of lifetime sexual partners are important characteristics that should be considered when implementing family planning programs focused on young women.
\end{abstract}

Keywords: Contraception; Contraceptive discontinuation; Undergraduate students; Emergency contraception; Sexual and Reproductive Health. 

Chofakian CBN. Contraceptive discontinuation and its relation to emergency contraception use among undergraduate women [thesis]. São Paulo: Escola de Enfermagem, Universidade de São Paulo; 2017.

\section{RESUMO}

Introdução: A dinâmica do uso dos métodos contraceptivos é importante entre os universitários, pois estes apresentam altas aspirações educacionais e profissionais, o que afeta a intenção reprodutiva. Ainda, por serem na maioria solteiros, os jovens alternam os métodos de acordo com o tipo de relacionamento. Neste contexto, a anticoncepção de emergência é uma opção, sobretudo nos casos de descontinuidades. Porém, pouco se sabe sobre as descontinuidades e sua relação com o uso da anticoncepção de emergência no Brasil. Objetivo: Analisar a frequência e os determinantes da descontinuidade contraceptiva em um período de 12 meses; avaliar o uso da anticoncepção de emergência após as descontinuidades, e avaliar as descontinuidades após o uso da anticoncepção de emergência. Métodos: Estudo de coorte retrospectivo, realizado com amostra probabilística de mulheres universitárias da Universidade de São Paulo. As alunas foram selecionadas por amostragem aleatória simples sem reposição $(n=1.679)$. Os dados foram coletados através de um questionário de autopreenchimento respondido online. No Stata 14.2, os dados foram analisados por meio de regressão logística multinomial e multivariada, e equações de estimação generalizadas. Resultados: Primeiro, observou-se que as jovens com relacionamentos casuais, com menor nível socioeconômico, matriculadas nos cursos de Humanas e Ciências da Saúde, com menos anos de experiência sexual, com múltiplos parceiros sexuais e que usavam métodos menos eficazes, apresentaram maior probabilidade de descontinuar uma ou várias vezes. Segundo, as usuárias de pílula e preservativo que tinham relacionamentos casuais, com menor nível socioeconômico e que tiveram gravidez anterior, foram mais propensas a descontinuar, abandonar ou mudar para um método menos eficaz. Terceiro, uma proporção significativa de mulheres não usou anticoncepção de emergência após descontinuarem ou abandarem o método. Quarto, a anticoncepção de emergência foi mais utilizada após inconsistências no uso do método. Quinto, as jovens que usaram um método antes do uso da anticoncepção de emergência, sem religião, com um relacionamento estável, e que tiveram um parceiro sexual na vida, foram mais propensas a usar contracepção após a anticoncepção de emergência. Sexto, as jovens com relacionamento estável, de nível socioeconômico mais baixo, matriculadas nos cursos de Humanas e que tiveram um parceiro sexual na vida tiveram maior probabilidade de mudar para um método menos eficaz após o uso da anticoncepção de emergência. Por fim, poucas jovens apresentaram descontinuidades dentro de 30 dias após o uso da anticoncepção de emergência. Conclusões: A descontinuidade contraceptiva difere por tipo de método. A anticoncepção de emergência é subutilizada após as descontinuidades. A parceria influência na dinâmica do uso de contraceptivos. Ainda, aspectos educacionais, nível socioeconômico e número de parceiros sexuais são características importantes a serem consideradas na implementação de programas de planejamento familiar focados em mulheres jovens.

Descritores: Anticoncepção; Descontinuidade contraceptiva; Estudantes universitários; Anticoncepção de emergência; Saúde Sexual e Reprodutiva. 



\section{LIST OF ILLUSTRATIONS}

\section{FIGURES}

Figure 1 - Conceptual framework illustrating contraceptive discontinuation and their relation to the use of emergency contraception

Figure 2 - Map showing the distribution of the campuses at University of São Paulo, Brazil in São Paulo State

Figure 3 - Flowchart of organizational structure of the women interviewed, according to sexual behavior and contraception use. São Paulo, 2015.

Figure 4 - Number of women discontinuing their method in the last 12-months, by measure of discontinuation and type of method used at the start of the contraceptive calendar (baseline). São Paulo, 2015

Figure 5 - Number of monthly of contraception that were discontinued during the calendar year, by measure of discontinuation and type of method used at

the start of the contraceptive calendar (baseline). São Paulo, 2015

Figure 6 - Probability of contraceptive discontinuation for any reason by method type (Kaplan-Meier estimates). São Paulo, Brazil, 2015

Figure 7 - Probability of contraceptive discontinuation for method-related reasons by method type (Kaplan-Meier estimates). São Paulo, Brazil, 2015

Figure 8 - Probability of abandonment or switching to less effective method reasons by method type (Kaplan-Meier estimates). São Paulo, Brazil, 2015.

Figure 9 - Using of emergency contraception in context or not of contraceptive discontinuation for method-related reasons. São Paulo, 2015

Figure 10 - Emergency contraception use in context of use and non-use of contraception. São Paulo, 201

\section{FRAMES}

Frame 1 - Summary of three chapters

Frame 2 - Description of the survey questionnaire.

Frame 3 - Coding of the dependent variables

Frame 4 - Coding of the dependent variables assessing EC use after contraceptive discontinuation.

Frame 5 - Coding of the dependent variables 



\section{LIST OF TABLES}

Table 1 - Sociodemographic and sexual and reproductive health characteristics of undergraduate women in the sample. São Paulo, Brazil - 2015

Table 2 - Sociodemographic and sexual and reproductive health characteristics of undergraduate women in the sample according to the type of contraceptive method used at baseline. São Paulo, Brazil - 2015

Table 3 - Proportion of undergraduate women according to frequency of discontinuation for any reason and for method-related reasons within 12 months, by sociodemographic and sexual and reproductive health characteristics. São Paulo, Brazil - 2015.

Table 4 - Correlates of contraceptive discontinuation for any reason and for method-related reasons, according to frequency of discontinuation within 12 months (comparison between one and more than one episode of discontinuation). São Paulo, Brazil - 2015.

Table 5 - Multinomial logistic regression of cumulative instances of contraceptive discontinuation for any reason, by sociodemographic and socioeconomic characteristics, educational background, sexual/reproductive and contraceptive behavior. São Paulo, Brazil - 2015.

Table 6 - Proportion of all months of contraceptive discontinuation according to the type of discontinuation, by type of contraceptive method. São Paulo, Brazil - 2015

Table 7 - Correlates of contraceptive discontinuation according to the type of discontinuation, by type of contraceptive method. São Paulo, Brazil 2015

Table 8 - Proportion of undergraduate women discontinuing oral pill according to the type of discontinuation. São Paulo - 2015

Table 9 - Proportion of undergraduate women discontinuing male condom according to the type of discontinuation. São Paulo - 2015

Table 10-Cox proportional hazards model of contraceptive discontinuation according to the type of discontinuation, by type of contraceptive method. São Paulo, Brazil - 2015.

Table 11 - Emergency contraception usage characteristics of undergraduate women in the sample. São Paulo, Brazil - 2015 . 
Table 12 - Sociodemographic and sexual and reproductive health characteristics of undergraduate women according to using of emergency contraception following discontinuation for method-related reasons and method abandonment. São Paulo, Brazil - 2015

Table 13 - Sociodemographic and sexual and reproductive health characteristics of undergraduate women by context of EC use (inconsistent use of contraception or in the context of non-regular contraception). São Paulo, Brazil - 2015

Table 14 - Sociodemographic, sexual and reproductive health characteristics of São Paulo university students according to the use of contraception within 30 days after emergency contraception use. São Paulo, Brazil 2015

Table 15 - Correlates of using contraception within 30 days after emergency contraception use. São Paulo, Brazil - 2015.

Table 16 - Proportion of university students according to contraceptive switching patterns after EC use, by sociodemographic and sexual and reproductive health characteristics. São Paulo, Brazil - 2015

Table 17 - Multinomial logistic regression of contraceptive switching patterns after emergency contraception use, by sociodemographic and socioeconomic characteristics, educational background, sexual/reproductive and contraceptive behavior. São Paulo, Brazil - 2015

Table 18 - Sociodemographic, sexual and reproductive health characteristics of São Paulo university students according to the consistent use of contraception after using emergency contraception. São Paulo, Brazil 2015

Table 19 - Reasons for discontinuation the contraceptive method by method type. São Paulo, Brazil - 2015 


\section{LIST OF ABBREVIATIONS}

\begin{tabular}{ll} 
ABEP & Associação Brasileira de Empresas de Pesquisa \\
AIC & Akaike Information Criterion \\
CDC & Centers for Disease Control and Prevention \\
DHS & Demographic and Health Survey \\
EC & Emergency Contraception \\
GEE & Generalized Estimating Equations \\
IBGE & Brazilian Institute of Geography and Statistics \\
IUD & Intrauterine Device \\
LARC & Long-Acting Reversible Contraception \\
LH & Luteinizing Hormone \\
LNG & Levonorgestrel \\
NSFG & National Survey of Family Growth \\
SES & Socioeconomic Status \\
SRH & Social and Reproductive Health \\
STATA & Statistical Software \\
STD & Sexually Transmitted Diseases \\
UK & United Kingdom \\
US & United Sates \\
USP & University of São Paulo \\
WHO & World Health Organization \\
\hline
\end{tabular}





\section{TABLE OF CONTENTS}

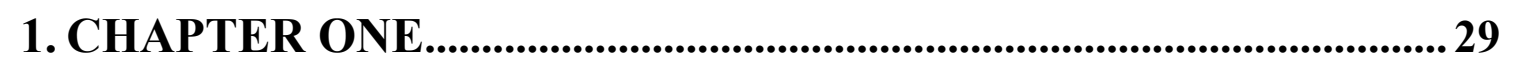

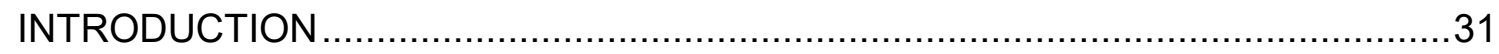

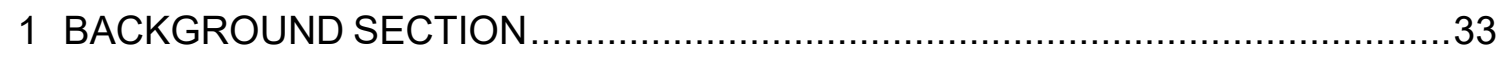

1.1 CONTRACEPTIVE CONTEXT IN BRAZIL ........................................................ 33

1.2 SEXUAL AND REPRODUCTIVE HEALTH IN YOUTH POPULATIONS IN

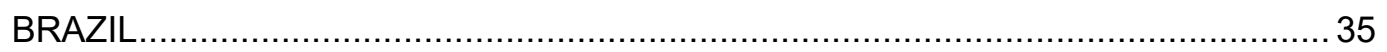

1.2.1 Unintended Pregnancies and Contraceptive Behaviors among youth in Brazil ..........................35

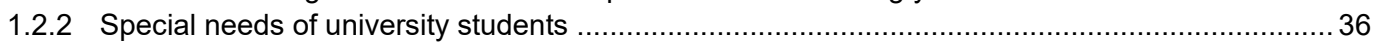

1.3 CONTRACEPTION DISCONTINUATION AND INCONSISTENT USE.......................38

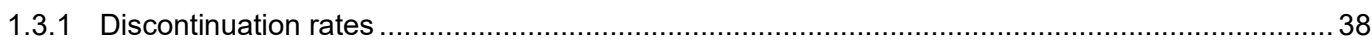

1.3.2 Switching versus abandonment in need of contraception.................................................. 40

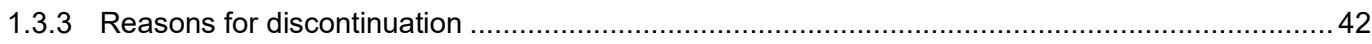

1.3.4 Contribution of discontinuation and inconsistent use to unintended pregnancies...................... 43

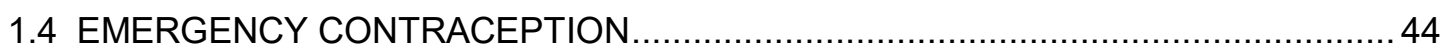

1.4.1 Emergency contraception to prevent pregnancy ........................................................ 44

1.4.2 Emergency contraception use in relation to method discontinuation ...................................... 47

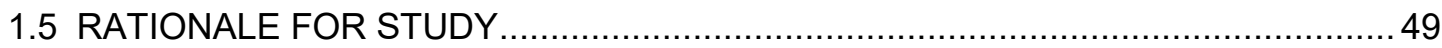

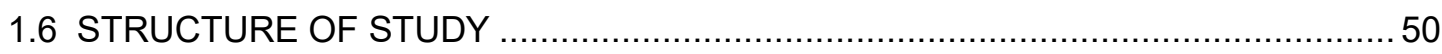

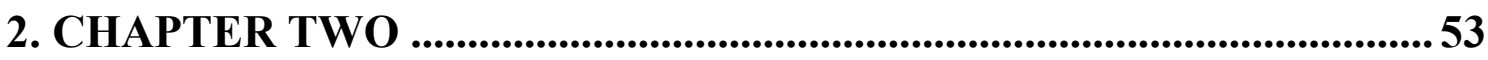

DISSERTATION AIMS, HYPOTHESIS AND CONCEPTUAL FRAMEWORK ............55

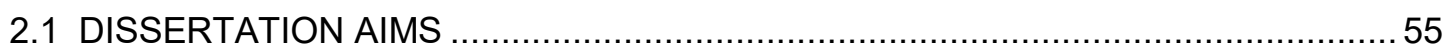

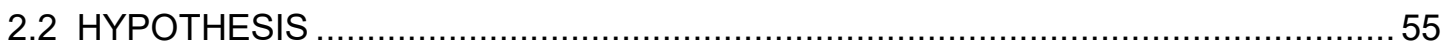

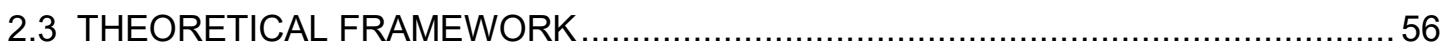

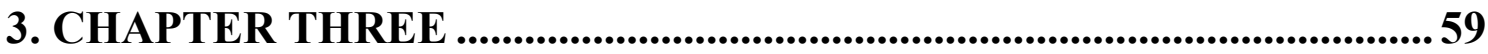

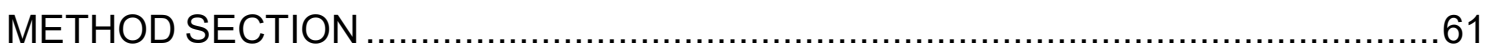

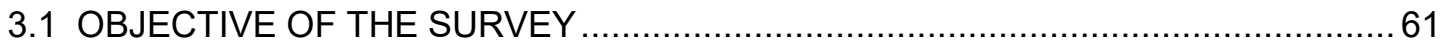

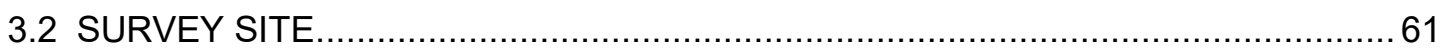

3.3 SAMPLING (FLOWCHART) AND DATA COLLECTION PROCEDURE .....................6 62

3.4 QUESTIONNAIRE

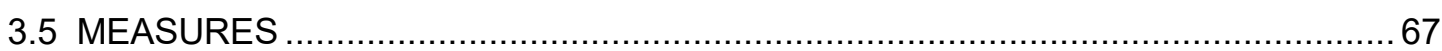

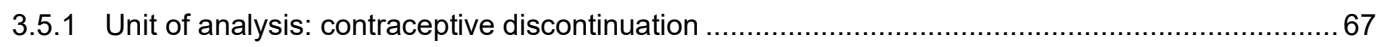

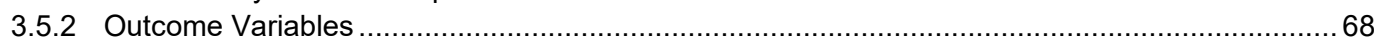

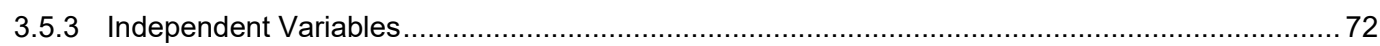

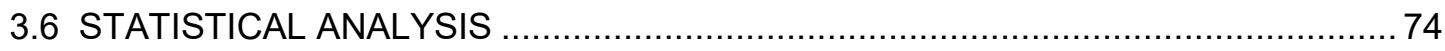

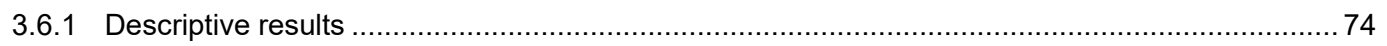

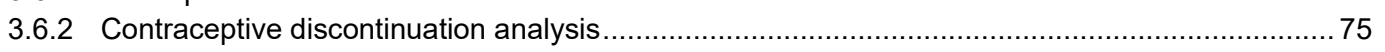

3.6.3 Emergency contraception analysis based on contraceptive calendar (12-months of

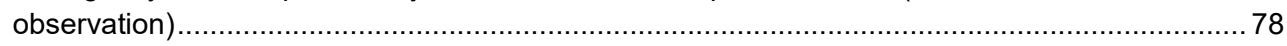

3.6.4 Emergency contraception analysis based on EC calendar (2-months of observation, 30 days before and 30 days after EC use)... 


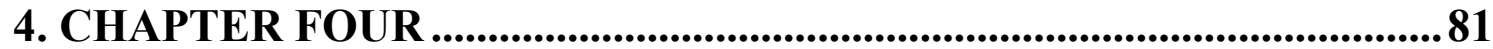

CONTRACEPTIVE DISCONTINUATION (CONTRACEPTIVE CALENDAR) ............ 83

4.1 BACKGROUND OF THE STUDY .............................................................. 83

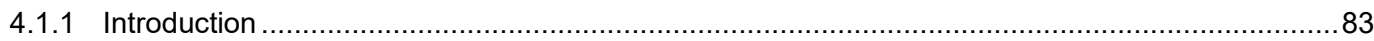

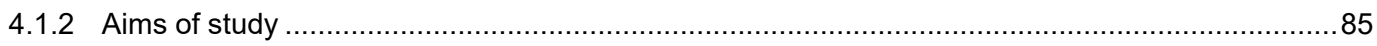

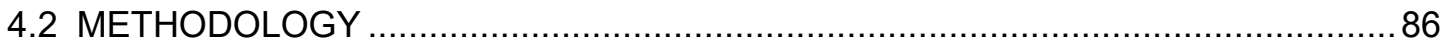

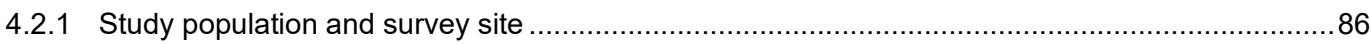

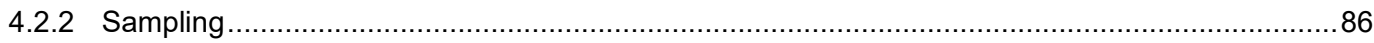

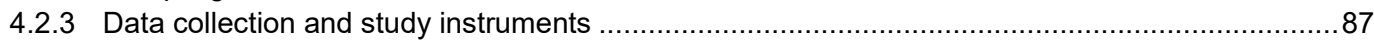

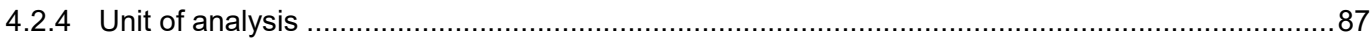

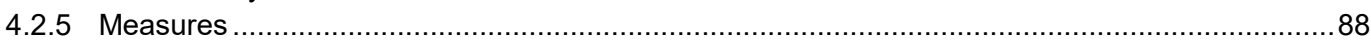

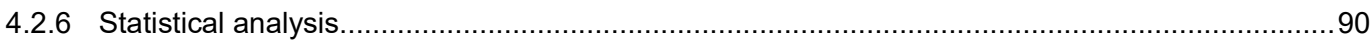

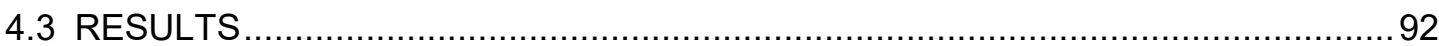

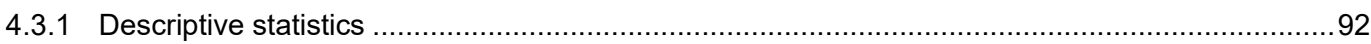

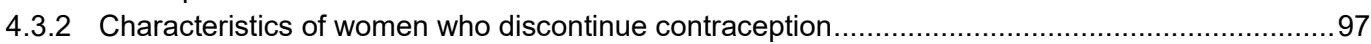

4.3.3 Monthly discontinuation of contraception ...................................................................... 110

4.3.4 Cumulative probabilities of discontinuation of new episodes of contraception:

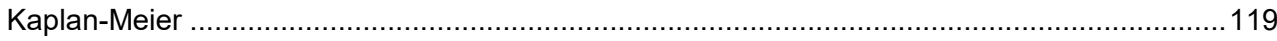

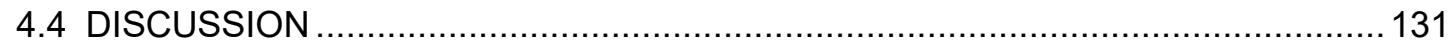

4.4.1 Contraceptive discontinuation according to frequency of discontinuation ................................ 131

4.4.2 Monthly discontinuation of contraception ..................................................................... 135

4.4.3 Cumulative probabilities of discontinuation of new episodes of contraception ......................... 138

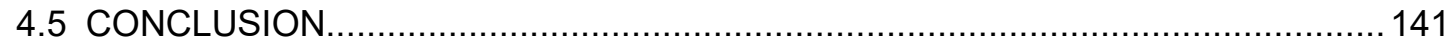

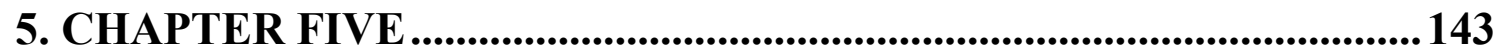

EMERGENCY CONTRACEPTION AND CONTRACEPTIVE DISCONTINUATION

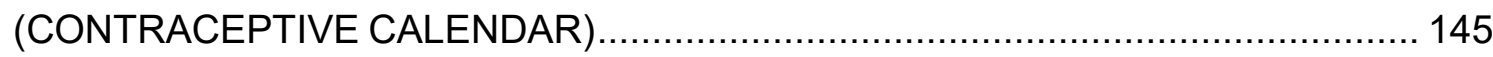

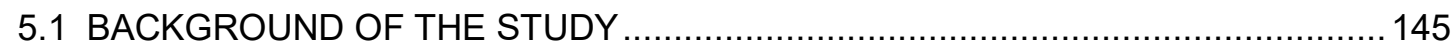

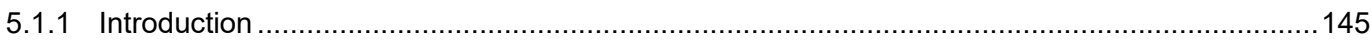

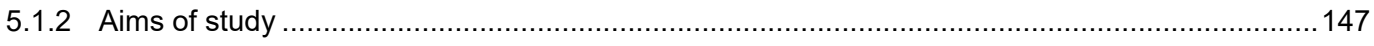

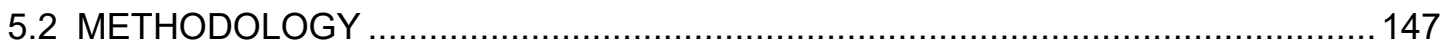

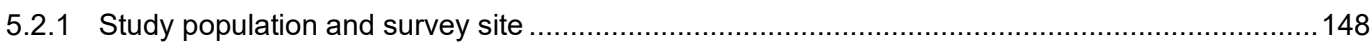

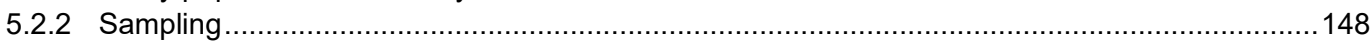

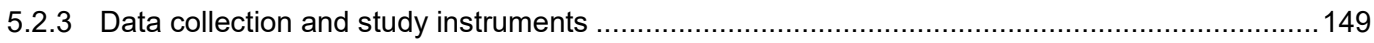

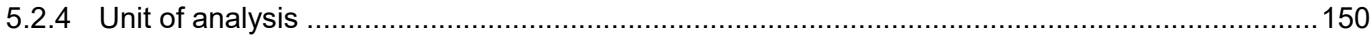

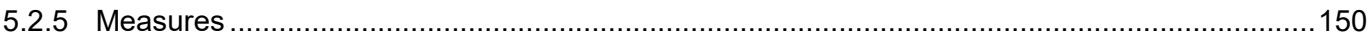

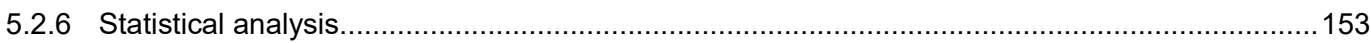

5.3 RESULTS OF USING EMERGENCY CONTRACEPTION BASED ON

CONTRACEPTIVE CALENDAR ………………………………………..... 154

5.3.1 Characteristics of women according to the last time that emergency contraception

was used in lifetime and in the 12-months prior to the survey

5.3.2 Emergency contraception in the context of contraceptive discontinuation for method-related reasons

5.3.3 Characteristics of women who used emergency contraception following contraceptive discontinuation for method-related reasons and method abandonment

5.3.4 Characteristics of women who used emergency contraception following inconsistent use of contraception or in the context of non-regular contraception.

5.4 DISCUSSION 163 
6. CHAPTER SIX.

CONTRACEPTIVE PATTERNS IN THE MONTH BEFORE AND AFTER

EMERGENCY CONTRACEPTION USE (EC CALENDAR) .................................171

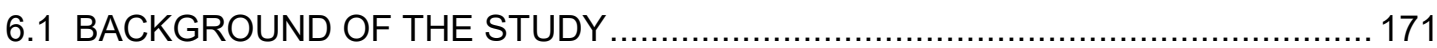

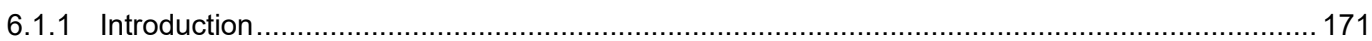

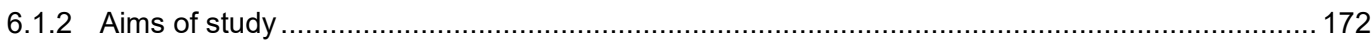

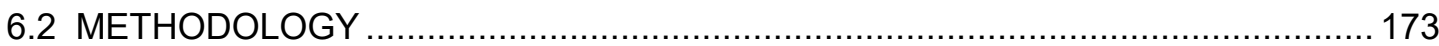

6.2.1 Study population and survey site

6.2.2 Sampling

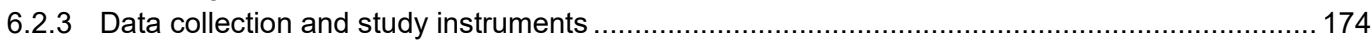

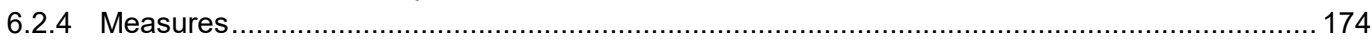

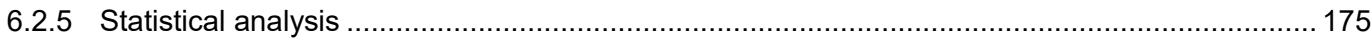

6.3 RESULTS OF USING EMERGENCY CONTRACEPTION BASED ON EMERGENCY CONTRACEPTION DAILY CALENDAR ..................................... 177

6.3.1 Characteristics of women who used contraception after using emergency

6.3.2 Correlates of using contraception within 30 days after emergency contraception

6.3.3 Characteristics of women according to contraceptive switching patterns after emergency contraception use......

6.3.4 Correlates of contraceptive switching patterns after emergency contraception use:

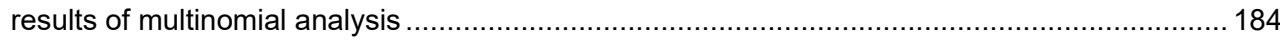

6.3.5 Characteristics of women who had gaps after using emergency contraception ...................... 186

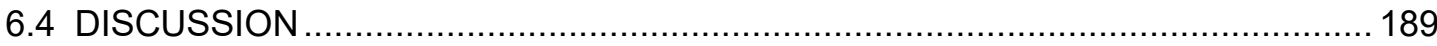

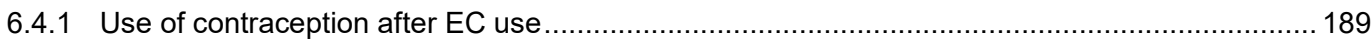

6.4.2 Contraceptive switching patterns after emergency contraception use ................................... 191

6.4.3 Gaps in contraception after emergency contraception use ............................................... 192

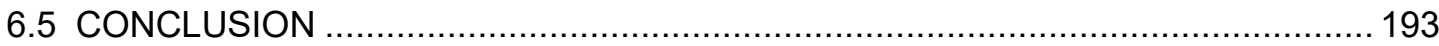

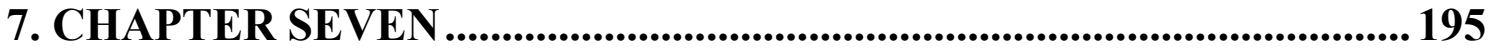

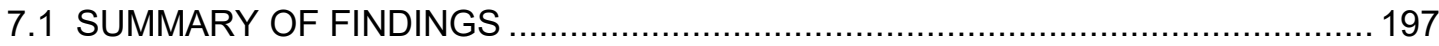

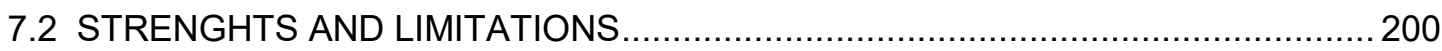

7.3 RECOMMENDATIONS FOR FUTURE RESEARCHES .................................... 204

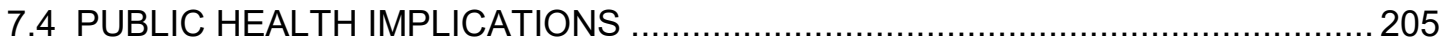

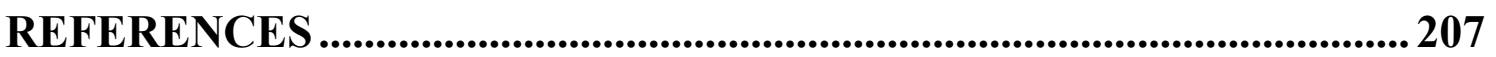

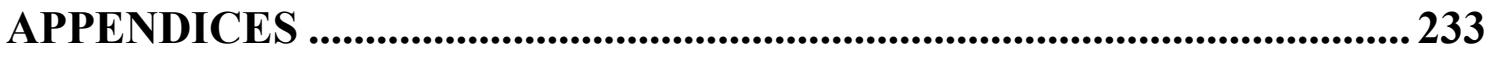

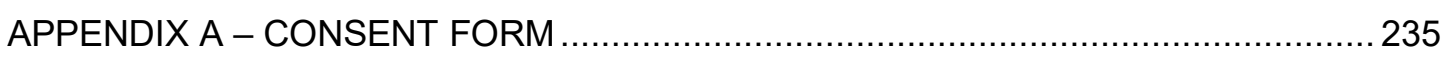

APPENDIX B - QUESTIONNAIRE (ENGLISH VERSION) ................................... 237

APPENDIX C - QUESTIONÁRIO (VERSÃO EM PORTUGUÊS) ............................... 249

APPENDIX D - INDEPENDENCE MODEL CRITERION (QIC) ................................... 263

APPENDIX E - REASONS FOR CONTRACEPTIVE DISCONTINUATION ................. 273

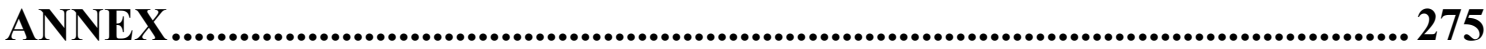

ANNEX - APPROVAL OF THE RESEARCH ETHICS COMMITTEE …...................... 277 



\section{PREFACE}

I am a midwife, I graduated at University of São Paulo, School of Arts, Sciences and Humanities in 2009. I started appreciating the reality of Sexual and Reproductive Health (SRH) of young women when I was an undergraduate student, in which I had the opportunity to participate on a project about contraceptive methods, women's health, and prenatal care with young women from a community in the city of São Paulo, Brazil. In addition, I worked with young women during the university internship. In these works, I identified areas for further research to better understand the problems of young people. So, I quickly fitted well and identified with female young people.

After I finalized my undergraduate course, I immediately started my master degree at University of São Paulo, School of Nursing in 2010, and Profa. Ana Luiza Vilela Borges welcomed me with "open arms". I realized a dream to work with contraception, especially with emergency contraception among adolescent people. In my master's degree, I again had the opportunity to be close to adolescents through lectures given at schools on contraceptive and sexual behaviors. My admiration for the subject and for this group only increased even more. In my $\mathrm{PhD}$, I was already sure that I would like to work with young people and contraception, and obviously with emergency contraception. At this time, Profa. Ana Luiza talked to me about a study that she and other authors conducted with young students at University of São Paulo, in which they had observed inconsistency in the contraceptive use. She presented me the contraceptive calendar and told me about her idea of doing something similar in relation to emergency contraception. The idea was sounded awesome for me and I was enthusiastic on contraceptive discontinuation issues surrounding sexual and reproductive health.

In 2015, I received a scholarship from a Brazilian government program, and I went to Baltimore to work with Profa. Caroline Moreau at Johns Hopkins University in 2016. She supported me in all this process and shared her knowledge of sexual and contraceptive behavior, and taught me how to analyze the contraceptive calendar, which is used in Demographic and Health Surveys. 
All these challenges motivated me throughout the study process. This study opened my eyes to the reality of fertility, sexuality and contraceptive needs of young people and how we can help them. Although I did not have direct contact with the young women who participated in my study, I had the opportunity to receive a lot of messages from them through E-mail, Facebook and WhatsApp. This approach helped me contextualize the problem of the study population. It was a privilege and grateful for me to be able to help these young women in some way. Certainly, I get much more than I give. 


\section{CHAPTER ONE}





\section{CHAPTER ONE}

\section{INTRODUCTION}

This document presents a study on contraceptive discontinuation among undergraduate women at University of São Paulo, Brazil. The present work builds on two studies conducted among Brazilian university students at University of São Paulo in 2002 and 2009 (Pirotta, Schor 2004; Borges et al., 2010). The study by Pirotta, Schor (2004) noted high proportions of contraceptive use, concomitantly with high proportions of pregnancies ended by abortion, which reveals that the contraceptive use was inadequate and inconsistent in this group. On the other hand, the study by Borges et al. (2010) pointed out that the emergency contraception (EC) use was a marker of the contraceptive discontinuation. Therefore, both studies noted a worrying aspect related to sexual and reproductive health among university women: the contraceptive use is frequent, but occurs in a discontinuous way. Although relevant, none of the previous studies measured contraceptive discontinuation and EC use in the context of contraceptive discontinuation. Thus, this study advances in relation to the two other studies mentioned, since it aims to understand the contraceptive practices among university students, which represents a specific group with high educational and professional perspectives, and which frequently use effective methods to postpone reproductive life (Longo et al., 2002; Sant'Anna et al., 2008; Veloso et al., 2014). The investigation of contraceptive practices among university students is justified by the fact that the level of knowledge and contraceptive access are supposedly higher among women with higher educational level. However, apparently, these are not the only aspects for the success of preventing an unintended pregnancy, since, even with knowledge and easy access to contraception, contraceptive discontinuation among university students can lead to unwanted outcomes, such as unintended pregnancy.

To summarize, one of the issues which is consistently raised in studies of contraceptive use in Brazil is the inconsistency and gaps in contraception use, and the lack of EC use after contraceptive discontinuation, all contributing to high proportions of pregnancies that are unintended. The specific focus of the study is to 
evaluate frequency and correlates of contraceptive discontinuation and how it relates to subsequent use of emergency contraception. More specifically, we will consider the following research questions:

- How often do undergraduate and young women discontinue their method of contraception in a 12-months period?

- What are the determinants of contraceptive discontinuation in a 12-months period and more specifically, what are the differences between woman who did not discontinue their method, woman who discontinue once, and those who discontinued their method several times in the period of 12-months?

- What is the monthly probability of method discontinuation for method-related reasons and of method abandonment over a 12-month period?

- What is the probability and correlates of using EC after contraceptive discontinuation?

- What are the patterns of contraceptive use after using EC?

- What determines the contraceptive discontinuation within a month following the use of EC?

The thesis is presented in a seven-chapter format where a variety of data and methods are employed to fully explore the topic. This introductory chapter presents information on the background context in relation to contraceptive discontinuation and EC in Brazil. We then present the specific aims of the study and outline the structure of the thesis. 


\section{BACKGROUND SECTION}

\subsection{CONTRACEPTIVE CONTEXT IN BRAZIL}

Brazil has recently undergone a rapid fertility transition with total fertility rates dropping below replacement, from 2.5 in 1996 to 1.8 in 2006 (Brasil, 2008a). At the same time Brazil, has seen a dramatic increase in modern contraceptive prevalence rates, estimated at $77 \%$ in the last national survey conducted in 2006 (Brasil, 2008a). While contraceptive prevalence rate is one of the proximate determinants of fertility and is used to monitor the effectiveness of Family Planning Programs in reducing unwanted fertility, prevalence alone is no longer sufficient in informing programs aimed at reducing the proportion of pregnancies reported as unintended, which remains high despite high contraceptive coverage (Boogarts, 1978; Lo at al., 2014). By implication, then, it is important to assess the dynamics of contraceptive use, beyond prevalence.

In Brazil, unmet need is estimated at $6 \%$ but $46 \%$ of pregnancies are reported as unintended (Brasil, 2008a; Berquó, Lima, 2008). This situation is comparable to other countries with high contraceptive coverage, such as the United Sates (U.S.), France or the United Kingdom (U.K.), where $33 \%$ to $45 \%$ of pregnancies are classified as unintended (Bajos et al., 2014, Moreau et al., 2014; Wellings et al., 2015; Finer, Zolna, 2016). Most of these pregnancies are due to inconsistent use or gaps in the use of contraception (Goulard et al., 2006; Frost, Darroch, 2008), which raises the issue of method choice/access and dynamics of use. In addition, it is important to underline that unintended pregnancy has been associated with increased risks of maternal morbidity, and health behaviors during pregnancy that are associated with adverse maternal and infant health outcomes, such as delayed prenatal care, premature birth, lower rates of breastfeeding, risk of miscarriage, having low birth weight infants, exposure to suicide and depression, and negative physical and mental health effects for children (Mayer et al., 1997; Santelli et al., 2003; Sereshti et al., 2005; Gipson, Koenig, Hindin, 2008; Cheng et al., 2009; CDC, 2011a; CDC, 2011b).

In Brazil, for limiting needs, sterilization is used by one third of women, but for spacing needs, the contraceptive landscape is dominated by pills or condoms, which are associated with high discontinuation rates and moderate failure rates (Brazil, 
2008a; Kost et al., 2008). In the last Demographic and Health Survey (DHS) survey conducted in 2006, a quarter of Brazilian women were relying on the contraceptive pill $(24.7 \%)$ and $12 \%$ used male condoms for the prevention of pregnancy (Brasil, 2008a). While very effective if used consistently, these methods are subject to failure because of inconsistent or errors of use (failure rates among pill and condom users are $9 \%$ and 18\%, respectively) (Trussell, 2011). In Brazil, the lack of trained professionals and limited contraceptive options (Heilborn et al., 2009; Vieira, Souza, 2011) contribute to skewed contraceptive distribution favoring user dependent methods (Moura, Silva, Galvão, 2007). Long-acting reversible contraception (LARC) such as implant or intrauterine device (IUD) are more effective (failure rates are $0.05 \%$ and $0.8 \%$, respectively (Trussell, 2011), but they are seldom used in Brazil ( $0.1 \%$ and $1.9 \%$, respectively) (Brasil, 2008a). While similar contraceptive patterns are observed in other contexts such as U.K., Ireland and Uganda (Lader, 2009; Lally et al., 2015; Nsubuga et al., 2016), recent efforts in a number of countries, including the U.S. and U.K, are seeing upward trends in the use of LARC mainly among young people, which are believed to have contributed towards lowering fertility rates among youth (National Institute for Health and Clinical Excellence, 2014; Secura et al., 2014; Ricketts, Klingler, Schwalberg, 2014; Kavanaugh, Jerman, Finer, 2015; Daniels et al., 2015; Lotke, 2015).

Suboptimal efficiency of contraceptive practices in Brazil (favoring moderate instead of highly effective methods) is a missed opportunity to ensure successful reproductive planning. A better understanding of contraceptive use dynamics, including discontinuation and use of back up options to reduce the risk of pregnancy after unprotected sex is an important step in informing more effective strategies to reduce unintended pregnancies. In the context of legal restrictions to abortion, the prevention of unintended pregnancy is a primary prevention strategy to reduce unsafe abortion, which is estimated at an annual average of 994,465 abortions, and responsible for $12 \%$ of maternal mortality in Brazil (Faúndes et al., 2007; MartinsMelo et al., 2014), and thus improve women's health. 


\subsection{SEXUAL AND REPRODUCTIVE HEALTH IN YOUTH POPULATIONS IN BRAZIL}

\subsubsection{Unintended Pregnancies and Contraceptive Behaviors among youth in Brazil}

The higher rates of unintended pregnancies across most developed countries occur among young women aged 20-24 (Diamond-Smith, Moreau, Bishai, 2014; Wellings et al., 2015; Coetzee, Ngunyulu, 2015; Finer, 2016; Moreau, Bohet, 2016). Similarly, in Brazil the highest burden of unintended pregnancies falls on youth (ages 15 to 24$)$ who are at the peak of their fertile years. Youth population (20 - 24 years old) represent $17.9 \%$ of the population in Brazil but account for $25 \%$ of unintended pregnancies (Berquó, Lima, 2008; IBGE, 2010). In case of unintended pregnancies, young women are also more likely to have an induced abortion, with peak of lifetime experience observed between 20 and 24 years (24\% in this age group) (Diniz, Medeiros, 2010).

While increase in contraceptive prevalence over time (increase of $11 \%$ between 1986 and 1996, and 4\% between 1996 and 2006) has potentially reduced unintended pregnancies (decrease from $22 \%$ in 1996 to $18 \%$ in 2006) among all women including young women (Brasil, 1997; Brasil, 2008a); social changes towards delaying the first birth are extending the number of years young women are exposed to the risk of unintended pregnancies. Although the average age at first birth has remained over the years (21 years) (Brasil, 2008a) and age at first intercourse has remained rather stable (15 years old) until 2006, recent trends are noticeable (Brasil, 2008a). Specifically, the proportion of women, mainly those with higher educational level, who have their first birth at 30 years or more has grown substantially in the last decade (14\% increase), representing now $32 \%$ of Brazilian women Brasil, 2008a; Brasil, 2014; IBGE, 2015), which means there is a growing number of years between first sex and first birth among women who are in the most fertile years of the reproductive life span (Brasil, 2014).

In the face of exposure to unintended pregnancy risk, a growing proportion of Brazilian youth $(77.1 \%)$ use modern contraceptive, mainly hormonal contraception (pill) $(44 \%)$, condom (16.8\%), and injectable (9.2\%) (Brazil, 2008a). These data reveal a breakthrough in the use of contraception in a 10-year period, as previous 
1996 DHS estimates indicated that only $66 \%$ of Brazilian youth were using modern contraceptive, especially hormonal contraception (39.5\%), condom (5\%), and injectable (3.6\%). The 2006 also reveals the sharp decline in the prevalence of female sterilization among young women (from 11.4\% in 1996 to 4\% in 2006) (Brasil, 2008a). While overall coverage has increased, the method mix indicates that women in Brazil favor methods that have moderate to high typical use failure rates which in turn contribute to unintended pregnancies and induced abortion (Frost, Singh, Finer, 2007a; Bradley, Croft, Rutstein, 2011; Sedgh et al., 2012).

A study published by Brazil's Ministry of Health based on a literature review from 1987 to 2008, noted that more than half of Brazilian young women who had induced abortions reported use of contraceptive methods at the time of conception (in particular the contraceptive pill), reflecting inconsistent or errors of use, in addition to frequent discontinuation (Brasil, 2008b). This is in line with other studies in high contraceptive prevalence countries indicating that most unintended pregnancies are attributable to incorrect or inconsistent contraceptive use (Jones, Darroch, Henshaw, 2002; Bajos et al., 2006; Schünmann, Glasier, 2006; Rash et al., 2007; Frost, Darroch, Remez, 2008; Moreau et al, 2010; Moreau et al, 2012; Wellings et al., 2015). A study conducted among French women aged 13-50 undergoing an elective abortion, observed that $66 \%$ of these women were using contraception at the time of conception (Moreau et al., 2010). Jones, Darroch \& Henshaw (2002) indicated that $53.3 \%$ of young women aged $20-24$ in the U.S. who had induced abortion were using a method in the month of conception, and they were the most likely of any age-group to have been using the pill (15\%) when they became pregnant.

These data illustrate the need not only to consider overall contraceptive prevalence, but more specifically, the dynamics of contraceptive use including discontinuation which is reported to be frequent in youth populations ( $47.3 \%$ of young women aged 20-24 in the U.S. discontinue contraception) (Pazol et al., 2015).

\subsubsection{Special needs of university students}

Undergraduate students represent a specific group among young people, with high educational and professional aspirations. Delaying childbearing generates a special demand for effective contraception until they reach professional stability (Longo et al., 2002; Sant'Anna et al., 2008; Veloso et al., 2014). While pregnancy 
rates are lower in this population compared to their less educated peers (Finer, Zolna, 2016), a higher proportion of these pregnancies are unintended (60\%), mostly related to contraceptive discontinuation (Bryant 2009; Trieu et al., 2011). A study conducted among undergraduate students in the U.S. estimated that continuous use of contraception could prevent about 12 million unwanted pregnancies every year (Ersek et al., 2011). In Brazil, studies conducted among undergraduate students in two states (Minas Gerais and Paraná) found that $29.3 \%$ and $65.9 \%$ of students, respectively, had used contraceptive methods inconsistently despite high levels of knowledge about contraception (Dessunti, Kings, 2012; Silva, Camargo, Iwamoto, 2014). Young women with higher education try to prevent unintended pregnancies more than others (Mosher, Jones, Abma, 2012), but while they use contraception whether the contraception fail, they are more likely to have an induced abortion (Finer, Zolna, 2011). In this scenario, young people with higher education are 3.8 times more likely to have an induced abortion than less educated youth, which contributes to potential maternal morbidity in the context of restrictive laws on abortion (Menezes, Aquino, 2009). High rates of contraceptive discontinuation resulting in unintended pregnancies amongst students at higher education institutions are also reported in other countries, including Asia, Africa, and the U.S. (Trieu et al., 2011; Mehra et al., 2012; Somba et al., 2014; Coetzee, Ngunyulu, 2015; Wang et al., 2015).

It is important to note that there are few people in Brazil attending tertiary educational. It is estimated that only $12.6 \%$ of Brazilians have a university degree (IBGE, 2015). Therefore, Brazil presents a relevant social and educational disparity, which needs to be considered in the context of sexual and reproductive health, as high educational level is related to the process of women postponing marital unions, using contraceptive methods and tending to have fewer unintended pregnancies (Pirotta, Schor, 2004). Unintended pregnancies represent a barrier to achieving academic success, besides impacting a life project encompassing the pursuit of economic autonomy, professional achievement and expectation to maintain or improve socioeconomic status in relation to the family of origin. Thereby, an unintended pregnancy has considerable social and psychological repercussions in the lives of university students (Pirotta, Schor, 2004).

In this context, investigating highly educated women allows us to understand the contraceptive practices of a "privileged group", which is motivated to prevent a 
pregnancy and less likely to face access barriers relative to lower socioeconomic population.

\subsection{CONTRACEPTION DISCONTINUATION AND INCONSISTENT USE}

\subsubsection{Discontinuation rates}

Contraceptive discontinuation is defined as switching a method of contraception or stopping a method altogether. Indicators typically discern discontinuation for any reason or for method-related reasons, the later excluding stopping a method to get pregnant or because women are no longer exposed to the risk of pregnancy (sterile or no partner) (Trussell, Vaughan, 1999).

In the U.S., overall, $68 \%$ of all methods are discontinued for any reason by the end of 12 months, and discontinuation rates for any reason range from $81.9 \%$ (for male condom users) to $47.4 \%$ (for oral pill users) (Vaughan et al., 2008). Moreau et al. (2009a) found lower contraceptive discontinuation rates among French women although similar patterns by method were also observed, with one-year discontinuation rates ranging, from $30.7 \%$ (for oral pill users) to $15 \%$ (for IUD users). In Brazil, $41.1 \%$ of all methods are discontinued for any reason within one year, and the discontinuation rate for any reason is higher for injectable $(61.8 \%)$, withdrawal $(60.1 \%)$, male condom $(59.8 \%)$, periodic abstinence $(46.3 \%)$, oral contraceptive (44.3\%), and IUD (5\%) (Ali, Cleland, Shah, 2012; Ferreira, 2014).

Discontinuation for method-related reasons pertains to situations when women stop the method despite having still a need for contraception. Reasons usually include dissatisfaction or problems with the method because of side-effects, health concerns, inconvenience of use, difficulties in access, high cost, or partner's opposition (Bradley, Schwandt, Khan, 2009). Discontinuation for method-related reasons is a more relevant indicator of discontinuation than discontinuation for any reasons in terms of pregnancy prevention, as it does not include discontinuation due to a desire to get pregnant or because of partner breakup (Ali, Cleland, Shah, 2012). Moreover, discontinuation for method-related reasons deserves specific attention, since it suggests a mismatch between women's desire and their practice that can potentially be resolved with better counselling (Hooper, 2010). 
Considering all methods, $47.1 \%$ of all methods are discontinued for methodrelated reasons within 12-months in the U.S., compared with $27.8 \%$ in Brazil (Vaughan et al., 2008; Ali, Cleland, Shah, 2012). Of particular concern are the high discontinuation rates of user dependent methods for method-related reasons. In the U.S., this estimate ranges from $57 \%$ (for male condom users) to $33 \%$ (for oral pill users), while $8 \%$ of IUDs and $13.1 \%$ of implants are discontinued for method-related reasons (Vaughan et al., 2008; Mansour, 2008; Castle, Askew, 2015). Similarly, Moreau et al. (2009) observed that contraceptive discontinuation for method-related reasons among user dependent methods in France, ranged from $38.9 \%$ (for withdrawal user) to $21.5 \%$ (for oral pill users), while discontinuation of IUDS for method-related reason was only $10.7 \%$. In Brazil, the method-related discontinuation within 12-months range from a high of $42.6 \%$ for male condom to $37.3 \%$ for injectable and $33.1 \%$ for oral pill - the most widely used methods among Brazilian youth (Ali, Cleland, Shah, 2012; Alano et al, 2012; Silva et al., 2010; Silva Camargo, Iwamoto, 2014).

Many factors are related to discontinuation, including external factors (such as quality of family planning services, family planning service environment, guidelines, among others), but also individual and partner factors (such as demographic characteristics, partner dissatisfaction, fertility motivations, among others) (Curtis, Blanc, 1997; Ali, Cleland, 1999; Curtis, Evens, Sambisa, 2011; Barden-O'Fallon, 2011a; Moreau et al., 2013). Prior studies indicate that women who are younger, who are black, and have higher parity are more likely to discontinue their methods (Ali, Cleland, 1995; Curtis, Blanc, 1997; Grady, Billy, Klepinger, 2002). Moreover, fertility desires, representing women's motivations to prevent a pregnancy is also related to contraceptive discontinuation (Blanc, 2001; Moreau et al., 2013).

Partners are also involved in method selection and continuation, although their level of influences is not totally comprehended (Barden-O'Fallon, 2011a). Earlier research on contraceptive discontinuation highlighted that lack of planning and sporadic sexual intercourse, as well as relationship dynamics and short duration of the relationship were factors contributing to use versus nonuse of contraception and contraceptive discontinuation (Manlove et al., 2003; Frost, Singh, Finer, 2007b; Sassler et al., 2009). Length of the relationship in particular is found to be associated with a tendency to relax contraceptive use when the partner is known and the relationship becomes stable (Aquino et al., 2003; Pirotta, Schor, 2004; Manlove, 
2007). Studies about the link between relationship status and contraceptive use is frequently analyzed in terms of motivation (Frost, Singh, Finer, 2007b; Sassler et al., 2009). According to Manlove, Ryan \& Franzetta, 2003, unmarried women use contraception less consistently in relationships that women report to be more serious. The authors suggest that motivation to avoid pregnancy is lower when the relationship develops more commitment. However, Reed et al. (2014) point out that the differences in consistency by relationship type or length probably occur because is more challenging to be consistent for a long than a short time. This also occurs in the beginning of a relationship, where there is need for negotiating contraception, mostly condoms because of STI considerations (Aquino et al., 2003; Manlove, 2007; Osei et al., 2014).

\subsubsection{Switching versus abandonment in need of contraception}

Not all women who discontinue contraception have an unmet need for contraception, since many women switch to another contraceptive, reducing their risk of unintended pregnancy. Nevertheless, it is important to note that switching in itself contributes to heighten risk of an unintended pregnancy, since failures are higher at the start of use of a method when women are still familiarizing themselves with the regimen (Peterson et al., 1998; Leite, Gupta, 2007; Ranjit et al., 2001; Trussell, 2004; Moreau et al., 2007).

After discontinuation, most women switch rather than abandon their method, and in most cases switching occurs within three months; so, switching methods is the primary reason for discontinuation (Vaughan et al., 2008; Moreau et al., 2009a; Ali, Cleland, Shah, 2012). Grady, Billy \& Klepinger (2002) observed that $40 \%$ of married women in the U.S. switch methods (stop a method to adopt a new contraceptive) within a two-year period. In a national telephone survey of a sample of nearly 2,000 women 18-44 years in the U.S., Frost, Singh \& Finer (2007b) found that nearly $25 \%$ of women switched their contraception in 12-months. In contrast, a national cohort study of women aged 18-49 in England, noted that $11.3 \%$ of women switched their method in 12-months, and only $1.8 \%$ switched for method-related reasons (Wellings et al., 2015). In addition, switching to another option for method-related reasons varies by contraceptive method. According to a national study conducted among women aged 18-44 in France, the frequency of switching for method-related reasons 
within 12 months is higher among withdrawal users (38.9\%), followed by condom (38.3\%), fertility awareness (34.5\%), oral pills users (21.5\%), and IUD (10.7\%).

In Brazil, 21.6\% of women switched their methods for method-related reasons within 12 months, and rates of switching for method-related reasons were higher for injectable (38.8\%), followed by male condoms (37.6\%), traditional methods $(29.6 \%)$, and oral pills (16.1\%) (Leite, Gupta, 2007). In addition, a cross-national study that selected nationally representative samples of women aged 18-44 in eight countries (including Brazil), observed that Brazil was the second country with the highest rate of switching from one hormonal contraceptive to another $(25 \%)$ (switching rates ranged from $12 \%$ in France to $28 \%$ in Russia) (Hooper, 2010). After discontinuing contraception for method-related reasons, Brazilian women were more likely to switch to any modern reversible method (21.3\%) than traditional method $(20.4 \%)$ (Ali, Cleland, Shah, 2012).

The probability of abandonment of contraception for method-related reasons is highest in the U.S. (25\%), compared with Brazil (10.34\%), France $(6.0 \%)$ and England (0.4\%) (Leite, Gupta, 2007; Vaughan et al., 2008; Moreau et al., 2009a; Wellings et al., 2015). Similarly, to switching, contraceptive abandonment for methodrelated reasons varies by method. In France and Brazil, highly effective methods users (pill, injectable, IUD or other hormonal methods) were more likely to abandon for method-related reasons contraceptive use than traditional methods users (Leite, Gupta, 2007; Moreau et al., 2009a). Besides side-effects, high rates of method abandonment in the Brazilian context may reflect lack of contraceptive options for women who stop their method (Castle, Askew, 2015), and may also reflect method stock-out (Bradley, Schwandt, Khan, 2009).

Abandonment and switching are more common among young women (Blanc et al., 2009, Barden-O'Fallon, 2011b). According to Grady et al. (2002), unmarried women in the U.S., younger and more highly educated had high rates of switching to the condom, and were more likely to abandon the oral pill, putting them at greater risk of unintended pregnancy. Similarly, a study conducted with women in England, found that stoppers and switchers were younger, better educated and more likely to be single (Wellings et al., 2015). In Brazil, 20.7\% of young women aged 20-24 switched their method and almost 10\% abandoned the method within the first year of use (Leite, Gupta, 2007). High rates of switching and abandonment among youth are probably related to the specific challenges they face in managing regular 
contraception across short-term and less stable relationships with periods of infrequent intercourse (Pirotta et al., 2004; Beadnell et al., 2005; Borges et al., 2010).

\subsubsection{Reasons for discontinuation}

The reasons for discontinuation varies by method. Reasons for discontinuation of condoms include the partner's opposition, vaginal irritation, latex allergies, desire to switch to an easier or more reliable method, and the perception that condoms are uncomfortable and interfere with sexual pleasure (Brunner Huber et al., 2006; Ersek et al., 2011; Davidoff-Gore, Luke, Wawire, 2011; Zembe et al., 2012; Mehra et al., 2014). Studies have suggested that use of condom is greater than the use of other methods at first intercourse, in the beginning of a relationship, and among those whose sexual intercourse is casual rather than stable - situations that are more common among youth (Santelli et al., 1997; Manlove, Ryan, Franzetta, 2003; Bastos et al., 2008; Raine et al., 2010; Beltzer et al., 2011). However, as relationships become more stable, many couples switch to hormonal methods, and the main reason to switch is the "supposed mutual trust", which indicates that they become less concerned about the prevention of sexually transmitted diseases (STDs) (Bastos et al., 2008; D'Antona et al., 2009; Shih et al, 2011; Goldstein, Upadhyay, Raine, 2013; Mehra et al., 2014).

The main reasons for discontinuation of hormonal contraceptives include "(non)compliance" with regular use (difficulty remembering, absence from home and hence lack of pills, loss of health insurance, depletion of supplies, lack of time, and difficulty keeping track of the ring), side-effects (headache, breast pain, yeast infections, nausea, weight gain, low libido, changes in menstrual flow) and health concerns (fear of hormone/cancer) (Jones, Darroch, Henshaw, 2002; Caruso et al., 2005; Leite, Gupta, 2007; Harvey et al., 2009; Castle, Askew, 2015; Inoue, Barratt, Richters, 2015).

The most common reason for discontinuing traditional methods is the desire to switch to a more effective method (Leite, Gupta, 2007; Vaughan et al., 2008; D'Antona et al., 2009; Bradley, Schwandt, Khan, 2009). Another common reason is pregnancy due to higher failure rates of these methods as compared to modern methods (Kost et al., 2008). 


\subsubsection{Contribution of discontinuation and inconsistent use to unintended pregnancies}

Unintended pregnancies are generally attributed to many complex and interconnected aspects, such as partnership and autonomy of women/gender relations; quality of health care; sexual and reproductive experience; factors related to contraception, which include: contraceptive failure, contraceptive nonuse, and incorrect or inconsistent use of contraceptive methods, among others (Langer et al., 2002; Prietsch et al., 2011; Finer, Zolna, 2011; Theme-Filha et al., 2016). In countries with moderate to high contraceptive prevalence, the majority of unintended pregnancies are the result of contraceptive discontinuation or failures due to inconsistent use of contraception (Jain, 1999; Trussell, 1999; Blanc, Curtis, Croft, 2002; Casterline, El-Zanaty, El-Zeini, 2003; Kost el al., 2008). A study in the US estimated that nearly $50 \%$ of the 3.1 million unintended pregnancies occurred to women who were not using contraception at the time of conception but had used contraception in the past (Finer, Henshaw, 2006).

In the same way, Blanc et al. (2002) noted that in 14 of 15 developed countries examined, more than half of unintended pregnancies were due to gap in use of contraception or failure due to errors of use, including in Brazil, Colombia, Jordan, and Peru. According to the authors of that study, the total fertility rate would drop by 20 to $48 \%$ in these 15 countries, by preventing births resulting from contraceptive discontinuation. Discontinuation for reasons other than a desire to get pregnant was also strongly associated with unintended pregnancies in Guatemala (17\%) (BardenO'Fallon, Speizer, White, 2008).

Additional research has associated discontinuation with induced abortion (Jain, 1999; Casterline, El-Zanaty, El-Zeini, 2003). Creanga et al. (2007) estimated that $60 \%$ of pregnancies resulting from contraceptive discontinuation among Romanian women resulted in induced abortion. In Armenia and Kazakhstan, these rates reached $80 \%$ (Bradley, Schwandt, Khan, 2009). In France, Bajos et al. (2006) observed that $50 \%$ of women who had an abortion had switched their contraception in the six months before the event. In this context, it is important to note that this association may be different in countries with legal restrictions on abortion, such as Brazil. 
Given the strong association between contraceptive discontinuation and unintended pregnancy, a better understanding of factors that favor sustainable use of contraception and reduce the risk of pregnancy after method discontinuation is critical to reduce levels of unintended pregnancy (Curtis, Evens, Sambisa, 2011).

\subsection{EMERGENCY CONTRACEPTION}

\subsubsection{Emergency contraception to prevent pregnancy}

Emergency contraception (EC) prevents women from becoming pregnant after unprotected sexual intercourse and may be used as a backup option, in particular in cases of contraceptive discontinuation with potential gaps in use (Raine et al., 2005; Borges et al., 2010).

EC levonorgestrel (LNG) pills are the only EC products available in Brazil until 2016, introduced in the public health programs in 2001 (Brasil, 2010; World Health Organization, 2012). LNG EC prevents pregnancy by delaying or inhibiting ovulation if is given before the Luteinizing Hormone (LH) peak, that is 24 to $48 \mathrm{~h}$ before ovulation (Brache et al., 2010). LNG EC is estimated to prevent between $52 \%$ and 94\% of pregnancies (Arowojolu et al., 2002; Hamoda et al., 2004; Creinin et al., 2006; Glasier et al., 2010), if given up to 120 hours after unprotected intercourse. While there are other EC methods that are more effective such, as the intrauterine device, mifepristone EC and ulipristal acetate, these methods were not available at the time of this research (Glasier et al., 2010; Cleland et al., 2012; Trussell, Raymond, Cleland, 2014).

Levels of use of EC are mostly a function of access conditions, and prescription of EC is one of the most important determinant to its use. In some countries, EC is obtainable only after a prescription, which can be a challenging and time-wasting, especially on holidays and weekends, because the primary health care is closed. In addition, some women think that request EC from health professionals is embarrassing, and others do not have access to primary health care services (Polis et al., 2010; Westley, Bass, Puig, 2016). In some countries, such as Brazil, women can buy EC at the pharmacy without a prescription (Borges et al., 2010; Tavares, Foster, 2016). In this context, a systematic review of the literature based on clinical trials comparing advanced provision to prescription only access shows substantial 
increases in usage in non-prescription status conditions (Polis et al., 2010). These results are confirmed at the population level where levels of use increase when prescription requirements are abandoned.

National estimates of EC use are difficult to compare as studies refer to different time frames (lifetime or annual incidence), different study populations (all women of reproductive age, young women, abortion patients) and different time periods extending over 15 years. Following the switch to non-prescription status, $17 \%$ of women 15-44 years old in France had ever used EC in 2004 (Moreau, Trussell, Bajos, 2006), 11\% of women 15-49 years old has done so in the U.S. in the period 2006-2010 (NHS Contraceptive Services, 2011/12), while 16\% of young women (average age 19.5 years) in Italy had ever used EC despite the prescription requirement (Tafuri et al., 2012), or annual incidence (7\% of women aged 16-49 in the U.K. had used EC in the past year, 2008 - 2009) (Daniels, Jones, Abma, 2013).

In Brazil, according to 2006 DHS Survey, 12\% of all women ever used EC, with the highest use rate observed among youths aged 20-24 (18.5\%) (Brazil, 2008a). EC use is significantly more frequent among Brazilian undergraduate students, ranging from $42.0 \%$ to $50.4 \%$ lifetime use (Borges et al, 2010; Silva et al., 2010; Alano et al., 2012). Although a substantial proportion of women have already used EC, EC is not used enough to have a public health impact in many countries, that is, EC is not utilized as often as needed to curve unintended pregnancy risk (Hu et al., 2005; Glasier et al., 2010; Palermo, Bleck, Westley, 2014; Santos et al., 2014; Nappi et al., 2014). Studies conducted in Scotland, France and Denmark over the last 15 years, observed that nine out of 10 women undergoing an abortion do not use EC to try to reduce the risk of becoming pregnant, a figure that has remained constant despite greater use of EC in the general population, (Sørensen et al., 2000; Moreau et al., 2005; Cameron et al., 2012). In Scotland, the availability of free EC from pharmacies did increase the proportion of EC use among women seeking an abortion (Cameron et al., 2012).

A number of studies have identified a number of barriers to EC use such as lack of knowledge or misperceptions of pregnancy risk (Moreau et al., 2005; Alano et al., 2012; Westley et al., 2013; Santos et al., 2013). A study based on literature review of global access to EC noted that the majority of women in high-income countries were aware of EC, but that this was not the case in middle- and low-income countries (Westley et al., 2013). However, a study carried out with high school students in 
Brazil, observed that the level of knowledge about EC did not interfere in the method use (Nascimento, 2012). Santos \& colleagues (2014) observed that no pregnancy risk awareness was associated with non-use of EC among women, on average 25 years old, in Brazil. However, awareness alone is not synonymous of using EC among women who need it (ESHRE Capri Workshop Group, 2015). Misinformation about the timeframe for use, and misperceptions about mode of action were associated with nonuse of EC among women undergoing an abortion in France (Moreau et al., 2005).

Research conducted in the U.K., France and Denmark consistently shows that underestimation of the chance of becoming pregnant is one of the reasons for nonuse of EC (Sørensen et al., 2000; Moreau et al., 2005; Lakha Glasier, 2006). According to Moreau et al. (2005) almost $61 \%$ of women undergoing an abortion France indicated that they did not use EC because they did not think could get pregnant. Similarly, another study conducted among women aged 16-46 in five European countries (France, Germany, Italy, Spain, and the U.K.) noted that the majority of women did not use EC when they needed it because they did not perceive themselves to be at risk of pregnancy (Nappi et al., 2014). In Brazil, study by Santos et al. (2014) observed that women who were not aware of pregnancy risk were three times more likely to non-use of EC than women who had pregnancy risk awareness.

In the country, other barriers to EC access and use prevail, including, stock outs in the public health sector, moral and cultural aspects, cost, inadequate disclosure of the places where it can be acquired, and concerns about EC deterring from regular contraception (Hardy et al., 2001; Costa et al, 2008; Alano et al., 2012; Faúndes et al, 2015; Tavares, Foster, 2016). In addition, studies have shown that the availability of $E C$ in the Brazilian scenario is not fully consolidated in primary health care, mainly due to moral and religious factors, and the lack of knowledge both from health professionals and users (Costa, Guilhem, Silver, 2006; Souza, Brandão, 2009; Figueiredo, Paula, 2012). A study carried out in São Paulo state, whose municipalities received remittances of EC from the Ministry of Health, shows that almost half of the primary health care services do not dispense EC (Figueiredo, Paula, 2012). The authors also point out a lack of technical preparation of health professional to deal with EC, i.e., misconceptions such as a belief that an "abusive" use of EC might occur in case the method is highly available (Souza, Brandão, 2009; Figueiredo, Paula, 2012). 
It is important to emphasize that not only in Brazil but also in other countries such as France, the U.S. and the U.K., EC users are mostly young and unmarried (Martin, 2004; Moreau et al., 2006; Lakha F, Glasier, 2006; Escobar et al., 2008; Cameron et al., 2011; Daniels, Jones, Abma, 2013); and the main reasons cited for EC use are: contraceptive abandonment, switching or failure of the contraceptive, i.e., contraceptive discontinuities (Moreau et al., 2006; Cameron et al., 2011).

Certainly, EC is a backup option to prevent unintended pregnancies, in particular in cases of contraceptive discontinuation with potential gaps in use (Raine et al., 2005; Borges et al., 2010).

\subsubsection{Emergency contraception use in relation to method discontinuation}

EC is mostly used to compensate for discontinuation and errors of the use of regular methods (mainly because of a ruptured condom and missed oral contraceptives), (Falk et al., 2001; Sorhaindo et al., 2002; Moreau et al, 2006). In this scenario, EC is considered a marker of inconsistent or errors of use of contraception rather than a regular method for women who are not using any other options (Jones, Darroch, Henshaw, 2002; Moreau et al., 2009a; Nappi et al., 2014).

Resumption of use of contraception use immediately after EC use is critical in limiting the risk of unintended pregnancy since EC failure rates are higher if there are several acts of unprotected intercourse in the same month (Glasier et al., 2011; Trussell, Raymond, Cleland, 2014. The risk is two- to three-fold higher among women who have other episodes of sexual intercourse in the same cycle that EC was used (Cheng, Che, Gülmezoglu, 2012). Moreover, EC can be the precursor of the regular contraceptive use; a concept referred to as "bridging" (Cameron, Glasier, 2010). In this context, Michie et al. (2014) noted that almost half (44\%) of women in Edinburgh who not using a hormonal method of contraception at the time of EC wished to use an effective method. In this context, while EC is not an effective option to replace regular contraception for women who have regular intercourse (WHO, 2004 ), it may still act as a bridge to regular contraception among the $32.2 \%$ sexually active Brazilian women at risk of pregnancy who do not use a regular method (Brasil, 2010; Mosher, Jones, 2010; Trussell, Raymond, Cleland, 2014). 
A number of studies indicate greater use of regular contraception after EC exposure; however, studies examining the type of contraceptive use after EC exposure (highly effective method or non-highly effective method) report inconsistent results. A prospective study of EC users in France show that while $8 \%$ of women switched from very effective to lower effective or nonuse of contraception after using EC, $20 \%$ of women moved in the other direction, that is they switched from less effective or no method to very effective method use after using EC (Moreau et al., 2009b). Also, in another study in France, Moreau et al. (2006) observed that $84 \%$ of women resumed use of a regular contraceptive after EC use, and almost $50 \%$ of women used highly effective method following EC use. Other study conducted in Jamaica, highlighted that $55 \%$ of women adopted an ongoing method of contraception following their first use of EC (Sorhaindo et al., 2002). In Minnesota, study found that $68 \%$ of women who were using non-highly effective method, switched to hormonal contraception after EC use (Sidebottom et al., 2008).

Other studies however, find the reverse is true. A case control study conducted among high risk women (16-24 years old) in California, indicate that women provided advanced supplies of EC were more likely than those in the control group (not given EC) to use less effective and less consistent contraception (Raine et al., 2000). Cameron et al. (2011) observed that despite the high use of contraception after the EC use among Scottish women (88\%), the use of effective ongoing contraception after EC (even from a specialist service) was not high. A case control study conducted among women aged 15-20 in Pennsylvania found higher reported condom use (77\%) in the advance EC group at follow-up (MacLean, 2004). Similarly, a case control study among Brazilian women aged 18-49, found a significant increase in regular contraceptive use among women who used EC; however almost $64 \%$ of women chose non-highly effective methods for ongoing contraception (Costa el at., 2008).

It is important to highlight that after EC use; some women do not resume use of regular contraception. In the French cohort of EC users, Moreau et al. (2009b) observed that $11 \%$ of these women did not use contraception six months after EC use. Similarly, $12 \%$ of women in Scotland did not use a regular contraception after EC use (Cameron et al., 2011). One factor that may probably contribute to the lack of bridging to prescription contraception is that women access EC in the pharmacy are not given proper counseling about more effective contraception (ESHRE Capri 
Workshop Group, 2015). According to Glasier et al (2010), less than half (43\%) of pharmacists supplying EC gave counseling about the importance of using contraception after EC. Although EC is to prescribed only by doctors and nurses in Brazil, it is sold without prescription in pharmacies. Study based on literature review which aimed to assess the policies for EC provision in pharmacies in the Brazilian context, observed that EC is also sold without any counseling by the pharmacists, since there is no specific policy in this regard (Paiva, Brandão, 2012). Even though counseling on EC by pharmacists is relevant, it is important to acknowledge that they also have doubts and misinformation (Brandão et al., 2016).

One randomized trial conducted in Jamaica gave a discount coupon for obtaining oral contraception in pharmacy for all women requesting EC (Chin-Quee et al., 2010). The intervention had no positive impact on use of effective contraception after using EC, as only $1 \%$ of coupons were redeemed, and only $13 \%$ of women in the intervention group and $11 \%$ of the control group used the oral pill for 2 months or more after requesting EC from a pharmacy. More than two-thirds of the women in the intervention group indicated that they did not want to use the oral pill. In a pilot study conducted in Edinburgh, women selected in pharmacies were randomized according three groups: standard care (pharmacists provided EC and verbal advice about the importance of using contraception after EC), one-month supply of progestogen-only oral contraceptive pills (POP), or an invitation to present the empty EC packet to a family planning clinic for contraceptive counseling. The proportion of women using effective contraceptive methods at follow-up was significantly greater in both the POP group and family planning clinic group, compared with standard care (Michie et al., 2014). The authors suggest that pharmacy-based interventions can increase the uptake of effective contraception after using EC.

\subsection{RATIONALE FOR STUDY}

The issue of contraceptive discontinuation is an important contributing factor in unintended pregnancy and induced abortion, and hence in the mortality and morbidity associated to reproduction. University students represent a singular group with both high need for contraception, high prevalence of contraceptive use, but high rates of contraceptive discontinuation resulting in frequent unintended pregnancy. In 
case of unprotected sexual intercourse, many of them use EC; however, there is little information about the circumstances of EC use after method discontinuation and the role of EC in bridging to more effective contraception in this population

No study has been done in Brazil focused on exploring the contraceptive discontinuation and their relation to the use of EC. The latest data on contraceptive discontinuities dates back to the 1996 DHS survey (Brazil, 2008a) with little insights on how overall practices and user dynamics have evolved ever since. These estimates are now over 20 years old and may not be an accurate reflection of young Brazilian women's current experience in using reversible contraceptive methods.

The present work based on two studies carried out with university students at University of São Paulo (Pirotta, Schor 2004; Borges et al., 2010) showing the use of contraception in this group appeared to be discontinuous, but this was not measured. We extend on these findings, by exploring contraceptive discontinuation, recourse to EC and its effect on bridging to more effective methods among college students.

\subsection{STRUCTURE OF STUDY}

This thesis is presented in seven chapters which are briefly detailed in this section. The first chapter reviews the literature and establishes the theoretical framework, presents the study rationale and outlines the topics that are addressed in the thesis.

The second chapter presents the methods used across studies, including the study population, survey site, and data collection procedures. We also present a detail description of the measures that are used in each chapter and the statistical analysis that was followed.

Each of the next three chapters (chapter 4, 5 and 6) presents a specific aim of the thesis. The chapters are organized by summarizing the important literature relevant to each specific topic, the method used for the specific analysis, description and discussion of specific topic of interest (discontinuation, EC use after discontinuation, contraceptive patterns of sue surrounding EC). A summary of the three chapters and their associated data and methods is provided in Frame 1 below.

Ultimately, the thesis is concluded in chapter 7 by a summary of the results of the study as a whole, along with policy implications and suggestions for further studies. 
Frame 1 - Summary of three chapters

\begin{tabular}{|c|c|c|c|}
\hline CHAPTER & 4 & 5 & 6 \\
\hline Data & $\begin{array}{l}\text { Retrospective cohort } \\
\text { study (longitudinal survey } \\
\text { data). }\end{array}$ & $\begin{array}{l}\text { Retrospective cohort } \\
\text { study (longitudinal survey } \\
\text { data). }\end{array}$ & $\begin{array}{l}\text { Retrospective cohort } \\
\text { study (longitudinal survey } \\
\text { data). }\end{array}$ \\
\hline Method & $\begin{array}{l}\text { Generalized estimating } \\
\text { equations and } \\
\text { multinomial logistic } \\
\text { regression. }\end{array}$ & Descriptive analysis & $\begin{array}{l}\text { Multivariate logistic } \\
\text { regression, and } \\
\text { multinomial logistic } \\
\text { regression. }\end{array}$ \\
\hline Study site & $\begin{array}{l}\text { University of São Paulo, } \\
\text { Brazil. }\end{array}$ & $\begin{array}{l}\text { University of São Paulo, } \\
\text { Brazil. }\end{array}$ & $\begin{array}{l}\text { University of São Paulo, } \\
\text { Brazil. }\end{array}$ \\
\hline Population & $\begin{array}{l}\text { Women aged } 18-24 \text { who } \\
\text { were enrolled in } \\
\text { undergraduate course of } \\
\text { all campuses at } \\
\text { University of São Paulo, } \\
\text { Brazil. }\end{array}$ & $\begin{array}{l}\text { Women aged } 18-24 \text { who } \\
\text { were enrolled in } \\
\text { undergraduate course of } \\
\text { all campuses at } \\
\text { University of São Paulo, } \\
\text { Brazil. }\end{array}$ & $\begin{array}{l}\text { Women aged 18-24 who } \\
\text { were enrolled in } \\
\text { undergraduate course of } \\
\text { all campuses at } \\
\text { University of São Paulo, } \\
\text { Brazil. }\end{array}$ \\
\hline Sample & $\begin{array}{l}\text { Women level sample: } \\
1,679 \text { women who used } \\
\text { a contraceptive method } \\
\text { within } 12 \text {-months prior to } \\
\text { the study. } \\
\text { Monthly discontinuation } \\
\text { of contraception sample: } \\
18,469 \text { observation } \\
\text { periods (months). } \\
\text { Contraceptive episode } \\
\text { level sample: } 1,230 \text { new } \\
\text { episodes of } \\
\text { contraception use. }\end{array}$ & $\begin{array}{l}\text { Women level sample: } \\
916 \text { women who used } \\
\text { EC in lifetime, and } 449 \\
\text { women who used EC } \\
\text { within } 12 \text {-months prior to } \\
\text { the study. } \\
\text { Monthly level sample: } \\
842 \text { months of } \\
\text { discontinuation for } \\
\text { method-related reasons, } \\
428 \text { months of method } \\
\text { abandonment, } 485 \\
\text { instances of EC in the } \\
\text { last } 12 \text {-months. }\end{array}$ & $\begin{array}{l}\text { Women level sample: } \\
916 \text { women who used } \\
\text { EC in lifetime, and } 691 \\
\text { women who used } \\
\text { contraception after EC } \\
\text { use. }\end{array}$ \\
\hline
\end{tabular}



2.CHAPTER TWO 



\section{CHAPTER TWO}

\section{DISSERTATION AIMS, HYPOTHESIS AND CONCEPTUAL FRAMEWORK}

\subsection{DISSERTATION AIMS}

Our specific aims are as follows:

1) Assess frequency and correlates of method discontinuation among undergraduate women in São Paulo within a 12-months period, according to the number of times women discontinued.

2) Assess frequency and correlates of method-specific contraceptive discontinuation among undergraduate women in São Paulo within a 12-months period.

3) Evaluate frequency of EC use after contraceptive discontinuation among undergraduate women in São Paulo. Assess differences in contraceptive patterns following discontinuation for women who use EC after discontinuation and those who do not use.

4) Describe contraceptive patterns (frequency and correlates) within a month after using EC among undergraduate women in São Paulo.

\subsection{HYPOTHESIS}

1) We hypothesize that the frequency of contraceptive discontinuation within a 12-months period varies by women's sociodemographic and partnership characteristics; and that women who discontinue once and several times differ according to these criteria. 
2) We hypothesize that the frequency of contraceptive discontinuation within a 12-months period varies by type of method, and it is frequent among user dependent methods.

3) We hypothesize that women take rarely advantage of EC after discontinuing contraception, and that EC use varies across sociodemographic and partnership characteristics.

4) We hypothesize that women resume use of effective contraception within a month after EC use, and they do not have changes in contraception after EC use. In addition, we hypothesize that women have gaps in contraception within a month after EC use, which vary across sociodemographic and partnership characteristics.

\subsection{THEORETICAL FRAMEWORK}

Figure 1 is a diagrammatic representation of the conceptual framework of contraceptive discontinuation dynamics and EC use on which this study is based. The figure demonstrates the process of contraceptive use as it occurs through time. First, at step 1 an individual can make the choice to use a specific contraceptive method, and therefore, an episode of use starts. This choice is influenced by a number of factors not only external to the individual such as supply environment, but also individual characteristics such as sociodemographic characteristics, type of relationship, the motivation to avoid pregnancy, among others.

Step 2 represents the length of the episode which, in the case of this study, can be anywhere from 1 to 12 months long. The line between step 1 and step 2 denotes the decision of the user to either continue their method, to switch to a different method or to abandon their method. Again, numerous factors may influence this decision and the central aim of this study is to understand which determinates are relating to contraceptive discontinuation among young women in Brazil. Also, step 2 exemplifies the importance of using EC at the time of switching or abandoning the method, which can be for any reasons or for method-related reasons. For those individuals who discontinue methods they are immediately returned to step 1 and the cycle begins again. 
Step 3 represents the possible consequences of contraceptive discontinuation and no EC use, such as unintended pregnancy, consequently induced abortion, and finally the maternal mortality. Each individual may complete this cycle of periods of use and non-use many times and may take similar or distinct pathway. 

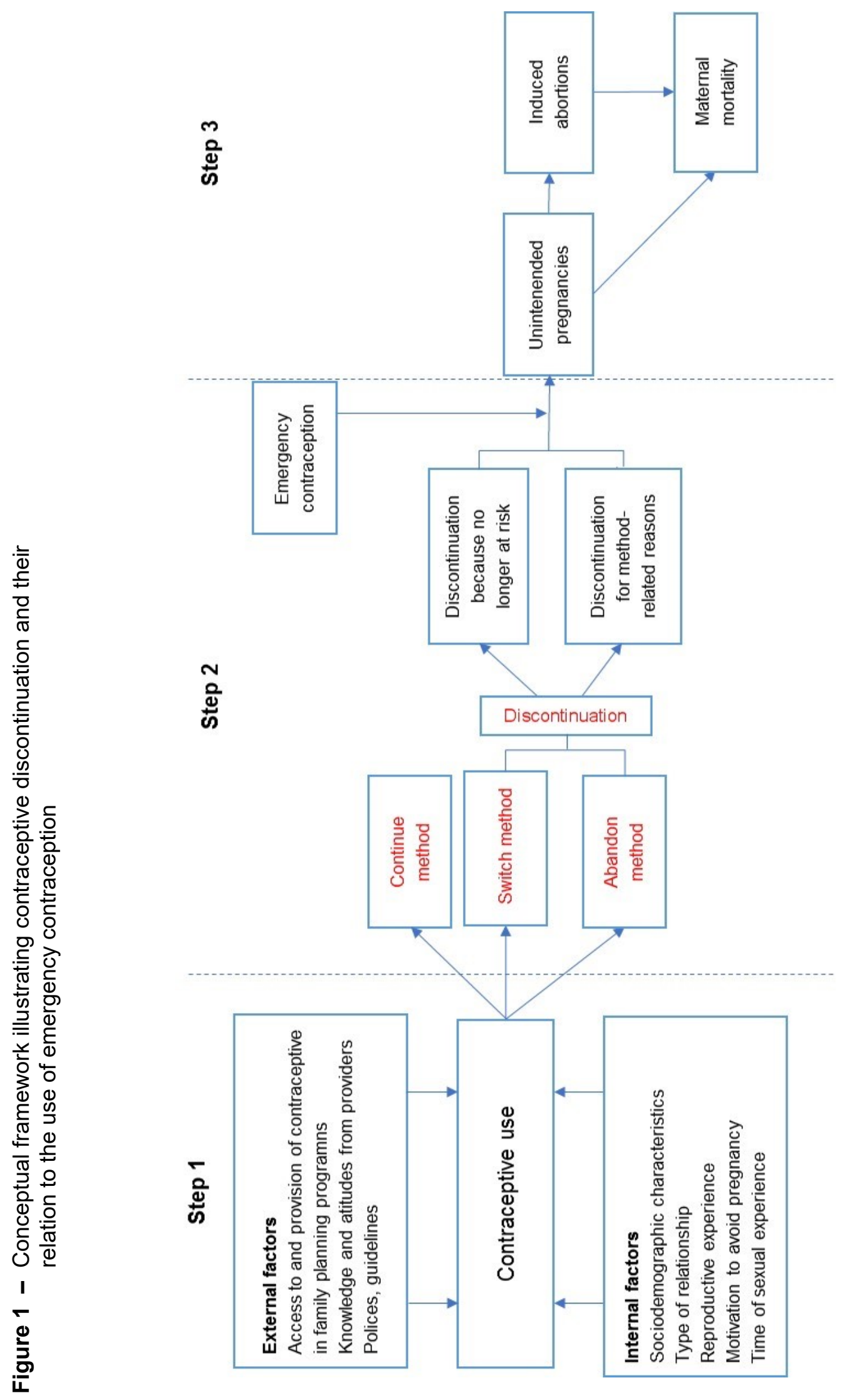



\section{CHAPTER THREE}

\section{METHOD SECTION}

\subsection{OBJECTIVE OF THE SURVEY}

This 12-month retrospective cohort study was conducted among a random sample of undergraduate women from University of São Paulo, Brazil, between June and July, 2015. The main objective of the study was to analyze contraceptive discontinuation and EC use. Women between the ages of 18 and 24 years old and enrolled in regular undergraduate course in all campuses of University of São Paulo, Brazil were eligible to participate in the study. They were selected by simple random sampling without replacement, and they were chosen electronically based on a list of all the email addresses of undergraduate students enrolled in the Electronic Computer Center of the University of São Paulo, organized in alphabetical order.

\subsection{SURVEY SITE}

The University of São Paulo is considered the largest institution of higher education and research in Brazil, under the responsibility of the São Paulo state government. The University of São Paulo offers undergraduate courses in all areas of knowledge. All courses are free and last from four to six years. There are eight campuses at University of São Paulo: one in São Paulo, capital, and seven in the state, in the cities of Bauru, Piracicaba, Pirassununga, Ribeirão Preto, São Carlos, Santos and Lorena (Figure 2). Altogether, there are 42 teaching units, offering 300 undergraduate courses in which 59,081 undergraduates were registered in 2015. According to data from the Statistical Yearbook of 2014, the university had 27,396 female students. 
Figure 2 - Map showing the distribution of the campuses at University of São Paulo, Brazil in São Paulo State
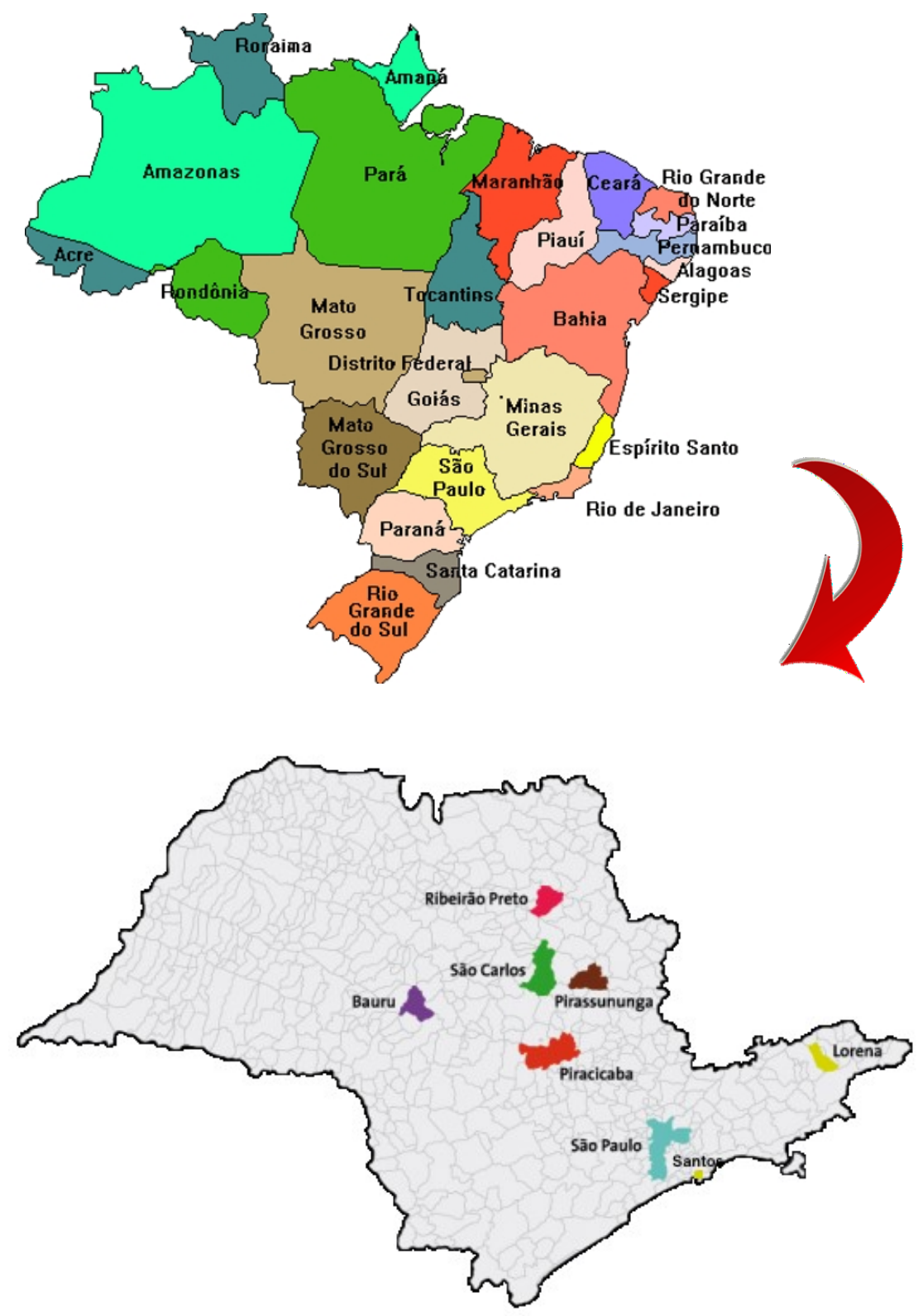

\subsection{SAMPLING (FLOWCHART) AND DATA COLLECTION PROCEDURE}

The sample included 1,026 undergraduate women, however after the pre-test $(n=50)$, only $10 \%$ of women answered the questionnaire; a response rate that was far lower than found in other surveys that used online questionnaires in Brazil (Bastos et 
al., 2008; Hooper, 2010). Therefore, considering the low response rate in the pretest, the sample size was tripled, and thus 3,078 women were randomly selected and invited to participate in the study.

After obtaining ethical approval to conduct the study from the Research Ethics Committee at University of São Paulo School of Nursing (CAAE Number: 39142514.4.0000.5392) (ANNEX I) and an authorization from the pro-rector at University of São Paulo, an electronic message was sent to all students who were selected to participate in the study. The research project (objectives, methodology, questions and time to answer the questions) was described in the email, and the student who had an interest in participating in the study could click on the study to complete a consent form (APPENDIX A).

In total, 2,182 undergraduate students (71\%) accessed the online questionnaire. However, 453 students who answered the questionnaire were not included because they did not meet inclusion criteria. In particular, students under the age of 18 years old $(n=2)$, students who had never had sexual intercourse $(n=358)$, and students who did not use any contraceptive method in the 12 month prior to the survey $(n=93)$ were excluded. The first group were excluded because it was necessary to obtain a permission from parents or guardians to participate in study, the second group because they were not at risk of pregnancy in the last 12 months, while the latter group was excluded because they could not discontinue a method. In order to analyze only women who were at risk pf becoming pregnant, other situations such as female sterilization and "want to become pregnant" were considered, however no woman reported these conditions. In addition, 50 women refused to participate in the study for different reasons, such as "did not want to answer questions related to sexuality" ( $n=10)$, some women felt "inadequate to participate because they were lesbians" $(n=12)$, some women answered that the theme of the research was against their religion $(n=5)$, others did not report the reason $(n=23)$. Therefore, the final study population comprised 1,679 undergraduate students between 18 and 24 years of age (Figure 3).

Students received reminder emails weekly to participate in the study (on average 10 times). Moreover, 14 students did not finish answering the questionnaire and had to answer the questions again at another time because uncompleted questionnaires were canceled. 
เ

ڤ્)

.

응

$\stackrel{\pi}{\circ}$

ह

$\frac{0}{2}$
$\frac{0}{0}$
$\frac{0}{0}$
$\frac{0}{\pi}$
$\frac{\pi}{x}$
0
0
0

오

음

흥

8

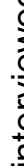

है

$\stackrel{1}{ \pm}$

¿

근

는

品

.

Nㅗㄱ․․

్ํํ

4
$\frac{0}{0}$
$\frac{1}{\pi}$
$\frac{0}{0}$
$\frac{1}{0}$
$\frac{0}{4}$

I

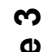

은
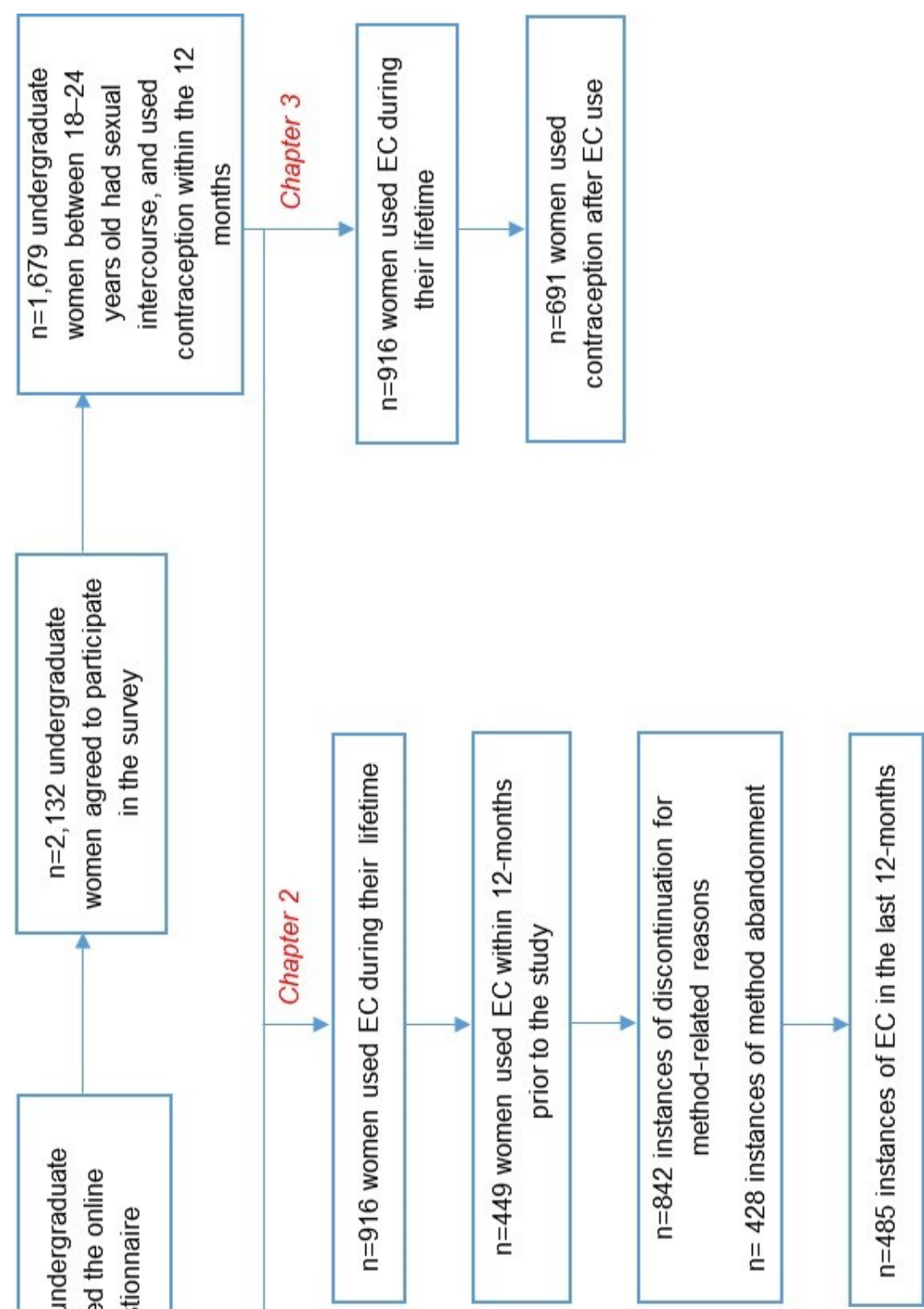

๙

तٓ
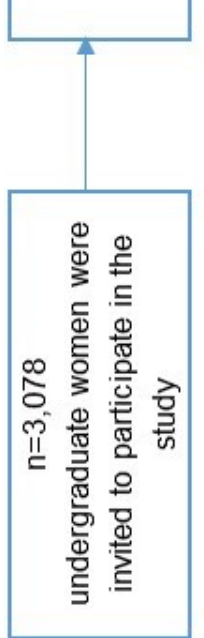
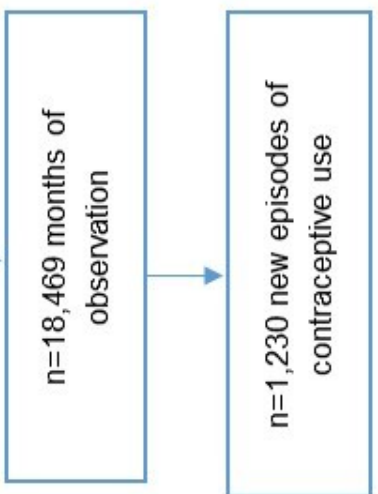


\subsection{QUESTIONNAIRE}

The data were collected online through Google Form, using a self-administered questionnaire that was pre-tested (APPENDICE B AND C). The questionnaire contained sociodemographic questions; questions about sexual and reproductive antecedents, questions about the use of contraceptive methods in the 12 months prior to the survey; and issues about the use of contraceptives surrounding the use of emergency contraception in the past 12 months. On average, it took 5-7 minutes to complete the questionnaire.

Questionnaire was structured with closed questions, and divided into modules:

Frame 2 - Description of the survey questionnaire

\begin{tabular}{|l|l|}
\hline \multicolumn{1}{|c|}{ MODULES } & \multicolumn{1}{|c|}{ OBJECTIVES } \\
\hline Sociodemographic context & $\begin{array}{l}\text { Identify the sociodemographic profile of the individual, such } \\
\text { age, race/ethnicity, religion, marital status. }\end{array}$ \\
\hline Socioeconomic context & $\begin{array}{l}\text { Identify the socioeconomic level of the individual. The } \\
\text { socioeconomic status was calculated according to Brazil's } \\
\text { Criterion of Economic Classification based on four } \\
\text { questions about household possessions (refrigerator, } \\
\text { television, computer, etc..) educational level of the head of } \\
\text { household, and public services near the residence (paved } \\
\text { street and piped water) (ABEP, 2015). }\end{array}$ \\
\hline Scholar context & $\begin{array}{l}\text { questions about school environment, such as the field of } \\
\text { study, part time or full time enrollment, campus and } \\
\text { scholarship. }\end{array}$ \\
\hline Sexual and reproductive bahavior & $\begin{array}{l}\text { questions explored past sexual and reproductive behavior, } \\
\text { such as age at first sexual intercourse, pregnancy history, } \\
\text { age at first pregnancy, previous abortions, among others. }\end{array}$ \\
\hline Contraceptive behavior & $\begin{array}{l}\text { Questions were based on current and last use of } \\
\text { contraception. }\end{array}$ \\
\hline
\end{tabular}


(continuação)

\begin{tabular}{|c|c|}
\hline MODULES & OBJECTIVES \\
\hline Contraceptive calendar & $\begin{array}{l}\text { First, a question identified women who had used } \\
\text { contraceptives in the } 12 \text { months prior to the study, reasons } \\
\text { for non-use contraception were asked of women who had } \\
\text { not used contraception during that time period. } \\
\text { Second, women who reported using contraception in the } \\
\text { past 12-months were asked to complete a contraceptive } \\
\text { calendar on a month-by-month basis (Bradley, Schwandt, } \\
\text { Khan, 2009). For each month, they indicated the type of } \\
\text { contraception used, reasons for discontinuation their } \\
\text { method, as well as the type of relationship, and occurrence } \\
\text { of pregnancy. In addition, they were asked about the use of } \\
\text { EC for each month. } \\
\text { Monthly use of contraception was assessed based on the } \\
\text { question: "What type of contraceptive were you using in } \\
\text { each month during the } 12 \text { previous months?" This question } \\
\text { was followed by a number of contraceptive methods from } \\
\text { which women could select just one method for each month } \\
\text { or they could indicate that they had not used a method. } \\
\text { Additionally, women were asked about the use of EC for } \\
\text { each month based on the questions: "Did you use } \\
\text { emergency contraception in the past 12-months?" "In } \\
\text { positive case, what months did you use it?" }\end{array}$ \\
\hline Emergency contraception & $\begin{array}{l}\text { Questions explored circumstances of last EC use, including } \\
\text { the type of relationship when EC was used, who bought the } \\
\text { medicine, prescription, site purchase location, time } \\
\text { between sexual intercourse and use of EC, among others. }\end{array}$ \\
\hline Emergency contraception calendar & $\begin{array}{l}\text { The contraceptive circumstances surrounding last EC use } \\
\text { were also explored } 30 \text { days before and } 30 \text { days after the } \\
\text { last use. Women were asked what type of contraception } \\
\text { they mostly used within } 30 \text { days before and } 30 \text { days after } \\
\text { the last time they used EC. } \\
\text { The specific questions included: "Did you use } \\
\text { contraception during the } 30 \text { days before/after of using } \\
\text { emergency contraception?", "What type of contraception } \\
\text { did you use in most of these } 30 \text { days (before and after EC } \\
\text { use)?", "Did you use the method continuously?" If women } \\
\text { answered no to this later question, an EC calendar was } \\
\text { made available, asking about use or non-use of } \\
\text { contraceptive method for each day (30-days). The main } \\
\text { question of the EC calendar was: "In these } 30 \text { days } \\
\text { before/after using the emergency contraception, which } \\
\text { days did you use the contraceptive method?". } \\
\text { Questions only allowed "no/yes" answers so it was only } \\
\text { possible to evaluate nonuse or abandonment of } \\
\text { contraception before/after EC use, not switching among } \\
\text { methods. }\end{array}$ \\
\hline
\end{tabular}

(conclusão) 


\subsection{MEASURES}

To explore discontinuation, each woman had a full one-year period of observation; however, we could not assess method duration at the time of discontinuation, because the date that women started using contraception was not collected in this study. For this reason, this study focuses on frequency of discontinuation within a 12-months period.

With respect to the EC calendar, each woman had two-months of observation (30-days before EC use and 30-days after EC use). Similarly, to the contraceptive calendar, the start date of using contraception before EC was not available, therefore we explore the prevalence of discontinuation one month before and one month after using EC.

\subsubsection{Unit of analysis: contraceptive discontinuation}

We considered three levels of analysis of contraceptive discontinuation, women level analysis, monthly discontinuation of contraception analysis, and contraceptive episode level analysis.

- Women level sample: we considered the full sample of 1,679 women for which we assessed the frequency of method discontinuation within 12 months.

- Monthly discontinuation of contraception sample: we partitioned the contraceptive calendar into monthly observations. Each woman contributed up to 12-months observations. A total of 18,469 months of observations were identified and are used as the analytical sample to investigate the factors related to monthly discontinuation of specific contraceptives.

- Contraceptive episode level sample: we partitioned the contraceptive calendar into segments of contraceptive use, defined as continuous months of use of the same method. Each woman contributes one or several episodes of contraception, based on the number of times she switches within the calendar year. A total of 3,937 episodes of use were identified. Among these, 1,230 were started during the calendar (new episodes), and are used as the analytical sample to investigate probabilities of discontinuation of new episodes of contraception over time. 


\subsubsection{Outcome Variables}

\subsubsection{Contraceptive discontinuation}

The dependent variables, i.e., variable whose value depends upon one or more other variables (response variable) for this research are constructed from the following central question which was asked of all women in the selected sample:

"What type of contraceptive were you using in each month during the 12 previous months?"

The response was based on the method women used in each particular month. We inferred method discontinuation by identifying when methods differed in two consecutive months ("month $\mathrm{n}$ " versus "month $\mathrm{n}+1$ "). We defined a monthly dichotomous discontinuation variable coded yes/no based on information that a method was not used in the following month.

In this study, the term "discontinuation" included women who switched to another method and those who abandoned their methods. Women were considered switchers if they initiated a method within a month of discontinuing their previous method. On the other hand, we considered discontinuation to be abandonment if the women did not use any other method during the follow-up period or resumed use of any method after experiencing at least one month of nonuse.

We defined three types of contraceptive discontinuation, i.e., discontinuation for any reason, discontinuation for method-related reasons (excludes discontinuation among women who don't need contraception, because they are seeking to get pregnant, are sterile or no longer gave a partner), and abandonment or switching to less effective method while still at risk to become pregnant (excludes discontinuation among women who don't need contraception and women who switched to more effective methods). We considered the following switched to represent a decline in contraceptive effectiveness: male condom to withdrawal/ fertility-awareness/ spermicide; oral pill to male condom/ withdrawal/ fertility-awareness/ spermicide/ diaphragms; IUD to male condom/ injectable/ oral pill/ spermicides/ vaginal ring/ patch/ diaphragms/ withdrawal/ fertility-awareness; injectable to male condom/ oral pill/spermicides/ diaphragms/ vaginal ring/ patch/ withdrawal/ fertility-awareness; and withdrawal/ fertility-awareness to spermicide (CDC, 2013). 
Altogether, three different dependent dichotomous variables were created at the monthly level: "discontinuation for any reason", "discontinuation for method-related reasons" and "abandonment or switching to less effective method".

Month discontinuation information was also summarized at the women level by a dichotomous variable "any discontinuation in the 12 months of observation" coded yes if a woman had at least one month of discontinuation. Additionally, a three category variable was created at the women level distinguishing women who had never continued a method during the 12 month, women who had discontinued one time and women who had discontinued several times during the 12 months of observation.

All the dependent variables are detailed below in Frame 3.

Frame 3 - Coding of the dependent variables

\begin{tabular}{|l|l|}
\hline \multicolumn{1}{|c|}{ DEPENDENT VARIABLES } & \multicolumn{1}{c|}{ CODE } \\
\hline Discontinuation for any reason & $\begin{array}{l}\text { 0: non-discontinuation (woman always used the same } \\
\text { method of contraception during the 12-months). } \\
1: \text { all situations of discontinuation. }\end{array}$ \\
\hline $\begin{array}{l}\text { Discontinuation for method-related } \\
\text { reasons }\end{array}$ & $\begin{array}{l}\text { 0: non-discontinuation for method related reasons (woman } \\
\text { always used the same method of contraception or only } \\
\text { discontinued their method because they were no longer at } \\
\text { risk of unintended pregnancy (seeking pregnancy, sterile } \\
\text { or had no partner). } \\
\text { 1: women who discontinued for method-related reasons } \\
\text { (discontinued their method while still at risk of unintended } \\
\text { pregnancy, including switching to more effective method, } \\
\text { or switching to less effective method or abandonment). }\end{array}$ \\
\hline $\begin{array}{l}\text { Abandonment or switching to less } \\
\text { effective method }\end{array}$ & $\begin{array}{l}\text { 0: non-abandon (woman always used the same method of } \\
\text { contraception or only discontinued their method because } \\
\text { they were no longer at risk of unintended pregnancy } \\
\text { (seeking pregnancy, sterile or had no partner) or switched } \\
\text { to more effective methods. } \\
1: \text { women who abandoned their methods or switched to } \\
\text { less effective method while still at risk. }\end{array}$ \\
\hline
\end{tabular}


(continuação)

\begin{tabular}{|l|l|}
\hline \multicolumn{1}{|c|}{ DEPENDENT VARIABLES } & \multicolumn{1}{c|}{ CODE } \\
\hline $\begin{array}{l}\text { Frequency of discontinuation for any } \\
\text { reason }\end{array}$ & $\begin{array}{l}\text { 0: woman did not discontinue their method over the 12- } \\
\text { months period. } \\
\text { 1: woman discontinued their method for any reason one } \\
\text { time over the 12-months period. }\end{array}$ \\
\hline $\begin{array}{l}\text { Frequency of discontinuation for } \\
\text { method-related reasons }\end{array}$ & $\begin{array}{l}\text { 0: woman discontinued their method for any reason more } \\
\text { 1: woman discontinued their method for method-related } \\
\text { reasons one time over the 12-months period. }\end{array}$ \\
\hline $\begin{array}{l}\text { 2: woman discontinued their method for method-related } \\
\text { reasons more than once over the 12-months period. }\end{array}$ \\
\hline
\end{tabular}

(conclusão)

\subsubsection{Emergency contraception based on contraceptive calendar}

The coding of the variables related to EC are presented in Frame 3.

Emergency contraception following discontinuation for method-related reasons, and method abandonment

To identify instances of EC use following discontinuation for method-related reasons and method abandonment, we used data collected in the 12-months contraceptive calendar. In the calendar, women could choose EC as one of the contraceptive used in a particular month. Based on this information, we identified EC use in the month following contraceptive discontinuation for method-related reasons and method abandonment. In addition, we identified EC use following inconsistent use or in the context of non-regular contraception.

The dependent variables related to EC were defined as dichotomous measures (no/yes), which are detailed below in Frame 4. 
Frame 4-Coding of the dependent variables assessing EC use after contraceptive discontinuation

\begin{tabular}{|c|c|}
\hline DEPENDENT VARIABLES & CODE \\
\hline $\begin{array}{l}\text { Emergency contraception use } \\
\text { following discontinuation for method- } \\
\text { related reasons }\end{array}$ & $\begin{array}{l}\text { 0: woman did not use EC in the month following } \\
\text { discontinuation for method-related reasons. } \\
\text { 1: woman used EC in the month following } \\
\text { discontinuation for method-related reasons }\end{array}$ \\
\hline $\begin{array}{l}\text { Emergency contraception use } \\
\text { following method abandonment }\end{array}$ & $\begin{array}{l}\text { 0: woman did not use EC in the month following method } \\
\text { abandonment. } \\
\text { 1: woman used EC in the month following method } \\
\text { abandonment. }\end{array}$ \\
\hline $\begin{array}{l}\text { Emergency contraception use } \\
\text { following inconsistent use }\end{array}$ & $\begin{array}{l}\text { 0: woman used EC in a month of inconsistent use of } \\
\text { contraception (switching and continuous use). } \\
\text { 1: woman did not used EC in a month of inconsistent } \\
\text { use of contraception; woman used EC following non- } \\
\text { regular contraception (abandonment and non-regular } \\
\text { contraception). }\end{array}$ \\
\hline
\end{tabular}

\subsubsection{Contraceptive patterns of use in the month after emergency contraception use based on emergency contraception calendar data}

To identify contraceptive utilization after using EC, we used a second contraceptive calendar, referred to the EC calendar, exploring contraceptive use within 30 days before and 30 days after the last instance of EC use. Only women who responded positively to ever having used EC: "Have you ever used emergency contraception?", were selected to answer the EC calendar. The dependent variable is based on responses to the following questions:

"What method did you most use within 30 days after the last time you used emergency contraception?" 
Our outcome variable measures contraceptive use over the full period of 30 days after EC use, the last time EC was use.

The dependent variables related to EC were defined as a dichotomous measure (no/yes), which are detailed below in Frame 5.

Frame 5 - Coding of the dependent variables

\begin{tabular}{|l|l|}
\hline \multicolumn{1}{|c|}{ DEPENDENT VARIABLES } & \multicolumn{1}{c|}{ CODE } \\
\hline $\begin{array}{l}\text { Contraceptive use after using } \\
\text { emergency contraception in the last } \\
\text { time }\end{array}$ & $\begin{array}{l}\text { 0: woman did not use contraception within } 30 \text { days after } \\
\text { EC use in the last time. } \\
1: \text { woman used contraception within } 30 \text { days after EC } \\
\text { use in the last time. }\end{array}$ \\
\hline $\begin{array}{l}\text { Contraceptive switching patterns after } \\
\text { emergency contraception use }\end{array}$ & $\begin{array}{l}\mathbf{0} \text { : woman did not change the contraceptive method after } \\
\text { before and after EC use. } \\
\text { 1: women switching to more effective method after EC } \\
\text { use in the last time; or women were not using a method } \\
\text { within } 30 \text { days before EC and started to use a method } \\
\text { after EC use. } \\
\text { 2: women switching to less effective method after EC use } \\
\text { in the last time; or women were using a method within } 30 \\
\text { days before EC and stopped to use it after EC use. }\end{array}$ \\
\hline $\begin{array}{l}\text { Gaps after using emergency } \\
\text { contraception in the last time }\end{array}$ & $\begin{array}{l}\mathbf{0} \text { : woman did not have gaps within } 30 \text { days after using } \\
\text { EC in the last time. } \\
\mathbf{1 :} \text { woman had gaps within } 30 \text { days after using EC in the } \\
\text { last time. }\end{array}$ \\
\hline
\end{tabular}

\subsubsection{Independent Variables}

Variables were selected on the basis of our conceptual framework related to contraceptive discontinuation and emergency contraception and previous literature reporting on the determinants of contraceptive discontinuation and EC use.

In all analysis, we considered the following sociodemographic and sexual health information 
- Sociodemographic variables included:

- age (18-19 or 20-24);

- race/ethnicity (white, black, other);

- religious affiliation (no religion, roman catholic, kardecista spiritualism doctrine, evangelical, other religion);

- relationship status (none; steady relationship, such as with boyfriend or living with a partner; and casual relationship).

- wage labor (no/yes);

- socioeconomic status (A/B, C - D/E) (ABEP, 2015). We stress that we classified the socioeconomic status as high $(A / B)$, and middle/low $(C-D / E)$.

- Educational information: field of study (human sciences, health sciences, exact sciences); type of enrollment (full-time or part-time); campus site (São Paulo, countryside).

- Sexual and reproductive health variables included:

- time since first sexual intercourse ( $\leq 1$ year, 2-3 years, $\geq 5$ years);

- number of sexual partners (1 partner, 2-3 partners, $\geq 4$ partners);

- pregnancy prior to 12-months calendar

- current use of contraceptive method (no/yes) \& type of current contraceptive method (highly effective method or non-highly effective method). Highly effective method includes hormonal contraception and an intrauterine device, while non-highly effective method includes condoms, spermicides, fertility-awareness and withdrawal);

- use of contraceptive method in the last sexual intercourse (no/yes) \& type of contraceptive method used in the last sexual intercourse (highly effective method or non-highly effective method);

- Ever use of EC.

Time varying information collected at each month (12-month) calendar was also considered in the analysis of monthly discontinuation of contraception and EC use following method discontinuation:

- Monthly use of contraception described in 4 categories (oral pill, male condom, other methods, no contraception);

- Monthly relationship status defined in 3 categories: steady, casual relationships, none; and change in relationship status yes/no from previous month; 
- Reasons for discontinuation if a method was discontinued (side effects, wanted a more effective method, criticism of the partner, too expensive or difficult to obtain, another reason).

In addition to the information described above, specific information about EC was considered in analysis of EC use following discontinuation. It included:

- Knows anyone who has used EC (no/yes);

- Past use of EC, including number of times (once, twice, three or more times) and timing of last use (up to two years ago, three or more years ago, do not remember);

- Ever had unprotected intercourse and not used EC (no/yes);

- Contraceptive method used at the time of EC use (oral pill, condom, withdrawal/fertility-awareness, injectable, other methods, no contraception).

Descriptive information about EC was also used to illustrate the circumstances of EC use. For each instance of EC use, we considered the following information:

- Reasons for using EC (by sheer insecurity, forgot to use some contraceptive method, the contraceptive method that was using failed, I did not want to use any contraceptive method, I was a victim of sexual violence);

- Person who took the initiative to use EC (woman, partner, both);

- prescription for EC (no/yes);

- EC source (pharmacy; boyfriend who brought; private doctor/health insurance; and national health system, which included primary health care and the Unified Health System, SUS).

- Timing of EC use after unprotected intercourse (<24 hours, $1-5$ days; $\geq 6$ days, do not remember).

\subsection{STATISTICAL ANALYSIS}

\subsubsection{Descriptive results}

Descriptive statistics of the study sample were conducted according to the sociodemographic characteristics, educational background, and sexual/reproductive/contraceptive indicators. In addition, we conducted a descriptive 
analysis of the sample according to type of contraceptive method used at baseline (oral pill, male condom, and other methods, i.e., methods less used among Brazilian women such as: injectable, withdrawal/fertility-awareness, patch, intrauterine device, diaphragms, implants, vaginal ring, female condoms, and spermicide). "Baseline", was defined as the earliest month in the 12-months calendar, i.e., the month farthest back in time. For women who reported using dual protection (oral pill and male condom), we prioritized the most effective method based on failure rates (Trussell, 2011; CDC, 2013), that is, they were included in the group "oral pill users".

\subsubsection{Contraceptive discontinuation analysis}

Analyzes of contraceptive discontinuation were performed in several steps: women level analysis, monthly discontinuation of contraception analysis, and contraceptive episode level analysis.

\section{Women level analysis}

Using women as the unit of observation, this analysis focused on frequency of discontinuation in the 12 months of observation.

1) To compare women who never discontinued their contraception over the last 12 months, to those who discontinued once and those who discontinued more than once, a bivariate analysis was conducted to investigate women's sociodemographic and sexual reproductive health characteristics according to the frequency of method discontinuation within the last 12-months. We consider two measures of discontinuation as previously described: discontinuation for any method, and discontinuation for method-related reasons. Abandonment or switching to less effective method was not contemplated in this analysis due to the small number of women who had switched or abandoned their method more than once $(n=20)$. Pearson's Chi-square test was used to assess the relationships between women's characteristics and method discontinuation.

2) The analysis of the determinants of contraceptive discontinuation according to the number of times a method was discontinued, was carried out using multinomial logistic regression, as the dependent variable was defined in three categories: no discontinuation (reference), 1 discontinuation, and $>1$ 
discontinuation (high rank of discontinuation). Multivariate analysis included the following independent variables: age, and race/ethnicity as well as factors that were the most likely associated with method discontinuation in bivariate analysis ( $p$ value $<0.10$ ) The criteria for including variables in the multinomial analysis were not only those that showed significance in the bivariate analysis, but also variables based on conceptual framework, that is, factors identified by previous studies as related to contraceptive use and discontinuation (as age, race/ethnicity, and religion). Previous pregnancy was not included in the multinomial analysis due to the small number of women reporting a previous pregnancy. The final model was chosen by using the Akaike Information Criterion (AIC), which measures the relative quality of statistical models, i.e., how well a model fits a dataset. Adjusted odds ratios and 95\% confidence intervals were estimated.

\section{Monthly discontinuation of contraception analysis}

Using calendar months as the unit of observation, this analysis focused on monthly probability of contraceptive discontinuation.

1) Since the risk of pregnancy is higher among women who discontinue contraception but are still at risk of an unintended pregnancy, we evaluated reasons for method discontinuation for all monthly instances of discontinuation, by distinguishing: discontinuation for any reason, discontinuation for methodrelated reasons, and abandonment or switch to a less effective method. These analyzes were stratified by method type (oral pill and male condom - main contraception utilized among Brazilian women). There were too few episodes of other barrier methods to perform a stratified analysis for this third category.

In the absence of a starting date relative to the method reported the first month of the calendar, it was not possible to estimate duration of use, and therefore we focused our analysis on monthly probabilities of discontinuation irrespective of the time women had been on the method. We exclude the last month of calendar data since information about discontinuation the following month is unavailable ("right-censored"). 
We evaluated the factors related to each of the "measures" of discontinuation for pills and for condoms using Chi-square tests (with a significance threshold adopted was $5 \%(p \leq 0.05))$.

Because women contributed 12 monthly observations, i.e., analysis of monthly discontinuation need to take into account correlations between months contributed by the same women. Accordingly, we used Generalized Estimating Equations (GEE). GEE is utilized in longitudinal data, and provides adjusted estimates for multiple observations contributed by the same individual (Liang, Zeger, 1986). Specifically, GEE is based on generalized linear models, and includes a working correlation matrix between observations belonging to the same individual. The specification of the correlation structure was conducted considering three possible structures: exchangeable, unstructured, and autoregressive. An exchangeable correlation structure means the correlation between observations belonging to the same individual remains the same over time. An unstructured correlation structure means that a different correlation value is assumed for each observation within the group, and the auto-regressive correlation structure is used when the data are correlated over time (Ballinger, 2004; Agranonik, 2009). The correlation structure which was more suited to the data and adopted in the final GEE model was exchangeable with logit link transformation function. The selection of the most appropriate correlation structure, was based on the Quasi-likelihood under the Independence Model Criterion (QIC) (APPENDIX D). Adjusted odds ratios and 95\% confidence intervals were estimated. We also included factors showing stronger associations in the bivariate analysis.

\section{Contraceptive episode level analysis}

Using a new contraceptive episode (segment of use of a particular method without stopping) as the unit of observation, this analysis focused on cumulative probability of discontinuation of episodes started in the last 12 months

1) Kaplan-Meier life-table were conducted to estimate the probabilities of contraceptive discontinuation (discontinuation for any reason, discontinuation for method-related reasons, and for abandonment or switching to less effective 
method) over time for new users. The analyzes were stratified by method type (oral pill or male condom). Only episodes that started during the calendar (new episodes), are included since the duration of use of methods started before the calendar is unknown (left censoring). Episodes that are still ongoing at the time of the survey were included and treated as right censored. The Log-Rank test was used to assess the differences in discontinuation rates by women's characteristics (Log-Rank test).

2) Cox proportional hazards models were used to estimate factors associate with method discontinuation in multivariate analysis. Separate models stratified by method type (oral pill or male condom), were run for: discontinuation for any reason, discontinuation for method-related reasons, and for abandonment or switching to less effective method. Shoenfeld Residuals test were used to assess the assumption that Hazard Ratios were proportionate over time for all covariates. Adjusted hazard ratios and $95 \%$ confidence intervals were estimated.

\subsubsection{Emergency contraception analysis based on contraceptive calendar (12-months of observation)}

We first explored the circumstances of EC use in last time it was used, among all women EC users and among who last used EC in the last 12-months.

Monthly discontinuation of contraception analysis

We explore factors associated with using EC following contraceptive discontinuation for method-related reasons, and conducted the same analysis focused on EC use after method abandonment during the 12-months prior to the survey. The comparison was between women used EC after discontinuing their method for method-related reasons versus those who did not use EC after discontinuing their method. Similarly, we distinguished women who used EC after method abandonment and those who did not use EC after method abandonment.

Next, we investigated the correlates of EC use in the context of inconsistent use of contraception (it includes instances of EC use following method switching and instances of EC use following inconsistent use of contraception that was not 
discontinued), versus EC use in the context of non-regular contraception (includes instances of EC use following method abandonment and instances of EC use following month where no contraception was used).

We do not explore EC use after discontinuation for any reason, since some woman stop contraception because they want to become pregnant or do not have partner, in which case EC is not needed.

Pearson's Chi-square tests were conducted to assess the relationships between EC use and each independent variable.

\subsubsection{Emergency contraception analysis based on EC calendar (2- months of observation, 30 days before and 30 days after EC use)}

\section{Women level analysis}

1) First, a bivariate analysis was conducted to investigate women's sociodemographic and sexual reproductive health characteristics according to the use of contraception within 30 days after EC use, using the EC calendar data. Highlights that we consider use of contraception within 30 days before EC as a key predictor of post EC contraceptive. The analysis of the determinants of using contraception within 30 days after EC use, was carried out using multivariate logistic regression. The criteria for including variables in the multivariate analysis were not only those that showed significance in the bivariate analysis, but also variables based on conceptual framework, that is, factors identified by previous studies as related to contraceptive use after EC use (as age, race/ethnicity, religion, socioeconomic status, and time since first sexual intercourse). Hosmer and Lemeshow's Test was used to assess how well the model fits the data. Adjusted odds ratios and $95 \%$ confidence intervals were estimated.

2) Second to analyze how EC affects contraceptive trajectories, we assessed changes in contraceptive use before and after EC use, using the EC calendar. We distinguished women who had no change in contraception after EC use (reference), women who switched to more effective method after EC use, and women who switched to less effective method after EC use. We consider use of 
contraception within 30 days before EC as a key predictor of post EC contraceptive. After conducting bivariate analysis, multinomial regression models were performed (dependent variable defined as a 3-categorical variable). Adjusted odds ratios and $95 \%$ confidence intervals were estimated. The final model was chosen based on prior knowledge and based on Akaike Information Criterion (AIC).

3) Finally, we investigated gaps in contraceptive use within 30-days post EC use, among all women who used contraception after EC, using EC calendar.

We stress that in all analysis, it was considered the last time that EC was used in the EC calendar. Pearson's Chi-square tests were conducted to identify the determinants of contraceptive use after EC and changes in contraceptive use after EC. All analyses were conducted using Stata 14.2 (Stata Corporation, College Station, TX, USA). 
4.CHAPTER FOUR 



\section{CHAPTER FOUR}

\section{CONTRACEPTIVE DISCONTINUATION (CONTRACEPTIVE CALENDAR)}

\subsection{BACKGROUND OF THE STUDY}

\subsubsection{Introduction}

Brazil has recently undergone a rapid fertility transition with total fertility rates dropping below replacement, from 2.5 in 1996 to 1.8 in 2006 (Brasil, 2008a). At the same time, Brazil has seen a dramatic increase in modern contraceptive prevalence rates, estimated at $77 \%$ in the last national survey conducted in 2006 (Brasil, 2008a). However, despite advances in the use of contraception and low unmet need for modern contraception $(6 \%)$, almost $46 \%$ of pregnancies are reported as unintended in Brazil (Brasil, 2008a; Berquó, Lima, 2008), a situation that is comparable to other countries with high contraceptive coverage (Bajos et al., 2014, Moreau et al., 2014; Wellings et al., 2015; Finer, Zolna, 2016).

The highest burden of unintended pregnancies across most developed countries, including Brazil, falls on youth (ages 15 to 24) who are at the peak of their fertile years (Berquó, Lima, 2008; IBGE, 2010; Diamond-Smith, Moreau, Bishai, 2014; Wellings et al., 2015; Coetzee, Ngunyulu, 2015; Finer, 2016; Moreau, Bohet, 2016). Youth population ( $20-24$ years old) represent $17.9 \%$ of the population in Brazil, but account for $25 \%$ of unintended pregnancies (Berquó, Lima, 2008; IBGE, 2010). In case of unintended pregnancies, young women are also more likely to have an induced abortion, with peak of lifetime experience observed between 20 and 24 years (24\% in this age group in Brazil) (Diniz, Medeiros, 2010). Social changes towards delaying the first birth are extending the number of years young women are exposed to the risk of unintended pregnancies. Specifically, the proportion of women at first birth aged 30 years has grown in the last decade in Brazil, which means that the gap between age at first sex (which has remained stable) and age at first is growing in some segments of the population (Brasil, 2008a; Brasil, 2014; IBGE, 
2015). As a result, there is a growing population of youth exposed to a potential risk of unintended pregnancy.

Most unintended pregnancies are due to inconsistent use or gaps in use of contraception (Goulard et al., 2006; Frost, Darroch, 2008), which raises the issue of method choice and dynamics of use. The contraceptive landscape in Brazil is dominated by oral pills and male condoms that are associated with high discontinuation rates and moderate failure rates (Brazil, 2008a; Kost et al., 2008; Trussell, 2011). In this context, contraceptive discontinuation is defined as switching a method of contraception or stopping a method altogether. Indicators typically discern discontinuation for any reason or for method-related reasons. The latter is potentially more concerning because women are still exposed to the risk of pregnancy when they stop their method (sterile or no partner) (Trussell, Vaughan, 1999). Altogether, $47.1 \%$ of all methods are discontinued for method-related reasons within 12-months in the U.S., compared with 27.8\% in Brazil (Vaughan et al., 2008; Ali, Cleland, Shah, 2012). Discontinuation rates methods for method-related reasons are particularly high in the case of user dependent methods (Ali, Cleland, Shah, 2012; Alano et al, 2012; Silva et al., 2010; Silva Camargo, Iwamoto, 2014). Many factors are related to discontinuation, including external factors (such as quality of family planning services, family planning service environment, guidelines, among others), and internal factors (such as demographic characteristics, partner, and fertility motivations) (Curtis, Blanc, 1997; Ali, Cleland, 1999; Curtis, Evens, Sambisa, 2011; Barden-O'Fallon, 2011a; Moreau et al., 2013).

Contraceptive use dynamics is of particular relevance to undergraduate students represent with high educational and professional aspirations, who are especially motivated to delay childbearing until they reach professional stability (Longo et al., 2002; Sant'Anna et al., 2008; Veloso et al., 2014). While overall pregnancy rates are lower in this population compared to their less educated peers (Finer, Zolna, 2016), a higher proportion of these pregnancies are unintended (60\%), and are mostly related to contraceptive discontinuation (Bryant 2009; Trieu et al., 2011). A study conducted amongst undergraduate students in the U.S. estimated that continuous use of contraception could prevent about 12 million unwanted pregnancies every year among this population (Ersek et al., 2011). In Brazil, studies conducted among undergraduate students in Minas Gerais and Paraná states found that $29.3 \%$ and $65.9 \%$ of students respectively, had used contraceptive methods inconsistently 
despite high levels of knowledge about contraception (Dessunti, Kings, 2012; Silva, Camargo, Iwamoto, 2014). As a result, young people with higher education are 3.8 times more likely to have an induced abortion than less educated youth, which contributes to potential maternal morbidity in the context of restrictive laws on abortion such as in Brazil (Pirotta, Schor, 2004; Menezes, Aquino, 2009; Dessunti, Kings, 2012; Silva, Camargo, Iwamoto, 2014).

In summary, a high proportion of young women are at risk of unintended pregnancies and, among those, university students represent a singular group with both high prevalence of contraception and high rates of contraceptive discontinuation. Investigating contraceptive use patterns among highly educated women allows us to understand such dynamics in a "privileged" population, which is less likely to face access barriers relative to lower socioeconomic populations. The frequency and extent of contraceptive gaps among young women in Brazil nowadays is not well documented. The latest data about contraceptive discontinuation in Brazil dates back to the DHS survey conducted in 1996 (Brazil, 2008a) with little insights on how overall practices and user dynamics have evolved since, and no insights on these issues among young women. The present study focuses on highly educated young women who are most motivated to prevent pregnancy.

\subsubsection{Aims of study}

The aim of this study is to assess the frequency and correlates of methodspecific contraceptive discontinuation within a period of 12 months. We also aim to identify sociodemographic and reproductive health factors related to the frequency of discontinuation ( 0,1 instance, $>1$ instance of method discontinuation) within the last 12 months. The research questions will address are:

- How often do women discontinue their method of contraception in a 12months period and what are the differences between woman who did not discontinue their method in the period of 12 months, woman who discontinued their method once, and those who had several episodes of discontinuation in the period of 12 months?

- What is the monthly probability of method discontinuation and the correlates of such events? 
- What is the cumulative probability of discontinuation of new episodes of contraception and the correlates of such events?

\subsection{METHODOLOGY}

This section outlines the sample, data collection procedures, measures and the stastical method used for the analysis.

\subsubsection{Study population and survey site}

A 12-month retrospective cohort study was conducted on a sample of undergraduate women from University of São Paulo, Brazil (the largest institution of higher education and research in Brazil), between June and July, 2015. Women between the ages of 18 and 24 years old enrolled in regular undergraduate course in any campus at University of São Paulo, Brazil, were eligible to participate in the study. They were selected by simple random sampling without replacement, and they were chosen electronically based on a list of all the email addresses of undergraduate students enrolled in the Electronic Computer Center of the University of São Paulo, organized alphabetically. The study obtained ethical approval from the Research Ethics Committee at University of São Paulo School of Nursing (CAAE Number: 39142514.4.0000.5392) (ANNEX I), an electronic message was sent to all students who were selected to participate in the study. The research project was described in the email, and the student who had an interest in participating in the study could click on the study to complete a consent form (APPENDIX A).

\subsubsection{Sampling}

A total of 3,078 women were randomly selected and invited to participate in the study. These women received an electronic message describing the research project and inviting the student to participate after completing a consent form. Students received reminder emails weekly to participate in the study (on average 10 times).

A total of 2,182 undergraduate students (71\%) answered the online questionnaire. However, the final study population comprised 1,679 undergraduate 
students between 18 and 24 years of age, since 50 women refused to participate in the study, and 453 students were not eligible for the study ( $<18$ years old $(n=2)$, had never had sexual intercourse $(n=358)$, and had not used any contraceptive method in the last 12 months $(n=93))$.

\subsubsection{Data collection and study instruments}

The data were collected online through Google Form, using a self-administered questionnaire that was previously pre-tested and took, on average, 5-7 minutes to complete (APPENDICES B AND C). The survey questionnaire collected information on sociodemographic characteristics, sexual and reproductive antecedents, and use of contraceptive methods in the 12 months prior to the survey. Women who reported that they used contraception in the past 12-months, completed a contraceptive calendar on a month-by-month basis (Bradley, Schwandt, Khan, 2009). In the contraceptive calendar the main methods were listed, and young women could select just one answer, that is, they were asked about the main contraception that they used per month. In addition, for each month in the calendar, the student provided information about the reasons for discontinuation, occurrence of pregnancy and their relational status with a partner.

\subsubsection{Unit of analysis}

We consider three levels of analysis for this chapter, women level analysis, monthly discontinuation of contraception analysis, and the contraceptive episode level analysis.

- Women level sample: as described above, we consider a sample of 1,679 women for which we assess the prevalence and frequency of method discontinuation within 12 months.

- Monthly discontinuation of contraception sample: we partition the contraceptive calendar into 12-months of contraceptive use. Each woman contributes up 12 months of observation, based on number of months she used contraception. A total of 18,469 months of use were identified and are 
used as the analytical sample to investigate the factors related to methodspecific monthly probability of discontinuation.

- Contraceptive episode level sample: we partition the contraceptive calendar into segments of contraceptive use, defined as continuous months of use of the same method. Each woman contributes one or several episodes of contraception, based on the number of times she switches within the calendar year. A total of 3,937 episodes of use were identified. Among these, 1,230 were started during the calendar (new episodes), and are used as the analytical sample to investigate cumulative probabilities of discontinuation of new episodes of contraception.

\subsubsection{Measures}

\section{Contraceptive discontinuation}

We define three measures of discontinuation: "discontinuation for any reason", "discontinuation for method related reasons", and "abandonment or switched to less effective method". These indicators are measured for each episode of use of contraception:

- "Discontinuation for any reason" refers to any instance when women stopped using their method regardless of the reason and regardless of what they did next (switched to another method or abandoned contraception).

- "Discontinuation for method-related reason" related to any instance when women stopped using their method while still in need of contraception (with a partner, not pregnant, not trying to conceive, not sterile), regardless of what they did next (switched to another method or abandoned contraception).

- "Abandonment or switched to less effective method" refers to any instance when women stopped using their method while still in need of contraception (with a partner, not pregnant, not trying to conceive, not sterile) and switched to a less effective method or abandoned contraception. We considered that women had switched to a less effective method if they initiated a method that was less effective than their previous method and if they were using the new method within a month of discontinuing the previous one. On the other hand, 
we considered that women had abandoned their method if they did not resume contraception within a month of discontinuation.

These three measures represent different levels of risk relative to unintended pregnancy, from lower to higher. Discontinuation for any reason includes women who stop their method because they are no longer at risk of pregnancy (no partner, sterile) or because they want to become pregnant. Discontinuation for method-related reasons only considers as a discontinuation an instance when women stop their method but are still exposed to the risk of unintended pregnancy (women who are no longer at risk are not discontinuing for methodrelated reasons, and therefore coded " 0 " for this measure). Finally, "Abandonment or switched to less effective method" only counts as discontinuation instances when women stop their method while still at risk and switch to a less effective method or to no method. Women who are no longer at risk or who switch to a more effective method are not switching to a less effective method or abandoning their method, and therefore coded "0" for this variable. An example of "abandonment or switched to less effective method" would be when women who switch from condom to withdrawal/ fertility-awareness/ spermicide; or who switch from oral pill to condom/ withdrawal/ fertility-awareness/ spermicide/ diaphragms. Method effectiveness is determined based on typical use failure rates that are published in the literature (Trussell, 2011).

We also define a summary measure for each woman indicating if she has discontinued any method in the 12-month period of observation. This summary measure is defined in 3 categories (any discontinuation, discontinued once, and discontinued>1), and it is an indicator measure for each individual woman.

\section{Women's sociodemographic and reproductive health history measures}

We consider women's sociodemographic characteristics as predictors of contraceptive discontinuation based on previous research findings. Specifically, we include age (18-19 or 20-24); race/ethnicity (white, black, other); religious affiliation (none, roman catholic, kardecista spiritualism doctrine, evangelical, other); socioeconomic status (high (A/B) - middle/low (C/D/E)) (ABEP, 2015). 
Because this study focuses on university students, we will consider their educational characteristics. This information includes field of study (human sciences, health sciences, exact sciences); period of study (full-time or part-time); and campus (São Paulo, countryside).

Sexual and reproductive health indicators are shown to be strongly associated with contraceptive discontinuation. In our study, we consider the type of relationship (steady, such as with boyfriend or living with a partner, casual relationship); time since first sexual intercourse ( $\leq 1$ year, 2-3 years, $\geq 5$ years); number of lifetime sexual partners (1 partner, 2-3 partners, $\geq 4$ partners); pregnancy history (no/yes); current contraceptive method (highly effective method or non-highly effective method).

\subsubsection{Statistical analysis}

Women level analysis

We first described the sociodemographic and sexual and reproductive indicators of the study sample and describe the distribution and correlates of women's contraceptive behaviors at baseline (first month of contraceptive calendar, recorded 12 months prior to the survey).

We then investigated women's sociodemographic and sexual reproductive health characteristics according to frequency of method discontinuation within the last 12 months. We distinguished women who had discontinued their method once, more than once or who never discontinued (reference). Method discontinuation was defined according to the two measures: discontinuation for any method, discontinuation for method related reasons. We did not investigate the factors related to abandonment or switching to less effective method as only 20 women had switched or abandoned their method more than once. After conducting bivariate analysis, multinomial regression models were performed (dependent variable defined as a 3-categorical variable). The multinomial analysis was adjusted for age, and race/ethnicity. Adjusted odds ratios and $95 \%$ confidence intervals were estimated. The final model was chosen based on prior knowledge and based on Akaike Information Criterion (AIC). 
Monthly discontinuation of contraception analysis

We investigated the correlates of monthly discontinuation for any reason, method related reasons and due to abandonment or switching to less effective contraception using bivariate and logistic regression techniques. We also conducted this analysis stratified by type of contraceptive method (oral pill or male condom). There were too few months of use of other barrier methods to perform a stratified analysis for this third category. Because women could contribute several months of contraceptive use, such months were not independent of each other. Therefore, after fitting the best logistic model, we conducted the analysis using Generalized Estimating Equation (GEE) modelling that accounts for intra-correlation among the months belonging to the same individual. We used an exchangeable correlation structure with logit link transformation function, i.e., the correlation among the observations of the individuals was based on the correlation matrix, and the value of QIC (APPENDIX D). Adjusted odds ratios and 95\% confidence intervals were estimated.

\section{Contraceptive episode level analysis}

Kaplan-Meier life-table were conducted to estimate the probabilities of contraceptive discontinuation over time for new users. Separate analysis stratified by method type (oral pill or condom), were run for: discontinuation for any reason, discontinuation for method-related reasons, and for abandonment or switching to less effective method. Only episodes that started during the calendar (new episodes) were considered in this analysis, i.e., episodes started before the $1^{\text {st }}$ month prior to the survey were excluded as the exact date of start was not known (left censoring); whereas the episodes which were ongoing at the time of survey (right censoring) were included and treated as censored. The Log-Rank test was used to assess the differences in discontinuation rates by women's characteristics (Log-Rank test). Lastly, Cox proportional hazards models were performed to evaluate the independent effect of each factor in multivariate analysis. A hazard ratio (HR) below 1.0 means that increases in the covariate reduces the hazard ("risk" or "likelihood") of discontinuation, while a HR above 1.0 increase the probability of discontinuation. Shoenfeld Residuals test were 
used to assess the assumption that HRs were proportionate over time for all covariates. Adjusted hazard ratios and $95 \%$ confidence intervals were estimated. All analyses were conducted using Stata 14.2 (Stata Corporation, College Station, TX, USA).

\subsection{RESULTS}

\subsubsection{Descriptive statistics}

The young women were, on average 21 years old (standard deviation=1.59), were white (caucasian), reported having no religion, were single and had a stable relationship. Most women were enrolled in the Human Sciences full-time program in São Paulo capital, and were from a high/medium socioeconomic status (Table 1). In addition, most young women had no scholarship (74.4\%), and only 169 (10.1\%) had wage labor with a formal contract (data not shown in table).

The average age of sexual debut was 17 years old ( $\mathrm{sd}=1.88$ ), with $17.3 \%$ reporting first intercourse before the age of 15 . Only $37(2.2 \%)$ women mentioned having been pregnant in the past, and $24(64.86 \%)$ of these pregnancies ended in abortion. The average age at first pregnancy was 19 years old $(\mathrm{sd}=2.13)$, and the majority of women $(n=32)$ who reported a pregnancy had been pregnant only once (data not shown in table).

A majority of young women were using contraception at the time of the survey (mainly oral contraception) and $92.61 \%$ had used a method at last intercourse. Likewise, $94.75 \%$ of women reported using a method 12 months prior to the survey (baseline corresponding to the earliest calendar month recorded). The distribution and determinants of contraceptive use at baseline are presented in the next section. 
Table 1 - Sociodemographic and sexual and reproductive health characteristics of undergraduate women in the sample. São Paulo, Brazil - 2015

\begin{tabular}{|c|c|c|}
\hline \multirow{2}{*}{ VARIABLES } & \multicolumn{2}{|c|}{ TOTAL } \\
\hline & $\mathbf{N}$ & $\%$ \\
\hline \multicolumn{3}{|l|}{ Sociodemographic characteristics } \\
\hline \multicolumn{3}{|l|}{ Age (years) } \\
\hline $18-19$ & 402 & 23.9 \\
\hline $20-24$ & 1277 & 76.1 \\
\hline \multicolumn{3}{|l|}{ Race/ethnicity } \\
\hline White (caucasian) & 1353 & 80.6 \\
\hline Black & 228 & 13.6 \\
\hline Other race/ethnicity* & 98 & 5.8 \\
\hline \multicolumn{3}{|l|}{ Religion } \\
\hline No religion & 775 & 46.2 \\
\hline Roman Catholic & 526 & 31.3 \\
\hline Kardecist Spiritualism Doctrine & 203 & 12.1 \\
\hline Evangelical & 105 & 6.3 \\
\hline Other religion ${ }^{* *}$ & 70 & 4.2 \\
\hline \multicolumn{3}{|l|}{ Type of relationship } \\
\hline Steady & 1102 & 65.6 \\
\hline Casual relationship or None & 577 & 34.4 \\
\hline \multicolumn{3}{|l|}{ Socioeconomic status } \\
\hline$A / B$ & 1326 & 79.0 \\
\hline$C-D / E$ & 353 & 21.0 \\
\hline \multicolumn{3}{|l|}{ Educational background } \\
\hline \multicolumn{3}{|l|}{ Field of study } \\
\hline Human Sciences & 688 & 41.0 \\
\hline Health Sciences & 621 & 37.0 \\
\hline Exact Sciences & 370 & 22.0 \\
\hline \multicolumn{3}{|l|}{ Period of study } \\
\hline Full-time & 855 & 50.9 \\
\hline Part-time & 824 & 49.1 \\
\hline \multicolumn{3}{|l|}{ Campus } \\
\hline São Paulo & 1106 & 65.9 \\
\hline Out of São Paulo & 573 & 34.1 \\
\hline
\end{tabular}


(continuação)

TOTAL

VARIABLES

N $\quad \%$

Sexual, reproductive and contraceptive behavior

Time since first sexual intercourse

$\leq 1$ years

$2-3$ years

$\geq 4$ years

Number of sexual partners in lifetime

1 partner

$2-3$ partners

$\geq 4$ partners

\section{Previous pregnancy}

No

Yes

\section{Current use of contraceptive method}

No

Yes

Type of current contraceptive method ( $n=1547)$

Highly effective method ${ }^{* * *}$

Non-highly effective method ${ }^{* * * *}$

Use of contraceptive method at the last sexual intercourse

No

Yes

Type of contraceptive method at the last sexual intercourse $(n=1555)$

Highly effective method ${ }^{* * *}$

\section{Use of contraceptive method at baseline (first calendar month)}

No

Yes

Type of contraceptive method at baseline (first calendar month)

Highly effective method ${ }^{* * *}$

Non-highly effective method ${ }^{* * * *}$

*Other race/ ethnicity include: asian origin and indigenous people.

${ }^{* *}$ Other religions include: Afro-Brazilian, Buddhism, Jewish, Muslim, Mormon, and Islam.

${ }^{* * *}$ Highly effective methods include: hormonal contraception and an intrauterine device.

${ }^{* * * *}$ Non-highly effective methods include: condoms, spermicides, fertility-awareness and withdrawal. 


\subsubsection{Descriptive statistics according to the type of contraceptive method used at baseline}

A majority of women $(70.9 \%)$ were using the pill 12-months prior to the survey, $23.7 \%$ used condoms while $5.4 \%$ relied on other natural or barrier methods. Associations between women's sociodemographic characteristics, sexual and reproductive health $(\mathrm{SRH})$ characteristics and the type of contraceptive method used at baseline are described in Table 2. While oral pills were the most popular methods used across all sociodemographic and SRH characteristics, results indicate higher pill usage among 20-24 year olds, among women who had more years of sexual experience, women who had had only one lifetime partner and who were in steady relationships. Conversely, young women (18-19 years old), women in casual relationships or who had more than one lifetime partner and had recently started their sexual life were more likely to rely on condoms. Condom use was also more frequent among women studying in the São Paulo campus.

Table 2 - Sociodemographic and sexual and reproductive health characteristics of undergraduate women in the sample according to the type of contraceptive method used at baseline. São Paulo, Brazil - 2015

\begin{tabular}{|c|c|c|c|c|}
\hline \multirow[t]{2}{*}{ VARIABLES } & $\begin{array}{c}\text { Oral pill } \\
(n=1190)\end{array}$ & $\begin{array}{l}\text { Condom } \\
(n=398)\end{array}$ & $\begin{array}{c}\text { Other } \\
\text { methods } \\
(n=91)\end{array}$ & \multirow[t]{2}{*}{$\mathbf{p}^{*}$} \\
\hline & $\%$ & $\%$ & $\%$ & \\
\hline \multicolumn{5}{|c|}{ Sociodemographic characteristics } \\
\hline Age (years) & & & & $<0.001$ \\
\hline $18-19$ & 63.0 & 31.3 & 5.7 & \\
\hline $20-24$ & 73.4 & 21.3 & 5.3 & \\
\hline Race/ethnicity & & & & 0.066 \\
\hline White (caucasian) & 72.3 & 22.3 & 5.4 & \\
\hline Black & 64.5 & 30.7 & 4.8 & \\
\hline Other race/ethnicity** & 66.3 & 26.5 & 7.1 & \\
\hline Religion & & & & 0.063 \\
\hline No religion & 69.0 & 24.9 & 6.1 & \\
\hline Roman Catholic & 73.4 & 21.9 & 4.8 & \\
\hline Kardecist Spiritualism Doctrine & 78.3 & 18.2 & 3.5 & \\
\hline Evangelical & 63.8 & 28.6 & 7.6 & \\
\hline Other religion ${ }^{* * *}$ & 61.4 & 32.9 & 5.7 & \\
\hline
\end{tabular}


(continuação)

\begin{tabular}{|c|c|c|c|c|}
\hline VARIABLES & $\begin{array}{l}\text { Oral pill } \\
(n=1190)\end{array}$ & $\begin{array}{c}\text { Condom } \\
(n=398)\end{array}$ & $\begin{array}{c}\text { Other } \\
\text { methods } \\
(n=91)\end{array}$ & $\mathbf{p}^{*}$ \\
\hline & $\%$ & $\%$ & $\%$ & \\
\hline Type of relationship & & & & 0.005 \\
\hline Steady & 73.4 & 21.3 & 5.3 & \\
\hline Casual relationship or None & 66.0 & 28.3 & 5.7 & \\
\hline Socioeconomic status & & & & 0.114 \\
\hline $\mathrm{A} / \mathrm{B}$ & 72.0 & 22.9 & 5.1 & \\
\hline$C-D / E$ & 66.6 & 26.6 & 6.8 & \\
\hline \multicolumn{5}{|l|}{ Educational background } \\
\hline Field of study & & & & 0.057 \\
\hline Human Sciences & 67.6 & 25.9 & 6.5 & \\
\hline Health Sciences & 71.7 & 23.0 & 5.3 & \\
\hline Exact Sciences & 75.7 & 20.8 & 3.5 & \\
\hline Period of study & & & & 0.138 \\
\hline Full-time & 73.0 & 22.2 & 4.8 & \\
\hline Part-time & 68.7 & 25.2 & 6.1 & \\
\hline Campus & & & & $<0.001$ \\
\hline São Paulo & 67.5 & 26.5 & 6.1 & \\
\hline Out of São Paulo & 77.5 & 18.3 & 4.2 & \\
\hline \multicolumn{5}{|c|}{ Sexual, reproductive and contraceptive behavior } \\
\hline Time since first sexual intercourse & & & & $<0.001$ \\
\hline$\leq 1$ year & 61.6 & 32.2 & 5.2 & \\
\hline $2-3$ years & 70.6 & 24.8 & 4.6 & \\
\hline$\geq 4$ years & 74.7 & 19.2 & 6.2 & \\
\hline Number of sexual partners in lifetime & & & & 0.004 \\
\hline 1 partner & 76.1 & 20.0 & 3.8 & \\
\hline $2-3$ partners & 66.0 & 27.8 & 6.2 & \\
\hline$\geq 4$ partners & 69.6 & 24.0 & 6.4 & \\
\hline Previous pregnancy & & & & 0.475 \\
\hline No & 71.1 & 23.6 & 5.4 & \\
\hline Yes & 62.2 & 29.7 & 8.1 & \\
\hline Total & 70.9 & 23.7 & 5.4 & \\
\hline
\end{tabular}

(conclusão)

${ }^{*}$ Pearson's chi-square test.

${ }^{* *}$ Race/ ethnicity include: asian origin and indigenous people.

${ }^{* * *}$ Other religions include: Afro-Brazilian, Buddhism, Jewish, Muslim, Mormon, and Islam.

****Highly effective methods include: hormonal contraception and an intrauterine device.

${ }^{* * * * *}$ Non-highly effective methods include: condoms, spermicides, fertility-awareness and withdrawal. 


\subsubsection{Characteristics of women who discontinue contraception}

Among the 1,679 women in the sample, 35.0\% $(n=587)$ discontinued a method in the last 12 months for any reason at least once, $27.63 \%(n=464)$ discontinued their method for method-related reasons and 18.2\% $(n=305)$ abandoned or switched to a less effective method. Alternatively, $10 \%$ of women still at risk of pregnancy $(n=159)$ switched to a more effective method (Figure 4). Side effects were the main reason for discontinuing oral pills for method-related reasons, while wanting a more effective method was the main reason for discontinuing a condom for method-related reasons. Reasons to method abandonment included side-effects for oral pill users, and criticism of the partner for male condom users (more details of method specific reasons for discontinuation by method are presented in APPENDIX E).

Figure 4 - Number of women discontinuing their method in the last 12-months, by measure of discontinuation and type of method used at the start of the contraceptive calendar (baseline). São Paulo, 2015

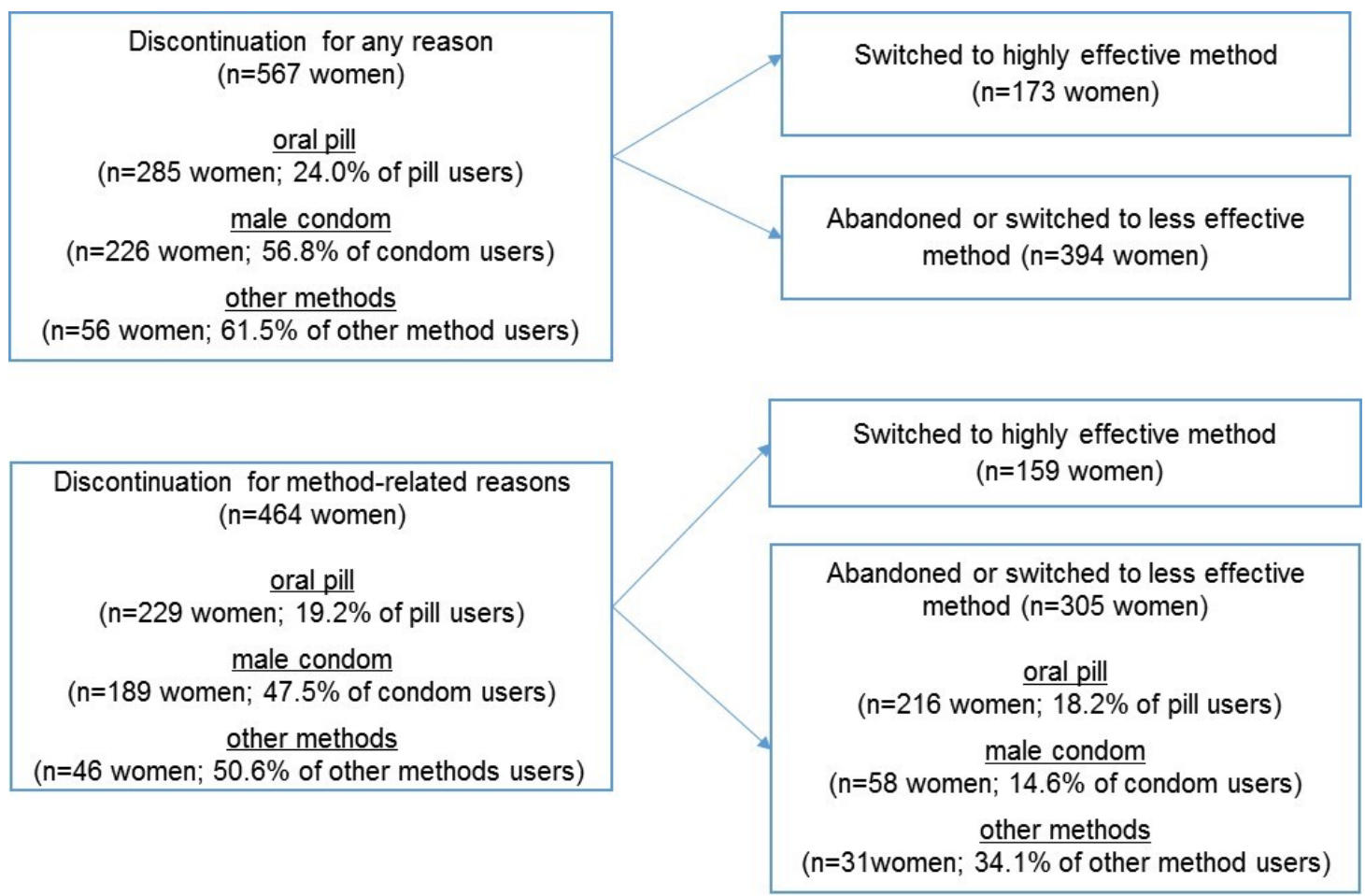

\subsubsection{Factors associated with women's contraceptive discontinuation according to frequency of discontinuation within 12 months}

We investigated women's sociodemographic and sexual reproductive health characteristics according to frequency of method discontinuation within the last 12 
months. We distinguished women who had discontinued their method once, more than once or who never discontinued.

Altogether, we found that $66 \%(n=1,112)$ of women never discontinued their method for any reason, $23.8 \%(n=400)$ discontinued their method for any reason once, and $9.9 \%(n=167)$ discontinued their method for any reason more than once. The same estimates related to discontinuation for method-related reasons indicate that $72 \%(n=1,215)$ never discontinued contraception for method-related reasons, $19 \%(n=322)$ discontinued their method for method-related reasons once, and 142 $(8.4 \%)$ discontinued for method-related reasons more than once.

Bivariate analyzes of factors related to the three groups (no discontinuation, discontinuation once or more than once) are presented in Table 3. Across the two indicators (discontinuation for any reason or for method-related reasons), discontinuation was mostly related to type of partnership and sexual and reproductive health indicators.

Women who reported several lifetime sexual partners were more likely to discontinue their method once or several times for any reason and for method-related reasons. Likewise, women in casual partnerships were more likely to discontinue their method for any reason or method-related reasons. Women who had been pregnant in the past and women using less effective methods at baseline (condom or other less effective methods) were also more likely to discontinue their method, relative to those who had never been pregnant or women using oral contraception at baseline.

Contraceptive discontinuation for method-related reasons also varied by women's sociodemographic background. Specifically, women from less privileged socioeconomic status (socioeconomic status $C-D / E$ ), were more likely to discontinue their method for method-related reasons, once and more than once. In addition, women who were part time students we more likely to discontinue their method for any or for method related reasons, as well as women enrolled in Human Sciences relative to other disciplines. Finally, women who reported other religious affiliation were more likely to discontinue for method-related reasons relative to other religious denominations. 


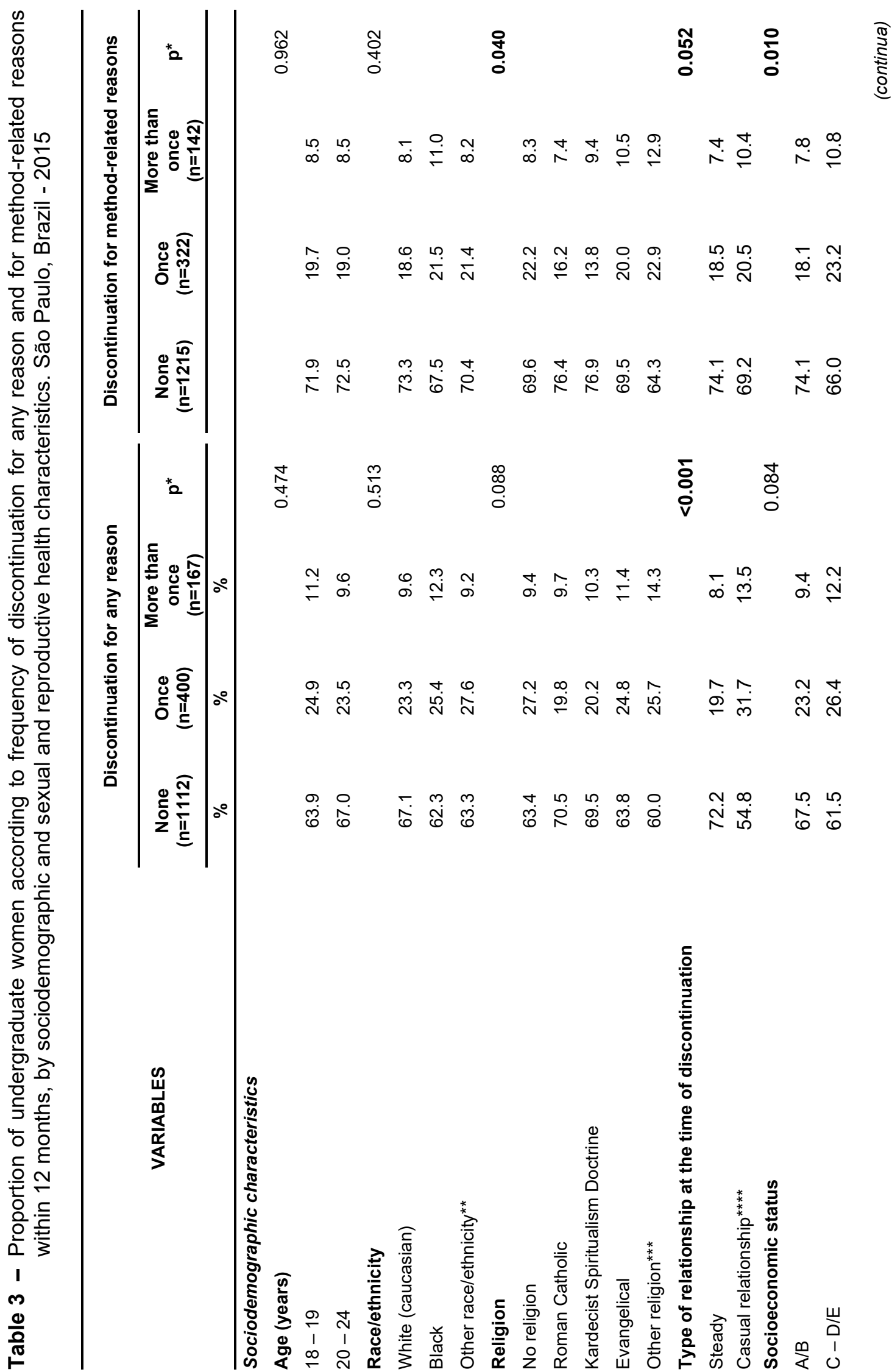




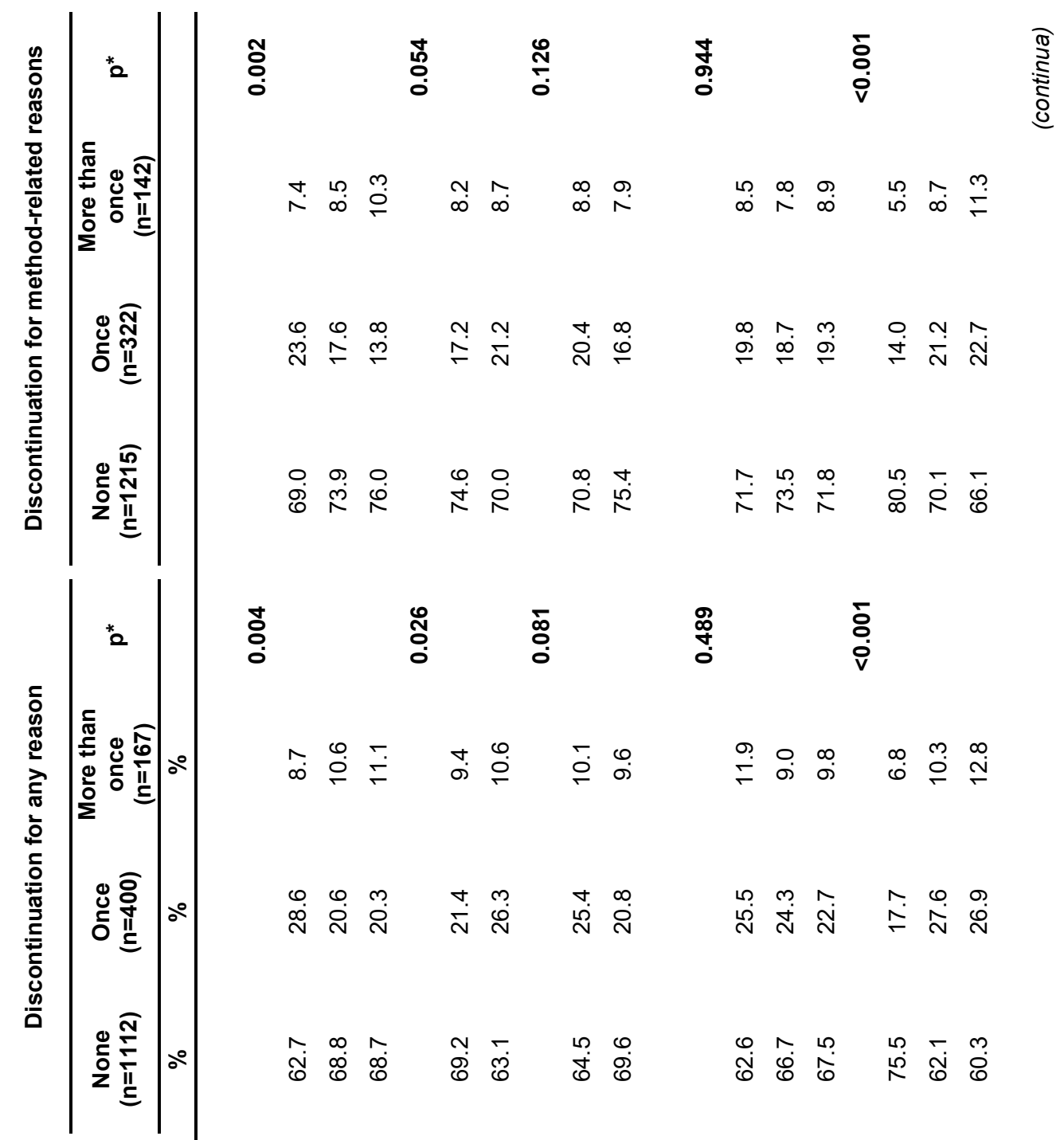

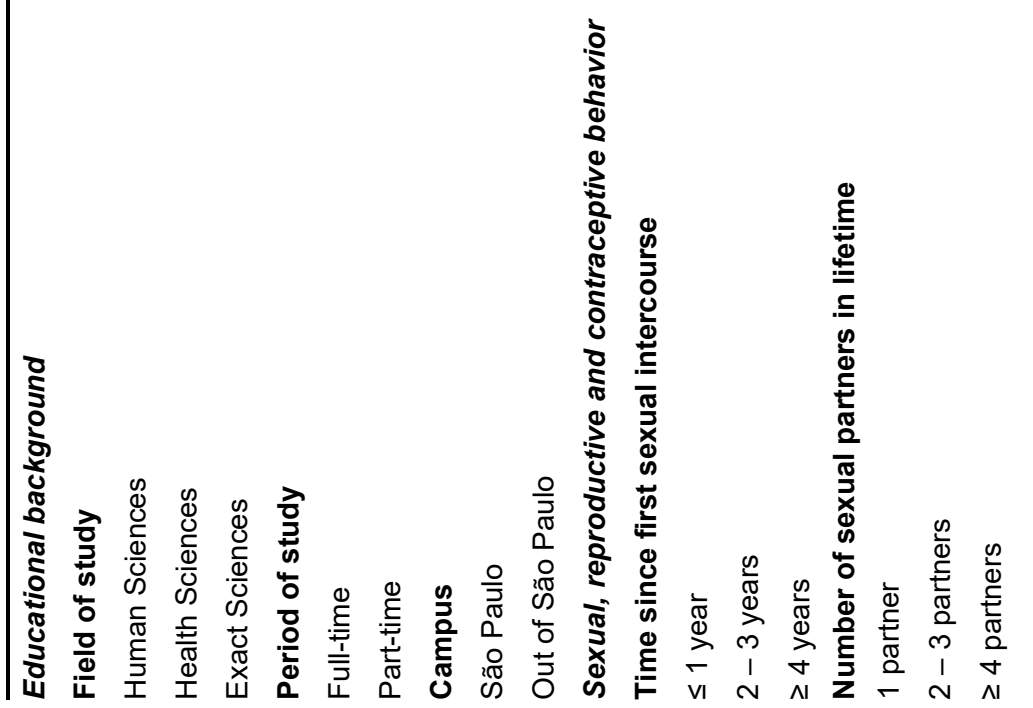




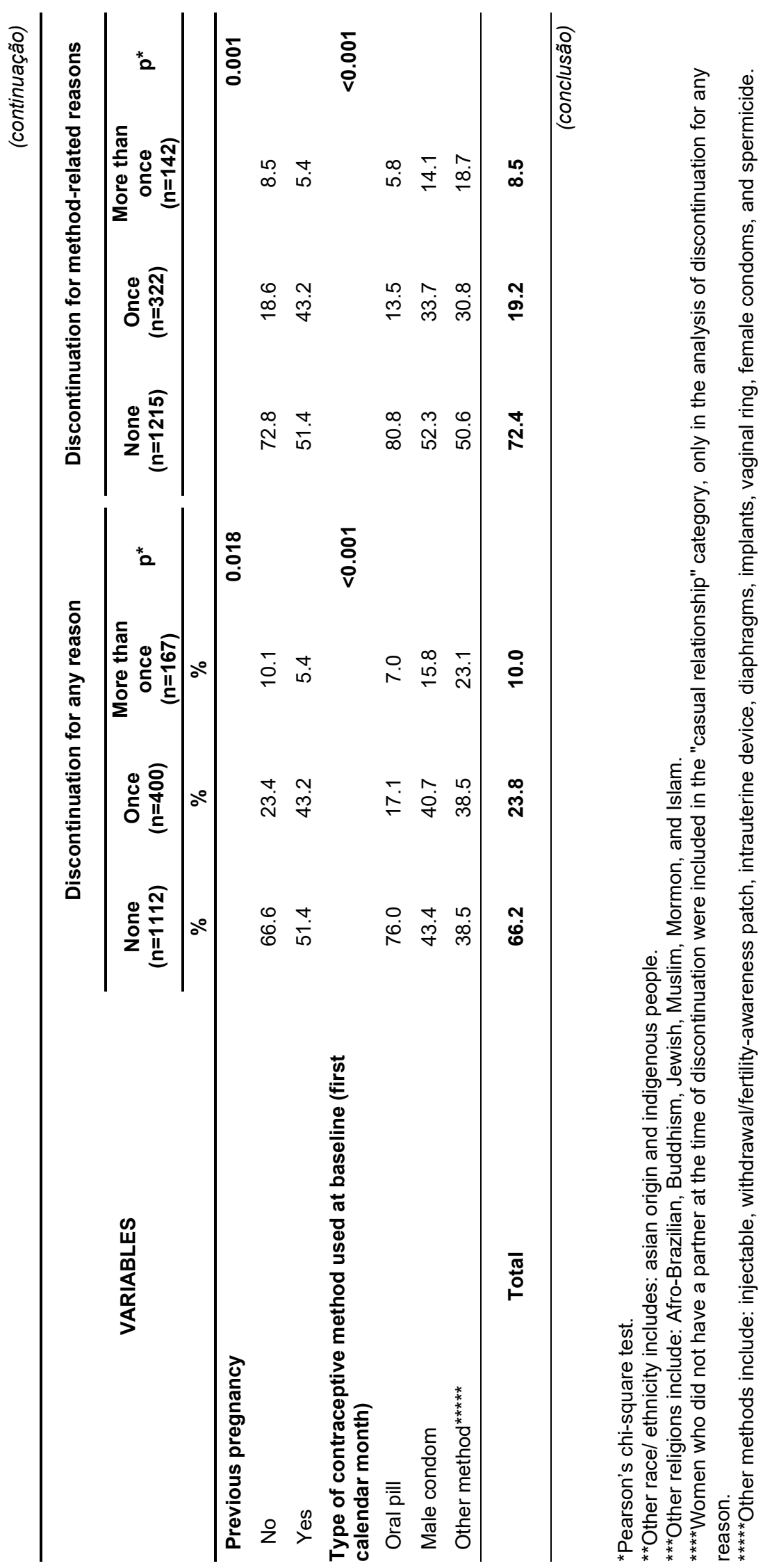


Subgroup comparison of women who discontinued once versus several times indicates that only field of study was related to multiple instances of discontinuation as opposed to one instance (Table 4). Women who were studying Exact Sciences were more likely to discontinue their method several times.

Only 12 women (1\% of the total sample) reported a pregnancy in the 12-months preceding the survey. Among those, 6 became pregnant because their method failed while the other 6 became pregnant after method discontinuation. Four (33.3\%) women who became pregnant reported that they were using the oral pill when the method failed or before discontinuation (data not shown in table). We emphasize that due to the few pregnancies observed in the 12-months, it was impossible to carry out deeper analyzes between pregnancies in the 12-months and contraceptive discontinuation. 


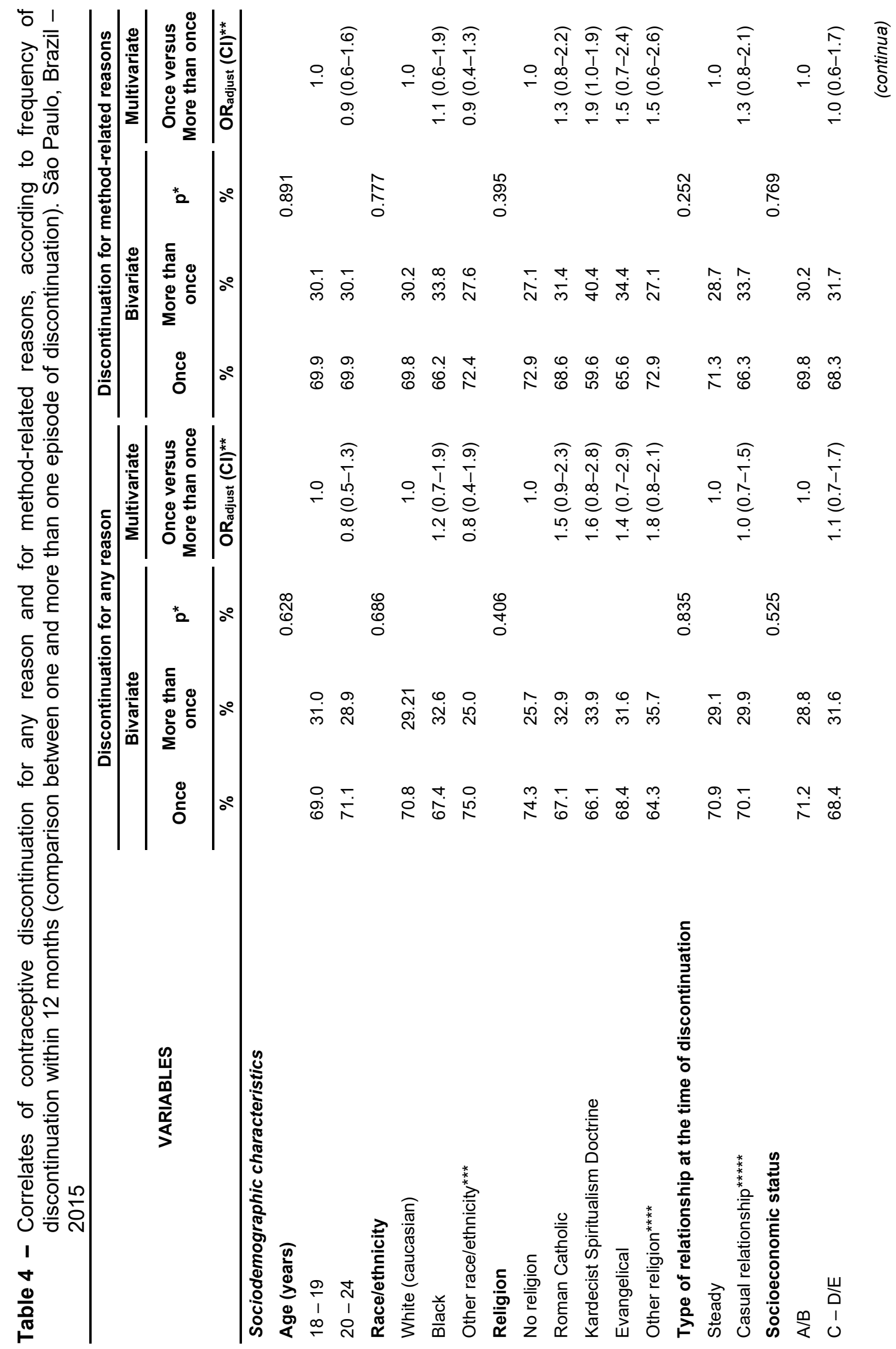




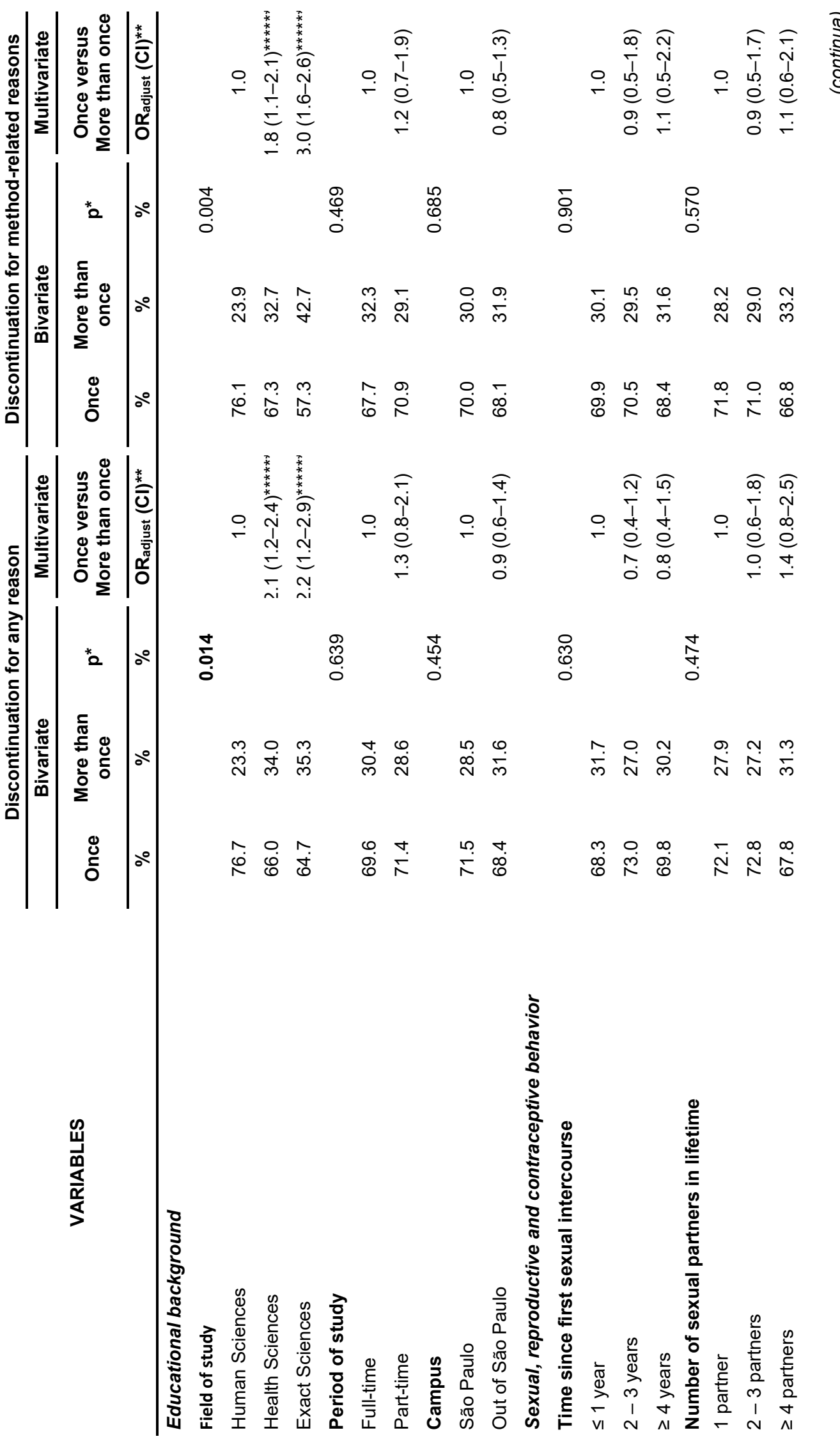



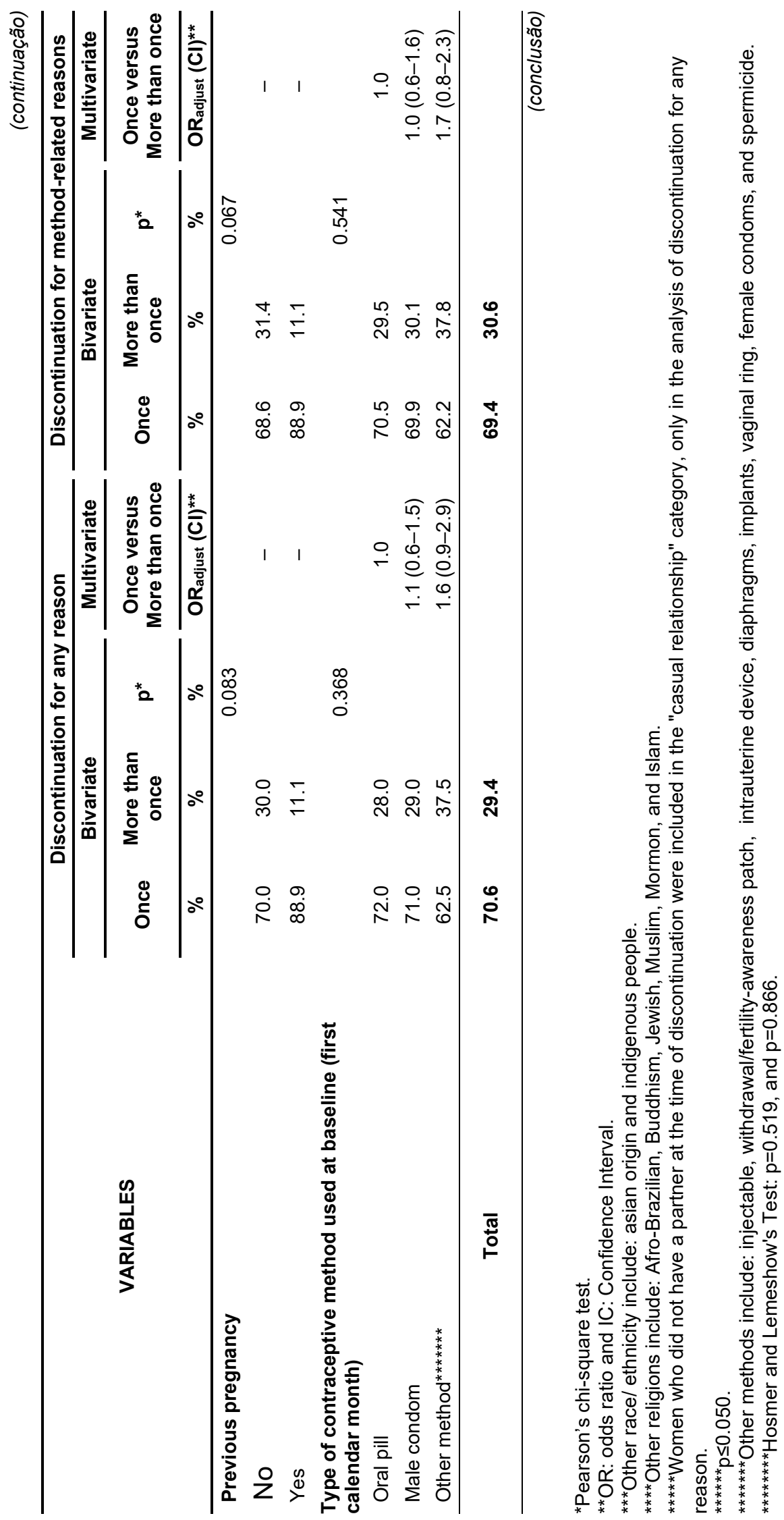


\subsubsection{Correlates of contraceptive discontinuation by frequency of discontinuation: results of multivariate analysis}

Table 5 presents the results of two multinomial regression models considering the odds of discontinuation for any reason once or more than once, and the odds of discontinuation for method-related reasons once or more than once. The reference category in both of these models are women who did not discontinue (for any reason in model 1 and for method-related reasons in model 2).

a) Discontinuation for any reason (Table 5 , columns 1,2 )

Confirming the results of the univariate analysis, multivariate analysis indicates that women who had casual relationship and who reported several lifetime sexual partners had higher odds of discontinuing their method once or several times. Women using less effective methods were also more likely to discontinue their method, once or several times, as compared to women using the oral pill. In addition, women who were Roman Catholic were less likely to discontinue their method once than women with no religion. There were additional factors related to discontinuation of a method several times relative to never discontinuing. Specifically, the odds of discontinuing several times versus never discontinuing were higher among students enrolled in Health Sciences or Exact Sciences, and enrolled in a part-time program. Conversely, students who had several years of sexual experience relative to those who had first sex less than a year before baseline were less likely to discontinue their methods once and several times over the last 12 months.

b) Discontinuation for method-related reasons (Table 5, columns 3,4)

Findings related to multivariate analysis of discontinuation for method related reasons one time or several times are reported in Table 4. Like in the previous analysis, number of sexual partners and use of less effective methods were related to higher odds of discontinuation for method-related reasons one or several times. In addition, women from less advantaged socioeconomic status, women enrolled in Human Sciences program (as compared to Exact Sciences) were more likely to discontinue for method-related reasons. 


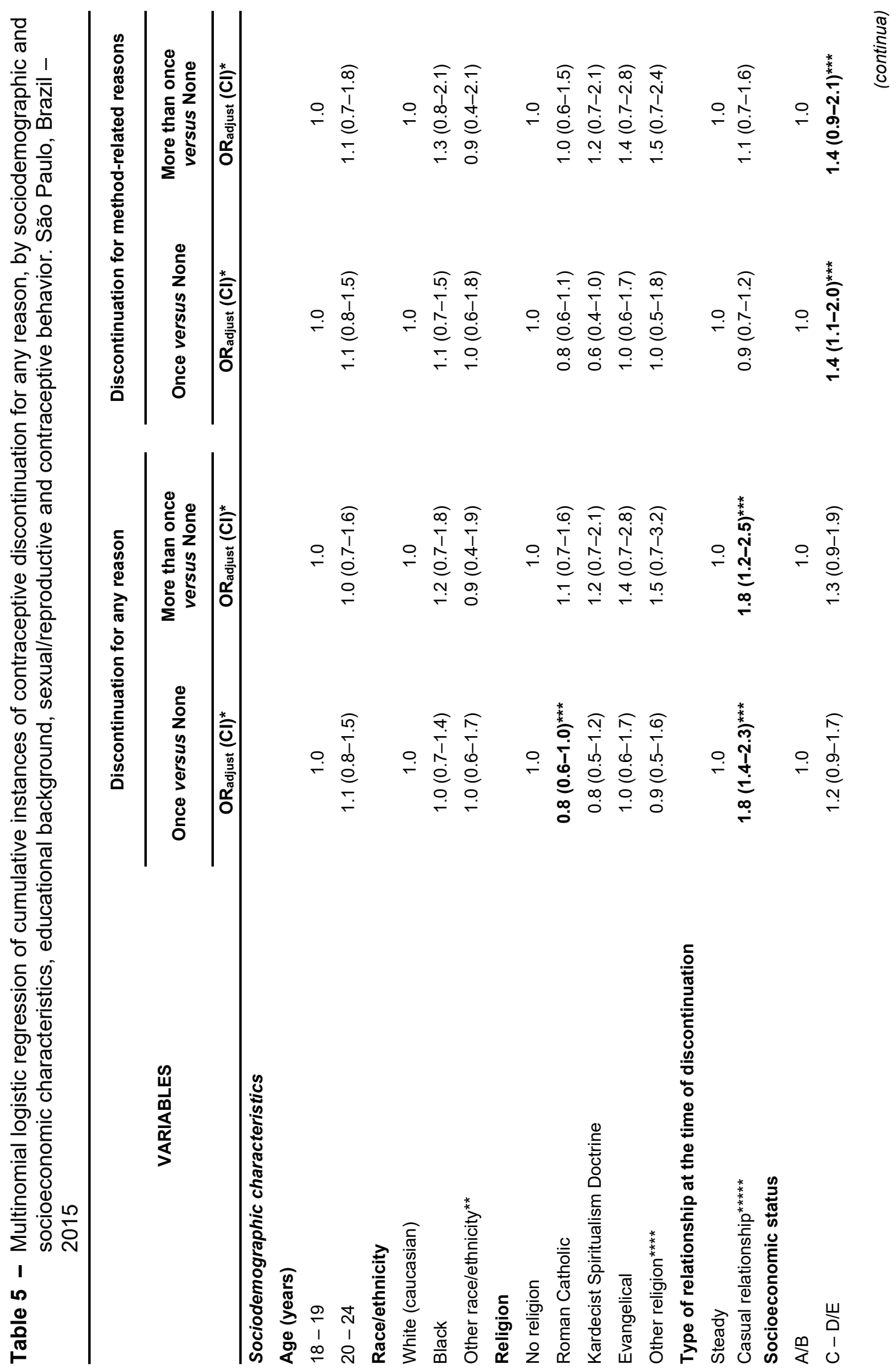




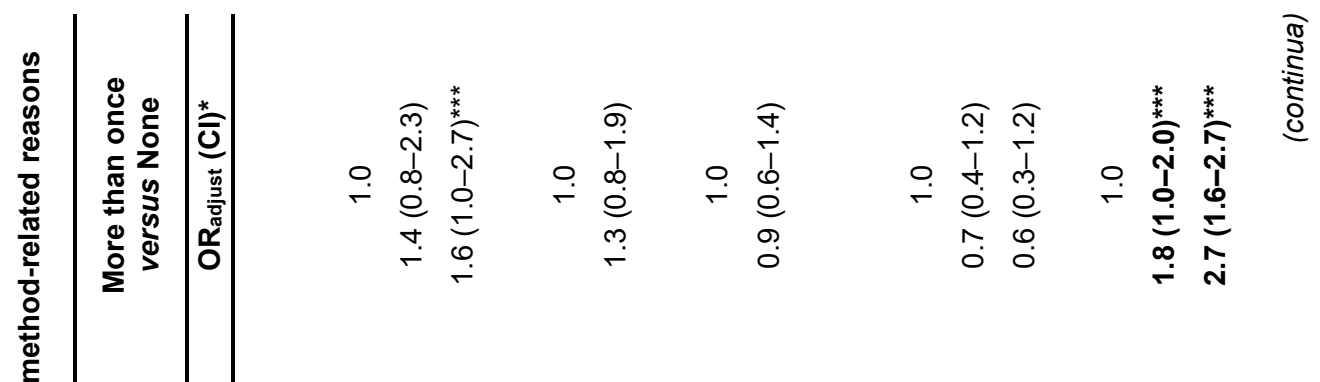

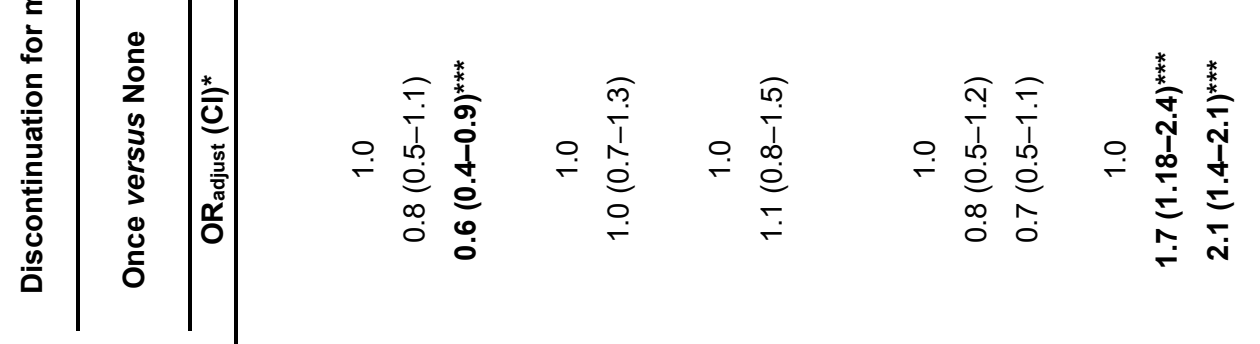

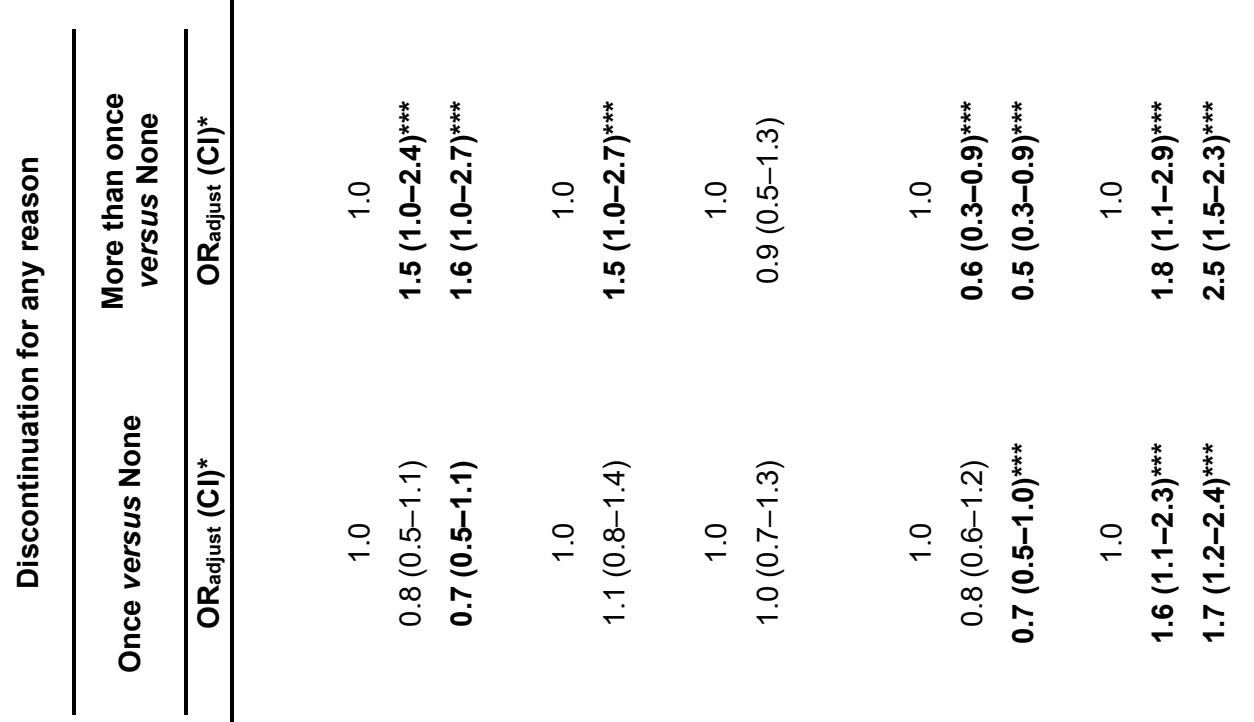

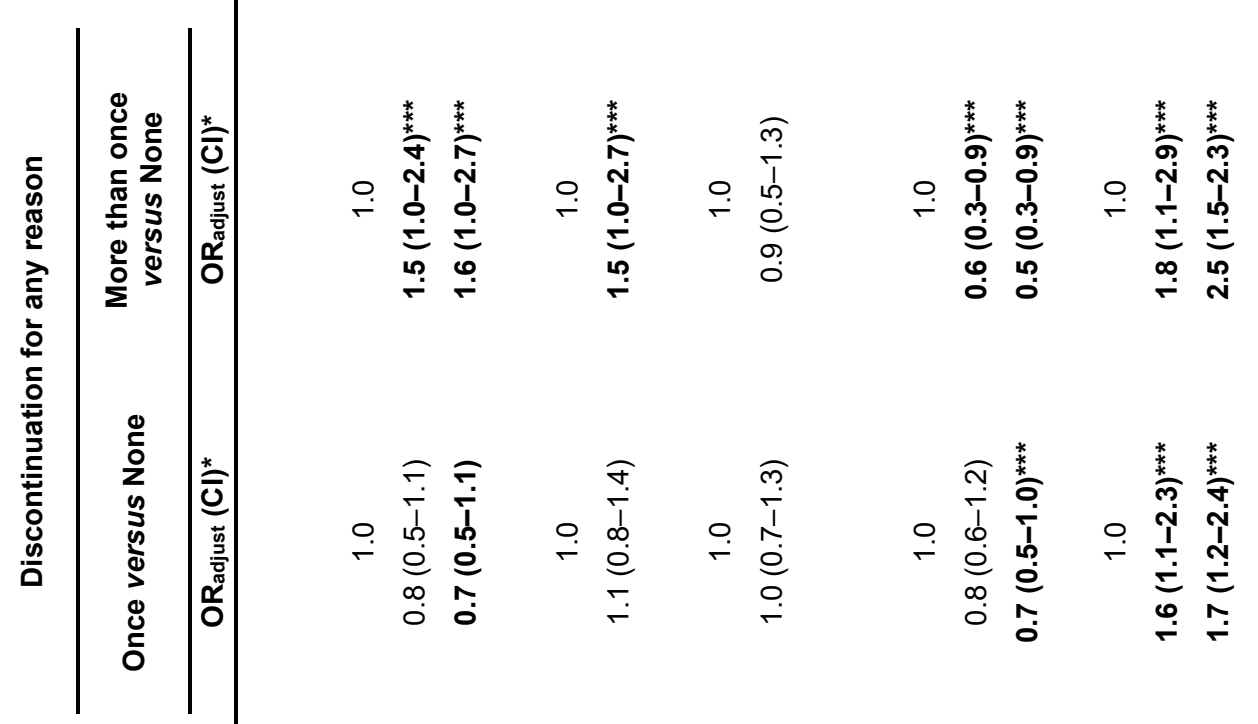




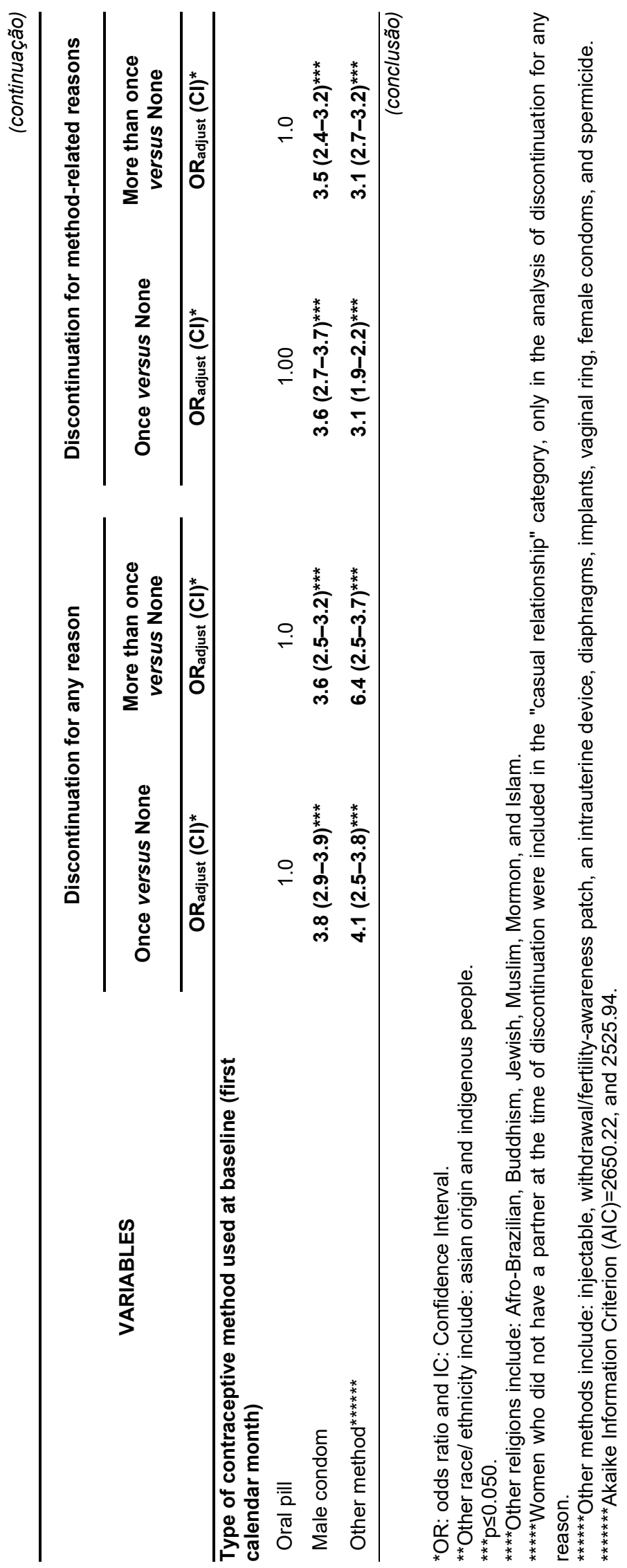




\subsubsection{Monthly discontinuation of contraception}

During the 12-months of the contraceptive calendar, the 1,679 women in the sample described 18,469 months of contraceptive use. The following results explore the correlates of monthly discontinuation for any reason, for method related reasons or the correlates of abandoning or switching to a less effective method.

A total of 966 months (discontinuation for any reason) were observed (Figure 5). Most months $(n=842)$ were due to method-related reasons, which representing $82 \%$ of all months of discontinuation. A total of 633 months of discontinuation lead to contraceptive abandonment or switching to less effective method while still at risk of becoming pregnant (3.43\% of all contraceptive months).

Figure 5 - Number of monthly of contraception that were discontinued during the calendar year, by measure of discontinuation and type of method used at the start of the contraceptive calendar (baseline). São Paulo, 2015

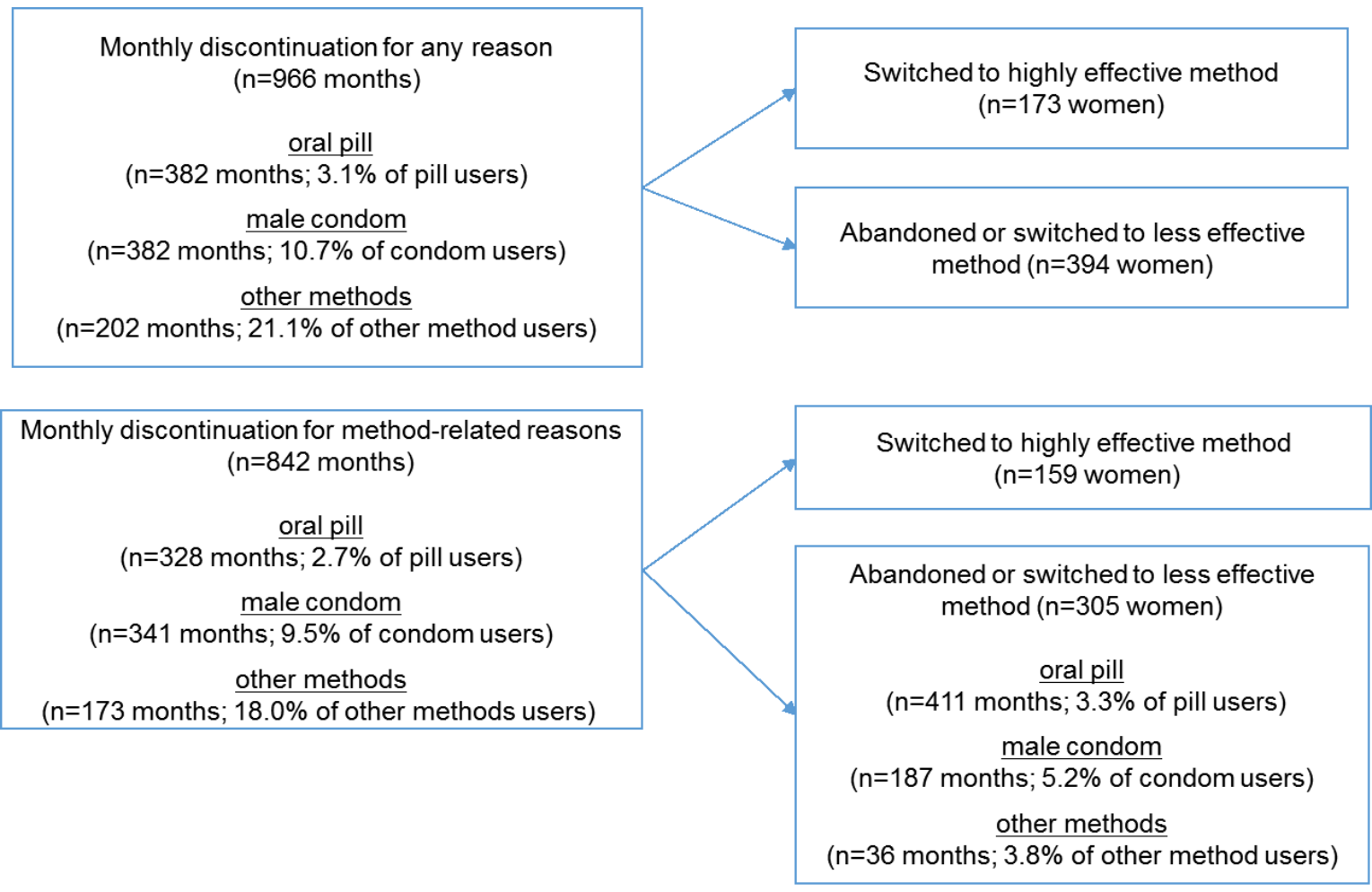




\subsubsection{Monthly discontinuation by type of contraceptive method}

Results from bivariate analysis presented in Table 6 identify several sets of factors related to monthly discontinuation for any reason, for method-related reasons, and for abandonment or switch to less effective method, by type of method. Discontinuation for any reason, for method-related and method abandonment were more frequent among women using the male condom as compared to those using oral pill.

As previously described in the women level analysis, monthly discontinuation for all 3 indicators of discontinuation was more frequent among women in casual relationships, not only for pill users, but also for condom users. Oral pill users were also more likely to discontinue their method for all 3 indicators of discontinuation if they had more than 1 sexual partner in their lifetime, and if they experienced a pregnancy in the past. In addition, pill users and condom users who had more years of sexual experience (mean time since first sexual intercourse) were more likely to discontinue their method for method-related reasons in the last 12 months.

Episode discontinuation also depended on women's social and educational background. Oral pill discontinuation across indicators was more frequent among women who identified as other religion (such as afro-Brazilian, Buddhism, Jewish, Muslim, Mormon, and Islam). Condom users who were black, were less likely to discontinue for any reason, also condom users who were older were less likely to abandon or switch to less effective method. Oral pill users from less advantaged socioeconomic status, as illustrated by income level and part-time student program, were more likely to discontinue their method for method-related reasons and to abandon or switch to less effective method. Oral pill users enrolled in the Human Sciences, attended the São Paulo campus were also more likely to discontinue contraception for any reason and for method-related reasons.

Finally, if women discontinued for any reason or for method-related reasons at the previous month, then the probability of a discontinuation for any reason or for method-related reasons at the next month were $22 \%$ and $21 \%$, respectively (data not shown in table). 


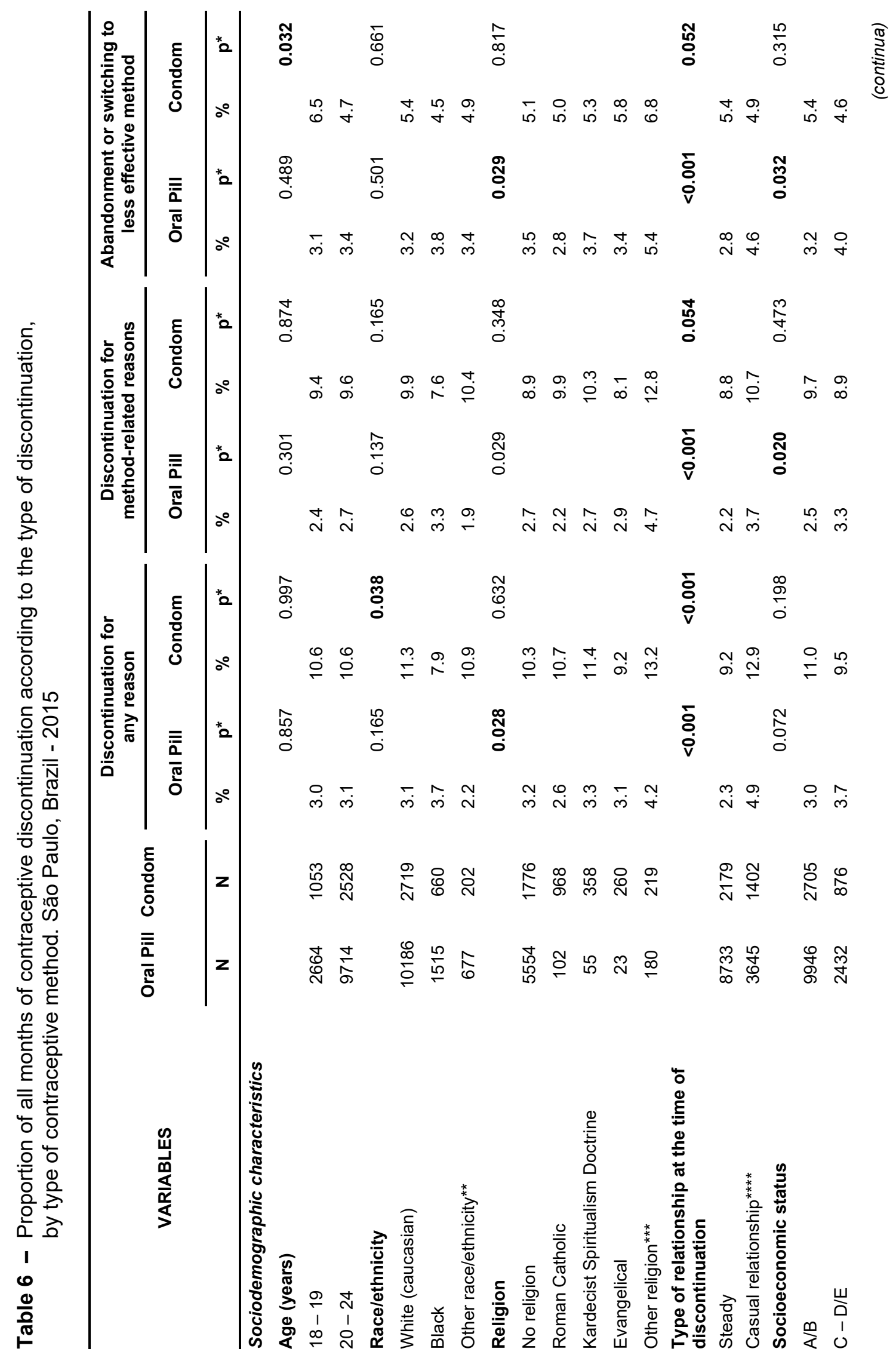




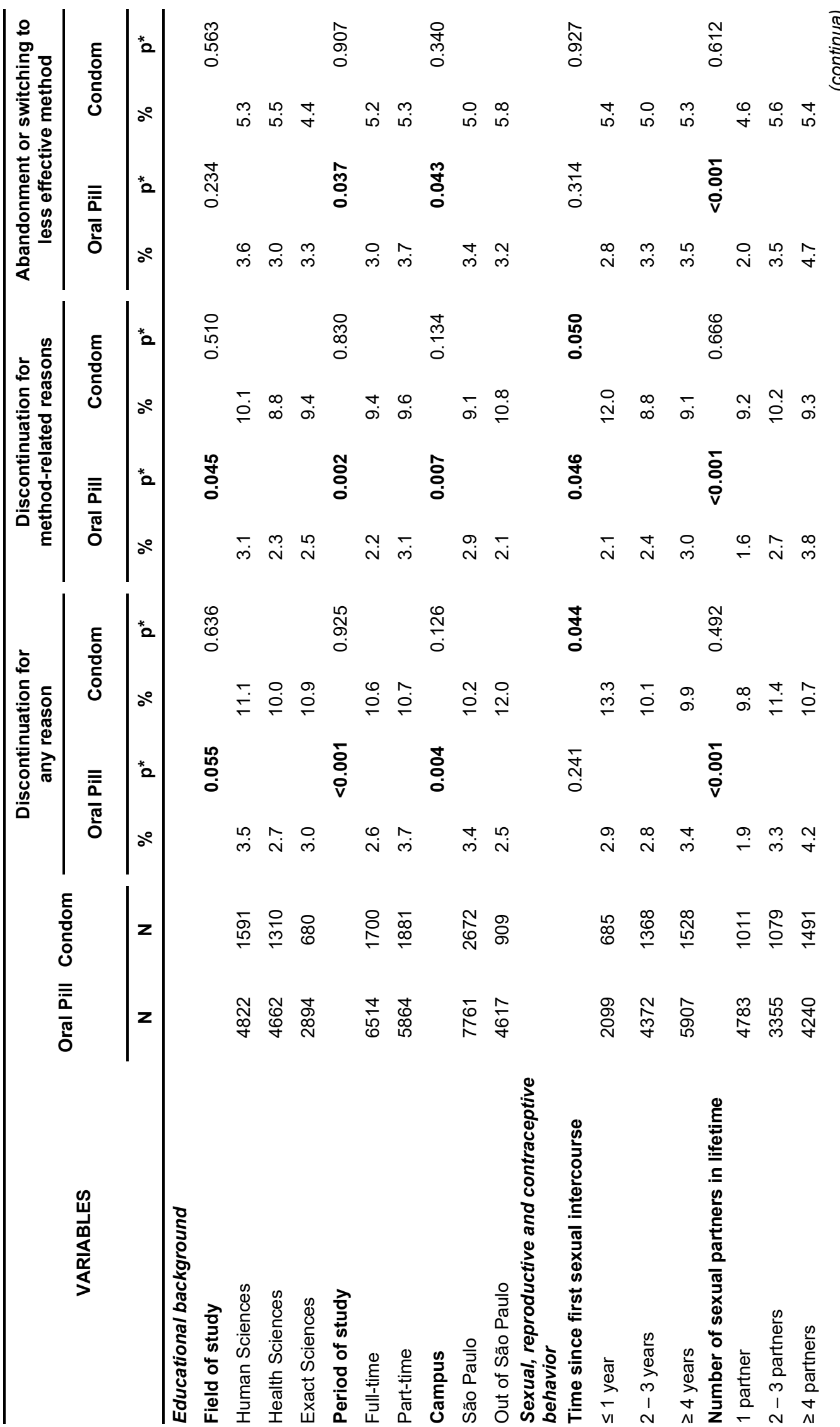


114 CHAPTER FOUR

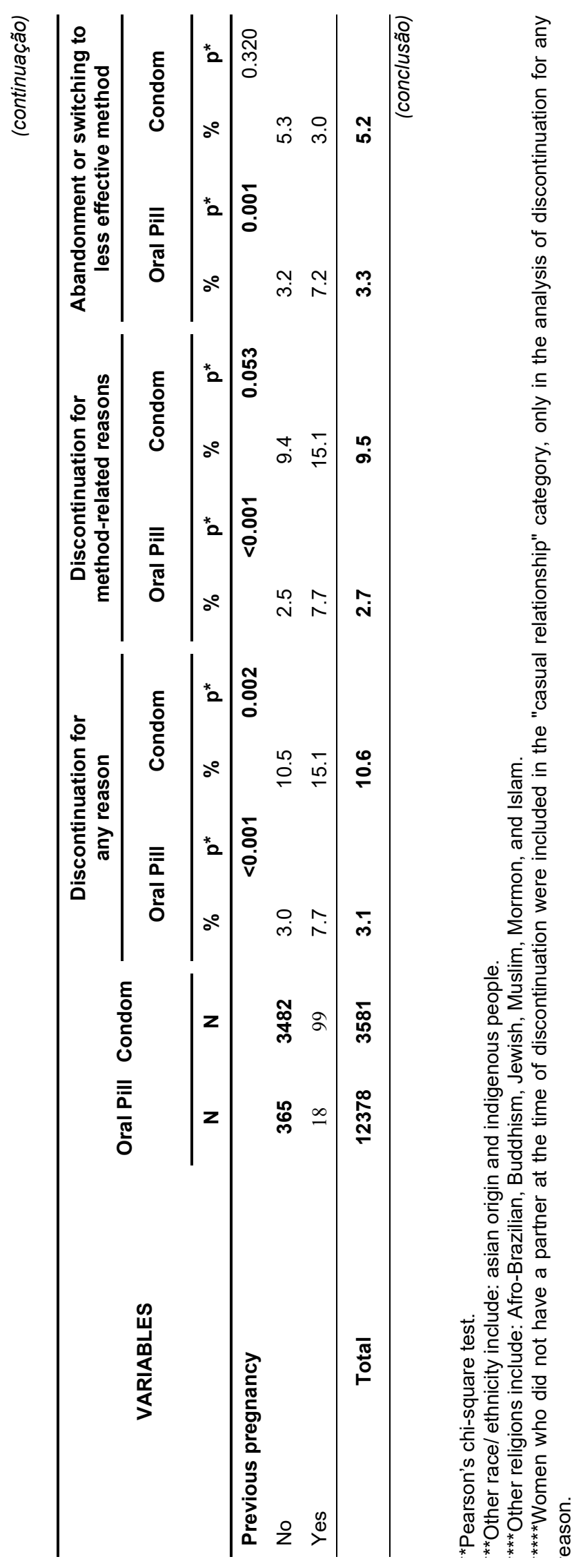




\subsubsection{Correlates of contraceptive discontinuation by type of contraceptive method: results from multivariate analysis}

Results of the Generalized Estimating Equations (GEE) models assessing the independent effect of each factor on discontinuation, (for any reason or for methodrelated reasons or for method abandonment) are presented in Table 7. Results are stratified by method as factors related to discontinuation differed by method.

The strongest determinant of method discontinuation across all methods and across all indicators was prior pregnancy, which increased the odds of discontinuation for any reason or for method-related reasons, but conversely reduced the odds of abandonment or switching to less effective methods.

Other determinants were method specific. For instance, the odds of condom discontinuation for any reason were lower among black women and were lower among women with more than 1 year of sexual experience. Conversely, the odds of condom discontinuation for any reason or for method-related reasons were higher among women with casual partners. This was also true in the case of pill discontinuation, in which the higher odds of pill discontinuation were in the case of casual partnership, related to discontinuation for any reason, for method-related reasons and method abandonment. Pill users were also more likely to discontinue their method for all 3 indicators of discontinuation if they were from a lower socioeconomic status and if they had more than 1 sexual partner in their lifetime. 


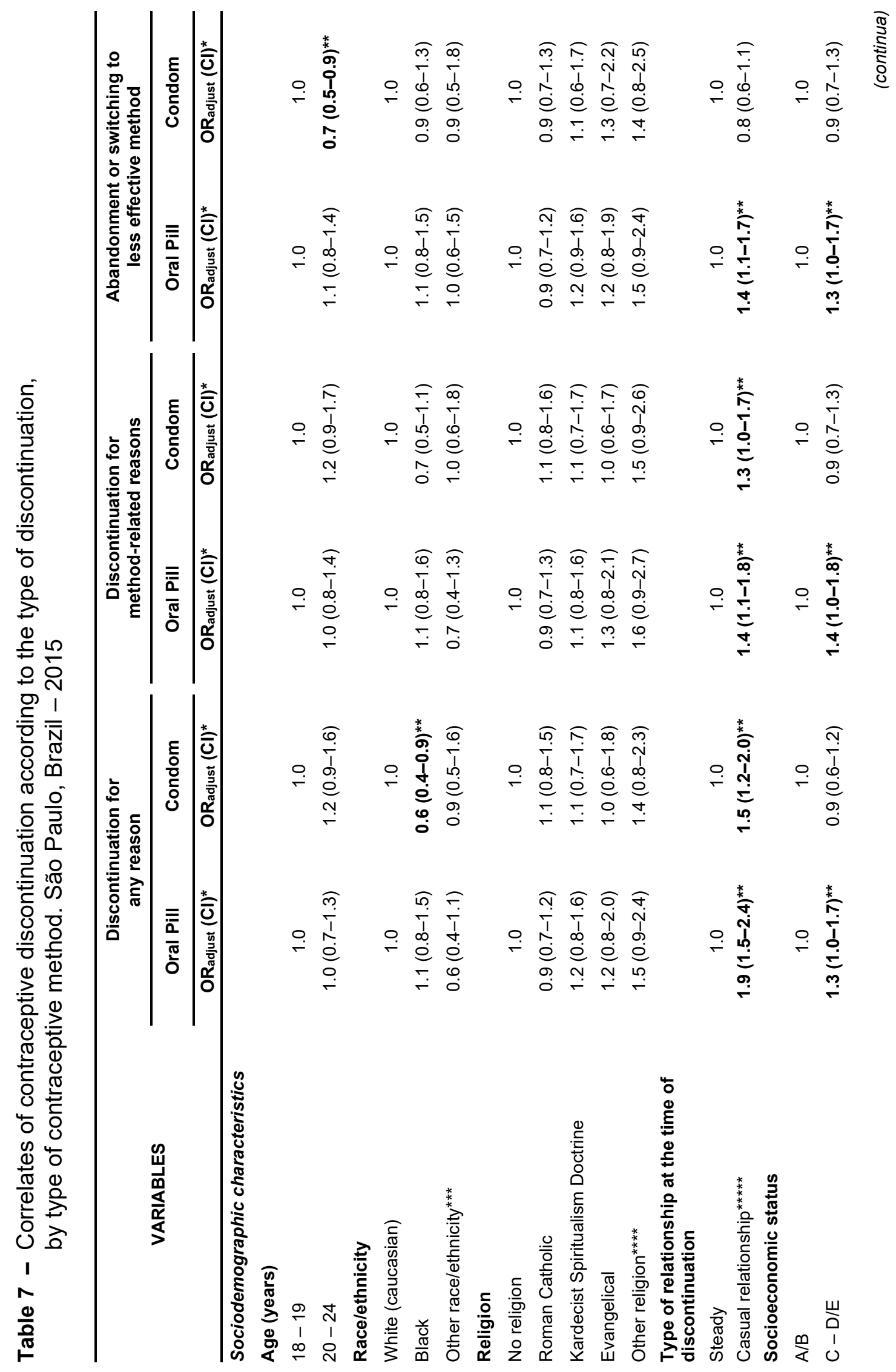




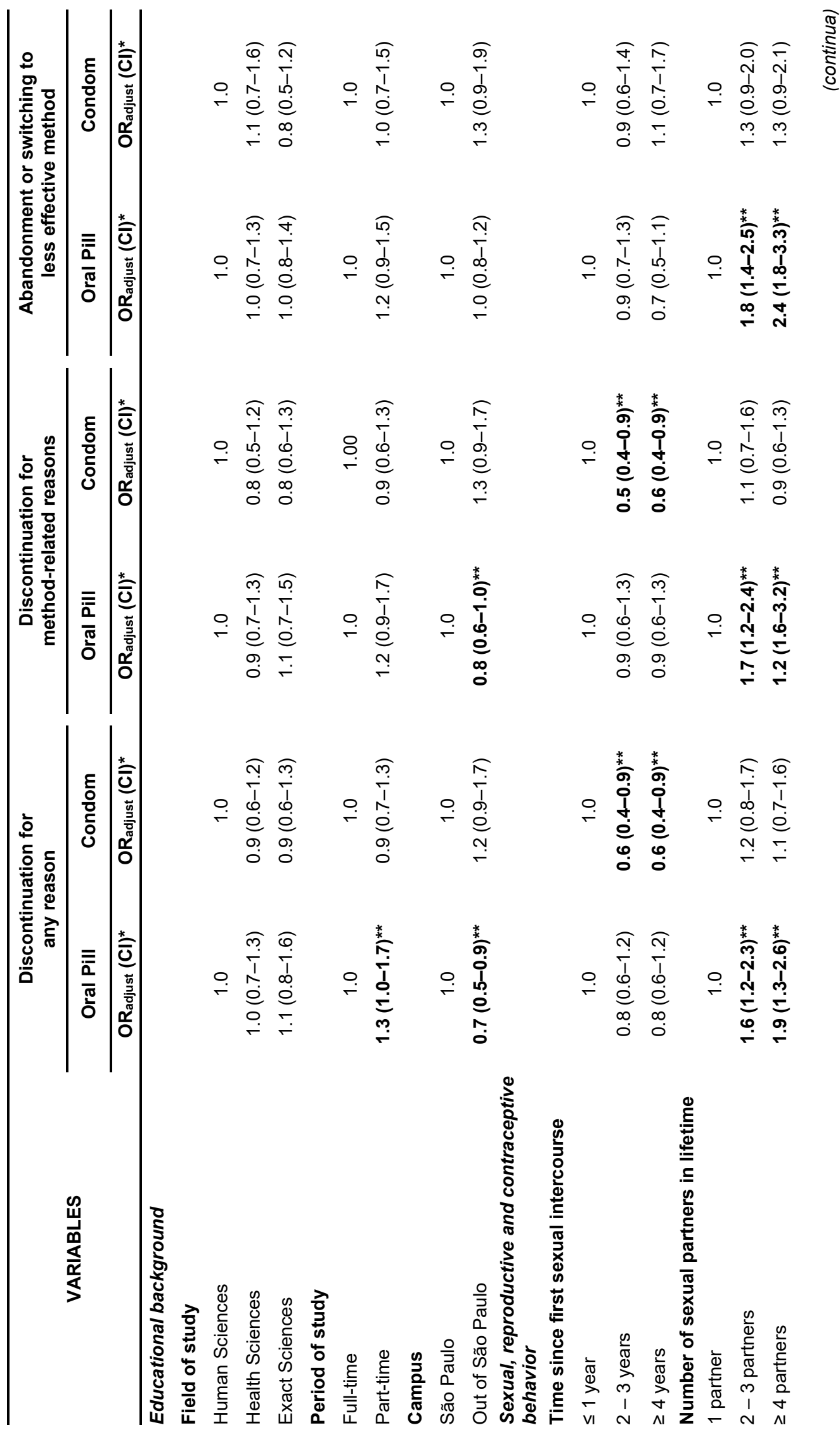




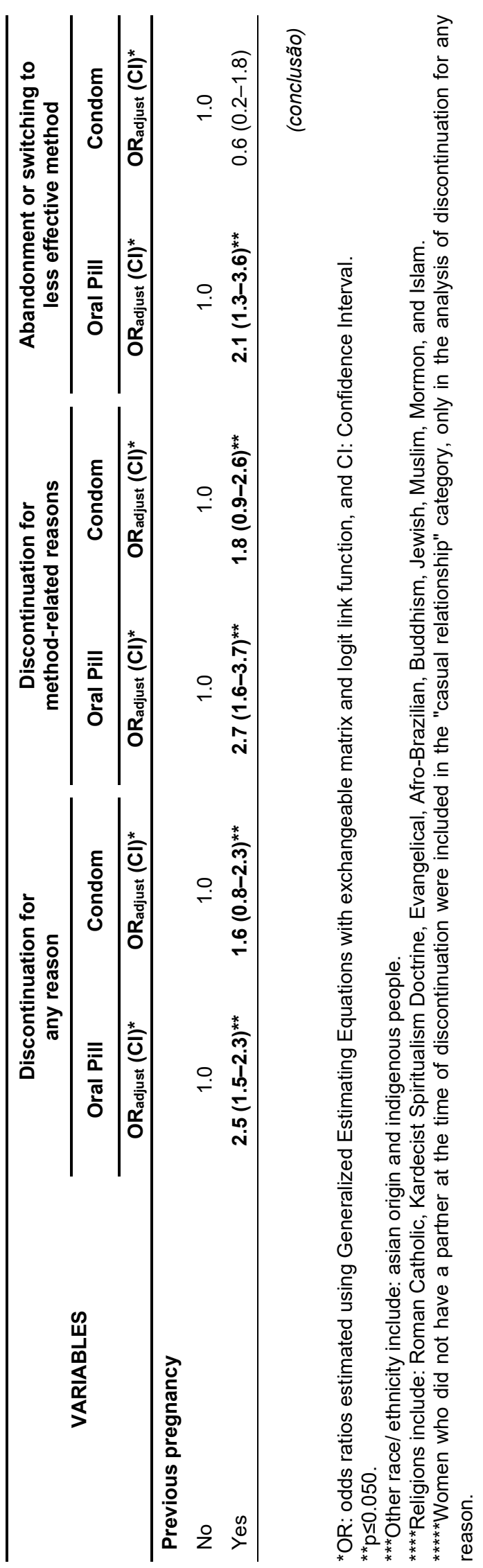




\subsubsection{Cumulative probabilities of discontinuation of new episodes of contraception: Kaplan-Meier}

Male condom users exhibited higher rates of discontinuation over time, when compared with oral pill users. It is noted that discontinuation for any reason and for method-related reasons were also twice as likely among women using the condom as compared to those using oral pills (Figure 6 and 7 ). However, oral pill users were more likely to abandon their method or switch to less effective method than condom users, when just new episodes of contraceptive use were analyzed (Figure 8).

Figure 6 - Probability of contraceptive discontinuation for any reason by method type (Kaplan-Meier estimates). São Paulo, Brazil, 2015

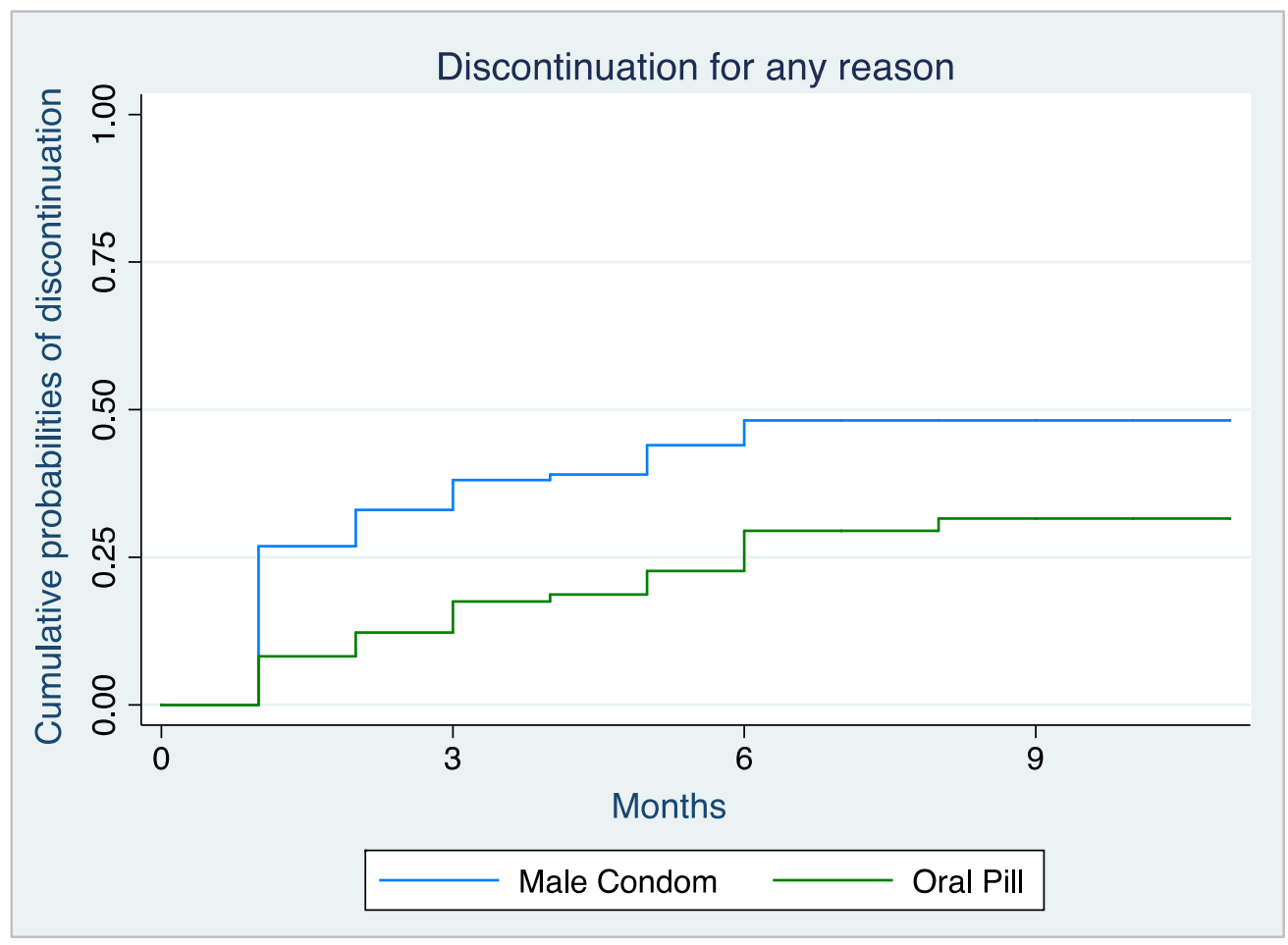


Figure 7 - Probability of contraceptive discontinuation for method-related reasons by method type (Kaplan-Meier estimates). São Paulo, Brazil, 2015

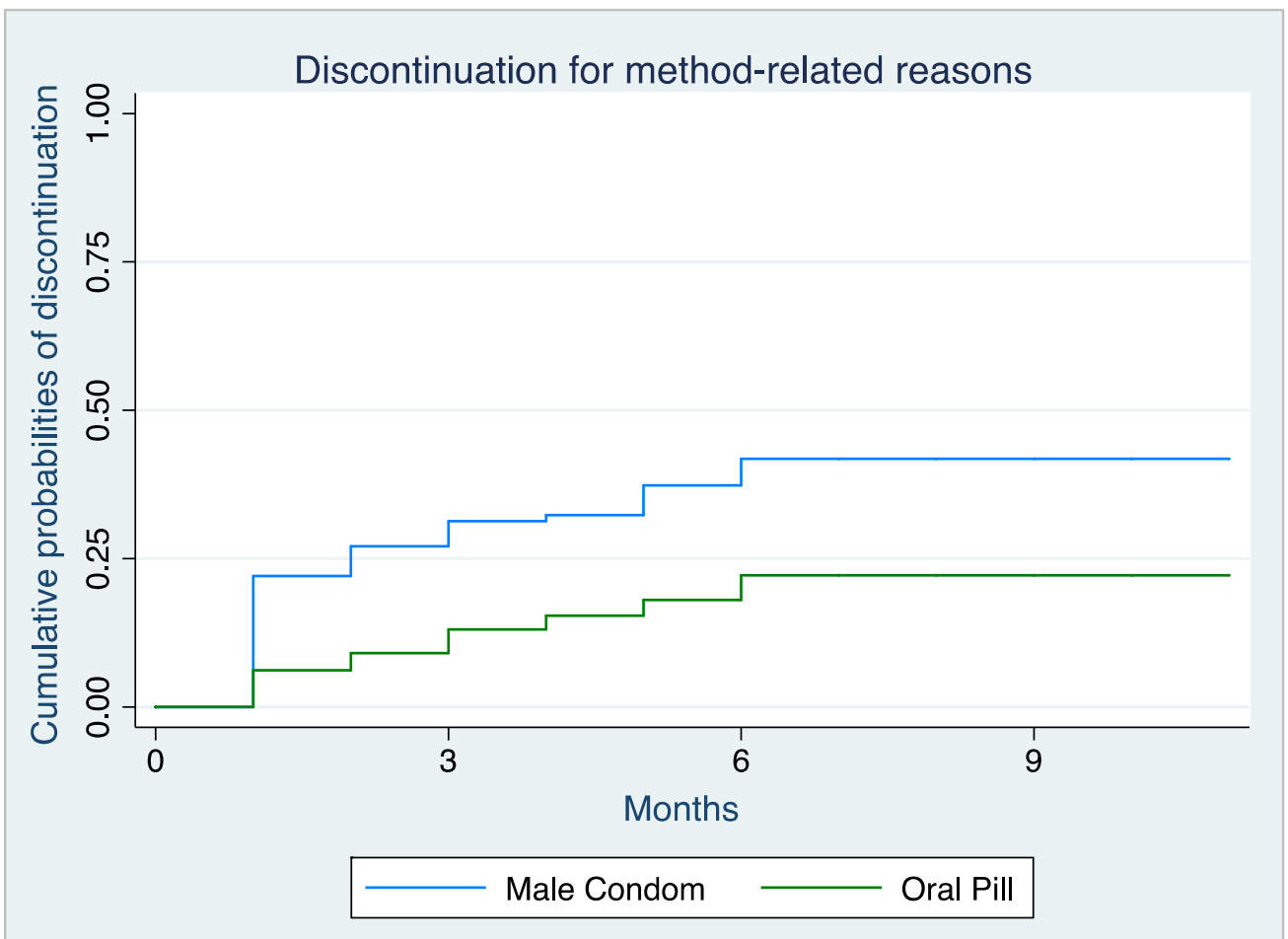

Figure 8 - Probability of abandonment or switching to less effective method reasons by method type (Kaplan-Meier estimates). São Paulo, Brazil, 2015

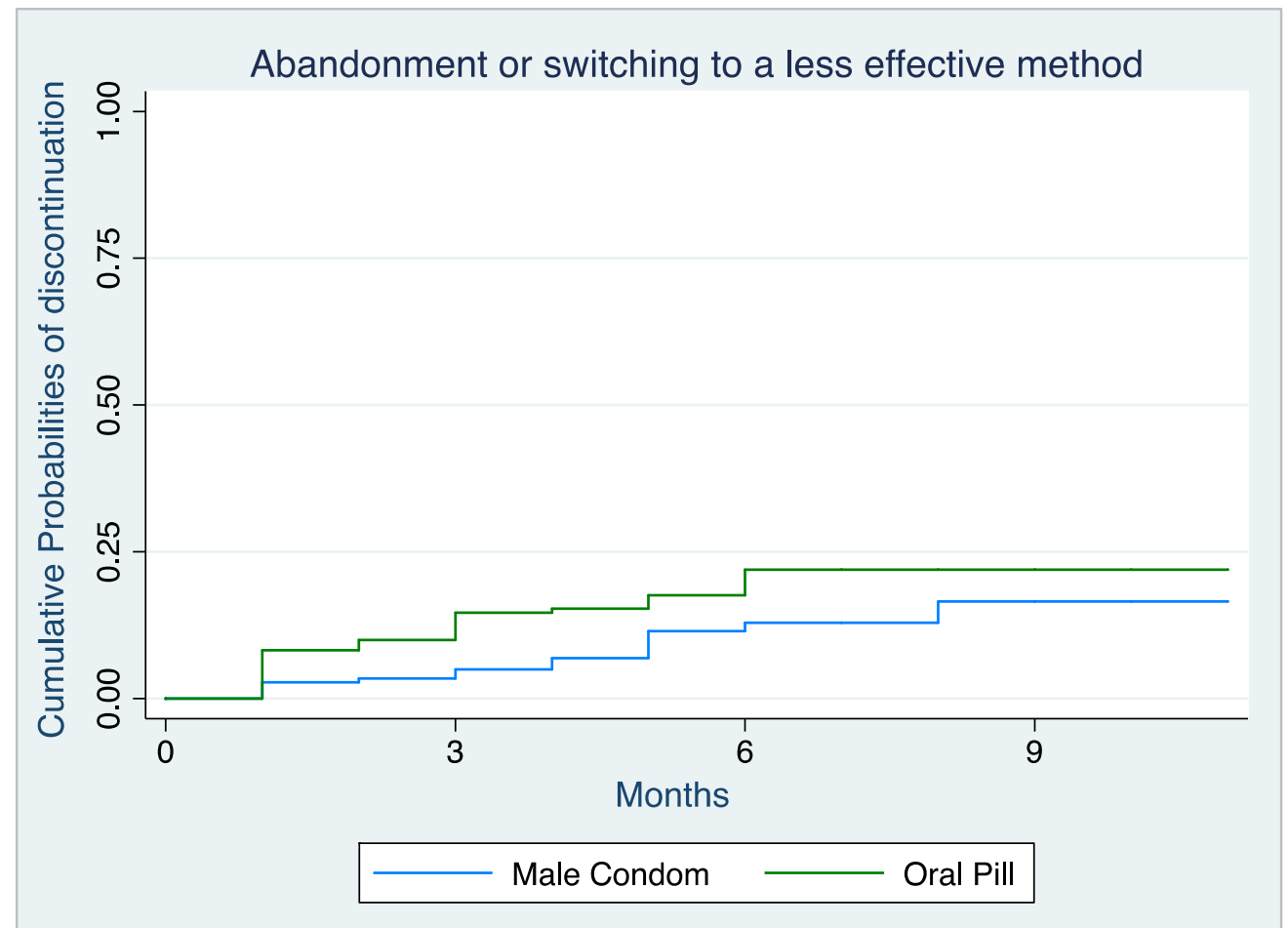


Table 8 and 9 present oral pill and male condom discontinuation rates, respectively, in 06 and 11 months after start of use, estimated by the Kaplan-Meier method. Altogether $27 \%$ of oral pill users discontinued use of the method for any reason by 11 months of use, $21 \%$ discontinued for method-related reasons, and $25 \%$ abandoned the method or switched to less effective method by 11 months of use. On the other hands, $46 \%$ of condom users discontinued their method for any reason by 11 months of use, $39 \%$ percent discontinued for method-related reasons, and $25 \%$ abandoned the method or switched to less effective method by 11 months of use.

Results of the survival analysis show few factors associated with early discontinuation. Oral pill users and male condom users who were single and had casual relationship were more likely to discontinue for any reason when compared to women who had steady relationship. Oral pill users who were practitioners of Kardecist Spiritualism Doctrine religion were more likely to abandon their method or switch to less effective method. Moreover, more years of sexual experience (mean time since first sexual intercourse), was significantly associated with a decreased in the likelihood of discontinuation for any reason and for method-related reasons among condom users. 


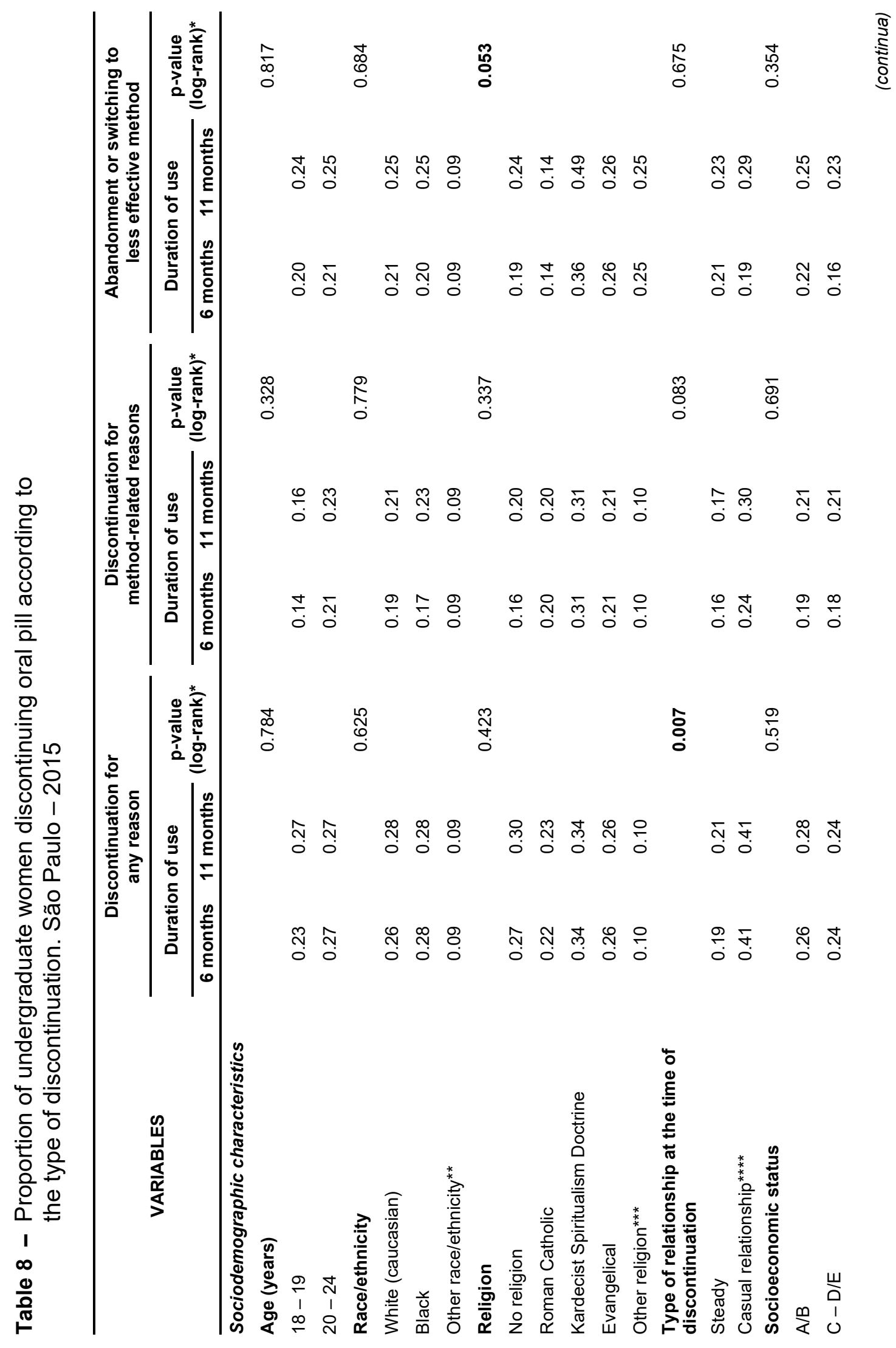




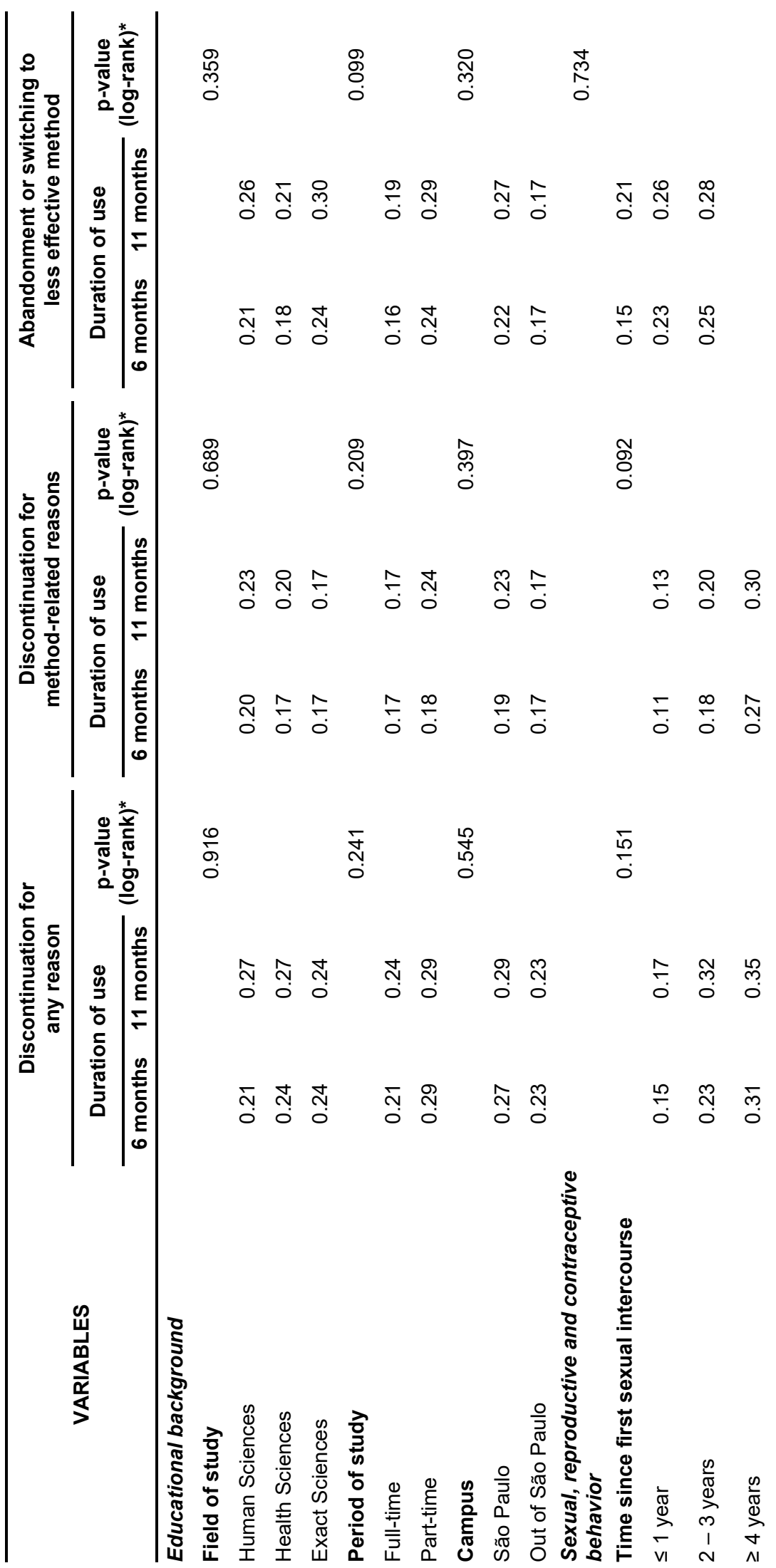




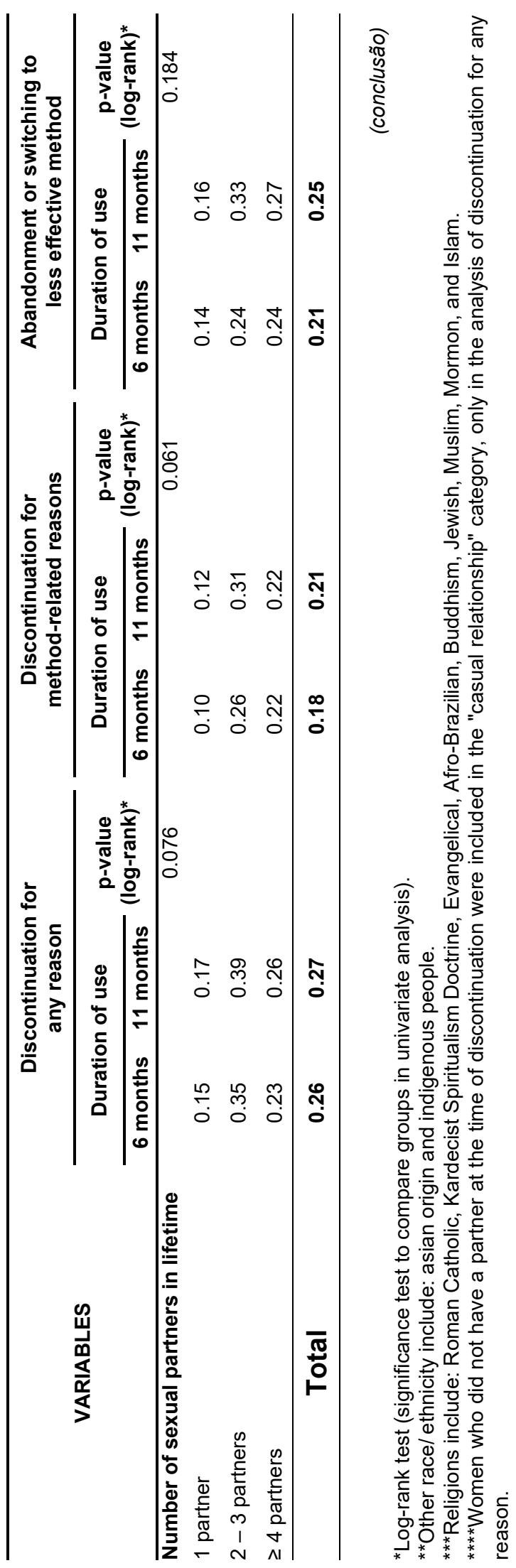




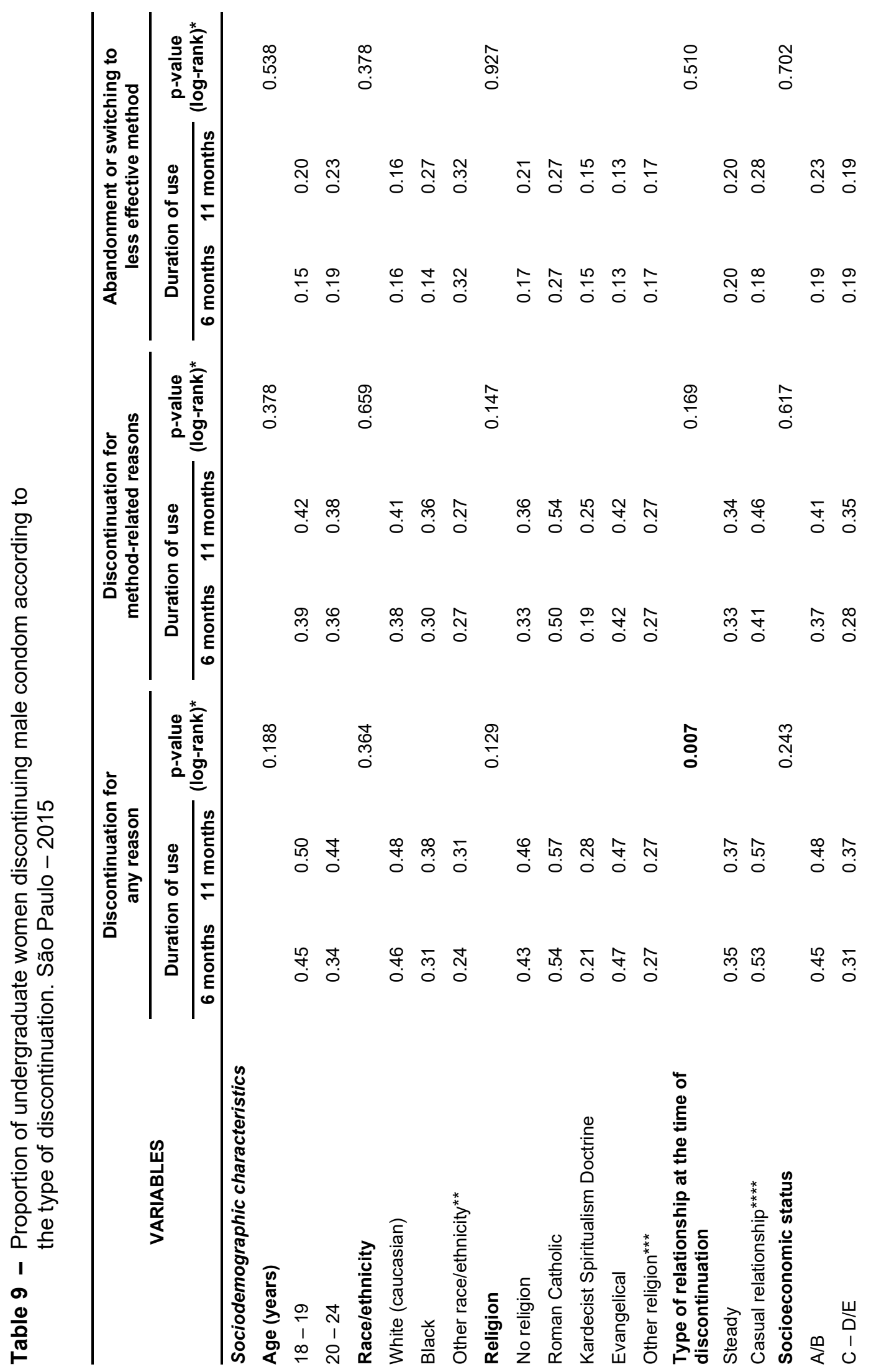




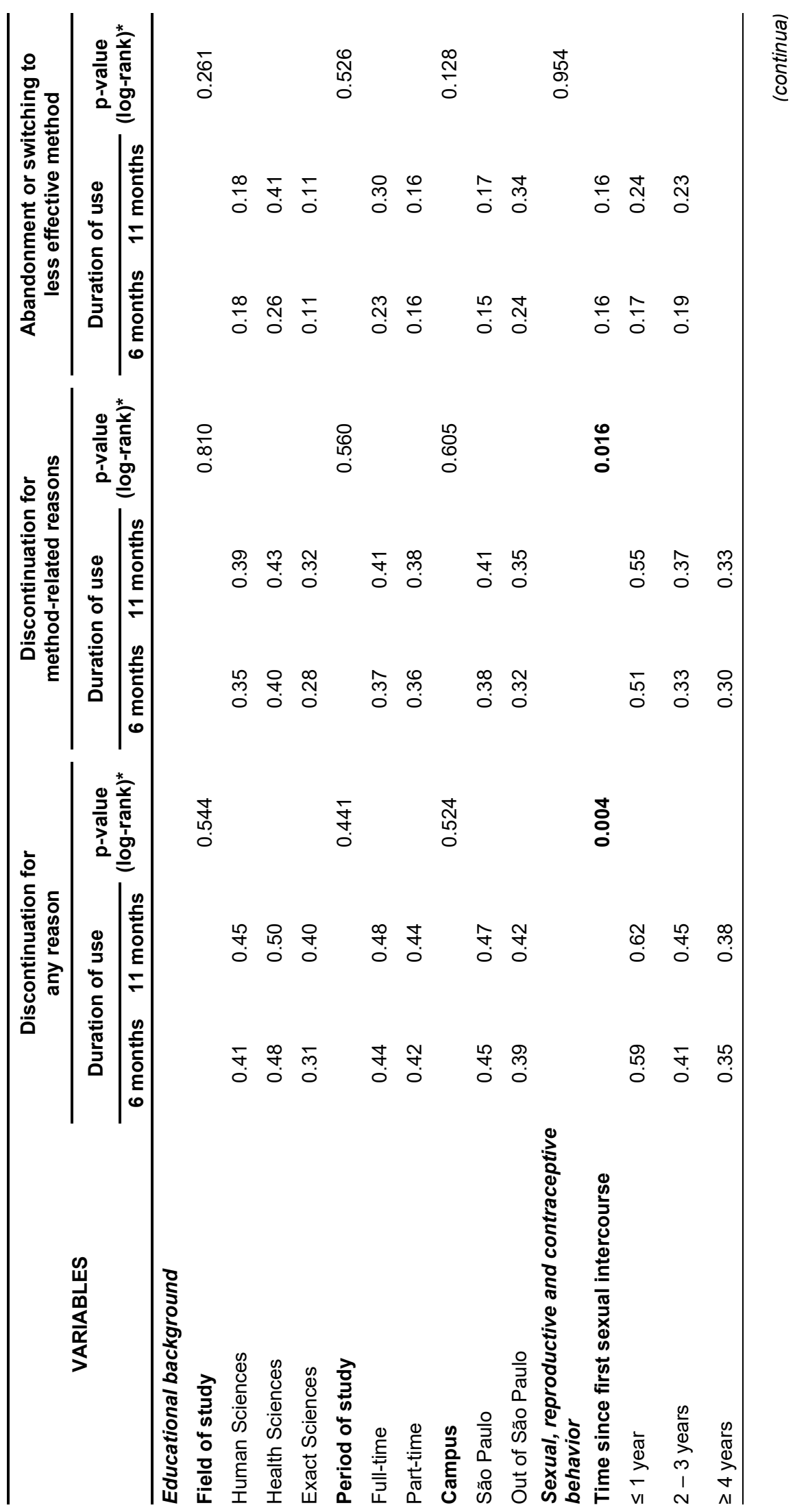




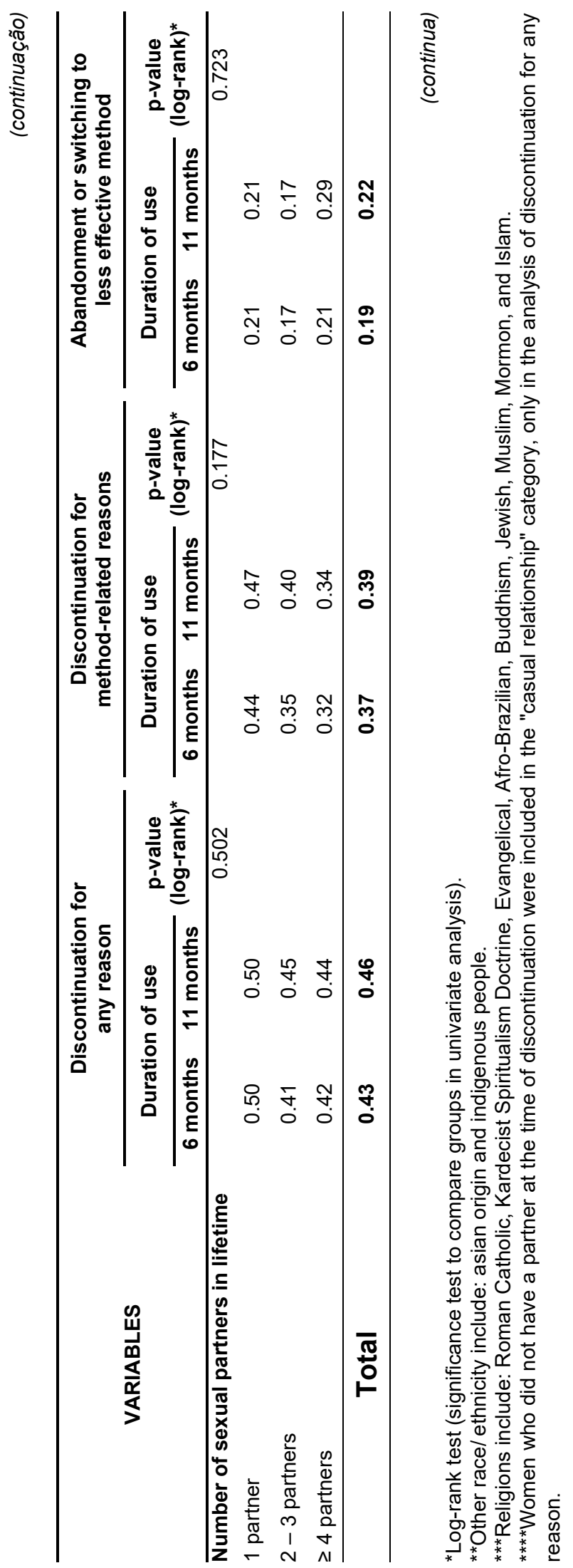




\subsubsection{Estimate of relative risks of discontinuation by method type: results from multivariate survival analysis using Cox's regression model}

The final Cox proportional hazards are demonstrated in Table 10. As noted previously, the models were stratified by method type. For all variables, the relative risks were constant over time.

The risk of experiencing an episode of discontinuation for any reason or for method-related reasons was higher among women who were single and had casual relationship, independently of method type used (oral pill or male condom). The risk of abandoning or switching to a less effective method among condom users who were practioners of Kardecist Spiritualism Doctrine religion was almost three times higher, when compared with women who had no religion. In addition, more years of sexual experience (mean time since first sexual intercourse) was found to be moderately related to a 30 percent reduction in the likelihood of discontinuation for any reason and for method-related reasons among condom users. However, oral pill users who had four or more years of sexual experience were more than twice as likely to discontinue their method for any reason. 


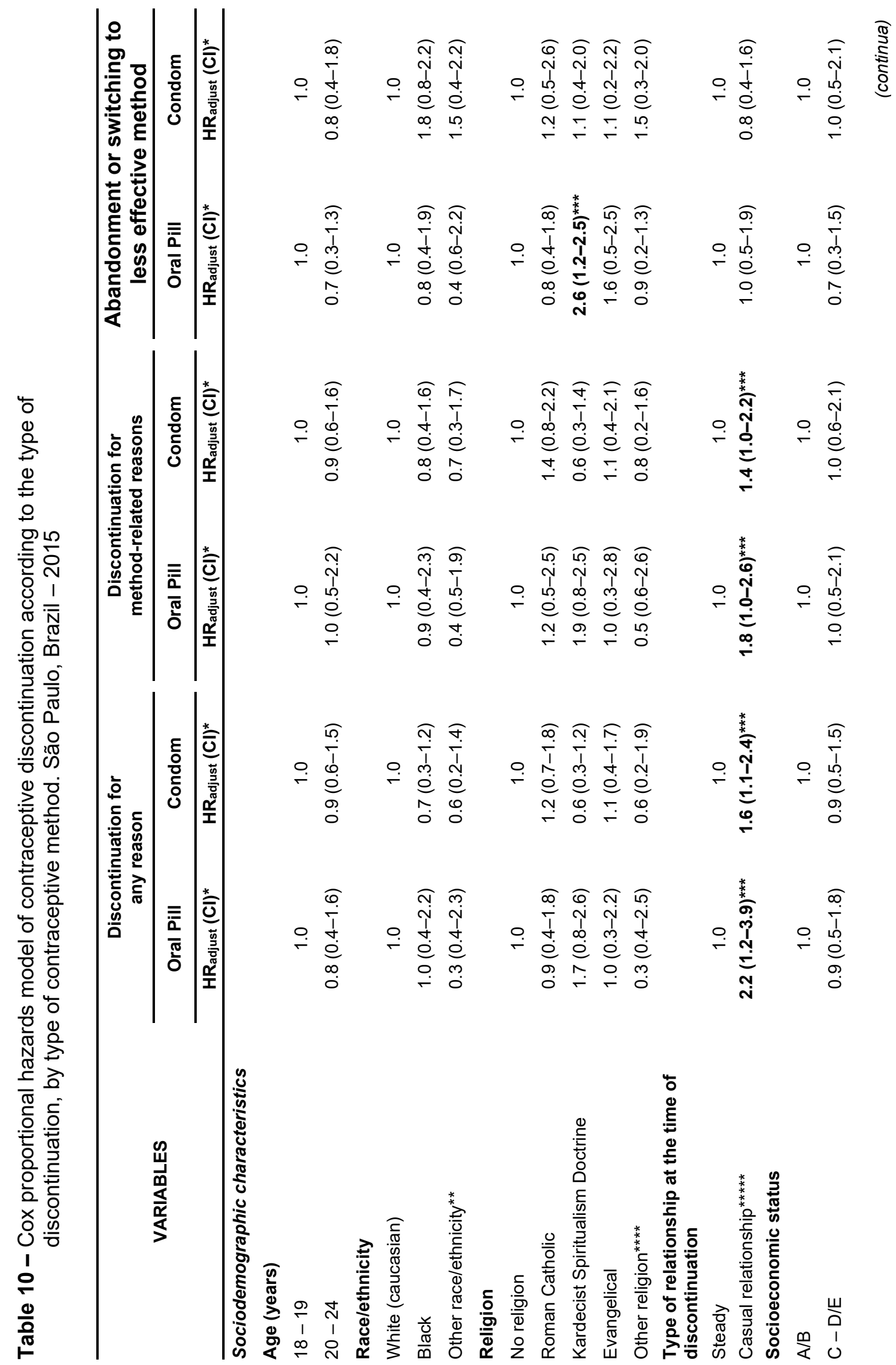




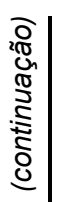

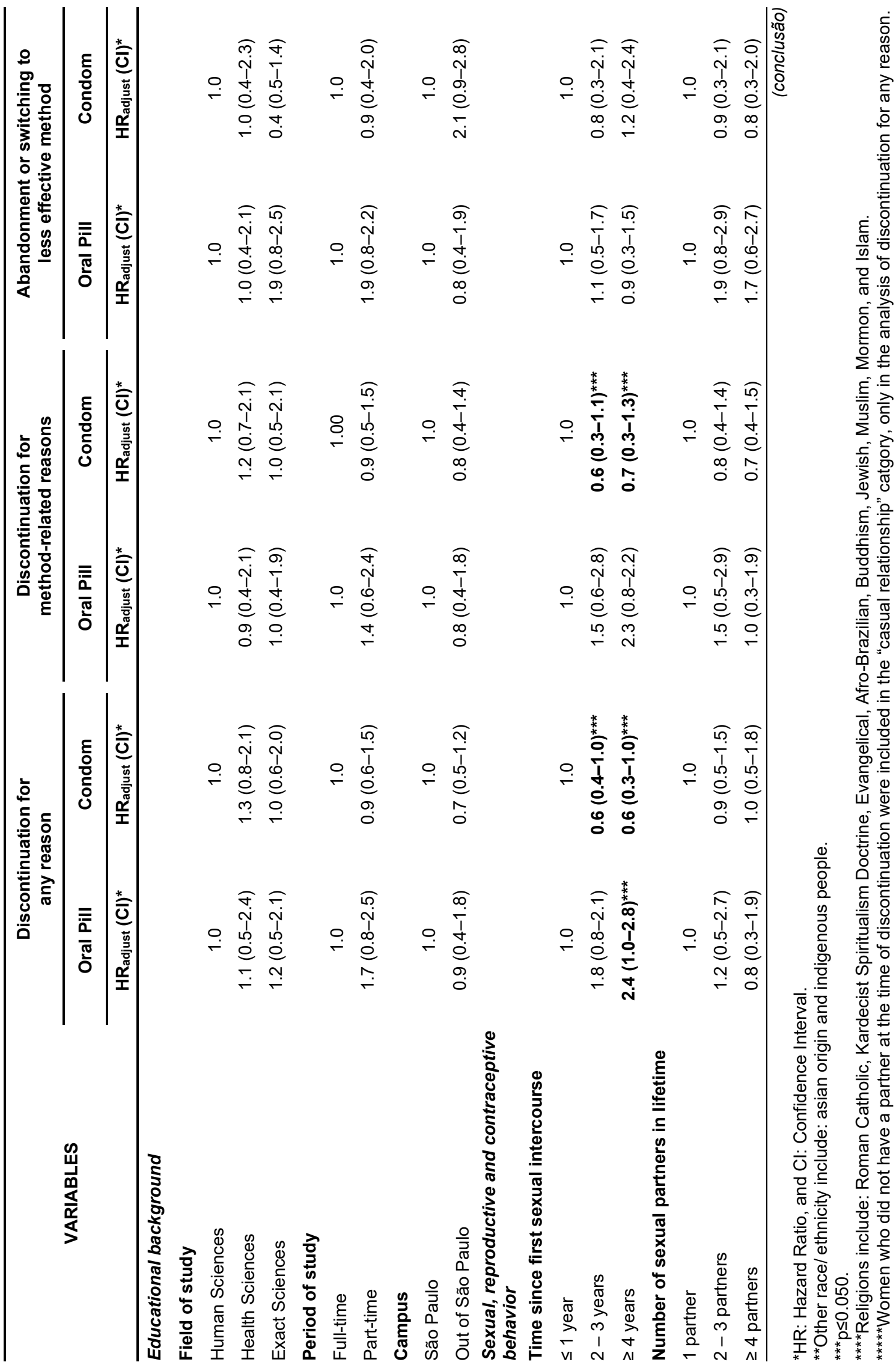




\subsection{DISCUSSION}

\subsubsection{Contraceptive discontinuation according to frequency of discontinuation}

This study is the first to provide estimates of frequency of contraceptive discontinuation among students in Brazil, using a retrospective calendar data. It is original in providing estimates of switching and abandonment of contraceptive method.

Our data show that contraceptive discontinuation is not a rare event among students in Sao Paulo: almost four out of 10 sexually active women had at least one episode of discontinuation for any reason over a period of a year; while three out of 10 women had at least one episode of discontinuation for method-related reasons, and two out of 10 women abandoned their method or switched to less effective method. Of particular concern were the high discontinuation rates of user dependent methods.

Although the comparison of discontinuation rates is difficult since the majority of studies did not contemplate undergraduate students, discontinuation rates observed in this study were lower when compared with other countries such as U.S. and Honduras; almost similar when compared to France; and higher when compared to England (Vaughan et al., 2008; Frost 2007a; Moreau et al., 2009a; Barden- O'Fallon, 2011b; Wellings et al, 2015). In addition, although our sample is different from DHS, and therefore comparison is limited; study by Ali, Cleland, Shah (2012) found similar patterns in discontinuation by method when they used data from Brazil collected in the 1996 DHS. It denotes that little changes in the contraceptive patterns has been observed in Brazil, in the last 20 years.

When new episodes of contraceptive use were considered (including only episodes that started during the calendar year), abandonment or switching to less effective method was higher among oral pill users than condom users; while the opposite was noted when monthly discontinuation was analyzed. Differences in the outcomes reflect differential patterns of discontinuation by method as a function of duration of use. Discontinuation of condoms was mainly related to criticism of the partner and wanting a more effective method, as in the literature (Davidoff-Gore, Luke, Wawire, 2011; Zembe et al., 2012; Mehra et al., 2014). Studies have 
suggested that as relationships become more stable, many couples switch from condom to hormonal methods, and the main reason to switch is the "supposed mutual trust", which indicates that they become less concerned about the prevention of STDs (Bastos et al., 2008; D'Antona et al., 2009; Shih et al, 2011; Goldstein, Upadhyay, Raine, 2013; Mehra et al., 2014). As expected, discontinuation of hormonal contraception observed in this study was related to side effects, such as also noticed in the literature (Castle, Askew, 2015; Inoue, Barratt, Richters, 2015). Hooper et al., (2010) reported that women who switched from oral pill because of side effects were high among Brazilian women, which suggests that the impact of side effects has relevant consequences for contraceptive use.

In Brazil, the lack of trained professionals and limited contraceptive options (Heilborn et al., 2009; Vieira, Souza, 2011) contribute to skewed contraceptive distribution favoring user dependent methods among young women, such as found in our study (Moura, Silva, Galvão, 2007). Unfortunately, suboptimal efficiency of contraceptive practices in Brazil (favoring moderate instead of highly effective methods) is a missed opportunity to ensure successful reproductive planning. This is confirmed with the fact that only six women were using IUD at baseline.

A potential line of our research was to address the frequency of method discontinuation, i.e., understanding the correlates responsible for women do not discontinue their contraception, discontinue once, or discontinue a lot of times; since the risk of pregnancy is highly among women with high rank of discontinuation. Limited research has examined how contraceptive use dynamics are related to socioeconomic characteristics in Brazil, especially socioeconomic status (Frost, Singh, Finer, 2007b; Frost, Darroch, 2008). In our study, women with lower socioeconomic status as measures by socioeconomic status using national eligibility criteria, Brazil Economic Classification (ABEP, 2015) were more likely to discontinue their method once or several times while still at risk. According to Jones, Mosher \& Daniels (2012), women from lowest income status are less likely to use contraceptive method and more likely to have gaps in use compared to women who are better-off financially. Frost, Singh \& Finer (2007b) noted that while poverty was not significant in predicting method switching, $25 \%$ of women under the federal poverty line switch their contraception within 12-months. Kost el at. (2008), also noted that socioeconomic status played a role in discontinuation of contraceptive use. Young students who were enrolled at a part-time program were also more likely to 
discontinue their method for any reason more than once. Students at the part-time program probably exercise activities paid out of the university, which may be related to belonging to less privileged socioeconomic status, and consequently a high probability of discontinuation, as explained above. We emphasize that though our study population represents an "elite", social inequalities influenced the methods use.

$\mathrm{SRH}$ characteristics are also related to contraceptive discontinuation; as the number of sexual partners increased, the percentage of discontinuation also increased. Our finding that a greater number of lifetime sexual partner was associated with greater risk of discontinuation (one time and more than once) was possibly due to the dynamism and the short duration of the relationship, typical of youth, since the contraception is subject to negotiation with every partner, and the potential need to rely on condoms for STDs prevention (Pirotta, Schor 2004; Manlove, 2007; Borges et al., 2010). Women who were in casual relationship were also more likely to discontinue once and more than once when compared with those who had a stable relationship. Similarly, Sassler et al. (2009) observed that couples who believed that they had a future together were more consistent in using contraception. In contrast, Frost, Singh \& Finer (2007a), noted that women living with their sexual partner were more likely to have a gap in contraception than unmarried women, the authors suggesting that cohabiters had a more committed relationship, which lead to a desire for pregnancy. Also, Vaughan et al. (2008) observed that married or cohabitates women were $16 \%$ less likely to resume use after discontinuation than other women. While studies do not consistently report the same partner effect, due to population selection and cultural context, research (BardenO'Fallon, 2011a) consistently shows that the partner has an important influence on contraceptive use dynamics, as also observed in our study.

In our study, women who had four or more years of sexual experience were on average $40 \%$ less likely to discontinue their method for any reason once or more than once. Women who had one or less year of sexual experience probably were using the method for the first time, which can contribute to the difficulty of adhesion and compliance to the method. Barden-O'Fallon et al. (2011a) observed that discontinuation was higher (45\%) among recent users, i.e., new user of family planning/new to method, or use of method one year or less.

Religious affiliation is a factor associated with sexual and contraceptive behaviors (Lammers et al. 2000; Meier 2003). Interestingly, Catholic women were $20 \%$ less 
likely to discontinue their method one time for any reason when compared with women with no religion. According to data from Brazilian Institute of Geography and Statistics (IBGE), Catholic religion is the main religion practiced among Brazilians (65\%) (IBGE, 2010). Similar to our outcomes, Grady and colleagues (2002) noted that unmarried women in U.S. with no religious affiliation were more likely to switch to less effective contraception. González et al. (2009) observed that young women in Chile who are non-Catholic religious affiliation presented higher risk for abandonment of their method. In contrast, Burdette et al. (2014) found that American Evangelical practioners were more likely to inconsistent contraception use than non-affiliates. It seems that religious objections do not interfere in the continuous use of contraception for some women. We stress that the variable religion in our study was based on affiliation, this by no means indicates that women attended the religion or were religious during the time of observation. Results of a national survey in Brazil showed that the majority of the Brazilian population declared to have a religion (95\%), however only a part of the population (37\%) attended a religious service at least once a week (Moreira-Almeida et al., 2010).

Women who were enrolled in Exact Sciences course were almost 2 times to discontinue their method for any reason and for method-related reasons more than once when compared with women who were enrolled in Human Sciences course. At the same time, they were less likely to discontinue their method one time. In addition, women who were enrolled at Health Sciences courses were also more likely to discontinue their method for any reason more than once. Inconsistencies in the use of highly effective contraception among Health Sciences students denote that the technical and scientific knowledge acquired in undergraduation classes does not necessarily mean a more planned contraceptive behavior.

The explanatory power of contraceptive discontinuation among women enrolled in different fields of study is limited, since there are no studies conducted with students that investigated the relationship between field of study/major and contraceptive discontinuation. This is the first study that addressed field of study in the context of discontinuation and more qualitative research is needed to elicited the associations observed. 


\subsubsection{Monthly discontinuation of contraception}

Adding to frequency of discontinuation analyzes, our study also examined monthly discontinuation of contraception by method type. Emphasize that most $(82 \%)$ of all instances of monthly discontinuation were due to method-related reasons, similar to findings in the literature (Vaughan et al., 2008; Moreau et al., 2009a; Ali, Cleland, Shah, 2012). Research has assessed that reduced need represents only for $7-20 \%$ of discontinuation of all reversible methods (Blanc, Curtis, Croft, 2002). In this context, discontinuation for method-related reasons is a more relevant indicator of discontinuation in terms of pregnancy prevention, as it does not include discontinuation due to a desire to get pregnant or because of partner breakup (Ali, Cleland, Shah, 2012). Moreover, discontinuation for method-related reasons deserves specific attention, since it suggests a mismatch between women's desire and their practice that can potentially be resolved with better counselling (Hooper, 2010). Less frequent, but most concerning are events of abandonment or switching to less effective method, which represented $3.4 \%$ of all instances of monthly discontinuation.

Although switching contributes to heighten the risk of an unintended pregnancy, since failures are higher at the start of use of a method when women are still familiarizing themselves with the regimen, the risk of an unintended pregnancy are higher when a woman abandon the method or switch to less effective method (Peterson et al., 1998; Leite, Gupta, 2007; Ranjit et al., 2001; Trussell, 2004; Moreau et al., 2007; Barden-O'Fallon et al., 2011). It is expected that $85 \%$ of women using reversible contraceptives become pregnant within a year if they abandon contraception altogether (Trussell et al., 2007). This reflects the difficulty for women to maintain contraceptive use or to adopt a new method after stopping their previous method, mainly due to the lack of method choice (Castle, Askew, 2015). Vaughan et al. (2008) investigated women aged $15-44$ in the U.S., and they observed that $25 \%$ of all reversible method segments are abandoned within a year for method-related reasons. In contrast, Barden-O'Fallon \& Speizer (2011b), noted that $57 \%$ of women in Honduras stopped their method for one month or more. Low rates of abandonment of contraception for method-related reasons is observed in France $(6.0 \%)$ and England (0.4\%) (Moreau et al., 2009a; Wellings et al., 2015). 
Examination of monthly discontinuation of contraception by method type, demonstrated that discontinuation for any reason, for method-related and method abandonment were more frequent among women using the male condom as compared to those using oral pill. Concomitantly, condom users were almost four-fold to discontinue their method for any reason and for method-related reasons once and more than once when compared with oral pill users. Findings from U.S. and France also revealed higher estimates for discontinuation among condom users than oral pill users (Vaughan et al., 2008; Mansour, 2008; Moreau et al., 2009a; Castle, Askew, 2015). Our results of discontinuation across methods show that discontinuation among condom users who had casual relationship were higher when compared with oral pill users who had casual relationship. Indeed, Frost \& Darroch (2008b) noted that women who reported a lower frequency of sexual intercourse were more likely to be condom users than women who had a higher frequency of intercourse. The fact that women in stable relationship, specially condom users, is less likely to discontinuation, supports our interpretation that discontinuation is frequently related to being in relationships that are short-term or to have low frequency of sexual intercourse. Further analysis addressing male condom, would improve our comprehension of the dynamics of use of this method.

Investigation of multiple factors associated with monthly discontinuation showed similar outcomes observed in the analyzes exploring frequency of discontinuation, but with some peculiarities once monthly discontinuation analyzes were stratified by method. Only oral pill users who had casual relationship were more likely to abandon or switch to less effective method, this result was not significant for male condom users. This result may be related to the fact that oral pill users in casual relationship are more concerned about the risk of sexually transmitted diseases when compared with oral pill users in stable relationship, which lead them to switch to less effective method, such as male condom. Oral pill users from low socioeconomic status were more likely to discontinue their method for any reason, for method-related reason and to abandon or switch to less effective method, however this result was not observed among male condom users. As the main reason for discontinuation among oral pill users are the side-effects, we can suppose that women from low socioeconomic status may not afford trying different brands of oral pill that best suits them, once they face side-effects. Primary health care services deliver just six brands of oral pills, while in pharmacies that can be found many more options. Therefore, the difficulty in 
getting adapted to the oral pill with the additional cost of accessing new brands, can lead to contraceptive discontinuation among oral pill users from low socioeconomic status. We stress that this assumption needs further research.

Additionally, oral pill users who had multiple sexual partners (as explained before) and who had a previous pregnancy, were more likely to discontinue their method for any reason, for method-related reasons and to abandon their method. The higher likelihood of discontinuation among women who got pregnant was contradictory of previous findings that the parity is a contributor to continuous use of contraception (Gray, McDonald, 2010; Daniels et al., 2015; Richters et al., 2016).

As for educational background, more specifically university campuses, oral pill users who were studying out of São Paulo, capital were $30 \%$ less likely to discontinuation for any reason and $20 \%$ less likely to discontinuation for methodrelated reasons when compared to women who were studying in São Paulo, capital. There are no studies that address discontinuation and compared the differences between women who were studying in a capital and those who were studying in small cities. It was curious to note this finding, since in São Paulo has more private pharmacies available 24 hours and more primary health care facilities widespread in the city, which may facilitate the continuous use of the method among women who live in capital.

Male condom users who had casual relationship, who had less year of sexual experience and who had previous pregnancy, were more likely to discontinuation for any reason and to discontinuation for method-related reasons. Also, younger male condom users were more likely to abandon their method or to switch to a less effective method. It was expected that male condom users who were in a casual relationship were more likely to discontinuation, since they have shorter relationships. Further insights from a qualitative research observed that although the respondents had beliefs about adequate male condom use in different types of relationship, their actions were no consistent with those beliefs frequently leading to gaps in contraception (Raine et al., 2010). According to the authors, the young men were knowledgeable about the importance of condom use in certain relationships for preventing STDs and unintended pregnancy and they also had intentions to use them; however, they reported gaps in use in casual relationship, and this occurred due to any reasons, including not wanting to use male condoms, alcohol, not having condom, or being "lost in the moment". 
Another important finding was the association between age and method abandonment. Consistent with our results, Vaughan et al. (2008), observed that the contraceptive use among condom users was almost $42 \%$ more likely to be discontinued if the user was 12-19 years old, compared to use by women aged 2029. Additionally, the author observed that condom users who never became pregnant, were $27 \%$ less likely to discontinued for method related-reasons when compared to women with children, which is also compatible with our results about the parity and contraceptive discontinuation among male condoms.

Other sociodemographic variables which presented association with discontinuation was race/ethnicity. Condom users who reported to be black were less likely $(40 \%)$ to discontinuation for any reason, which is contradictory with other studies (Frost, Singh, Finer, 2007b; Kost et al., 2008; Rocca, Harper, Raine-Bennett, 2013).

As for sexual experience, male condom users who had one or less year of sexual experience may have used the method for few months, which propels them to discontinue their method for method-related reasons. Equally, Barden O'Fallon et al. (2011) noted that new users and women who were using their method for one or less year were nearly $73 \%$ more likely to discontinue their method for method-related reasons when compared to women who were using their method for more than one year.

\subsubsection{Cumulative probabilities of discontinuation of new episodes of contraception}

As for new episodes of contraception, we observed that male condom users presented higher cumulative probabilities of discontinuation for any reason and for method-related reasons over time, when compared to oral pill users. On the other hand, oral pill users had cumulative probabilities of method abandonment a bit higher than male condom users. In addition, $21 \%$ of oral pill user discontinued their method for method-related reasons by 11 months of use, compared with $39 \%$ of male condom users. Almost similar, $25 \%$ of oral pill user abandoned or switched to a less effective method by 11 months of use, compared with $22 \%$ of male condom users. Data from 60 DHS conducted between 1990 and 2009 in 25 countries, including 
Brazil, showed that about half of pill users have stopped their method by the end of the third year, compared with one-third of condom users (Ali, Cleland, Shah, 2012).

Although our outcomes of cumulative probabilities of discontinuation are consistent with others conducted in a variability of settings (Vaughan et al., 2008; Mansour, 2008; Moreau et al., 2009a; Barden-O'Fallon et al., 2011b; Castle, Askew, 2015), it is disturbing to note that a relevant proportion of undergraduate students, which was expected that they had low rates of discontinuation due to the high level of education, presented a sizeable likelihood of discontinuation for method-related reasons and method abandonment. Also, considering that the relationships among young people are dynamics, it is noteworthy that almost $40 \%$ of condom users discontinued and $22 \%$ abandon their method, and it should be remembered that the condom is the only contraceptive that prevents STDs.

Consistent with our other analyzes of contraceptive discontinuation, our outcomes of new episodes of contraception showed that oral pill users and male condom users who were in a casual relationship presented higher risk of experiencing discontinuation for method-related reasons. Also, observed and discussed before, male condom users who reported have one or less year of sexual experience, presented higher risk of discontinuation when compared with condom users who had more years of sexual experience; however, it was surprising to note that the opposite was true for oral pill users. Additionally, male condom users who were practitioners of Kardecist Spiritualism Doctrine religion presented higher risk of abandoning their method or switching to less effective method than women who had no religion. Although religion is constantly associated with contraceptive behaviors (Hall, Moreau, Trussell, 2012; Patton, Hall, Dalton, 2015; Freedman, Stulberg, 2016), there are no studies national and international that address the religion "Kardecist Spiritualism Doctrine", probably because this religion is restricted to some countries, and there are few practioners of this religion in Brazil (IBGE, 2010).

This study provides an exploratory and descriptive framework on contraceptive discontinuation among young people in Brazil. The up-to-date analysis of women's contraceptive method behavior provides a solid platform for future research. The most strengths of our study are the ability to comprehend the contraceptive discontinuation among undergraduate students, since the frequency and extent of contraceptive gaps among young women in Brazil nowadays is not well-known. We stress that this is the first study that addressed field of study in the context of 
contraceptive discontinuation. Most of the studies that contemplate young people do not address the educational background, which has been shown to be associated with contraceptive discontinuation in our analyzes.

This study has some limitations which need to be considered while interpreting our results. First, the study was carried out only in one university, although contemplated all campuses of this university, it may not be representative of Brazil university female students, and therefore results may not be generalizable to other universities in Brazil. Second, an important question is the methodological issue of recall bias, due to retrospective nature of the contraceptive method history calendar. Third, another limitation refers to the grouping of "switching to a less effective method" with "method abandonment", a resource used due to the low number of women who abandoned their methods and therefore, which would make some analyzes impossible. Although women who abandon their method or switching to a less effective method represent women at high risk of unintended pregnancies, we understand that contraceptive behavior differs between the two categories. Fourth, there is no corresponding contraceptive method history calendar for men. Therefore, equivalent analyses for men cannot be investigated. Future consideration to men is also necessary, since the involvement of the partner impact in the contraceptive behavior (Manning et al., 2009; Manlove et al., 2011; Wildsmith, Manlove, StewardStreng, 2015). Fifth, we did not evaluate contraceptive failures, since it was not our objective. However, we recognize that failure of contraceptive method is an important outcome to study because it can lead to immediate risk of unintended pregnancy. Sixth, only few reasons for discontinuation were collected. In actuality, there are numerous reasons for discontinuing a contraceptive method, so we recognize our analyses of reasons for discontinuation are probable overgeneralized. Seventh, our analysis is limited to two contraceptive methods (oral pill and male condom), since the other methods were poorly reported by our study population. In Brazil, modern contraceptive methods are used on a limited scale (Brasil, 2008a). Another study conducted with university students at University of São Paulo, also observed a concentration in the use of these two methods (Borges et al., 2010).

Finally, a key limitation is related to methodological: in our analysis of monthly discontinuation we right-censored episodes of use that did not end before the date of interview; however, in this analysis we did not left-censored episodes that start 
before the calendar period initiated. In contrast, when we analyzed the cumulative probabilities of discontinuation of new episodes of contraception we right-censored the episodes that did not finish before the date of interview, and also left-censored episodes that began before the calendar period. Therefore, we exclude all the first episodes of discontinuation, and the women who used the same contraceptive method consistently through the entire contraceptive calendar; highlights that women who started a contraception before calendar period tend to be more consistent users. By excluding these women, who were at risk of contraceptive discontinuation but did not discontinue during the contraceptive calendar, we probably overestimating the discontinuation rates.

\subsection{CONCLUSION}

We conclude that few young women discontinued their method for methodrelated reasons; however, we stress that a relative proportion of women abandoned their method or switched to a less effective method. Additionally, we conclude that the frequency of discontinuation within 12-months is low, most of women who discontinued their method for any reason or for method-related reasons, discontinued just once during the 12-months.

We find that contraceptive discontinuation does differ by type of contraceptive method. Oral pill was the most contraceptive method used 12-months prior to the survey, following by male condom. However, young women who were using male condom were more likely to discontinued their method (any reason, method-related reasons and method abandonment); although we also observed (in analysis of new episodes of contraception) that oral pill users were more likely to abandonment or switching to a less effective method when compared with male condom users.

The variables most strongly associated with contraceptive discontinuation for any reason, discontinuation for method-related reasons, and abandonment or switching to a less effective method were type of relationship, number of partners, and sexual experience, which appeared in most analyzes. In addition, socioeconomic status was a significant variable, except for the analysis of new episodes of contraception.

Drawing insights from our outcomes, we believe that a larger comprehending of young's concerns and experience using contraception could help primary health care 
providers reshape counseling strategies to improve adequate contraceptive continuation. Further researches are needed to explore the issues that influence contraceptive dissatisfaction which leading to contraceptive discontinuation among young people. These issues include women's social and demographic characteristics, which have shown to be associated with contraceptive behaviors in Brazil (Pirotta, Schor 2004; Borges et al., 2010).

While method abandonment is an important outcome to study because it leads to immediate risk of unintended pregnancy, a key limitation when analyzing this outcome is that women's choice of new method sometimes is not taken into account. In contrast, method switching is essential within women's reproductive life course because the rate of switching and type of switching negatively or positively affects reproductive health outcomes (Steele, Curtis, 2003). We noted that, on one hand, method switching may compromise women's protection and, as such, make them more susceptible to unintended pregnancy (Grady et al. 2002; Vaughan et al. 2008). Conversely, it may improve women's reproductive health, in general, if they switch from less to more effective contraception.

Contraceptive discontinuation is a particularly significant issue for adolescents and young women, since they tend to have more limited access, and face more barriers than older women in family planning programs, as well as more unpredictable and irregular sexual activity, and probably have lower knowledge about using contraceptive methods properly. Therefore, high quality family planning services are necessary, especially in a country where abortion is restricted, like Brazil. In this context, initiatives to improve young women's knowledge and access to all contraception are required. Adequate, accurate and detailed information on the importance of consistent contraceptive use, and issues around side-effects should be emphasized in order to minimize contraceptive discontinuation, whether during medical consultations or students discussion meetings around the units. Furthermore, researchers could work together with university students to try to solve the major problems about contraceptive and sexual behaviors in this population. 
5.CHAPTER FIVE 



\section{CHAPTER FIVE}

\section{EMERGENCY CONTRACEPTION AND CONTRACEPTIVE DISCONTINUATION (CONTRACEPTIVE CALENDAR)}

\subsection{BACKGROUND OF THE STUDY}

\subsubsection{Introduction}

Nearly $46 \%$ of pregnancies are reported as unintended in Brazil (Brasil, 2008a; Berquó, Lima, 2008). In this context, emergency contraception (EC) can prevent pregnancy after unprotected sexual intercourse (Raine et al., 2005). However, the options of EC in Brazil are limited. EC levonorgestrel pills are the only EC products available in Brazil, introduced in public health programs in 2001 (Brasil, 2010; WHO, 2012). While there are other EC methods that are more effective such, as the intrauterine device, mifepristone EC and ulipristal acetate, these methods were not available at the time of this study (Glasier et al., 2011; Cleland et al., 2012; Trussell, Raymond, Cleland, 2014). In addition, studies have shown that the institutionalization of EC in the Brazilian scenario is not fully consolidated in primary health care system, mainly due to moral and religious factors, and the lack of knowledge from health professionals and users (Costa, Guilhem, Silver, 2006; Souza, Brandão, 2009; Figueiredo, Paula, 2012).

National estimates of EC use are difficult to compare as studies refer to different time frames (lifetime or annual incidence), different study populations (all women of reproductive age, young women, abortion patients) and different time periods extending over 15 years. Following the switch to non-prescription status, $17 \%$ of women 15-44 years old in France had ever used EC in 2004 (Moreau, Bajos, Trussell, 2006), 11\% of women 15-49 years old has done so in the US in the period 2006-2010 (NHS Contraceptive Services, 2011/12), while 16\% of young women (average age 19.5 years) in Italy had ever used EC despite the prescription requirement (Tafuri et al., 2012). 
In Brazil, according to 2006 DHS, $12 \%$ of all women ever used EC, with the highest use rate observed among youths aged 20-24 (18.5\%) (Brazil, 2008a). EC use is significantly more frequent among Brazilian undergraduate students, ranging from $42.0 \%$ to $50.4 \%$ lifetime use (Borges et al, 2010; Silva et al., 2010; Alano et al., 2012). These age patterns are also observed in other developing countries such as France, the U.S. and the U.K. (Martin, 2004; Gainer et al., 2005; Moreau et al., 2006; Lakha F, Glasier, 2006; Escobar et al., 2008; Cameron et al., 2011; Daniels, Jones, Abma, 2013).

Although a substantial proportion of women have already used EC, EC is not used enough to have a public health impact in many countries, that is, EC is not utilized as often as needed to curve unintended pregnancy risk (Hu et al., 2005; Glasier et al., 2010; Palermo, Bleck, Westley, 2014; Nappi et al., 2014). Studies conducted in Scotland, France and Denmark over the last 15 years, observed that nine out of 10 women undergoing an abortion do not use EC to try to reduce the risk of pregnancy, a figure that has remained constant despite greater use of EC in the general population, (Sørensen et al., 2000; Moreau et al., 2005; Cameron et al., 2012).

Researchers have shown that EC is mostly used to compensate for discontinuation and errors of use of regular methods (mainly because of a ruptured condom and missed oral contraceptives) (Falk et al., 2001; Sorhaindo et al., 2002; Moreau et al, 2006). In Brazil, discontinuation for method-related reasons range from $42.6 \%$ for male condom to $33.1 \%$ for oral pill - the most widely used methods among Brazilian youth (Ali, Cleland, Shah, 2012; Alano et al, 2012; Silva et al., 2010; Silva Camargo, Iwamoto, 2014). In case of contraceptive discontinuation with potential gaps in use, EC becomes especially important and may be used as a backup option (Borges et al., 2010).

A better understanding of EC use in relation to contraceptive use dynamics, including discontinuation is an important step in informing more effective strategies to reduce unintended pregnancies. In the context of legal restrictions to abortion, the prevention of unintended pregnancy is a primary prevention strategy to reduce unsafe abortion, which is estimated at an annual average of 994,465 abortions, and responsible for $12 \%$ of maternal mortality in Brazil (Faúndes et al., 2007; MartinsMelo et al., 2014), and thus improve women's health. 
Notwithstanding, no study has been done in Brazil focused on exploring EC in relation to the contraceptive discontinuation. The latest data on contraceptive discontinuation dates back to the 1996 DHS survey (Brazil, 2008a) with little insights on how overall practices and user dynamics have evolved ever since.

\subsubsection{Aims of study}

This study focuses on the factors that are related to EC use. First we exam the context of EC use the last time it was used among women who ever used EC and then focus our analysis on recent use of EC reported in the 12-month calendar. We specifically focus our attention to EC use following contraceptive discontinuation, bridging this analysis with our previous exploration of contraceptive discontinuation among university students in São Paulo. Acknowledging that most women use EC in relation to inconsistent use of a regular method rather than in the context of nonuse of contraception, we also investigate the factors related to EC use following inconsistent use versus EC use related to nonuse of contraception. Our specific research questions are the following:

- What are the contraceptive circumstances and access conditions related to the last time of using EC among women who reported ever using the method?

- What are the contraceptive circumstances and access conditions related to the last time of using EC among women who reported using the method in the past 12-months?

- What are the factors related to EC use in the context of contraceptive discontinuation (for method related reasons of method abandonment)?

- What are the differences between women who use EC following inconsistent use of contraception, versus those who use EC in context of non-regular contraception?

\subsection{METHODOLOGY}

This section outlines the study population, methods of data collection, the measures and the statistical method used for the analysis. 


\subsubsection{Study population and survey site}

We conducted a 12-months retrospective cohort study with a probabilistic sample of undergraduate female students from University of São Paulo, Brazil. Students were selected electronically by simple random sampling without replacement based on a list of all the email addresses of undergraduate students organized alphabetically. Eligibility criteria to participate in this study included being between 18 and 24 years old, and being enrolled in regular undergraduate course in any of the campuses of University of São Paulo, Brazil. All students who were selected received an electronic message, and those who agreed to participate in the study completed an electronic consent form (APPENDIX A). Further selection criteria included ever having sexual intercourse and having used contraception any time during the last 12 months since the study focuses on contraceptive discontinuation. The ethical approval to conduct this study was obtained from the Research Ethics Committee at University of São Paulo School of Nursing (CAAE Number: 39142514.4.0000.5392) (ANNEX I).

\subsubsection{Sampling}

Among the 3,078 undergraduate students who were randomly selected and invited to participate in the study, 2,182 (71\%) answered the online questionnaire. However, the final study population included 1,679 undergraduate students, since 50 women refused to participate in the study, and 453 students were not eligible for the study (< 18 years old $(n=2)$, had never had sexual intercourse $(n=358)$, and had not used any contraceptive method in the last 12 months $(n=93))$.

In this analysis, we further identified 4 study samples:

1) The first sample comprises women who reported ever using EC ( $n=916)$, for research question 1.

2) The second sample comprises women who indicated using EC in the last 12months $(n=449)$ to address question 2. 
3) The third sample comprises women who discontinued use of contraception, for research question 3. Building on our previous analysis of method discontinuation, we defined contraceptive discontinuation for method-related reasons as a time when women stopped using their method (switched to another method or abandoned contraception) while still in need of contraception (with a partner, not pregnant, not trying to conceive, not sterile). In addition, we defined method abandonment as women who stopped using their method while still in need of contraception, with no resumption of use within a month of discontinuation. Altogether, 464 women discontinued their contraception for method related reasons and a subsample of 151 of these women abandoned contraception.

4) Finally, we consider all instances of EC use following inconsistent use of contraception ( $n=432)$, and all instances of EC use in the context of non-regular contraception $(n=53)$ to address question 4.

\subsubsection{Data collection and study instruments}

A self-administered questionnaire was constructed and made available through Google Form, which took on average between 5 and 7 minutes to complete (APPENDICES B AND C). The questionnaire collected information on women's sociodemographic characteristics, their sexual and reproductive antecedents, and the contraceptive method mostly used, in the 12-months prior to the survey. Women who reported using contraception in the past 12-months, answered a monthly contraceptive calendar, modeled off of the study by Bradley and colleagues conducted in 2009 (Bradley, Schwandt, Khan, 2009). In addition, we collected information on monthly use of EC in the last 12-months, that is, women were asked if they used EC in each month of the contraceptive calendar.

Independently of using EC in the last 12-months, women were also questioned if they had already used EC in lifetime. In positive case, they were specially asked to describe the circumstances of the last time that they used EC, including the type of relationship when EC was used, who bought the medicine, prescription, site purchase location, time between sexual intercourse and use of EC, among others. 


\subsubsection{Unit of analysis}

Our unit of analysis was different based on our research objective:

- For question 1, we conducted a women level analysis exploring the circumstances in which they used EC for the last time in lifetime.

- For question 2, we conducted a women level analysis exploring the circumstances in which they used EC for the last time in the last 12-months.

- For question 3, we conduct a monthly use level analysis, where we partitioned the contraceptive calendar into 12-months of contraceptive use and specifically selected months of observations following discontinuation for method-related reasons or months of observations following method abandonment for analysis. We identified 842 months of observation that followed discontinuation for method-related reasons, and 428 months of observation that followed method abandonment. These observations are used as the analytical samples to investigate the factors related to EC use following contraceptive discontinuation for method-related reasons or method abandonment.

- For question 4, we also conduct a monthly use level analysis, by selecting all calendar months in which women reported using EC in order to compare instances of EC use resulting from inconsistent use of contraception versus instances of EC use related to non-use of contraception or method abandonment.

\subsubsection{Measures}

EC use

We define four measures of EC use: "EC use following discontinuation for method-related reasons", "EC use following method abandonment", "EC use following inconsistent use of contraception", and "EC use in the context of nonregular contraception". These indicators are measured for each episode of use of EC: 
- "EC use following discontinuation for method-related reasons" refers to instances of using EC when women stopped using their method while still in need of contraception (with a partner, not pregnant, not trying to conceive, not sterile), regardless of what they did next (switched to another method or abandoned contraception).

- "EC use following abandonment" related to instances of using EC when women stopped using their method while still in need of contraception (with a partner, not pregnant, not trying to conceive, not sterile), and they did not resume contraception within a month of discontinuation.

- "EC use following inconsistent use of contraception" refers to instances of using EC when women switching their method while still in need of contraception (with a partner, not pregnant, not trying to conceive, not sterile); and instances of using EC when women use their method continuously. We consider this latter situation as "inconsistent use of contraception," because we assume that for women to use EC when they use their method continuously, it is because they probably had inconsistencies in the use of their contraception.

- "EC use in context of non-regular contraception" refers to instances of using EC when women stopped using their method while still in need of contraception (with a partner, not pregnant, not trying to conceive, not sterile) and did not resume contraception within a month of discontinuation; and instances of using EC when women were not using any contraception.

\section{Emergency contraception history}

For our first and second research questions, to explore the circumstances of the last time that EC was used in lifetime and in the past 12-months, we considered the information based on previous research findings. Specially, we include knows anyone who have used EC (no/yes); past use of EC; ever had unprotected intercourse and not used EC (no/yes); used contraceptive method when using EC (no/yes); contraceptive method used at the time of EC use (oral pill, condom, withdrawal/fertility-awareness, injectable, other methods, no contraception); reasons for using EC (by sheer insecurity, forgot to use some contraceptive 
method, the contraceptive method that was using failed, I did not want to use any contraceptive method, I was a victim of sexual violence); prescription for EC (no/yes); EC source (pharmacy, boyfriend who brought, private doctor/health insurance, and national health system, which included primary health care and the Unified Health System, SUS).

In addition, detailed informations about contraception, partner and time of using EC were contemplated, such as ever had unprotected intercourse and not used EC (no/yes); used contraceptive method when using EC (no/yes); contraceptive method used at the time of EC use (oral pill, condom, withdrawal/fertilityawareness, injectable, other methods, no contraception); type of relationship when used EC (steady, such as with boyfriend or living with a partner, casual relationship); and person who took the initiative to use EC (woman, partner, both); number of times EC was used (once, twice, three or more times); timing of last use (up to two years ago, three or more years ago, do not remember); time of EC use after unprotected sexual intercourse ( $<24$ hours, $1-5$ days, $\geq 6$ days, do not remember).

For our third and fourth questions, to investigate the EC use following discontinuation for method-related reasons and method abandonment; and use of EC following inconsistent use of contraception versus in context of non-regular contraception, respectively; we considered the women's sociodemographic characteristics and sexual and reproductive health indicators that showed to be associated with EC use according to previous research:

Women's sociodemographic and reproductive health history measures

We consider women's sociodemographic characteristics as predictors of EC use based on previous research findings. Specifically, we include age (18-19 or 2024); race/ethnicity (white, black, other); religious affiliation (none, roman catholic, kardecista spiritualism doctrine, evangelical, other); socioeconomic status (high $(A / B)$ - middle/low (C/D/E)) (ABEP, 2015).

Because this study focuses on university students, we will consider their educational characteristics. This information includes field of study (human 
sciences, health sciences, exact sciences); period of study (full-time or parttime); and campus (São Paulo, countryside).

Sexual and reproductive health indicators are found to be strongly associated with EC use. In our study, we considered the following correlates of EC use: type of relationship (steady, such as a boyfriend or living with a partner, casual relationship); time since first sexual intercourse ( $\leq 1$ year, 2-3 years, $\geq 5$ years); number of sexual partners (1 partner, 2-3 partners, $\geq 4$ partners); pregnancy history (no/yes); current contraceptive method (highly effective method or nonhighly effective method).

\subsubsection{Statistical analysis}

We only conducted descriptive analysis due to the small number of women reporting EC use in the last 12-months.

We first explored the circumstances of the last time that EC was used in lifetime, and also in the past 12-months among undergraduate students. Posteriorly, we investigated the correlates of using EC following contraceptive discontinuation for method-related reasons in the 12-months prior to the survey (which it includes instances of EC use following method switching and instances of EC use following method abandonment), and after the correlates of EC use following method abandonment in the 12-months prior to the survey (which it includes only instances of method abandonment). While women could theoretically report several episodes of EC use after method discontinuation, there were only few months of discontinuation reported by the same women, which reduces the issue of inter-correlation between observations.

In the last phase of the analysis we compared factors related to EC use following inconsistent use of contraception (including instances of EC use following method switching and instances of EC use following inconsistent use of the same contraception), to factors related to EC use in the context of non-regular contraception (which includes instances of EC use following method abandonment and instances of EC use following month where no contraception was used). 
We performed Pearson's Chi-square tests to assess the relationships between EC use and each independent variable. All analyses were conducted using Stata 14.2 (Stata Corporation, College Station, TX, USA).

\subsection{RESULTS OF USING EMERGENCY CONTRACEPTION BASED ON CONTRACEPTIVE CALENDAR}

\subsubsection{Characteristics of women according to the last time that emergency contraception was used in lifetime and in the 12- months prior to the survey}

Most young women in this study had used EC (54.6\% of the total sample of 1,679 women) sometime in their life, and $16.5 \%$ had used EC in the 12-months prior to the study. Most last instances of EC use (77.2\%) occurred within two years of the date of the survey.

Table 11 shows the characteristics of the last instance of EC use anytime during women's lifetime and in the 12-months prior to the survey. Findings related to the last time EC used anytime during in lifetime and in the 12-months prior to the survey were almost similar. The most frequent cited reason for using EC (almost $40 \%$ in both cases) was uncertainty about the effectiveness of contraceptive method that was used, while the second most cited reason was forgetting to use contraception. It is noteworthy that more than $50 \%$ (in both cases) of university women were using some contraceptive method when they used EC, with oral pill being the most cited method.

Most young women acquired EC in commercial pharmacies without a prescription. Women and their partners both took the initiative to use for lifetime use EC but women were more likely to take the initiative when EC was used in the last 12 months.

Slightly more than $70 \%$ of women used EC within 24 hours after sexual intercourse, and most of them used it one time only. Yet a significant proportion of young women (almost $40 \%$ ) were found to be needing EC more than once as that they reported having had unprotected intercourse (in their lifetime and in the 12months), but did not use EC. 
Table 11 - Emergency contraception usage characteristics of undergraduate women in the sample. São Paulo, Brazil - 2015

\begin{tabular}{|c|c|c|c|c|}
\hline \multirow{3}{*}{ VARIABLES } & \multicolumn{4}{|c|}{ Use of $E C^{*}$ in the last time } \\
\hline & \multicolumn{2}{|c|}{ Lifetime } & \multicolumn{2}{|c|}{ Last 12-months } \\
\hline & $\mathbf{N}$ & $\%$ & $\mathbf{N}$ & $\%$ \\
\hline \multicolumn{5}{|l|}{ Knows anyone who has used EC } \\
\hline No & 21 & 2.3 & 10 & 2.2 \\
\hline Yes & 895 & 97.7 & 439 & 97.8 \\
\hline \multicolumn{5}{|l|}{ Reasons for using EC } \\
\hline By sheer insecurity & 364 & 39.7 & 179 & 39.9 \\
\hline Forgot to use some contraceptive method & 232 & 25.3 & 115 & 25.6 \\
\hline The contraceptive method that was used failed & 198 & 21.6 & 86 & 19.1 \\
\hline I didn't want to use any contraceptive method & 118 & 12.9 & 67 & 14.9 \\
\hline I was a victim of sexual violence & 04 & 0.4 & 02 & 0.5 \\
\hline \multicolumn{5}{|l|}{ Type of relationship when EC was used } \\
\hline Steady (such as with boyfriend or living with a partner) & 593 & 64.7 & 260 & 57.9 \\
\hline Casual relationship & 323 & 35.3 & 189 & 42.1 \\
\hline \multicolumn{5}{|l|}{ Person who took the initiative to use EC } \\
\hline Woman & 425 & 46.4 & 226 & 50.3 \\
\hline Partner & 56 & 6.1 & 20 & 4.5 \\
\hline Both & 435 & 47.5 & 203 & 45.2 \\
\hline \multicolumn{5}{|l|}{ Acquisition of EC with prescription } \\
\hline No & 902 & 98.5 & 443 & 98.7 \\
\hline Yes & 14 & 1.5 & 06 & 1.3 \\
\hline \multicolumn{5}{|l|}{ Sources for obtaining the EC } \\
\hline Pharmacy & 876 & 95.6 & 437 & 97.4 \\
\hline Boyfriend who bought & 32 & 3.5 & 01 & 0.2 \\
\hline Health clinic or private doctor /health insurance & 05 & 0.5 & 10 & 2.0 \\
\hline $\begin{array}{l}\text { National health system (such as primary health care and } \\
\text { Unified Health System) }\end{array}$ & 03 & 0.4 & 02 & 0.4 \\
\hline \multicolumn{5}{|l|}{ Time using the EC } \\
\hline$<24$ hours & 707 & 77.2 & 343 & 76.4 \\
\hline $1-5$ days & 202 & 22.0 & 100 & 22.3 \\
\hline$\geq 6$ days & 02 & 0.2 & 02 & 0.4 \\
\hline Don't remember & 05 & 0.6 & 04 & 0.9 \\
\hline \multicolumn{5}{|l|}{ Number of times that used EC } \\
\hline Once & 350 & 38.2 & 133 & 29.6 \\
\hline Twice & 249 & 27.2 & 100 & 22.3 \\
\hline Three or more times & 317 & 34.6 & 216 & 48.1 \\
\hline
\end{tabular}


(continuação)

\begin{tabular}{|c|c|c|c|c|}
\hline \multirow{3}{*}{ VARIABLES } & \multicolumn{4}{|c|}{ Use of EC* in the last time } \\
\hline & \multicolumn{2}{|c|}{ Lifetime } & \multicolumn{2}{|c|}{ Last 12-months } \\
\hline & $\mathbf{N}$ & $\%$ & $\mathbf{N}$ & $\%$ \\
\hline \multicolumn{5}{|c|}{ Ever had unprotected intercourse and did not use EC } \\
\hline No & 541 & 59.1 & 267 & 59.5 \\
\hline Yes & 375 & 40.9 & 182 & 40.5 \\
\hline \multicolumn{5}{|c|}{ Used contraception at the time of EC use } \\
\hline No & 362 & 39.5 & 172 & 38.3 \\
\hline Yes & 554 & 60.5 & 277 & 61.7 \\
\hline Total & 916 & 100.0 & 449 & 100.0 \\
\hline \multicolumn{5}{|c|}{ Type of contraceptive method at the time of EC use } \\
\hline Oral pill & 283 & 51.1 & 152 & 54.9 \\
\hline Male condom & 250 & 45.1 & 114 & 41.2 \\
\hline Withdrawal/Fertility-awareness & 12 & 2.2 & 05 & 1.8 \\
\hline Injectable & 03 & 0.5 & 03 & 1.1 \\
\hline Other methods ${ }^{* *}$ & 06 & 1.1 & 03 & 1.1 \\
\hline \multirow[t]{2}{*}{ Total } & 554 & 100.0 & 277 & 100.0 \\
\hline & & & \multicolumn{2}{|c|}{ (conclusão) } \\
\hline
\end{tabular}

\subsubsection{Emergency contraception in the context of contraceptive discontinuation for method-related reasons}

During the 12-months of the contraceptive calendar, 442 women reported using EC contributing to 485 months in which EC was used. In most of the cases, EC was used when women were using a method, probably in relation to incorrect use, and not as a consequence of stopping a method. Specifically, 277 instances of EC use occurred when women reported using the same method during the 12-months, reflecting potential inconsistent use of contraceptives, such as missing pill or condom breakage (Figure $9-\mathrm{C}$ ). On the other than, 155 instances of EC use followed method switching (Figure 9 - A). Both continuous use or method switching correspond to EC use in the context of a breach in contraceptive protection, which accounts for the majority of EC usage (89\%). Only few observations of EC use occurred in the context of non-regular contraception. A total of 45 instances of EC 
followed the 428 months where contraception was abandoned (Figure 9 - B); and only 8 instances of EC use followed the 1,126 months where no contraception was used (Figure $9-\mathrm{D}$ ).
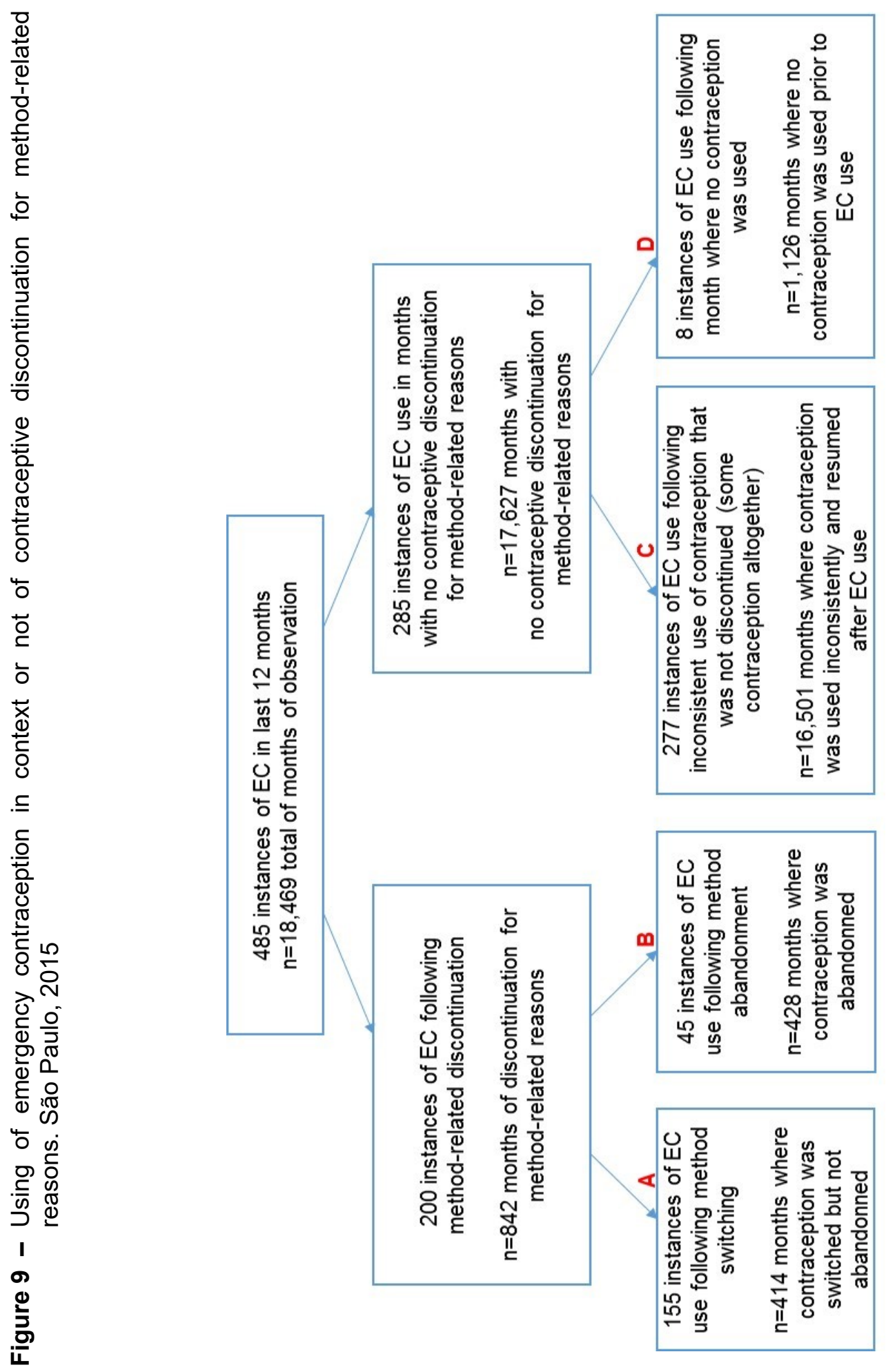
Figure 10 - Emergency contraception use in context of use and non-use of contraception. São Paulo, 201

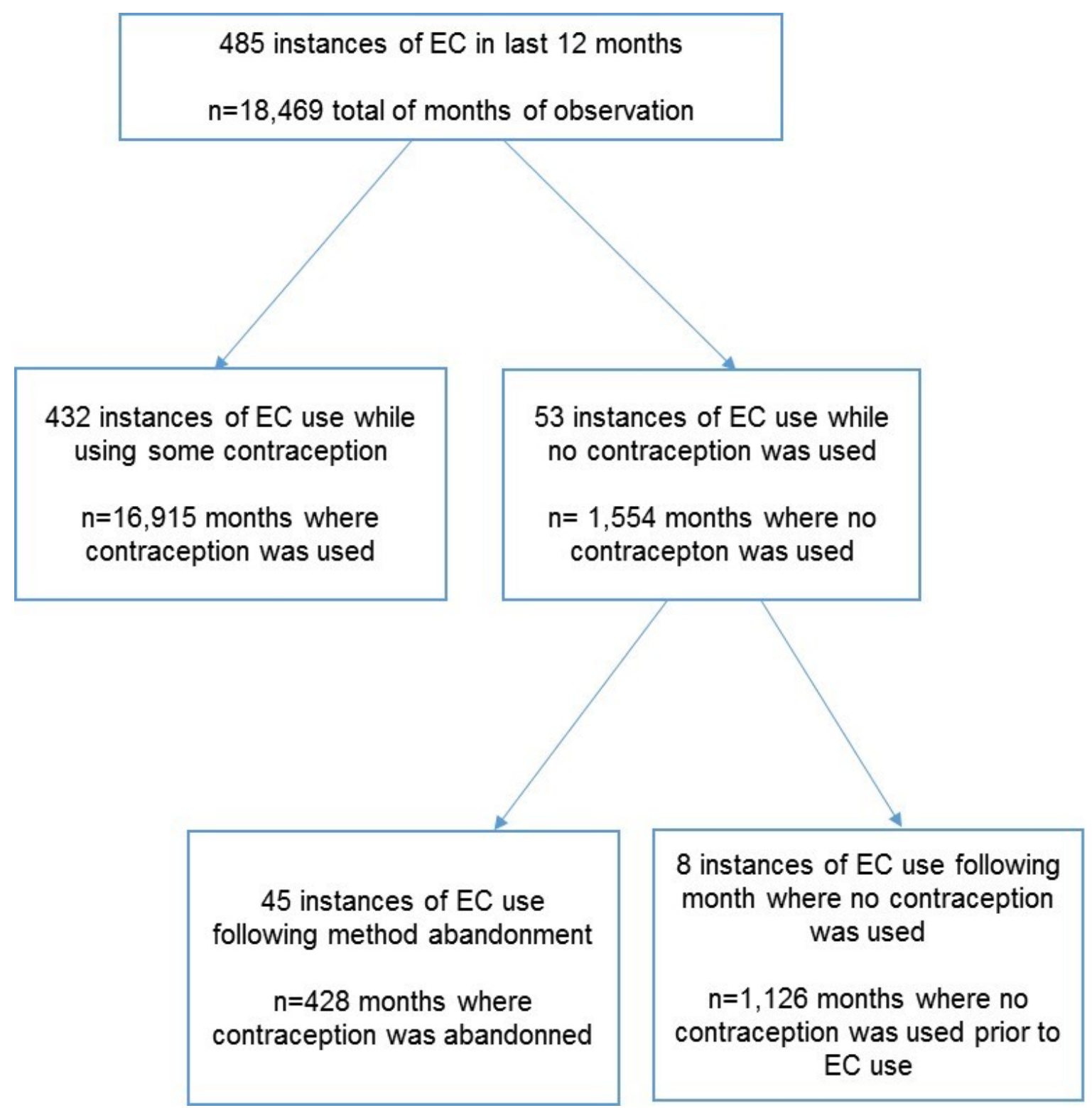

\subsubsection{Characteristics of women who used emergency contraception following contraceptive discontinuation for method-related reasons and method abandonment}

A majority of women (76.2\%) who were at risk of becoming pregnant did not use EC following contraceptive discontinuation for method-related reasons (Figure $\mathbf{9}$ - A 
and B). Furthermore, only $10.5 \%$ of women abandoned contraception while still at risk used EC the following month (Table 12) (Figure 9 - only B).

Few variables were related to EC use after discontinuation for method-related reasons. Women who were younger (18-19 aged), and women who had no pregnancy history were more likely to use EC following method discontinuation. Likewise, women who were enrolled in a part-time program were more likely to use EC following method abandonment.

Table 12 -Sociodemographic and sexual and reproductive health characteristics of undergraduate women according to using of emergency contraception following discontinuation for method-related reasons and method abandonment. São Paulo, Brazil - 2015

\begin{tabular}{|c|c|c|c|c|c|c|}
\hline \multirow{3}{*}{ VARIABLES } & \multicolumn{3}{|c|}{$\begin{array}{l}\text { Discontinuation for } \\
\text { method-related reasons }\end{array}$} & \multicolumn{3}{|c|}{ Method abandonment } \\
\hline & Total & $\begin{array}{l}\text { Used } \\
\text { EC** }\end{array}$ & \multirow{2}{*}{$\mathrm{p}^{* *}$} & Total & $\begin{array}{l}\text { Used } \\
\text { EC** }\end{array}$ & \multirow{2}{*}{$\mathbf{p}^{\star *}$} \\
\hline & $\mathbf{N}$ & $\%$ & & $\mathbf{N}$ & $\%$ & \\
\hline \multicolumn{7}{|l|}{ Sociodemographic characteristics } \\
\hline Age (years) & & & 0.034 & & & 0.548 \\
\hline $18-19$ & 213 & 29.1 & & 117 & 12.0 & \\
\hline $20-24$ & 629 & 21.9 & & 311 & 10.0 & \\
\hline Race/ethnicity & & & 0.133 & & & 0.760 \\
\hline White (caucasian) & 671 & 22.4 & & 322 & 10.5 & \\
\hline Black & 132 & 28.0 & & 67 & 11.9 & \\
\hline Other race/ethnicity ${ }^{* * *}$ & 39 & 33.3 & & 29 & 6.9 & \\
\hline Religion & & & 0.252 & & & 0.178 \\
\hline No religion & 396 & 23.3 & & 201 & 8.0 & \\
\hline Roman Catholic & 241 & 22.0 & & 115 & 15.7 & \\
\hline Kardecist Spiritualism Doctrine & 97 & 21.7 & & 51 & 5.9 & \\
\hline Evangelical & 53 & 35.9 & & 33 & 12.1 & \\
\hline Other religion $\mathrm{n}^{\star \star \star \star}$ & 55 & 27.3 & & 28 & 14.3 & \\
\hline $\begin{array}{l}\text { Type of relationship at the time of } \\
\text { discontinuation }\end{array}$ & & & 0.818 & & & 0.437 \\
\hline Steady & 484 & 23.9 & & 242 & 9.5 & \\
\hline Casual relationship ${ }^{* * * * *}$ & 358 & 23.2 & & 186 & 11.8 & \\
\hline Socioeconomic status & & & 0.617 & & & 0.278 \\
\hline $\mathrm{A} / \mathrm{B}$ & 639 & 0.41 & & 323 & 9.6 & \\
\hline$C-D / E$ & 203 & 0.35 & & 105 & 13.3 & \\
\hline
\end{tabular}


(continuação)

\begin{tabular}{|c|c|c|c|c|c|c|}
\hline \multirow{3}{*}{ VARIABLES } & \multicolumn{3}{|c|}{$\begin{array}{l}\text { Discontinuation for } \\
\text { method-related reasons }\end{array}$} & \multicolumn{3}{|c|}{ Method abandonment } \\
\hline & \multirow{2}{*}{$\begin{array}{c}\text { Total } \\
\mathbf{N}\end{array}$} & \multirow{2}{*}{$\begin{array}{c}\begin{array}{c}\text { Used } \\
\text { EC* }^{*}\end{array} \\
\%\end{array}$} & \multirow[t]{2}{*}{$\mathbf{p}^{* *}$} & Total & $\begin{array}{l}\text { Used } \\
\text { EC* }^{*}\end{array}$ & \multirow[t]{2}{*}{$\mathbf{p}^{* *}$} \\
\hline & & & & $\mathbf{N}$ & $\%$ & \\
\hline \multicolumn{7}{|l|}{ Educational background } \\
\hline Field of study & & & 0.662 & & & 0.281 \\
\hline Human Sciences & 384 & 23.7 & & 181 & 13.3 & \\
\hline Health Sciences & 290 & 25.2 & & 157 & 8.3 & \\
\hline Exact Sciences & 168 & 21.4 & & 90 & 8.9 & \\
\hline Period of study & & & 0.736 & & & 0.026 \\
\hline Full-time & 387 & 24.3 & & 210 & 7.1 & \\
\hline Part-time & 455 & 23.3 & & 218 & 13.8 & \\
\hline Campus & & & 0.293 & & & 0.179 \\
\hline São Paulo & 581 & 22.7 & & 275 & 12.0 & \\
\hline Out of São Paulo & 261 & 26.1 & & 153 & 7.8 & \\
\hline \multicolumn{7}{|l|}{ Sexual and reproductive behavior } \\
\hline Time since first sexual intercourse & & & 0.293 & & & 0.378 \\
\hline$\leq 1$ year & 163 & 26.4 & & 73 & 15.1 & \\
\hline $2-3$ years & 285 & 25.6 & & 159 & 9.4 & \\
\hline$\geq 4$ years & 394 & 21.3 & & 196 & 9.8 & \\
\hline Number of sexual partners in lifetime & & & 0.366 & & & 0.346 \\
\hline 1 partner & 47 & 22.6 & & 93 & 8.6 & \\
\hline $2-3$ partners & 54 & 21.3 & & 131 & 13.7 & \\
\hline$\geq 4$ partners & 99 & 26.0 & & 204 & 9.3 & \\
\hline Previous pregnancy & & & 0.037 & & & 0.328 \\
\hline No & 808 & 24.4 & & 420 & 10.5 & \\
\hline Yes & 34 & 8.8 & & 08 & 12.5 & \\
\hline $\begin{array}{l}\text { Type of contraceptive method when } \\
\text { abandoned the method }\end{array}$ & & & 0.126 & & & 0.001 \\
\hline Oral pill & 333 & 20.4 & & 243 & 7.0 & \\
\hline Male condom & 341 & 25.5 & & 157 & 12.7 & \\
\hline Other method ${ }^{* * * * * *}$ & 168 & 27.4 & & 28 & 28.6 & \\
\hline 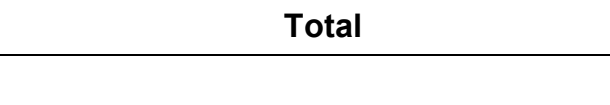 & 842 & 23.8 & & 428 & 10.5 & \\
\hline $\begin{array}{l}{ }^{*} \mathrm{EC}=\text { Emergency contraception. } \\
{ }^{* *} \text { Pearson's chi-square test. } \\
{ }^{* \star *} \text { Other race/ ethnicity include: asian origin and i } \\
{ }^{* * \star *} \text { Other religions include: Afro-Brazilian, Buddhi } \\
{ }^{* * * * *} \text { Women who did not have a partner at the tim } \\
\text { category, only in the analysis of discontinuation } \mathrm{fo}\end{array}$ & $\begin{array}{l}\text { igenous } \\
\text {, Jewish } \\
\text { of discon } \\
\text { any reas }\end{array}$ & $\begin{array}{l}\text { ple. } \\
\text { luslim, Mc } \\
\text { uation we }\end{array}$ & $\begin{array}{l}\text { non, and } \\
\text { included }\end{array}$ & e "casual & elations & רclusão) \\
\hline
\end{tabular}




\subsubsection{Characteristics of women who used emergency contraception following inconsistent use of contraception or in the context of non-regular contraception}

As previously indicated, most women (90.6\%) used EC following inconsistent or incorrect use of contraception, only $10.4 \%$ of women used EC in context of nonregular contraception (Table 13). In the following section, we compare factors related to EC use in the context of regular contraception (Figure $\mathbf{9}-\mathbf{A}$ and $\mathbf{C}$ ); versus EC use in the context of non-regular contraception (Figure 9 - B and D).

Our results show that young women who were in a steady relationship, who may come from a high privileged socioeconomic status, who were enrolled in a full-time program, and who were using oral pill, were more likely to use EC in situations of inconsistent use of contraception. However, women who were in a casual relationship, who may come from a less socioeconomic status, who were enrolled in a part-time program, and who were using male condom (as compared to oral pill), were more likely to use EC in the context of non-regular contraception. These findings mostly reflect differences in regular contraceptive usage between the groups (male condom users and oral pill users).

Table 13 - Sociodemographic and sexual and reproductive health characteristics of undergraduate women by context of EC use (inconsistent use of contraception or in the context of non-regular contraception). São Paulo, Brazil - 2015

\begin{tabular}{|c|c|c|c|c|}
\hline \multirow{3}{*}{ VARIABLES } & \multirow{3}{*}{$\begin{array}{c}\text { Total } \\
\mathbf{N}\end{array}$} & \multicolumn{2}{|c|}{$E C^{*}$ use } & \multirow{3}{*}{$p^{* *}$} \\
\hline & & \multirow{2}{*}{$\begin{array}{c}\begin{array}{l}\text { Inconsistent use } \\
\text { of contraception }\end{array} \\
\%\end{array}$} & \multirow{2}{*}{$\begin{array}{c}\begin{array}{c}\text { Non-regular } \\
\text { contraception }\end{array} \\
\%\end{array}$} & \\
\hline & & & & \\
\hline \multicolumn{5}{|c|}{ Sociodemographic characteristics } \\
\hline Age & & & & 0.242 \\
\hline $18-19$ & 132 & 86.4 & 13.6 & \\
\hline $20-24$ & 353 & 90.1 & 9.9 & \\
\hline Race/ethnicity & & & & 0.579 \\
\hline White (caucasian) & 375 & 88.5 & 11.5 & \\
\hline Black & 75 & 89.3 & 10.7 & \\
\hline Other race/ethnicity ${ }^{* * *}$ & 35 & 94.3 & 5.7 & \\
\hline
\end{tabular}


(continuação)

\begin{tabular}{|c|c|c|c|c|}
\hline \multirow{3}{*}{ VARIABLES } & \multirow{3}{*}{$\begin{array}{c}\text { Total } \\
\mathbf{N}\end{array}$} & \multicolumn{2}{|c|}{ EC* use } & \multirow{3}{*}{$\mathbf{p}^{* *}$} \\
\hline & & \multirow{2}{*}{$\begin{array}{c}\text { Inconsistent use } \\
\text { of contraception } \\
\%\end{array}$} & \multirow{2}{*}{$\begin{array}{c}\begin{array}{c}\text { Non-regular } \\
\text { contraception }\end{array} \\
\%\end{array}$} & \\
\hline & & & & \\
\hline Religion & & & & 0.181 \\
\hline No religion & 228 & 91.2 & 8.8 & \\
\hline Roman Catholic & 130 & 83.9 & 16.1 & \\
\hline Kardecist Spiritualism Doctrine & 59 & 93.2 & 6.8 & \\
\hline Evangelical & 41 & 90.2 & 9.8 & \\
\hline Other religion ${ }^{* * * *}$ & 27 & 85.2 & 14.8 & \\
\hline $\begin{array}{l}\text { Type of relationship at the tim } \\
\text { discontinuation }\end{array}$ & & & & 0.021 \\
\hline Steady & 276 & 90.6 & 9.4 & \\
\hline Casual relationship ${ }^{* * * * *}$ & 209 & 87.1 & 12.9 & \\
\hline Socioeconomic status & & & & 0.029 \\
\hline $\mathrm{A} / \mathrm{B}$ & 367 & 89.9 & 10.1 & \\
\hline$C-D / E$ & 118 & 86.4 & 13.6 & \\
\hline \multicolumn{5}{|l|}{ Educational background } \\
\hline Field of study & & & & 0.149 \\
\hline Human Sciences & 202 & 87.1 & 12.9 & \\
\hline Health Sciences & 178 & 92.7 & 7.3 & \\
\hline Exact Sciences & 105 & 86.7 & 13.3 & \\
\hline Period of study & & & & 0.011 \\
\hline Full-time & 245 & 92.7 & 7.4 & \\
\hline Part-time & 240 & 85.4 & 14.6 & \\
\hline Campus & & & & 0.395 \\
\hline São Paulo & 313 & 88.2 & 11.8 & \\
\hline Out of São Paulo & 172 & 90.7 & 9.3 & \\
\hline \multicolumn{5}{|c|}{ Sexual, reproductive and contraceptive behavior } \\
\hline Time since first sexual interco & & & & 0.153 \\
\hline$\leq 1$ year & 98 & 83.7 & 16.3 & \\
\hline $2-3$ years & 169 & 89.9 & 10.1 & \\
\hline$\geq 4$ years & 218 & 90.8 & 9.8 & \\
\hline \multicolumn{4}{|c|}{ Number of sexual partners in lifetime } & 0.144 \\
\hline 1 partner & 115 & 91.3 & 8.7 & \\
\hline $2-3$ partners & 150 & 84.7 & 15.3 & \\
\hline$\geq 4$ partners & 220 & 90.9 & 9.1 & \\
\hline
\end{tabular}


(continuação)

\begin{tabular}{|c|c|c|c|c|}
\hline \multirow{3}{*}{ VARIABLES } & \multirow{3}{*}{$\begin{array}{c}\text { Total } \\
\mathbf{N}\end{array}$} & \multicolumn{2}{|c|}{ EC* use } & \multirow{3}{*}{$\mathbf{p}^{* *}$} \\
\hline & & $\begin{array}{l}\text { Inconsistent use } \\
\text { of contraception }\end{array}$ & $\begin{array}{c}\text { Non-regular } \\
\text { contraception }\end{array}$ & \\
\hline & & $\%$ & $\%$ & \\
\hline Previous pregnancy & & & & 0.263 \\
\hline No & 475 & 88.8 & 11.2 & \\
\hline Yes & 10 & 100.0 & 0.0 & \\
\hline Total & 485 & 89.07 & 10.93 & \\
\hline Type of contraceptive method ${ }^{* * * * *}$ & & & & 0.024 \\
\hline Oral pill & 260 & 93.5 & 6.5 & \\
\hline Male condom & 172 & 88.4 & 11.6 & \\
\hline Other method ${ }^{* \star * \star * *}$ & 45 & 82.2 & 17.8 & \\
\hline Total & 477 & 90.6 & 9.4 & \\
\hline
\end{tabular}

(conclusão)

${ }^{\star} \mathrm{EC}=$ Emergency contraception.

**Pearson's chi-square test.

${ }^{* * *}$ Other race/ ethnicity include: asian origin and indigenous people.

$* * * *$ Other religions include: Afro-Brazilian, Buddhism, Jewish, Muslim, Mormon, and Islam.

*****Women who did not have a partner at the time of discontinuation were included in the "casual relationship" category, only in the analysis of discontinuation for any reason.

$* * * * * \star$ Other methods include: injectable, withdrawal/Fertilty-awareness patch, an intrauterine device, diaphragms, implants, vaginal ring, female condoms, and spermicide.

\subsection{DISCUSSION}

This is the first paper from Brazil to evaluate EC use following contraceptive discontinuation among women who are at risk of becoming pregnant. A significant proportion of women in our study had used EC (55\% in lifetime and $17 \%$ within the last 12-months). Lifetime estimates of EC use were similar to other studies conducted among Brazilian undergraduate students (Borges et al, 2010; Silva et al., 2010; Alano et al., 2012), and estimated from the American College Health Association (ACHA), indicating that $16.3 \%$ of college students who completed the National College Health Assessment survey had used EC in the last 12-months (ACHA, 2015). However, our frequencies are higher than among young women in most other countries (Tafuri et al., 2012; Daniels, Jones, Abma, 2013; Nappi et al., 2014; Wellings et al., 2015). 
A majority of young women in our study used EC following inconsistent use of their method or in the context of switching to another method. This is consistent with findings that a majority of women use EC while using regular contraception (Jones, Darroch, Henshaw, 2002; Moreau et al., 2009b; Nappi et al., 2014). The main reason for using EC in the 12-months prior to our survey was "by sheer insecurity". Comparably, a study conducted with women aged 18-44 in France, noted that EC was predominantly used in situations of inconsistent contraceptive use or contraceptive errors, with only $15 \%$ of EC instances of use reported by women using no contraception (Moreau et al., 2009b). The same was true in Williamson's study in Scotland (Williamson, 2009).

According to Borges et al. (2010) the use of EC is not only related to inconsistencies in use of ongoing contraception, but grounded in women's strength of motivations to prevent pregnancy, which in turn in shaped by women's educational and professional expectations. In the study by Pirotta \& Schor (2004), university students at University of São Paulo reported that the perfect age for having a first child was around 30 , and the ideal family model was to have two children. Consequently, the authors found that the majority of pregnancies (52\%) among university students were terminated by a miscarriage, similar to our study (65\%).

A significant proportion of women did not use EC after discontinuing or abandoning contraception while still at risk of pregnancy. Approximately, threequarter of women who were at risk did not use EC following discontinuation for method-related reasons and almost $90 \%$ of women did not use EC following method abandonment. This finding is extremely relevant, since it indicates that the EC is underutilized among a highly educated population in a context of high use of contraceptive methods. Lack recognition of pregnancy risk are shown to deter women from using EC despite having had unprotected intercourse (Raine 2005; Moreau 2005; Sørensen, Pedersen, Nyrnberg, 2000; Free, Lee, Ogden, 2002; Free, Ogden, 2005; Goulard et al., 2006; Nappi et al., 2014; Santos et al., 2014). In the same line, we also found that $40 \%$ of women in our study reported having had unprotected sexual intercourse within 12-months prior to the survey and had not used EC to reduce the risk of pregnancy. Similar results were reported in a 6-month condom clinical trial where 830 couples reported more than 1000 acts of unprotected intercourse and almost 500 condom failure, but only 16 used of EC (Walsh et al., 2003). Low perception of pregnancy risk may be related to a number of factors: some 
women assume they are having sexual intercourse in a "safe period" of their menstrual cycle; others think their risk of pregnancy is low because they are postpartum or breastfeeding; or simply perceive the risk of becoming pregnant to be low; and some may assume their partner is sterile (Jones, Mosher, Daniels, 2012). In this context, Nappi et al. (2014) noted that nearly half of women in five European countries, who were at risk of pregnancy, believed that the risk of pregnancy at another time than during the mid-cycle period was insignificant or low.

Some studies have noted that misperceived of pregnancy risk and nonuse of EC are more common among young women from disadvantaged socioeconomic status (Jones, Darroch, Henshaw, 2002; Williamson, Buston, Sweeting, 2009; Westley, Schwarz, 2012). Nevertheless, as most of the young women in our study were from high socioeconomic status, low recourse of EC in case of unprotected sex may concern women regardless of their socioeconomic status in Brazil.

Our results show that more than sociodemographic characteristics, educational background and reproductive/contraceptive behaviors were associated with EC use following discontinuation for method-related reasons and method abandonment. Women who were younger and who were never pregnant were more likely to use EC following discontinuation for method-related reasons; while women who were enrolled in a part-time course and using condoms (as compared to pills) were more likely to use EC when contraception was abandoned. It is possible that "period of study" reflects women's socioeconomic status, which is shown to contribute to use of contraception (Anasel, Mlinga, 2014; Lindh, Hognert, Milsom, 2016; Ross, Hardee, 2016). Moreau, Trussell \& Bajos (2006) observed that $6 \%$ of women who were potentially at unintended pregnancy and who belonged to low socioeconomic status in France had used EC in the last 12-months prior to the survey, compared to $3 \%$ of women from high socioeconomic status. An alternative explanation is that women who were studying part-time had more available time to access the $E C$, needs to be taken in a short time frame (Trussell, Raymond, Cleland, 2014).

In our study, we found that pill users were less likely to use EC following method abandonment as compared to condom users. A possible explanation is that a majority of pill users discontinue their method due to side effects (Castle, Askew, 2015; Inoue, Barratt, Richters, 2015), and do not want to use a hormonal postcoital method they assume would have similar side effects. Rocca et al. (2007) observed that side effects was one of the main reasons for the women aged 15-24 in the USA 
not to use EC when indicated. Other studies noted the same findings (Aiken, Gold, Parker, 2005; Nguyen, Zaller, 2009; Meng et al., 2009). However, it is important to highlight that even among condom users, EC use following method abandonment was low in our study (almost 13\%). Similarly, a study conducted among condom users observed that only $39 \%$ of women who had not used condoms consistently used EC (Nelson, 2006). Jones, Darroch \& Henshaw (2002) noted that only 3\% of women who had experienced condom breakage or slippage, $2 \%$ who reported inconsistent use of condoms; and fewer than $1 \%$ of women who had taken the pill inconsistently had used EC as a backup.

Women who were in a casual relationship and who were using male condom (as compared to oral pill), were more likely to use EC in context of non-regular contraception. Other authors have also noted that women in casual sexual relationships were more likely to use EC than those in more stable or long-term relationships (Goulard et al., 2006; Bastianelli et al., 2016). A possible explanation for this association could include a flexibility in the use of contraceptives when the partner is known and the relationship becomes stable (Pirotta, Schor, 2004). However, this finding contrasts with the results of the Donadiki et al. (2013), who revealed that young women (18-26 years) in stable relationship were $73 \%$ more likely to use EC than women in unstable relationship.

The strengths of our study include the innovate findings that were never presented in Brazil, and our ability to check for some significant variables, including socio-demographic factors and variables associated with sexual and reproductive behaviors. The use of a contraceptive also allows situating EC within the context of women's contraceptive trajectories.

There are also a number of limitations that should be acknowledged. As this is a retrospective study, recall bias may lead to an underestimation of EC use over one year period of time. Our study sample comprises only undergraduate students, and, since education level is associated with contraceptive use, the result cannot be generalized to the overall population. In addition, although our study encompassed several campuses at University of São Paulo the results cannot be generalized to all Brazilian undergraduate students, such as private universities. Replication of this study among other student populations would allow an assessment of EC use across diverse student settings. Another limitation of our study is that we did not collect data on reasons for use or non-use of EC. Questions on intention to become pregnant, 
desire to avoid STIs and socioeconomic status (SES), life purposes, and among others; must be incorporated in future investigations.

\subsection{CONCLUSION}

We conclude that the majority of undergraduate students in our study probably do not use EC in situations where the method is required, i.e., following discontinuation for method-related reasons and method abandonment, potentially reflecting a lack of pregnancy risk recognition.

Future studies, including qualitative work are indispensable to understand why undergraduate college students are not using EC following discontinuation for method-related reasons and method abandonment, specially in a country with restrictive abortion laws such as Brazil. Moreover, recognizing factors that affect with students' ability or choices to prevent unintended pregnancy are relevant in promoting a healthy college environment.

We stress that it is important for young women to be well knowledgeable about contraception. A study conducted with high school students in Brazil, noted that the majority of adolescents did not obtain information about EC in schools or with health professionals (Chofakian et al., 2014). According to the authors, not only health services but also school environment contributes little to the knowledge of sexuality and reproductive life. Reproductive health education as well as family planning counseling are the tools for responsible sexual behavior among youth (Keletzian et al., 2012). Also, appropriate and effective sexual health measures to support undergraduate students are strongly recommended and could stimulate responsible sexual behavior as a Public Health priority. 




\section{CHAPTER SIX}

\section{CONTRACEPTIVE PATTERNS IN THE MONTH BEFORE AND AFTER EMERGENCY CONTRACEPTION USE (EC CALENDAR)}

\subsection{BACKGROUND OF THE STUDY}

\subsubsection{Introduction}

When used after unprotected sexual intercourse within time limits, emergency contraception (EC) can avoid an unintended pregnancy (Trussell, Raymond, Cleland, 2014). It is a backup option to prevent pregnancy, and a potential precursor to regular contraception; a concept referred to as "bridging" (Cameron, Glasier, 2010). Michie et al. (2014) noted that almost half (44\%) of women in Edinburgh who were not using a hormonal method of contraception at the time of EC use indicated that they wished to use an effective method. In this context, while EC is not an effective option to replace more effective contraception for women who have regular intercourse (WHO, 2004), it may still facilitate transitions towards more effective contraception among the $32.2 \%$ sexually active Brazilian women at risk of pregnancy who do not use a regular method (Brasil, 2010; Mosher, Jones, 2010; Trussell, Raymond, Cleland, 2014).

A number of studies indicate greater use of regular contraception after EC exposure; however, studies examining the type of contraceptive used after EC (highly effective method or non-highly effective method) report inconsistent results. A prospective study of EC users in France shows that while $8 \%$ of women switched from very effective to lower effective or to no contraception after using EC, $20 \%$ of women moved in the other direction, that is they switched from less effective or no method to very effective method use after using EC (Moreau et al., 2009b). In another study in France, Moreau et al. (2006) observed that $84 \%$ of women resumed use of a regular contraceptive after EC use, and almost $50 \%$ of women used highly effective methods following EC use. A study conducted in Minnesota, highlighted that $68 \%$ of women who were using non-highly effective method, switched to hormonal 
contraception after EC use (Sidebottom et al., 2008). Other studies however, find the reverse is true. A case control study conducted among high risk women (16-24 years old) in California, indicates that women provided advanced supplies of EC were more likely than those in the control group (not given EC) to use less effective and less consistent contraception (Raine et al., 2000). Cameron et al. (2001) observed that despite the high use of contraception after EC use among Scottish women (88\%), the use of effective ongoing contraception after EC (even from a specialist service) was low. Even when EC bridges to more effective methods, a significant proportion of women remain at high risk of unintended pregnancy after using EC: $11 \%$ of women in the French study did not use contraception in the six months after EC use (Moreau et al.; 2009b).

Contraceptive discontinuation is an important contributor to unintended pregnancy and induced abortion in countries with high contraceptive prevalence, as it is associated with gaps in use and inconsistent use of new methods. Discontinuation is a particular issue among young college women in Brazil who are highly motivated to prevent a pregnancy, have high contraceptive coverage, but struggle in their daily management of contraception as exemplified in the high rates of method discontinuation in this population (Bryant 2009; Borges et al., 2010; Trieu et al., 2011; Dessunti, Kings, 2012; Silva, Camargo, Iwamoto, 2014; Somba et al., 2014). In case of unprotected sexual intercourse, a significant proportion (although not a majority) use EC; however, there is little information about their opportunity to bridge to more effective methods. In addition, it is noteworthy that some findings of the studies mentioned were controversial, denoting the need to understand this issue in Brazil.

\subsubsection{Aims of study}

The aim of this study is to describe contraceptive patterns (frequency and correlates) 1-month after using EC, among female university students in São Paulo. The research questions we will address are:

- Do women use contraception after using EC? What are the correlates of using contraception after using EC?

- Do women switch contraceptives after using EC and what are the switching patterns observed? What are the correlates of method switching after EC use? 
- Are there contraceptive gaps after using EC? What are the correlates of continuous use of contraception after using EC?

\subsection{METHODOLOGY}

This section summaries the sample, data collection procedures, measures and the statistical method used for the analysis.

\subsubsection{Study population and survey site}

This study is part of a larger project exploring contraceptive use dynamics and EC use over 1 year of observation among university students in São Paulo, Brazil. The study was designed as a 12-month retrospective cohort study, conducted among a probability sample of undergraduate women from University of São Paulo, Brazil (the largest institution of higher education and research in Brazil), between June and July, 2015. Women between the ages of 18 and 24 years old enrolled in regular undergraduate course in any campus at University of São Paulo, Brazil, were eligible to participate in the study. They were selected by simple random sampling without replacement, and they were chosen electronically based on a list of all the email addresses of undergraduate students enrolled in the Electronic Computer Center of the University of São Paulo, organized alphabetically. The research project was described in the email, and the student who had an interest in participating in the study could click on the study to complete a consent form (APPENDIX A). The study obtained Ethical approval from the Research Ethics Committee at University of São Paulo School of Nursing (CAAE Number: 39142514.4.0000.5392) (ANNEX I).

\subsubsection{Sampling}

A total of 3,078 women were randomly selected and invited to participate in the project. Students received reminder emails weekly to participate in the study (on average 10 times). A total of 2,182 undergraduate students $(71 \%)$ answered the online questionnaire. However, the final study population comprised 1,679 undergraduate students between 18 and 24 years of age, since 50 women refused to 
participate in the study, and 453 students were not eligible for the study (< 18 years old $(n=2)$, had never had sexual intercourse $(n=358)$, and had not used any contraceptive method in the last 12 months $(n=93))$. In the present study, we focus on the 916 women who ever used EC.

\subsubsection{Data collection and study instruments}

The data were collected online through Google Form, using a self-administered questionnaire that was previously pre-tested and took, on average, 5-7 minutes to complete (APPENDICES B AND C). Women who reported they had ever use EC completed an EC calendar describing contraceptive usage at the time they last used EC. Specifically, they indicated what contraception they used within 30 days prior to EC use and within 30 days after EC use. Women were questioned about any use of contraception before and after EC, and in case they responded positively, were asked about the method they used within 30-day time periods before and after EC use.

\subsubsection{Measures}

Our primary outcome measure (question 1) relates to any use of contraception within 30 days after EC use.

We consider use of contraception within 30 days before EC as a key predictor of post EC contraceptive use. We also used this information to build our secondary outcome measure (question 2), exploring change in contraceptive utilization between before and after EC use. Three category indicators of change in contraceptive behaviors post EC was considered:

- "No change in contraception" refers to women who had not changed their contraception between 30 days before and 30 days after using EC (this included women who did not use contraception before and after EC).

- "Switching to more effective method" refers to women who changed to more effective method after EC use. Women who started using a method after EC use were included in this category. The contraceptive effectiveness was based on a study by CDC (2013). 
- "Switching to less effective method" refers to women who changed to less effective method after EC use. Women who stopped using a method after EC were included in this category.

Our third outcome variable (question 3) relates to gaps in contraceptive use within 30 days after EC use, which was defined based on contraceptive discontinuation or not within 30 days after EC use.

Women's sociodemographic and reproductive health history measures

We consider women's sociodemographic characteristics as predictors of contraceptive use after EC use, based on prior research findings. Specifically, we include age (18-19 or 20-24); race/ethnicity (white, black, other); religious affiliation (none, roman catholic, kardecista spiritualism doctrine, evangelical, other); socioeconomic status (high (A/B) - middle/low (C/D/E)) (ABEP, 2015).

Because this study focuses on university students, we will consider their educational characteristics. This information includes field of study (human sciences, health sciences, exact sciences); period of study (full-time or part-time); and type of campus (São Paulo, countryside).

Sexual and reproductive health indicators are shown to be strongly associated with contraceptive use after EC use. In our study, we consider the type of relationship (steady, casual relationship or living with a partner); time since first sexual intercourse ( $\leq 1$ year, 2-3 years, $\geq 5$ years); number of lifetime sexual partners (1 partner, 2-3 partners, $\geq 4$ partners); pregnancy history (no/yes); use of contraception within 30 days prior to EC use (no/yes); and type of contraceptive method used within 30 days prior to EC use (oral pill, male condom, and other methods).

\subsubsection{Statistical analysis}

1) First, a bivariate analysis was conducted to investigate women's sociodemographic and sexual reproductive health characteristics according to the use of contraception within 30 days after EC, using the EC calendar data. We considered use of contraception within 30 days before EC as a key predictor of 
post EC contraceptive in this analysis. We then conducted multivariate logistic regression to identify the independent effects of these factors on contraceptive use post EC use. The criteria for including variables in the multivariate analysis were not only those that showed significance in the bivariate analysis, but also variables based on our conceptual framework, that is, factors identified by previous studies as related to contraceptive use after EC use (as age, race/ethnicity, religion, socioeconomic status). The multivariate analysis also included field of study, period of study, campus, time since first sexual intercourse, and previous pregnancy. Hosmer and Lemeshow's Test was used to assess how well the model fitted the data. Adjusted odds ratios and 95\% confidence intervals were estimated.

2) Second to analyze how EC affects contraceptive trajectories, we assessed changes in contraceptive use before and after EC use, using the EC calendar. We distinguished women who had no change in contraception after EC use (reference), women who switched to more effective method after EC use, and women who switched to less effective method after EC use. After conducting bivariate analysis, multinomial regression models were performed (dependent variable defined as a 3-categorical variable). Adjusted odds ratios and $95 \%$ confidence intervals were estimated. The final model was chosen based on prior knowledge and based on Akaike Information Criterion (AIC).

3) Finally, we investigated gaps in contraceptive use within 30-days post EC use, among all women who used contraception after EC, using EC calendar.

We stress that in all analysis, we explore the circumstances of last EC use, which was the episode investigated in the EC calendar. Pearson's Chi-square tests were conducted to identify the determinants of contraceptive use after EC and changes in contraceptive use after EC. All analyses were conducted using Stata 14.2 (Stata Corporation, College Station, TX, USA). 


\subsection{RESULTS OF USING EMERGENCY CONTRACEPTION BASED ON EMERGENCY CONTRACEPTION DAILY CALENDAR}

\subsubsection{Characteristics of women who used contraception after using emergency contraception}

A majority of women $(75.4 \%)$ used contraception within 30 days after having used EC (Table 14). The strongest predictor of contraception post EC was use of contraception within 30 days before EC. $92.9 \%$ of women who used contraception within 30 days prior to EC use, resumed use of contraception after EC use, while $40.7 \%$ of women who were not using contraception prior to EC, used contraception after. However, we found no difference in contraceptive use after EC between women who used condoms, pills or other methods prior to EC use.

Few other factors were related to use of contraception after EC. Women who were in a casual relationship, who were enrolled in a part-time program, who reported several lifetime sexual partners, and who had never been pregnant before were less likely to use contraception after using EC. A majority of women used oral pills after EC use $(61.9 \%)$, followed by male condom (32.0\%), and other methods (4.1\%) (data not shown in table).

Table 14 - Sociodemographic, sexual and reproductive health characteristics of São Paulo university students according to the use of contraception within 30 days after emergency contraception use. São Paulo, Brazil - 2015

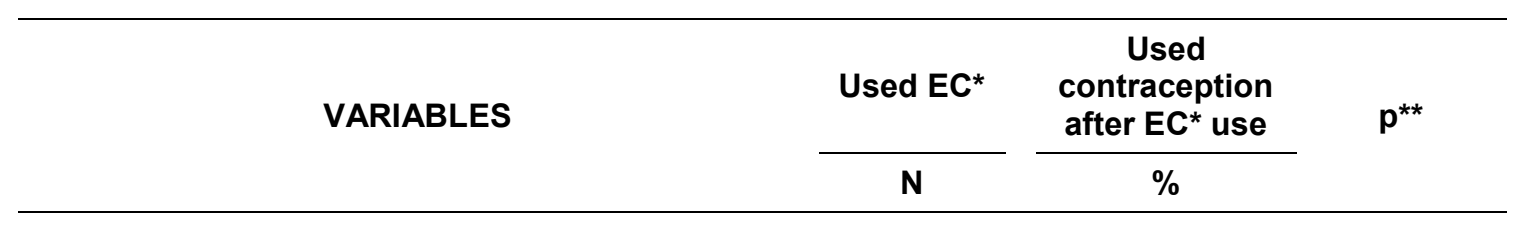

Sociodemographic characteristics

Age (years)

$18-19$

217

699

$20-24$

Race/ethnicity

White (caucasian)

Black

Other race/ethnicity ${ }^{\star \star \star}$
$713 \quad 74.5$

$141 \quad 75.9$

$62 \quad 85.5$
0.504

73.7

76.0

0.153

5.9 
(continuação)

\begin{tabular}{|c|c|c|c|}
\hline \multirow[t]{2}{*}{ VARIABLES } & Used EC* & $\begin{array}{c}\text { Used } \\
\text { contraception } \\
\text { after EC* use }\end{array}$ & $\mathbf{p}^{* *}$ \\
\hline & $\mathbf{N}$ & $\%$ & \\
\hline Religion & & & 0.186 \\
\hline No religion & 458 & 77.1 & \\
\hline Roman Catholic & 259 & 73.4 & \\
\hline Kardecist Spiritualism Doctrine & 102 & 79.4 & \\
\hline Evangelical & 62 & 64.5 & \\
\hline Other religion ${ }^{\star * \star *}$ & 35 & 77.1 & \\
\hline Type of relationship & & & $<0.001$ \\
\hline Steady & 591 & 80.5 & \\
\hline Casual relationship & 325 & 66.2 & \\
\hline Socioeconomic status & & & 0.747 \\
\hline$A / B$ & 697 & 75.2 & \\
\hline$C-D / E$ & 219 & 76.3 & \\
\hline \multicolumn{4}{|l|}{ Educational background } \\
\hline Field of study & & & 0.172 \\
\hline Human Sciences & 383 & 72.3 & \\
\hline Health Sciences & 333 & 78.1 & \\
\hline Exact Sciences & 200 & 77.0 & \\
\hline Period of study & & & 0.038 \\
\hline Full-time & 454 & 78.4 & \\
\hline Part-time & 462 & 72.5 & \\
\hline Campus & & & 0.182 \\
\hline São Paulo & 589 & 74.0 & \\
\hline Out of São Paulo & 327 & 78.0 & \\
\hline \multicolumn{4}{|l|}{ Sexual and reproductive behavior } \\
\hline Time since first sexual intercourse & & & 0.286 \\
\hline$\leq 1$ year & 114 & 70.2 & \\
\hline $2-3$ years & 313 & 74.8 & \\
\hline$\geq 4$ years & 489 & 77.1 & \\
\hline Number of sexual partners in lifetime & & & 0.005 \\
\hline 1 partner & 219 & 83.6 & \\
\hline $2-3$ partners & 278 & 74.1 & \\
\hline$\geq 4$ partners & 419 & 72.1 & \\
\hline
\end{tabular}


(continuação)

\begin{tabular}{|c|c|c|c|}
\hline VARIABLES & Used EC* & $\begin{array}{c}\text { Used } \\
\text { contraception } \\
\text { after EC* use }\end{array}$ & $\mathbf{p}^{* *}$ \\
\hline & $\mathbf{N}$ & $\%$ & \\
\hline Previous pregnancy & & & 0.084 \\
\hline No & 888 & 75.0 & \\
\hline Yes & 28 & 89.3 & \\
\hline Used contraceptive method prior to EC use & & & $<0.001$ \\
\hline No & 308 & 40.7 & \\
\hline Yes & 608 & 92.9 & \\
\hline Total & 916 & 75.4 & \\
\hline $\begin{array}{l}\text { Type of contraceptive method used prior to EC } \\
\text { use }\end{array}$ & & & 0.933 \\
\hline Oral pill & 236 & 92.8 & \\
\hline Male condom & 255 & 93.3 & \\
\hline Other method ${ }^{* * * * *}$ & 117 & 92.3 & \\
\hline Total & 608 & 92.9 & \\
\hline
\end{tabular}

${ }^{*} \mathrm{EC}=$ Emergency contraception.

${ }^{* *}$ Pearson's chi-square test.

***Other race/ ethnicity include: asian origin and indigenous people.

${ }^{* * * *}$ Other religions include: Afro-Brazilian, Buddhism, Jewish, Muslim, Mormon, and Islam.

${ }^{* \star * \star *}$ Other methods include: injectable, withdrawal/Fertilty-awareness patch, an intrauterine device, diaphragms, implants, vaginal ring, female condoms, and spermicide.

\subsubsection{Correlates of using contraception within $\mathbf{3 0}$ days after emergency contraception use: results of multivariate analysis}

Results of the multivariate logistic regression assessing the independent effect of each factor on contraceptive use after using EC are presented in Table 15.

The strongest determinant of using contraception after EC use was use of contraception within 30 days before EC. Women who used contraception within 30 days prior to EC use were 3 times more likely to use contraception after EC than women who did not use contraception before EC use.

Other determinants were religion, type of relationship and number of lifetime sexual partners. Women were less likely to use contraception after EC use if they 
were affiliated Evangelical, were in a casual relationship, and had more than 1 sexual partner in their lifetime.

Table 15 - Correlates of using contraception within 30 days after emergency contraception use. São Paulo, Brazil - 2015

VARIABLES $\frac{\text { Use of contraception after EC* use }}{\text { OR }_{\text {adjust }}(\mathrm{Cl})^{\star *}}$

Sociodemographic characteristics

Age (years)

$18-19$

1.0

$20-24$

$1.2(0.7-1.9)$

Race/ethnicity

White (caucasian)

1.0

Black

$1.5(0.8-2.5)$

Other race/ethnicity***

$1.8(0.8-2.3)$

\section{Religion}

No religion

1.0

Roman Catholic

$0.8(0.5-1.2)$

Kardecist Spiritualism Doctrine

$0.8(0.4-1.6)$

Evangelical

$0.5(0.2-0.9)^{\star * * *}$

Other religion ${ }^{* * * * *}$

$1.0(0.3-2.7)$

Type of relationship

Steady

1.0

Casual relationship

$0.6(0.4-0.9)^{\star \star \star *}$

Socioeconomic status

A/B

1.0

$C-D / E$

$1.1(0.7-1.7)$

\section{Educational background}

Field of study

Human Sciences

1.0

Health Sciences

$1.4(0.8-2.3)$

Exact Sciences

$1.2(0.7-2.1)$

Period of study

Full-time

1.0

Part-time

$0.8(0.5-1.3)$ 
(continuação)

VARIABLES

Use of contraception after EC* use

$\mathrm{OR}_{\text {adjust }}(\mathrm{Cl})^{* *}$

\section{Campus}

São Paulo

Out of São Paulo

Sexual and reproductive behavior

Time since first sexual intercourse

$\leq 1$ year

$2-3$ years

$\geq 4$ years

Number of sexual partners in lifetime

1 partner

$2-3$ partners

$\geq 4$ partners

Previous pregnancy

No

Yes

Used contraceptive method prior to EC use

No

Yes

${ }^{*} E C$ : emergency contraception.

${ }^{* *}$ OR: odds ratio and IC: Confidence Interval.

${ }^{* * *}$ Other race/ ethnicity include: asian origin and indigenous people.

$* * * * p \leq 0.050$

*****Other religions include: Afro-Brazilian, Buddhism, Jewish, Muslim, Mormon, and Islam.

$* * * * * *$ Hosmer and Lemeshow's Test: $p=0.984$.

\subsubsection{Characteristics of women according to contraceptive switching patterns after emergency contraception use}

We investigated women's sociodemographic and sexual reproductive health characteristics according to contraceptive switching patterns after EC use. We compare contraceptive methods used 30 days prior and 30 days after EC use. Therefore, we distinguished women who had no change in contraception after EC use, women who changed to more effective method after EC use, and women who changed to less effective method after EC use. 
Altogether, we found that $64.4 \% \quad(n=590)$ of women had not changed contraception or were consistently not using contraception after EC use; $29.3 \%$ $(n=268)$ switched to more effective method after EC use; and 6.3\% ( $n=58)$ switched to less effective methods or no method after EC use; or they were using a method within 30 days before EC and stopped to use it after EC.

Bivariate analyzes of factors related to the three groups (no change, switching to more effective method or switching to less effective method) are presented in Table 16. Change patterns were mostly related to type of relationship, socioeconomic status, field of study, and number of sexual partners in lifetime.

Women in stable relationships were less likely to switch contraceptive status or method as compared to women in casual ones, while women in casual relationships were more likely to switch to less effective or no method. Women in the Exact Science were also less likely to switch while women in the Human Sciences were more likely to switch to less effective or no method. Finally, women who had only 1 lifetime sexual partner were more likely to switch to less effective methods after EC use.

Table 16 - Proportion of university students according to contraceptive switching patterns after EC use, by sociodemographic and sexual and reproductive health characteristics. São Paulo, Brazil - 2015

\begin{tabular}{|c|c|c|c|c|c|}
\hline \multirow{3}{*}{ VARIABLES } & \multirow[b]{2}{*}{ Total } & \multicolumn{3}{|c|}{$\begin{array}{l}\text { Contraceptive switching patterns } \\
\text { after EC* use }\end{array}$} & \multirow{3}{*}{$\mathbf{p}^{* *}$} \\
\hline & & $\begin{array}{c}\text { No } \\
\text { switching }\end{array}$ & $\begin{array}{l}\text { Switching } \\
\text { to more } \\
\text { effective } \\
\text { method }\end{array}$ & $\begin{array}{l}\text { Switching } \\
\text { to less } \\
\text { effective } \\
\text { method }\end{array}$ & \\
\hline & $\mathbf{N}$ & $\%$ & $\%$ & & \\
\hline \multicolumn{6}{|c|}{ Sociodemographic characteristics } \\
\hline Age (years) & & & & & 0.965 \\
\hline $18-19$ & 217 & 65.0 & 29.0 & 6.0 & \\
\hline $20-24$ & 699 & 64.2 & 29.3 & 6.5 & \\
\hline Race/ethnicity & & & & & 0.795 \\
\hline White (caucasian) & 713 & 63.7 & 29.9 & 6.4 & \\
\hline Black & 141 & 66.6 & 28.4 & 5.0 & \\
\hline Other race/ethnicity ${ }^{* * *}$ & 62 & 66.7 & 24.2 & 8.1 & \\
\hline
\end{tabular}


(continuação)

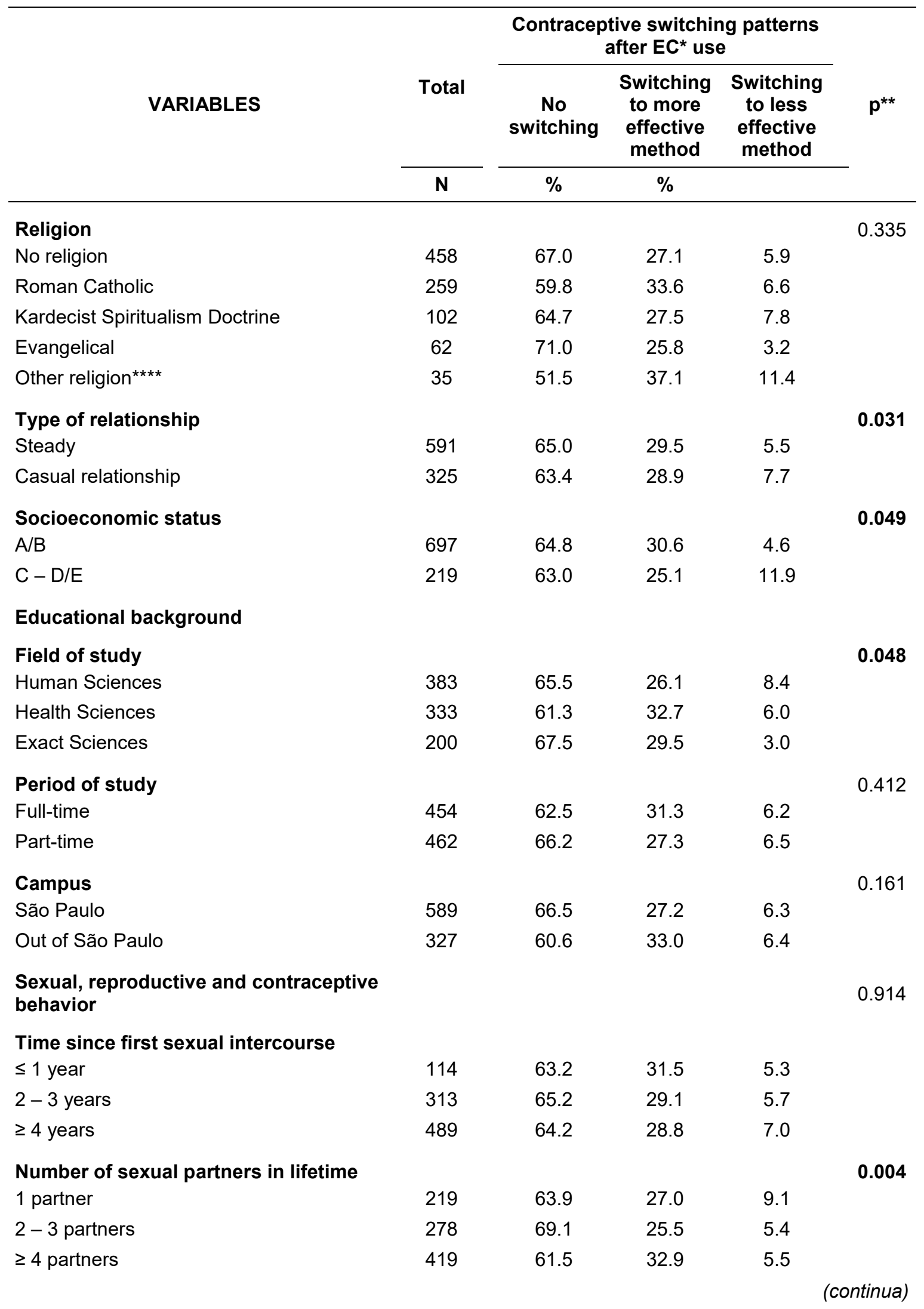


(continuação)

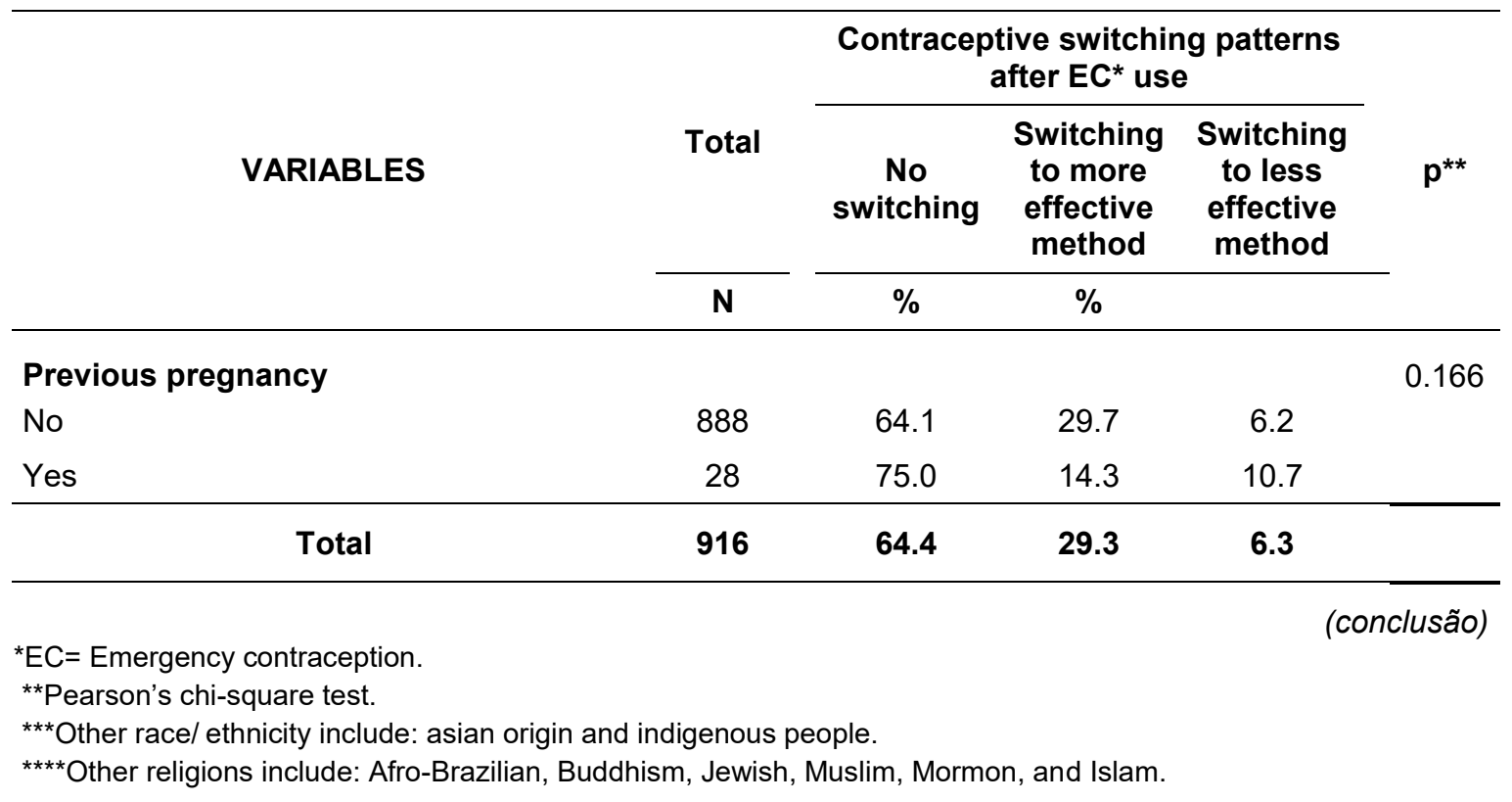

\subsubsection{Correlates of contraceptive switching patterns after emergency contraception use: results of multinomial analysis}

Table 17 presents the results of the multinomial regression model considering the odds of switching to more effective method after EC use, and the odds of switching to less effective method after EC use. The reference category in this model is women who had no change in contraception after EC use.

Confirming the results of the univariate analysis, multivariate analysis indicates that women who had stable relationship, who belonged to high socioeconomic status group, who were enrolled in the Health Sciences program, and who reported several lifetime sexual partners had higher odds of switching to more effective method after EC use. On the other hand, women who were in casual relationships, who belonged to lower socioeconomic status group, who were enrolled in the Human Sciences program, and who had 1 lifetime sexual partner, had higher odds of switching to a less effective method after EC use. 
Table 17 - Multinomial logistic regression of contraceptive switching patterns after emergency contraception use, by sociodemographic and socioeconomic characteristics, educational background, sexual/reproductive and contraceptive behavior. São Paulo, Brazil - 2015

\begin{tabular}{|c|c|c|}
\hline \multirow{3}{*}{ VARIABLES } & \multicolumn{2}{|c|}{$\begin{array}{l}\text { Contraceptive switching } \\
\text { patterns after EC* use }\end{array}$} \\
\hline & $\begin{array}{l}\text { Switching to } \\
\text { more effective } \\
\text { method }\end{array}$ & $\begin{array}{l}\text { Switching to less } \\
\text { effective method }\end{array}$ \\
\hline & OR $R_{\text {adjust }}(\mathrm{Cl})^{\star *}$ & OR $\operatorname{adjust}(\mathrm{Cl})^{\star \star}$ \\
\hline
\end{tabular}

Sociodemographic characteristics

Age (years)

$18-19$

1.0

1.0

$20-24$

$1.1(0.7-1.5)$

$1.0(0.5-2.1)$

Race/ethnicity

White (caucasian)

1.0

1.0

Black

$0.9(0.6-1.5)$

$0.9(0.4-2.2)$

Other race/ethnicity ${ }^{* * *}$

$0.8(0.4-1.6)$

$1.3(0.5-1.6)$

\section{Religion}

No religion

1.0

1.0

Roman Catholic

$1.3(0.9-1.8)$

$1.5(0.8-2.1)$

Kardecist Spiritualism Doctrine

$1.0(0.6-1.6)$

$1.4(0.6-2.2)$

Evangelical

$0.8(0.4-1.6)$

$0.7(0.2-2.1)$

Other religion ${ }^{* * * *}$

$1.8(0.9-2.0)$

$2.3(0.7-2.4)$

Type of relationship

Steady

1.0

1.0

Casual relationship

$0.8(0.2-1.0)^{\star * * * *}$

$2.3(0.4-0.9)^{\star * \star * *}$

Socioeconomic status

A/B

1.0

1.0

$C-D / E$

$0.6(0.3-0.9)^{* * * * *}$

$1.7(0.3-1.0)^{\star \star \star \star \star *}$

Educational background

Field of study

Human Sciences

1.0

1.0

Health Sciences

$1.2(0.2-0.8)^{* * *}$

$0.5(0.3-1.0)^{\star * *}$

Exact Sciences

$1.0(0.6-1.5)$

$0.2(0.2-0.7)^{\star * *}$

Period of study

Full-time

1.0

1.0

Part-time 1

$0.9(0.6-1.3)$

$0.7(0.4-1.4)$

(continua) 
(continuação)

\begin{tabular}{|c|c|c|}
\hline \multirow{3}{*}{ VARIABLES } & \multicolumn{2}{|c|}{$\begin{array}{l}\text { Contraceptive switching patterns after } \\
\qquad \mathrm{EC}^{*} \text { use }\end{array}$} \\
\hline & $\begin{array}{l}\text { Switching to } \\
\text { more effective } \\
\text { method }\end{array}$ & $\begin{array}{l}\text { Switching to less } \\
\text { effective method }\end{array}$ \\
\hline & $\mathrm{OR}_{\text {adjust }}(\mathrm{Cl})^{* *}$ & OR adjust $(\mathrm{Cl})^{* *}$ \\
\hline \multicolumn{3}{|l|}{ Campus } \\
\hline São Paulo & 1.0 & 1.0 \\
\hline Out of São Paulo & $1.2(0.9-1.8)$ & $1.6(0.8-2.0)$ \\
\hline \multicolumn{3}{|l|}{ Sexual and reproductive behavior } \\
\hline \multicolumn{3}{|l|}{ Time since first sexual intercourse } \\
\hline$\leq 1$ year & 1.0 & 1.0 \\
\hline $2-3$ years & $0.9(0.5-1.5)$ & $0.7(0.2-1.9)$ \\
\hline$\geq 4$ years & $0.9(0.5-1.6)$ & $0.6(0.2-1.8)$ \\
\hline \multicolumn{3}{|c|}{ Number of sexual partners in lifetime } \\
\hline 1 partner & 1.0 & 1.0 \\
\hline $2-3$ partners & $1.7(0.4-1.0)^{\star * * * *}$ & $0.7(0.2-0.9)^{* \star * * \star}$ \\
\hline$\geq 4$ partners & $1.9(0.6-1.0)^{\star \star \star \star \star *}$ & $0.3(0.4-1.0)^{* \star * \star *}$ \\
\hline \multicolumn{3}{|l|}{ Previous pregnancy } \\
\hline No & 1.0 & 1.0 \\
\hline Yes & $0.4(0.2-1.4)$ & $1.1(0.3-1.9)$ \\
\hline \multicolumn{3}{|c|}{$\begin{array}{l}{ }^{*} \text { EC: emergency contraception. } \\
\text { ** }{ }^{*} \text { : } \text { : odds ratio and IC: Confidence Interval. } \\
{ }^{* * *} \text { Other race/ ethnicity include: asian origin and indigenous people. } \\
{ }^{* * * *} \text { Other religions include: Afro-Brazilian, Buddhism, Jewish, Muslim, Mormon, and Islam. } \\
{ }^{* * * * \star} \leq \leq 0.050 \text {. } \\
\end{array}$} \\
\hline
\end{tabular}

\subsubsection{Characteristics of women who had gaps after using emergency contraception}

Among of women who used some contraception after EC use ( $n=691), 52$ (7.5\%) women had gaps after using EC, i.e., they did not use contraceptive continuously during a month (Table 18).

Women who belonged to other race/ethnicity as asian origin and indigenous people, women who were in a casual relationship, women who belonged to less privileged socioeconomic status, and women who reported several lifetime sexual partners were more likely to have gaps after using EC. 
Table 18 - Sociodemographic, sexual and reproductive health characteristics of São Paulo university students according to the consistent use of contraception after using emergency contraception. São Paulo, Brazil - 2015

\begin{tabular}{cccc}
\hline & \multicolumn{3}{c}{ Gaps after using EC } \\
\cline { 2 - 4 } VARIABLES & Total & Yes & \multirow{2}{*}{$\mathbf{p}^{* *}$} \\
& $\mathrm{~N}$ & $\%$ & \\
\hline
\end{tabular}

Sociodemographic characteristics

Age (years)

$18-19$

$20-24$

Race/ethnicity

White (caucasian)

Black

Other race/ethnicity ${ }^{* \star *}$

Religion

No religion

Roman Catholic

Kardecist Spiritualism Doctrine

Evangelical

Other religion ${ }^{* * * *}$

Type of relationship

Steady

Casual relationship

Socioeconomic status

A/B

$C-D / E$

\section{Educational background}

Field of study

Human Sciences

Health Sciences

Exact Sciences

Period of study

Full-time

Part-time
160

531

9.4

7.0

0.053

$531 \quad 8.5$

$107 \quad 1.9$

$53 \quad 9.4$

353

190

9.0

81

4.2

8.6

40

5.0

27

11.1

476

7.4

215

7.9

524

6.9

167

9.6

0.024

0.048

0.266

0.048

277

8.3

260

5.8

154

9.1

356

5.9

335

9.3
0.380

0.095

(continua) 
(continuação)

\begin{tabular}{|c|c|c|c|}
\hline \multirow[b]{2}{*}{ VARIABLES } & \multicolumn{3}{|c|}{ Gaps after using EC* } \\
\hline & $\begin{array}{c}\text { Total } \\
\mathbf{N}\end{array}$ & $\begin{array}{c}\text { Yes } \\
\%\end{array}$ & $\mathbf{p}^{* *}$ \\
\hline Campus & & & 0.340 \\
\hline São Paulo & 436 & 8.3 & \\
\hline Out of São Paulo & 255 & 6.3 & \\
\hline \multicolumn{4}{|l|}{ Sexual and reproductive behavior } \\
\hline Time since first sexual intercourse & & & 0.580 \\
\hline$\leq 1$ year & 80 & 5.0 & \\
\hline $2-3$ years & 234 & 8.6 & \\
\hline$\geq 4$ years & 377 & 7.4 & \\
\hline Number of sexual partners in lifetime & & & 0.039 \\
\hline 1 partner & 183 & 3.3 & \\
\hline $2-3$ partners & 206 & 8.7 & \\
\hline$\geq 4$ partners & 302 & 9.3 & \\
\hline Previous pregnancy & & & 0.496 \\
\hline No & 666 & 7.7 & \\
\hline Yes & 25 & 4.0 & \\
\hline Type of contraceptive method used & & & 0.993 \\
\hline Oral pill & 428 & 7.5 & \\
\hline Male condom & 235 & 7.7 & \\
\hline Other method $\mathrm{d}^{* * * *}$ & 28 & 7.1 & \\
\hline Total & 691 & 7.5 & \\
\hline
\end{tabular}

(conclusão)

${ }^{*} \mathrm{EC}=$ Emergency contraception.

${ }^{* *}$ Pearson's chi-square test.

${ }^{* * *}$ Other race/ ethnicity include: asian origin and indigenous people.

${ }^{* * * *}$ Other religions include: Afro-Brazilian, Buddhism, Jewish, Muslim, Mormon, and Islam.

***** Other methods include: injectable, withdrawal/Fertilty-awareness patch, an intrauterine device, diaphragms, implants, vaginal ring, female condoms, and spermicide. 


\subsection{DISCUSSION}

\subsubsection{Use of contraception after EC use}

The current study describes contraceptive behaviors after EC use among undergraduate students, and more specifically contraceptive switching patterns after EC use and the gaps in contraception after EC use. Our findings show that most women $(75 \%)$ used contraceptive method within 30 days after EC use. This study confirms the outcomes of a number of others, undertaken in a variability of settings: U.K. (Michie et al., 2014); France (Moreau et al., 2006), U.S. (MacLean, 2004), China (Lo et al., 2004), Scotland (Cameron et al., 2001) - most of women use an effective method after using EC. According to Moreau et al. (2009b), almost $90 \%$ of women in France used a regular contraceptive after 6-months EC use, and almost $60 \%$ of women continued using or switched to highly effective methods following EC use. A study by Costa et al. (2008) conducted with women aged 18-49 in six cities in Brazil, reported a significant increase in regular contraceptive use among women who used EC. Other studies however, find the reverse is true (Cameron et al., 2001; Raine et al., 2000). Also, case-control studies conducted with adolescents in Sweden (Ekstrand et al., 2013), and also in U.S. (Gold et al., 2004), noted no differences between advanced EC and control groups in reported contraception use following EC use.

One notable aspect of our findings was the relative proportion of women $(41 \%)$ who were not using contraception within 30 days prior to EC use, and started to use a method after EC. According to some studies, EC can be a "bridge" to regular contraception (Cameorn, Glasier, 2010; Mosher, Jones, 2010; Trussell, Raymond, Cleland, 2014). As in U.S. (Sidebottom et al., 2008), Jamaica (Sorhaindo et al., 2002), and Scotland (Cameron et al., 2001), a relevant proportion of women (49\%, $55 \%$ and $65 \%$, respectively) who were using no method or a less effective method adopted an ongoing effective method of contraception following the use of EC.

In our multivariate analysis, we observed that the strongest predictor of contraception post EC is the use of contraception prior to EC. Women who used contraception within 30 days prior to EC use were 3 times more likely to use contraception after EC than women who were not using contraception before. It means that women who use a method after EC are mostly women who have more 
intimacy and commitment with contraceptive behavior; so, women who did not use a contraception and use EC, need more attention in family planning programs in order to promote the adoption of an effective and regular method to avoid an unintended pregnancy. This outcome also reveals that the method used regularly are not abandoned after EC use, as previously observed in other studies (Belzer et al., 2003; Raine et al., 2005).

Our results also revealed that women who were practioner of Evangelical religion were less likely to use contraception after EC when compared to women who had no religion. This statement is consistent with the survey by Jones, Mosher \& Daniels (2012), who observed that Baptist and Fundamentalist Protestant women were less likely to use oral pill (21\%) and male condom (12\%), compared with women with no religious affiliation (31\% and 16\%, respectively). Other studies have also shown that religious affiliation is associated with sexual and contraceptive behaviors (Hall, Moreau, Trussell, 2012; Patton, Hall, Dalton, 2015; Freedman, Stulberg, 2016). Moreover, type of relationship, and number of lifetime sexual partners were also associated to use of contraception after EC use.

As expected, we found that women in casual relationship were $40 \%$ less likely to use method after EC use than women who had stable relationship. This finding is consistent with other studies in different setting (Pulerwitz et al., 2002; Frost, Singh, Finer, 2007b; Sassler et al., 2009). According to Raine et al. (2010), the trust, communication, and intimacy between partners is low in casual relationships, which rendres difficult contraceptive decision-making. In addition, the authors observed in the narratives of young men that they expected the woman not to become pregnant in casual relationship; however, the conversation about this is limited in uncommitted relationships.

Women who had several sexual lifetime partners in our study were less likely to use a contraceptive method following EC use. However, one hypothesis for this finding is that the number of sexual partners may be related to the relationship dynamics, i.e., women who have more sexual lifetime partners could be more involved in casual relationships, which is related to a lower use of contraception. Although there is no study that associates contraceptive use after EC with the number of sexual lifetime partners, some researchers have related contraceptive use with number of sexual partners. Most of them presented contrary results when compared to our findings (Manlove, Ryan, Franzetta, 2004; Moreau et al., 2006; 
Davies et al., 2006; Cavazos-Rehget al., 2010; Donadiki et al., 2013). A study on factors related to contraceptive methods among female higher education students in Greece observed that women who had more than 2 sexual lifetime partners was more likely to use oral pill, and also EC (Donadiki et al., 2013). Another study conducted with youths in the U.S., observed that the probability of using contraception was reduced by $20 \%$ for each additional partner that a woman had (Manlove, Ryan, Franzetta, 2004).

\subsubsection{Contraceptive switching patterns after emergency contraception use}

Considering contraceptive switching patterns after using EC, our multinomial analysis showed that changes in contraception after EC use was rare; almost $65 \%$ of women had not changed contraceptive status or method after use EC. It means that the majority of women use EC in context of inconsistent use, probably in situations of missing oral pills, breakage and slippage of male condoms, or partner did not withdraw on time. Data from a similar study among young women aged 18-24 at University of São Paulo showed that EC is more likely to be used in case of inconsistent use of ongoing contraception than in case of lack of use (Borges et al., 2010). According to the authors, EC can be understood as a marker for discontinuity in ongoing contraception. Not only in Brazil, but other studies from different countries have also observed the same findings (Sorhaindo et al., 2002; Jones, Darroch, Henshaw, 2002; Raine et al., 2005; Moreau et al., 2009a; Nappi et al., 2014).

Raine et al. (2010) observed that most young women aged 16-24 in U.S. used EC in circumstances of highly inconsistent use of contraception. According to the authors, women who had somewhat inconsistent use of contraception and women who use contraception consistently had $50 \%$ and $70 \%$, respectively, less chance to use EC, when compared to women who had highly inconsistent contraception use. Moreover, a study conducted with U.S. women having abortions, observed that $65 \%$ of women who used EC had done as a backup to contraception: $11 \%$ of women were using oral pill, $40 \%$ were using male condom (17\% described inconsistent use and $23 \%$ breakage or slippage), and $14 \%$ were using other methods (Jones, Darroch, Henshaw, 2002). Another study conducted among women presenting for EC to pharmacies in the U.K., observed that most of women used contraception at time of 
EC, especially male condoms (Michie et al., 2014). Therefore, it appears that EC is used as a back-up to regular contraceptive methods. However, a study conducted with teenagers in the U.S. observed indicated that the most common reason for requesting $\mathrm{EC}$ was nonuse of contraceptive (Cwiak et al., 2016).

Most women switched to more effective methods (almost 30\%) while 6\% switched to less effective methods. Likewise, Moreau et al. (2009b) observed that $20 \%$ of women aged 18-44 in France switched to highly effective method in 6months following EC use, compared to $8 \%$ who switched to non-highly effective method. According to the authors, the use of EC was no associated with a modification in contraceptive behaviors.

As in the multivariate analysis, the type of relationship was associated to contraceptive switching patterns after EC use. Women in casual relationship were two times more likely to switch to less effective methods after EC use. Other studies (Bastos et al., 2008; Bataglião, Mamede, 2011) have showed that contraceptive behavior in youth is related to the type of relationship, with negotiations occurring at each new partnership, with potential gaps or switch to less effective methods in the context of STI prevention.

Sexual history behaviors were also associated with switching patterns after EC use. Women who had multiple lifetime sexual partners were almost two times more likely to switch to more effective methods when compared with women who had 1 lifetime sexual partners. It is well-documented that contraceptive use is associated with multiple aspects of sexual behavior, including numbers of sexual partners in lifetime (Frost, Singh, Finer, 2007a; Manlove et al., 2011; Manlove et al., 2014; Reed et al., 2014).

\subsubsection{Gaps in contraception after emergency contraception use}

For the endpoint of this study, and contrary to our expectations, few women $(7.5 \%)$ had gaps after using EC. This finding may be related to the short time analyzed (1-month after using EC). The pattern of this event was consistent with findings of previous studies (Lo et al., 2004; Sidebottom, 2008; MacLean, 2010). A case-control study that assessed the advance provision of EC with among women with 18-24 years old in the U.S., observed an increase of consistent use of oral pill from enrollment to follow-up in both groups (Raine et al., 2000). Another study 
undertaken with among women aged <16-24 in U.S., observed consistent condom use at 6-month follow-up after provision of EC in pharmacy (Harper et al., 2005). Indeed, studies based on contraceptive use following EC use, noted that consistency of method use during the year of follow-up is quite remarkable, which also suggests that, the use of EC does not appear to affect the use of regular contraception (Lo et al., 2004; Figueiredo, Puppo, Segri, 2008; Alano et al., 2012).

The strongest point of our study was to comprehend the contraceptive dynamic within 30 days after using EC among a potential group of women at high risk of unintended pregnancy and induced abortions. Understanding this dynamic can assist in the improvement of programs for young people in primary health care system in Brazil, especially in terms of increasing the availability of the method, since EC does not interfere with the routine use of contraceptive methods. However, our study has several limitations that need to be discussed.

First, our population of undergraduate students from a public university is not necessarily generalizable to all populations of youth. Second, although we questioned young women about the use of contraception 1-month before and 1month after EC use, we did not know with accuracy if they had any unprotected sexual intercourse during this time, and therefore, we did not quantify the frequency of unprotected sexual intercourse. This study is a complement of another broader project, so data on EC use was limited. Because we were limited to 1-month intervals, we did not think we could get accurate data about number of unprotected sexual intercourse. Risk for pregnancy and the impact of EC use certainly is related to the frequency of unprotected sexual intercourse. Lastly, our retrospective study relied on self-reported data for an evaluation of sexual, reproductive history characteristics, and contraceptive use, which can be subject to recall bias.

\subsection{CONCLUSION}

First of all, we conclude that most women in our sample use contraceptive method within 30-days after EC use; also, the use of contraception after EC use among women who were not using a method within 30 days prior to EC use was a relevant issue. Second, we conclude that EC is mainly used in situations of inconsistency use of contraception, since the majority of women in our study had no 
change in contraception after EC use. A positive finding was the switching to more effective methods among women who had changes in contraception after EC. Finally, we conclude that continuous use of contraceptives is not a rare event, since gaps in contraception following EC use was infrequent among our sample.

Our findings of EC - particularly related to EC as potentially "bridge" to regular contraception and the few gaps observed after EC use - may positively reflect in the issues of unintended pregnancy, and induced abortions. However, it is important that the medical community and the family planning services address and comprehend how youth use contraceptive method, in order to avoid inconsistency in its use, and consequently, an unnecessary use of EC.

Unintended pregnancies resulting from inconsistent use of contraception could be decreased by couples' increased reliance on male condoms and by increased adherence to daily oral pill. Therefore, counseling to educate youth alike on the boundaries of EC and to stimulate the correct use of ongoing contraception, along with the availability of the method, should be strongly considered in primary health care in Brazil.

A recent pilot study in Scotland found that a simple intervention in which pharmacists provided women presenting for EC with a cycle of oral pills significantly increased the probability of the women using effective contraception following EC use (Michie et al., 2014). Also, a case control study conducted among high risk women (15-19 years old) in Sweden, indicate that women provided advanced supplies of EC were more likely than those in the control group (not given EC) to reported a shorter time interval from unprotected sexual intercourse to EC intake, without any evidence of decreased use of contraceptives (Ekstrand et al., 2013). Therefore, expanding EC access and implementing advanced supply of EC in the Unified Health System (SUS) could benefit several Brazilian women, specially those who are at risk to unintended pregnancy.

Furthermore, although our results show that the use and consistency of contraception after EC use among undergraduate students were consistent with other studies and was relevant, since there are no studies that approached this scenario in Brazil, the time analyzed (1-month before EC use and 1-month after EC use) was not enough for an in-depth analysis. Therefore, we would recommend that future researches in Brazil address contraceptive use after accessing EC considering a longer length. 



\section{CHAPTER SEVEN}

\subsection{SUMMARY OF FINDINGS}

This section summarizes the key findings of the current study. In addition, limitations of the study were discussed, as were implications of the findings and future research possibilities.

Trends over the last half century show worldwide changes in sexual and reproductive health behaviors with increases in modern contraceptive use in Brazil (Brasil, 2008a). However, the sexual and reproductive health of all women in Brazil continues to be a serious public health concern, since the unintended pregnancies are higher especially due to contraceptive discontinuation, and there are limitations in implementing sexual and reproductive rights in the country (Brasil, 2008a; Berquó, Lima, 2008).

During the course of this study, a number of research gaps became apparent. This is the first Brazil study to describe young women's patterns of contraceptive use and use of EC in context of contraceptive discontinuation, and these quantitative findings should be further explored with other groups of women throughout the Brazil. Our study was developing to expand other two prior researches (Pirotta, Schor 2004; Borges et al., 2010) on contraceptive behavior undertaken with young people in Brazil.

Contraceptive calendar is applicable for this study because it contains contraceptive histories for a representative sample of women between the ages of 18 and $24(n=1,679)$. In addition, we created a "EC calendar" based on the contraceptive calendar, to comprehend the dynamics of contraceptive discontinuation before and after using EC.

In chapter 3, examine whether contraceptive discontinuation for any reason, for method-related reasons and abandonment or switching to a less effective method is a common event among undergraduate students, also we verify the frequency of discontinuation, and if contraceptive discontinuation differs by type of method contraceptive. We find that that few young women discontinued their method for any reason $(35 \%)$, method-related reasons $(28 \%)$; however, a relative proportion of women $(18 \%)$ abandoned their method or switched to a less effective method. 
Additionally, we conclude that the frequency of discontinuation within 12-months is low, most of women who discontinued their method for any reason or for methodrelated reasons, discontinued just once during the 12-months (24\% and 19\%, respectively). We find that contraceptive discontinuation does differ by type of contraceptive method. Oral pill was the most contraceptive method used 12-months prior to the survey, following by male condom. However, according to the analysis of monthly discontinuation, we find that young women who were using male condom $(10 \%)$ were more likely to discontinued their method for method-related reasons than oral pill users (3\%), and also to method abandonment (5\% of condom users against $3 \%$ of pill users); though we also observed (in analysis of new episodes of contraception) that oral pill users (3\%) were a bit more likely to abandonment or switching to a less effective method when compared with male condom users $(2 \%)$.

The differences among the results can be explained by the exclusion of women who used the same contraception continuously, and the exclusion of the firsts discontinuation episode, when we analyzed the probability of discontinuation of new episodes of contraception. On one hand, the analysis of the new episodes of contraception presents an overview of the relative risks of discontinuation. Conversely, they possible overestimating the discontinuation rates due to these exclusions. Similarly, the analysis of monthly discontinuation has pros and cons. The analysis of monthly discontinuation does not present this problematic, but on the other hand this analysis was not left-censored, that is, women who had initiated their method before the calendar period started (considered in most cases consistent users) were maintained in the analysis. Contraceptive discontinuation between women who have used a contraceptive some years with new users is totally different, since the likelihood of new users discontinuing the method is much greater. The performance of both analysis was important to compare the findings, which further deepened the study.

In chapter 4, we focus on using EC following discontinuation for method-related reasons and method abandonment. Additionally, we investigated the use of EC following inconsistent use of contraception or EC use in the context of non-regular contraception. One notable aspect of the evaluation findings is that the majority of women used EC in context of continuous use of the method, in cases of errors in the method, or in the occurrence of possible contraceptive gaps when women switching for another method. It means that the use of EC in context of inconsistent use 
$(90.6 \%)$ was higher than in context of non-regular contraception $(9.4 \%)$, which is a positively finding. However, when we focus only on women who had discontinued their method for method-related reasons and women who abandoned their method, we observed that a relevant proportion of women did not use EC in situations of pregnancy risk. Only $24 \%$ of women who are at risk to become pregnant used EC following discontinuation for method-related reasons, and $11 \%$ of women used EC following method abandonment. A relevant proportion of young women in our study probably do not recognize they be at risk of pregnancy, which lead to non-use of EC in situations where the method is required, i.e., following discontinuation for methodrelated reasons and method abandonment.

In chapter 5 investigates the use of contraception before and after EC use during 1-month, through "EC calendar". We also examined if the contraceptive utilized was the same before and after EC use, that is, whether the woman really used EC in context of inconsistent use. In addition, we evaluated contraceptive gaps after EC use. Our findings show that the contraceptive discontinuation 1-month before and 1month after using EC is not high (33\% and $25 \%$, respectively). We also revealed that EC is mainly used in situations of inconsistency use of contraception, since the majority of women in our study used the same method before and after EC used $(72 \%)$, that is, few women use EC in context of unprotected sexual intercourse. Gaps in contraception following EC use was also low than predictable (7.5\%).

The main point was that the type of relationship, socioeconomic status, sexual experience, sexual partners, and type of contraceptive were strong variables that were associate with contraceptive discontinuation and were common in most analyzes. As for type of relationship, although type of relationship relationship was strongly associate with contraceptive discontinuation, and with EC use in the context of discontinuation, this study cannot assess the mediating effects of relationship dynamics/quality on contraceptive discontinuation. Recent studies, especially those using young people samples, have observed the importance of these relationship dynamics as having both a direct and mediating effect on contraceptive use (Manning et al,. 2009; Gibbs et al., 2014; Manlove et al., 2014). Perhaps diary data as collected by the Barber \& colleagues (2011) would be best to capture quality of the relationship at the time of discontinuation.

This study address a variety types of contraceptive discontinuation (discontinuation for any reason, discontinuation for method-related reasons, and 
method abandonment), that has been not recently investigated in Brazil, and provides an update to research by considering discontinuation by type of contraceptive method as well as EC in context of contraceptive discontinuation. Understanding contraceptive discontinuation is significant because it has negatively and positively reproductive consequences for women throughout their life course, especially among young women who the contraceptive trajectories are dynamic. In addition, from the life course perspective, comprehending contraceptive and reproductive behaviors among young people are important, because family (and union) formation has experienced a major transformation over the last decade with delays in marriage (Manning, Brown, 2014; IBGE, 2015). It means that a growing population of youth exposed to a potential risk of unintended pregnancy.

For the endpoint of this viability study, we are well aware of the limitations specially of using retrospective measures of contraceptive behaviors in this study, but we believe that our results can contribute to understand the contraceptive dynamic, and the use of EC among Brazilian young women in context of contraceptive discontinuation.

\subsection{STRENGHTS AND LIMITATIONS}

The most strengths of our study are the ability to comprehend the contraceptive discontinuation among undergraduate students, since the frequency and extent of contraceptive gaps among young women in Brazil nowadays is not well-known. In addition, this is the first study from Brazil to evaluate the EC following a contraceptive discontinuation, and is also original in evaluating contraceptive discontinuation before and after using EC, among young women who are at risk to become pregnant. There are few studies that assess discontinuation among Brazilian women, but none of them have already included EC. Therefore, our study can help to understand the scenario of contraceptive discontinuation among young women in Brazil, which it has significant implications for the prevention of unintended pregnancies and subsequences induced abortions.

We stress that this is the first study that addressed field of study in the context of contraceptive discontinuation. Most of the studies that contemplate university 
students do not address the educational background, which has been shown to be associated with contraceptive discontinuation in our analyzes.

Our data provide a rich and detailed picture of contraceptive behavior among a cohort of female undergraduate students in Brazil. However, this study has some limitations which need to be considered while interpreting our results.

- The study was carried out only in one university, although contemplated all campuses of this university, it may not be representative of Brazil university female students, and therefore results may not be generalizable to other universities in Brazil.

- Because of the retrospective nature of the contraceptive method history calendar, may there were recall bias. However, starting with the National Survey of Family Growth (NSFG) and now in succeeding studies, the female interview uses a life history calendar as a remembrance aid for the pregnancy and contraceptive history (Bradley, Schwandt, Khan, 2009). Notwithstanding these methodological strategies, we recognize that the recollection of contraceptive methods may be problematic.

- Another limitation refers to the grouping of "switching to a less effective method" with "method abandonment", a resource used due to the low number of women who abandoned their methods and therefore, which would make some analyzes impossible. Although women who abandon their method or switching to a less effective method represent women at high risk of unintended pregnancies, we understand that contraceptive behavior differs between the two categories.

○ There is no corresponding contraceptive method history calendar for men. Therefore, equivalent analyses for men cannot be investigated. Future consideration to men is also necessary, since the involvement of the partner impact in the contraceptive behavior (Manning et al., 2009; Manlove et al., 2011; Wildsmith, Manlove, Steward-Streng, 2015).

- Another limitation of this study relates to chosen methodology in which leftcensored episodes were not included in analysis of cumulative probabilities of new episodes of contraception. This causes the loss of a significant amount of data and potentially leads to over estimates of discontinuation rates because 
long time users who use consistently throughout the entire observation period are excluded due to left-censoring.

- The questionnaire contained a predetermined list of contraceptive methods for undergraduate students to choose from. There are a variety of issues regarding to this that limit our understanding of their contraceptive use. Firstly, in the "Contraceptive Calendar" the main methods were listed, and young women could select just one answer, that is, they were asked about the main contraception that they used per month; so, it was possible that women used several methods in the same month, also it was possible that particular methods were under-reported or forgotten.

- The oral pill and male condoms are effective contraceptive methods when they are used properly. However, undergraduate students were not asked about this important aspect of contraceptive use. In addition, young women were not asked why they used specific contraceptive methods at each month.

- Some data collected refer to the time of research, which made difficult the time specific indicators of sociodemographic and socioeconomic. Our contraceptive calendar did not include a time-varying measure of sociodemographic and socioeconomic and so we were unable to capture changes in these segments which may be consequential for discontinuation. Religion is another variable used in the analyses. However, this variable is based on affiliation, this by no means indicates that women attended the religion or were religious during the time of observation. Consequently, results related to religious affiliation must be carefully interpreted.

- We did not evaluate contraceptive failures, since it was not our objective. However, we recognize that failure of contraceptive method is an important outcome to study because it can lead to immediate risk of unintended pregnancy.

- Only few reasons for discontinuation were collected. In actuality, there are numerous reasons for discontinuing a contraceptive method, so we recognize our analyses of reasons for discontinuation are probable overgeneralized.

- Our analysis is limited to two contraceptive methods (oral pill and male condom), since the other methods were poorly reported by our study 
population. In Brazil, modern contraceptive methods are used on a limited scale, irrespective of women's age (Brasil, 2008a).

- Because of the environment of the study which included sensitivity matter and self-reporting, information bias could be introduced which may have affected reliability of the results. Response bias can exist whether university students who have grown exhausted of completing surveys, opt to satisfice rather than cognitively choose the most appropriate responses (Barge, Gehlbach, 2011). Satisficing can include young women choosing the intermediate response rather than making an authentic choice, or answering all sections with the same response, leading to false responses. Satisficing can lead to invalid inferences about the data. In addition, the probability that interviewed provided socially satisfactory responses is a limitation to the validity of the inferences made using the data collected. However, the fact that the study questionnaire was online, and consequently quick and easy to answer, may have minimized these aspects. Also, the use of self-reports by university students has been found to be a precise way to collect information (Pike, 2011).

- Only few reasons for contraceptive discontinuation were collected. In actuality, there are numerous reasons for discontinuing a contraceptive method, so we recognize our analyses of reasons for discontinuation are probable overgeneralized. Seventh, our analysis is limited to two contraceptive methods (oral pill and male condom), since the other methods were poorly reported by our study population. In Brazil, modern contraceptive methods are used on a limited scale (Brasil, 2008a).

- Our study did not collect data on reasons for use or non-use of EC in the "EC calendar".

- Although we questioned young women about the use of contraception 1month before and after EC use, we did not know with accuracy if they had any unprotected sexual intercourse during this time, and therefore, we did not quantify the rate of unprotected sexual intercourse. Finally, the "EC calendar" was just limited to 1-month interval. 


\subsection{RECOMMENDATIONS FOR FUTURE RESEARCHES}

The topics of contraceptive discontinuation and emergency contraception are extensive open for research. Because these topics have been and remain a controversial theme it might not be easy to conduct research, but it is important in helping to understand the contraceptive dynamics, especially among university students. The up-to-date analysis of women's contraceptive method behavior provides a solid platform for future research. Areas for possible research include, but are not limited to:

- A qualitative study addressing focus groups could be undertaken with women in reproductive ages or EC users to get the whole picture of their needs, opinions, and beliefs. This could guide future interventions to reduction unintended pregnancies.

- A longitudinal study of undergraduate students beginning as freshman through senior year to investigate sexual activity as well as EC use could be conducted.

- Studies could be conducted to investigate diverse education modes to determine how much education is required to provoke contraceptive behavior change. Are brochures and posters effective? Can the media be used to spread adequate information to women? How much acquaintance is needed to dismiss misconceptions about EC? Do on-line classes improve knowledge and behavior modification? Are presentations better than television programs? Are direct interventions better option than group interventions?

- It would be useful to examine the emerging questions around sexual pleasure, sources of contraceptive knowledge, and personality. This would provide a more complete understanding of the role of contraceptive discontinuation and method switching in women's lives in Brazil, which could help to develop suitable sexual and reproductive health interventions.

- Future studies should approach and discuss with men about the importance of consistent contraceptive use and the risks of unintended pregnancy. Prospective studies on contraceptive use patterns are also recommended. 
- Targeting people who are important to the students: probably if parents, pharmacy workers and health professionals understand EC better, they may be more accepting its use. If they are more accepting of its use, then undergraduate students may be more likely to use it.

- Other possibility to consider are group discussions in student residence at university, or making sexual health classes obligatory and increasing the amount of time spent in those classes on teaching about contraception, and EC.

\subsection{PUBLIC HEALTH IMPLICATIONS}

The main public health implication of contraceptive discontinuation is the unintended pregnancy and the amount of health, economic and social consequences that it causes. We believe that the public health impact of contraception will not be concretized until all women who desire to prevent pregnancies are using their method of choice continuously and effectively.

The public health implications of this study comprise an important contribution to the dearth of literature about contraceptive discontinuation among young women in Brazil. At the public health programming level, outcomes from this study can lead to intervention efforts to improve unintended pregnancy prevention among young women.

Lastly, access to contraceptive methods needs to be improved in primary health care system in Brazil, and clinical counselling and public health education efforts could focus on informing young women about the importance of effective and consistent use of contraception. We believe that a larger comprehending of young's concerns and experience using contraception could help primary health care providers reshape counseling strategies to improve adequate contraceptive continuation. In addition, appropriate and effective sexual health measures to support undergraduate students are strongly recommended and could stimulate responsible sexual behavior as a Public Health priority. 




\section{REFERENCES}

Aiken AM, Gold MA, Parker AM. Changes in young women's awareness, attitudes, and perceived barriers to using emergency contraception. J Pediatr Adolesc Gynecol. 2005;18(1):25-32.

Alano GM, Costa LN, Mirand LR, Galato D. Conhecimento, consumo e acesso à contracepção de emergência entre mulheres universitárias no sul do Estado de Santa Catarina. Cienc Saúde Coletiva. 2012;17(9):2397-404.

Ali M, Cleland J. Contraceptive discontinuation in six developing countries: a causespecific analysis. Int Fam Plan Perspect. 1995;64(3):92-97.

Ali M, Cleland J. Determinants of contraceptive discontinuation in six developing countries. J Biosoc Sci. 1999;31(3):343-60.

Ali MM, Cleland J, Shah IH. Causes and consequences of contraceptive discontinuation: evidence from 60 Demographic and Health Surveys. Geneva: World Health Organization; 2012. Available at: http://apps.who.int/iris/bitstream/10665/ 75429/1/9789241504058 eng.pdf.

American College Health Association. American college health association-national college health assessment II: reference group executive summary spring 2015. Hanover, MD: American College Health Association; 2015. Available at: http://www.acha-ncha.org/docs/NCHA-II WEB SPRING 2015 REFERENCE GRO UP EXECUTIVE SUMMARY.pdf.

Anasel MG, Mlinga UJ. Determinants of contraceptive use among married women in Tanzania: Policy implication. African Population Studies. 2014;28(2):978-88.

Aquino EML, Heilborn ML, Knauth D, Bozon M, Almeida MC, Araújo J, et al. Adolescência e reprodução no Brasil: a heterogeneidade dos perfis sociais. Cad Saúde Pública. 2003;19 Suppl 2:S377-88.

Arowojolu AO, Okewole IA, Adekunle AO. Comparative evaluation of the effectiveness and safety of two regimens of levonorgestrel for emergency contraception in Nigerians. Contraception. 2002;66:269-73. 
Associação Brasileira de Empresas de Pesquisa (ABEP). Critério de classificação econômica Brasil. Dados com base no levantamento socioeconômico. CCEB, 2015. Available at: http://www.abep.org/criterio-brasil.

Bajos N, Lamarche Vadel A, Gilbert F, Ferrand M, Moreau C. Cocon group. Contraception at the time of abortion: high-risk period or high-risk women? Hum Reprod. 2006;21:2862-7.

Bajos N, Le Guen M, Bohet A, Panjo H, Moreau C; FECOND group. Effectiveness of family planning policies: the abortion paradox. PLoS One. 2014;9(3):e91539. DOI: 10.1371/journal.pone.0091539. eCollection 2014.

Ballinger GA. Using Generalized Estimating Equations for longitudinal data analysis. Org Research Methods. 2004;7(2):127-50.

Barden-O'Fallon JL, Speizer IS, White JS. Association between contraceptive discontinuation and pregnancy intentions in Guatemala. Rev Panam Salud Publica. 2008;23(6):410-7.

Barden-O'Fallon J, Speizer IS, Cálix J, Rodriguez F. An analysis of contraceptive discontinuation among female, reversible method users in urban Honduras. Stud Fam Plann. 2011a;42(1):11-20.

Barden-O'Fallon J, Speizer I. What differentiates method stoppers from switchers? Contraceptive discontinuation and switching among Honduran women. Int Perspect Sex Reprod Health. 2011b;37(1):16-23. DOI: 10.1363/3701611.

Barge S, Gehlbach $\mathrm{H}$. Using the theory of satisficing to evaluate the quality of survey data. Research in Higher Education. 2011;53(2):182-200. DOI:10.1007/s11162-0119251-2.

Bastianelli C, Rosato E, Farris M, Benagiano G. Emergency contraception: a survey of 1773 women. Eur J Contracept Reprod Health Care. 2016;21(6):455-461.

Bastos MR, Borges ALV, Hoga LAK, Fernandes MP, Contin MV. Práticas contraceptivas entre jovens universitárias: o uso da anticoncepção de emergência. Texto Contexto Enferm. 2008;17(3):447-56. 
Bataglião EML, Mamede FB. Conhecimento e utilização da contracepção de emergência por acadêmicos de enfermagem. Esc. Anna Nery. 2011;15(2):284-90.

Beadnell B, Morrison DM, Wilsdon A, Wells EA, Murowchick E, Hoppe M, Gillmore MR, Nahom D. Condom use, frequency of sex, and number of partners: multidimensional characterization of adolescent sexual risk-taking. J Sex Res. 2005, 42(3):192-202.

Beltzer N, Moreau C, Bajos N; groupe CSF. Prevention of unintended pregnancies: toward a dual protection at sexual debut? Rev Epidemiol Sante Publique. 2011; 59(1):15-21. DOI: 10.1016/j.respe.2010.10.006.

Belzer M, Yoshida E, Tejirian T, Tucker D, Chung K. Advanced supply of emergency contraception for adolescent mothers increased utilization without reducing condom or primary contraception use. J Adolesc Health. 2003;32(2):122-3.

Berquó E, Lima LP. Intenções reprodutivas e planejamento da fecundidade. In: Elza Berquó E, Garcia S, Lago T, organizadores. Relatório Final da Pesquisa Nacional de Demografia e Saúde da Criança e da Mulher - PNDS 2006. Brasília: Ministério da Saúde; 2008. p. 203-04.

Blanc AK. The effect of power in sexual relationships on sexual and reproductive health: an examination of the evidence. Stud Fam Plann. 2001;32(3):189-213.

Blanc AK, Curtis SL, Croft TN. Monitoring contraceptive continuation: links to fertility outcomes and quality of care. Stud Fam Plann. 2002;33(2):127-40.

Blanc AK, Tsui AO, Croft TN, Trevitt JL. Patterns and trends in adolescent's contraceptive use and discontinuation in developing countries and comparisons with adult women. Int Perspect Sex Reprod Health. 2009;35(2):63-71.

Bongaarts, J. A framework for analyzing the proximate determinants of fertility. Popul Dev Rev. 1978;4:105-132.

Borges ALV, Fujimori E, Hoga LAK, Contim M. Práticas contraceptivas entre jovens universitários: uso da anticoncepção de emergência. Cad Saúde Pública. 2010; 26(4):816-26. DOI:10.1590/S0102-311X2010000400023. 
Brache V, Cochon L, Jesam C, Maldonado R, Salvatierra AM, Levy DP, Gainer E, Croxatto HB. Immediate preovulatory administration of $30 \mathrm{mg}$ ulipristal acetate significantly delays follicular rupture. Hum Reprod. 2010;25:2256-63.

Bradley SEK, Schwandt HM, Khan S. Levels, Trends, and Reasons for Contraceptive Discontinuation. DHS: Demographic and Health Research Division: Report. United States; 2009. Available at: http://www.measuredhs.com/pubs/AS20/AS20.pdf.

Bradley SEK, Croft TN, Rutstein SO: DHS Analytical Studies No. 22. The Impact of Contraceptive Failure on Unintended Births and Induced Abortions: Estimates and Strategies for Reduction. Maryland: ICF Inc; 2011.

Brandão ER, Cabral CS, Silva MV, Bastos LL, Paiva SP, Oliveira NVBV, Szabo I. O olhar do farmacêutico sobre a contracepção de emergência. In: Figueiredo R, Borges ALV, Paula SHB, organizadores. 1 ed. São Paulo: Instituto de Saúde; 2016. p.186.

Brasil. Ministério da Saúde. Secretaria da Ciência, Tecnologia e Insumos Estratégicos. Departamento de Ciência e Tecnologia. Pesquisa Nacional de Demografia e Saúde 1996: relatório. Rio de Janeiro; 1997. Available at: https://dhsprogram.com/pubs/pdf/FR77/FR77.pdf.

Brasil. Ministério da Saúde. Secretaria da Ciência, Tecnologia e Insumos Estratégicos. Departamento de Ciência e Tecnologia. PNDS: 2006: Pesquisa Nacional de Demografia e Saúde da Criança e da Mulher: relatório. Brasília: Ministério da Saúde; 2008a. Available at: http://bvms.saude.gov.br/bvs/publicacoes/ relatório pnds 2006.pdf.

Brasil. Ministério da Saúde. Aborto e Saúde Pública: 20 anos de pesquisa no Brasil. Brasília: Ministério da Saúde; 2008b. Available at: http://bvsms.saude.gov.br/bvs/ publicacoes/livro aborto.pdf.

Brasil. Ministério da Saúde. Saúde sexual e saúde reprodutiva. Brasília: Ministério da Saúde; 2010. Available at: http://189.28.128.100/dab/docs/publicacoes/cadernos ab/abcad26.pdf. 
Brasil. Ministério da Saúde. Secretaria de Vigilância em Saúde. Departamento de Análise de Situação em Saúde. Saúde Brasil 2013: Uma análise da situação de saúde e das doenças transmissíveis relacionadas à pobreza. Brasília: Ministério da Saúde; 2014. Available at: http://bvsms.saude.gov.br/bvs/publicacoes/saude brasil 2013 analise situacao saude.pdf.

Brunner Huber LR, Hogue CJ, Stein AD, et al. Contraceptive use and discontinuation: findings from the contraceptive history, initiation, and choice study. Am J Obstet Gynecol. 2006;194:1290-5.

Bryant, KD. Contraceptive use and attitudes among female college students. ABNF J. 2009;20(1):12-6.

Burdette AM, Haynes SH, Hill TD, Bartkowski JP. Religious variations in perceived infertility and inconsistent contraceptive use among unmarried young adults in the United States. J Adolesc Health. 2014;54(6):704-9. DOI: 10.1016/j.jadohealth .2013.11.002. Epub 2014 Jan 1.

Cameron ST, Glasier A, Johnstone A, Rae L. Ongoing contraception after use of emergency contraception from a specialist contraceptive service. Contraception. 2011;84(4):368-71. DOI: 10.1016/j.contraception.2011.02.012.

Cameron ST, Gordon R, Glasier A. The effect on use of making emergency contraception available free of charge. Contraception. 2012;86(4):366-9. DOI: 10.1016/j.contraception.2012.02.018.

Caruso S, Agnello C, Intelisano G, et al. Prospective study on sexual behavior of women using 30 microg ethinylestradiol and $3 \mathrm{mg}$ drospirenone oral contraceptive. Contraception. 2005;72:19-23.

Casterline J, El-Zanaty $\mathrm{F}$ and El-Zeini L. Unmet need and unintended fertility: longitudinal evidence from Upper Egypt. International Family Planning Perspectives. 2003;29(4):158-66.

Castle S, Askew I. Contraceptive discontinuation: reasons, challenges, and solutions. Population Council, 2015. [report]. Available at: http://ec2-54-210-230-186.compute1.amazonaws.com/wp-content/uploads/2015/12/FP2020 ContraceptiveDiscontinuati on SinglePage Final 12.08.15.pdf. 
Cavazos-Rehg PA, Krauss MJ, Spitznagel EL, Schootman M, Peipert JF, Cottler LB, Bierut LJ. Type of contraception method used at last intercourse and associations with health risk behaviors among US adolescents. Contraception. 2010;82(6):549-55. DOI: 10.1016/j.contraception.2010.05.007.

Centers for Disease Control and Prevention (CDC). Unintended pregnancy prevention, 2011a. Available at: http://www.cdc.gov/reproductivehealth/Unintended Pregnancy/index.htm.

Centers for Disease Control and Prevention (CDC). Pregnancy risk assessment monitoring system (PRAMS): PRAMS and unintended pregnancy, 2011b. Available at: http://www.cdc.gov/PRAMS/UP.htm.

Centers for Disease Control and Prevention (CDC). U.S. selected practice recommendations for contraceptive use, 2013: adapted from the World Health Organization selected practice recommendations for contraceptive use, 2nd edition. MMWR Recomm Rep. 2013;62(RR-05):1-60. Available at: http://www.cdc.gov/mmwr/ $\mathrm{pdf} / \mathrm{rr} / \mathrm{rr} 62 \mathrm{e} 0614 . \mathrm{pdf}$.

Cheng D, Schwarz E, Douglas E, Horon I. Unintended pregnancy and associated maternal preconception, prenatal and postpartum behaviors. Contraception 2009; 79(3):194-98.

Chin-Quee DS, Wedderburn M, Otterness C, Janowitz B, Chen-Mok M. Bridging emergency contraceptive pill users to regular contraception: results from a randomized trial in Jamaica. Contraception 2010;81:133-9.

Chofakian CBN, Borges ALV, Fujimori E, Hoga LAK. Conhecimento sobre anticoncepção de emergência entre adolescentes do Ensino Médio de escolas públicas e privadas. Cad. Saúde Pública. 2014;30(7):1525-36.

Cleland K, Zhu H, Goldstuck N, Cheng L, Trussell J. The efficacy of intrauterine devices for emergency contraception: a systematic review of 35 years of experience. Hum Reprod. 2012;27(7):1994-2000. DOI: 10.1093/humrep/des140.

Coetzee MH, Ngunyulu RN. Assessing the use of contraceptives by female undergraduate students in a selected higher educational institution in Gauteng. Curationis. 2015;38(2):1535. DOI:10.4102/curationis.v38i2.1535. 
Costa AM, Guilhem D, Silver LD. Planejamento familiar: autonomia das mulheres sob questão. Rev Bras Saúde Mater Infant. 2006;6(1):75-84. DOI: 10.1590/S151938292006000100009.

Costa NFP, Ferraz EA, Souza CT, Silva CFR, Almeida MG. Access to emergency contraception: old barriers and new questions. Rev Bras Ginecol Obstet. 2008;30(2): $55-60$.

Creanga AA, Acharya R, Ahmed S, Tsui AO. Contraceptive discontinuation and failure and subsequent abortion in Romania: 1994-99. Stud Fam Plann. 2007; 38(1):23-34.

Creinin MD, Schlaff W, Archer DF, Wan L, Frezieres R, Thomas M, Rosenberg M, Higgins J. Progesterone receptor modulator for emergency contraception: a randomized controlled trial. Obstet Gynecol. 2006;108:1089-97.

Curtis SL, Blanc AK. Determinants of contraceptive failure, switching, and discontinuation: an analysis of DHS contraceptive histories. DHS Analytical Reports. Calverton, MD, USA: Macro International; 1997.

Curtis S, Evens E, Sambisa W. Contraceptive discontinuation and unintended pregnancy: an imperfect relationship. IntPerspect Sex Reprod Health. 2011; 37(2):58-66.

Cwiak C, Howard B, Hsieh J, Ricciotti N, Sucato GS. Sexual and Contraceptive Behaviors among Adolescents Requesting Emergency Contraception. J Pediatr Adolesc Gynecol. 2016;29(6):643-647. DOI: 10.1016/j.jpag.2016.06.003.

D'Antona AO, Chelekis JA, D'Antona MF, Siqueira AD. Contraceptive discontinuation and non-use in Santarém, Brazilian Amazon. Cad Saúde Pública. 2009;25(9):202132.

Daniels $\mathrm{K}$, Jones J, Abma JC. Use of emergency contraception among women aged 15-44: United States, 2006-2010. NCHS data brief no 112. Hyattsville, MD: U.S. Department of Health and Human Services, Centers for Disease Control and Prevention, National Center for Health Statistics; 2013. 
Daniels K, Daugherty J, Jones J, Mosher W. Current contraceptive use and variation by selected characteristics among women aged 15-44: United States, 2011-2013. Natl Health Stat Report. 2015; 86:1-15. Available at: http://www.cdc.gov/nchs/ data/nhsr/nhsr086.pdf.

Davidoff-Gore A, Luke N, Wawire S. Dimensions of poverty and inconsistent condom use among youth in urban Kenya. AIDS Care. 2011;23(10):1282-90. DOI:10.1080/09540121.2011.555744.

Davies SL, DiClemente RJ, Wingood GM, Person SD, Dix ES, Harrington K, Crosby RA, Oh K. Predictors of inconsistent contraceptive use among adolescent girls: findings from a prospective study. J Adolesc Health. 2006;39(1):43-9.

Dessunti EM, Reis AOA. Vulnerabilidade às dst/aids entre estudantes da saúde: estudo comparativo entre primeira e última série. Cienc Cuid Saude. 2012;11:27483. DOI: 10.4025/cienccuidsaude.v11i5.17738.

Diamond-Smith NG, Moreau C, Bishai DM. Reducing unintended pregnancies: a microsimulation of contraceptive switching, discontinuation, and failure patterns in France. Stud Fam Plann. 2014;45(4):429-41. DOI: 10.1111/j.17284465.2014.00006.x.

Diniz D, Medeiros, M. Aborto no Brasil: uma pesquisa domiciliar com técnica de urna. Ciênc Saúde Coletiva. 2010;15(1):959-66. DOI: 10.1590/S1413-81232010000 700002.

Donadiki EM, Jimenez-Garcla R, Velonakis EG, Hernandez-Barrera V, Sourtzi P, Lopez de Andres A, Jimenez-Trujillo I, Pino CG, Carrasco-Garrido P. Factors related to contraceptive methods among female higher education students in Greece. J Pediatr Adolesc Gynecol. 2013; 26(6):334-9. DOI: 10.1016/j.jpag.2013.06.011.

Ekstrand M, Tydén T, Darj E, Larsson M. Twelve-month follow-up of advance provision of emergency contraception among teenage girls in Sweden-a randomized controlled trial. Ups J Med Sci. 2013;118(4):271-5.

Ersek JL, Brunner Huber LR, Thompson ME, Warren-Findlow J. Satisfaction and discontinuation of contraception by contraceptive method among university women. Matern Child Health J. 2011;15(4):497-506. DOI: 10.1007/s10995-010-0610-y. 
Escobar B, Román C, Muños C, López F. Perfil biosocial de las usuarias que demandan la píldora de anticoncepción de emergência en un centro de salud de Santiago, 2006-2007. Rev Chil Obstet Ginecol. 2008;73(4):223-7.

ESHRE CapriWorkshop Group. Emergency contraception. Widely available and effective but disappointing as a public health intervention: a review. Hum Reprod. 2015; 30(4):751-60. DOI: 10.1093/humrep/dev019.

Falk G, Falk L, Hanson U, Milsom I. Young women requesting emergency contraception are, despite contraceptive counseling, a high risk group for new unintended pregnancies. Contraception. 2001;64(1):23-7.

Faúndes A, Simoneti RM, Duarte GA, Andalaft-Neto J. Factors associated to knowledge and opinion of gynecologists and obstetricians about the Brazilian legislation on abortion. Rev Bras Epidemiol. 2007; 10(1): 6-18. DOI: 10.1590/S1415$790 \times 2007000100002$.

Ferreira JM, Nunes FR, Modesto W, Gonçalves MP, Bahamondes L. Reasons for Brazilian women to switch from different contraceptives to long-acting reversible contraceptives. Contraception. 2014;89(1):17-21. DOI: 10.1016/j.contraception.2013. 09.012 .

Figueiredo R, Puppo LR, Segri NJ. Comportamento sexual e preventivo de adolescentes de São Paulo: um estudo com estudantes do ensino médio. BIS, Bol Inst Saúde. 2008;(46):31-3.

Figueiredo R, Paula BHS. Distribuição da contracepção de emergência nos municípios do estado de São Paulo: avaliação de dispensa em serviços e fluxos estabelecidos. Reprod Clim. 2012; 27(2):64-72.

Finer LB, Henshaw SK. Disparities in rates of unintended pregnancy in the United States, 1994 and 2001. Perspect Sex Reprod Health. 2006; 38:90-6.

Finer LB, Zolna MR. Unintended pregnancy in the United States: incidence and disparities, 2006. Contraception. 2011;84(5):478-85. DOI: 10.1016/j.contraception. 2011.07.013.

Finer LB, Zolna MR. Declines in unintended pregnancy in the United States, 20082011. N Engl J Med. 2016;374(9):843-52. DOI: 10.1056/NEJMsa1506575. 
Free C., Lee RM, Ogden J. Young women's accounts of factors influencing their use and non-use of emergency contraception: in-depth interview study. BMJ. 2002;325: 1393-6.

Free C, Ogden, J. Emergency contraception use and non-use in young women: the application of a contextual and dynamic model. Br J Health Psychol. 2005;10(2):23753.

Freedman LR, Stulberg DB. The research consortium on religious healthcare institutions: studying the impact of religious restrictions on women's reproductive health. Contraception. 2016;94(1):6-10. DOI: 10.1016/j.contraception.2016.03.015.

Frost JJ, Singh S, Finer LB. Factors associated with contraceptive use and nonuse, United States, 2004. Perspect Sex Reprod Health. 2007a;39(2):90-9.

Frost JJ, Singh S, Finer LB. U.S. women's one-year contraceptive use patterns, 2004. Perspect Sex Reprod Health. 2007b;39(1):48-55.

Frost JJ, Darroch JE, Remez L. Improving contraceptive use in the United States. Brief. New York: Guttmacher Institute; 2008. N.1. Available at: http://www.guttmacher.org/pubs/2008/05/09//mprovingContraceptiveUse.pdf.

Frost JJ, Darroch JE. Factors associated with contraceptive choice and inconsistent method use, United States, 2004. Perspect Sex Repro Health. 2008b; 40:94-104.

Gainer E, Prudhomme M, Perriot Y, Leroux MC, Bouyer J. A prospective study of the provision of emergency contraception in French family planning centers. Gynecol Obstet Fertil. 2005;33(6):403-8.

Gibbs L, Manning WD, Longmore M, Giordano PC. Qualities of romantic relationships and consistent condom use among dating young adults. In: Bourgois $L$, Cauchois S, editors. Contraceptives: Predictors of use, role of cultural attitudes \& practices and levels of effectiveness. Hauppauge, New York: Nova Science Publishers, Inc.; 2014. p.157-182.

Gipson JD, Koenig MA, Hindin MJ. The effects of unintended pregnancy on infant, child and parental health. A review of the literature. Studies Fam Plann 2008; 39(1): 18-38. 
Glasier AF, Cameron ST, Fine PM, et al. Ulipristal acetate versus levonorgestrel for emergency contraception: a randomised non-inferiority trial and meta-analysis. Lancet. 2010; 375:555-62.

Gold MA, Wolford JE, Smith KA, Parker AM. The effects of advance provision of emergency contraception on adolescent women's sexual and contraceptive behaviors. J PediatrAdolesc Gynecol. 2004;17(2):87-96.

Goldstein RL, Upadhyay UD, Raine TR. With pills, patches, rings, and shots: who still uses condoms? A longitudinal cohort study. J Adolesc Health. 2013;52(1):77-82. DOI: 10.1016/j.jadohealth.2012.08.001.

González E, Molina T, Montero A, Martínez V, Molina R. Factors associated with maintenance of contraception among adolescents. Rev Méd Chile. 2009.137(9):1187-192. http://dx.doi.org/10.4067/S0034-98872009000900007.

Goulard H, Moreau C, Gilbert F, Job-Spira N, Bajos N; Cocon Group. Contraceptive failures and determinants of emergency contraception use. Contraception. 2006;74(3):208-13.

Grady WR, Billy JO, Klepinger DH. Contraceptive method switching in the United States. Perspect Sex Reprod Health. 2002;34(3):135-45.

Gray E, McDonald P. Using a reproductive life course approach to understand contraceptive method use in Australia. J Biosoc Sci. 2010;42(1):43-57. DOI: $10.1017 /$ S0021932009990381.

Hall KS, Moreau C, Trussell J. Lower use of sexual and reproductive health services among women with frequent religious participation, regardless of sexual experience. J Womens Health (Larchmt). 2012;21(7):739-47. DOI: 10.1089/jwh.2011.3356.

Hamoda $\mathrm{H}$, Ashok PW, Stalder C, et al. A randomized trial of mifepristone (10 mg) and levonorgestrel for emergency contraception. Obstet Gynecol. 2004;104:1307-13.

Hardy EE, Duarte GA, Osis MJD, Arce XE, Possan M. Anticoncepção de emergência no Brasil: facilitadores e barreiras. Cad Saúde Pública. 2001;17(4):1031-5. 
Harvey C, Seib C, Lucke J. Continuation rates and reasons for removal among Implanon ${ }^{\circledR}$ users accessing two family planning clinics in Queensland, Australia. Contraception. 2009;80:527-32.

Heilborn ML, Portella AP, Brandão ER, Cabral CS, Grupo CONPuSUS. Contraception and family planning services as viewed by users of three clinics in the Unified National Health System, Rio de Janeiro State, Brazil. Cad Saúde Pública. 2009;25(2):S269-78.

Hooper DJ. Attitudes, awareness, compliance and preferences among hormonal contraception users: a global, cross-sectional, self-administered, online survey. Clin Drug Investig. 2010;30(11):749-63. DOI: 10.2165/11538900-000000000-00000.

Hu X, Cheng L, Hua X, Glasier A. Advanced provision of emergency contraception to postnatal women in China makes no difference in abortion rates: a randomized controlled trial. Contraception. 2005;72:111-6.

Inoue K, Barratt A, Richters J. Does research into contraceptive method discontinuation address women's own reasons? A critical review. J Fam Plann Reprod Health Care. 2015;41(4):292-9. DOI: 10.1136/jpprhc-2014-100976.

Instituto Brasileiro de Geografia e Estatística (IBGE). Censo demográfico 2010. Características gerais da população: resultados gerais da amostra. Rio de Janeiro; 2010. Available at: http://biblioteca.ibge.gov.br/visualizacao/periodicos/94/cd 2010 religiao deficiencia.pdf.

Instituto Brasileiro de Geografia e Estatística (IBGE). Pesquisa Nacional de Saúde. Ciclos de vida. Brasil e grandes regiões. Rio de Janeiro; 2015. Available at: http://biblioteca.ibge.gov.br/visualizacao/periodicos/135/rc 2013 v40.pdf.

Jain A. Should eliminating unmet need for contraception continue to be a program priority? International Family Planning Perspectives, 1999,25(Suppl.):S39-S43;S49.

Jones RK, Darroch JE, Henshaw SK. Contraceptive use among US women having abortions in 2000-2001. Perspect Sex Reproduct Health. 2002;34:294-303.

Jones J, Mosher W, Daniels K. Current contraceptive use in the United States, 20062010, and changes in patterns of use since 1995. Natl Health Stat Report. 2012;(60):1-25. 
Kavanaugh ML, Jerman J, Finer LB. Changes in Use of Long-Acting Reversible Contraceptive Methods Among U.S. Women, 2009-2012. Obstet Gynecol. 2015; 126(5):917-27. DOI: 10.1097/AOG.0000000000001094.

Keletzian E, Koumousidis A, Dimopoulos S, et al: Contraceptive consciousness and sexual behavior in three different female age groups in Greece: a retrospective study of the evolution during the last three decades. Clin Exp Obstet Gynecol. 2012; 39:160.

Kost K, Singh S, Vaughan B, Trussell J, Bankole A. Estimates of contraceptive failure from the 2002 National Survey of Family Growth. Contraception. 2008;77(1):10-21.

Lader D. Contraception and sexual heath, 2008/09 [Opinions survey report no. 41]. Newport: Office for National Statistics; 2009. Available at: http://www.ons.gov.uk/ons/ rel/lifestyles/contraception-and-sexual-health/2008-09/index.html.

Lakha F, Glasier A. Unintended pregnancy and use of emergency contraception among a large cohort of women attending for antenatal care or abortion in Scotland. Lancet. 2006;368:1782-7.

Lally K, Nathan-V Y, Dunne S, McGrath D, Cullen W, Meagher D, Coffey JC, Dunne C. Awareness of sexually transmitted infection and protection methods among university students in Ireland. Ir J Med Sci. 2015;184(1):135-42.

Lammers C., Ireland M., Resnick, M., Blum R. Influences on adolescent's decision to postpone onset of sexual intercourse: A survival analysis of virginity among youths aged 13 to 18 years. J Adolesc Health. 2000;26(1):42-8.

Langer A. El embarazo no deseado: impacto sobre lasalud y la sociedad en América Latina y el Caribe. Pan Am J Public Health. 2002;11(3):192-205. DOI: 10.1590/S1020-49892002000300013.

Leite IC, Gupta N. Assessing regional differences in contraceptive discontinuation, failure and switching in Brazil. Reprod Health. 2007; 4:6.

Liang KY, Zeger SL. Longitudinal data analysis using generalized linear models. Biometrika. 1986;73:13-22. 
Lindh I, Hognert $\mathrm{H}$, Milsom I. The changing pattern of contraceptive use and pregnancies in four generations of young women. Acta Obstet Gynecol Scand. 2016; 95(11):1264-72. DOI: 10.1111/aogs.13003.

Lo SST, Fan SY, Ho PC, Glasier AF. Effect of advanced provision of emergency contraception on women's contraceptive behaviour: a randomized controlled trial. Hum Reprod. 2004;19(10):2404-10.

Longo LAFB. Juventude e contracepção: um estudo dos fatores que influenciam o comportamento contraceptivo das jovens brasileiras de 15 a 24 anos. Rev Bras Estud Popul. 2002;19(2):229-47.

Lotke PS. Increasing Use of Long-Acting Reversible Contraception to Decrease Unplanned Pregnancy. Obstet Gynecol Clin North Am. 2015;42(4):557-67. DOI: 10.1016/j.ogc.2015.07.008.

MacLean R. Teenagers given advance emergency contraception still use pill and condoms. Perspect Sex Reprod Health. 2004;36(3):134-5. DOI: 10.1111/j.19312393.2004.tb00205.x.

Manlove J, Ryan S, Franzetta K. Patterns of contraceptive use within teenagers' first sexual relationships. Perspect Sex Reprod Health. 2003;35(6):246-55.

Manlove J, Ryan S, Franzetta K. Contraceptive use and consistency in U.S. Teenagers' most recent sexual relationships. Perspect Sex Reprod Health. 2004; 36(6): 265-75. DOI: 10.1363/psrh.36.265.04.

Manlove J, Ryan S, Franzetta K. Contraceptive use patterns across teens' sexual relationships: the role of relationships, partners, and sexual histories. Demography. 2007;44(3):603-21.

Manlove J, Welti K, Barry M, Peterson K, Schelar E, Wildsmith E. Relationship characteristics and contraceptive use among young adults. Perspect Sex Reprod Health. 2011; 43:119-28. DOI:10.1363/4311911.

Manlove J, Welti K, Wildsmith E, Barry M. Relationship types and contraceptive use within young adult dating relationships. Perspect Sex Reprod Health. 2014; 46:41-50. DOI:10.1363/46e0514 
Manning WD, Flanigan CM, Giordano PC, Longmore MA. Relationship dynamics and consistency of condom use among adolescents. Perspect Sex Reprod Health. 2009; 41(3):181-90. DOI:10.1363/4118109.

Manning WD, Brown SL, Payne KK. Two decades of stability and change in age at first union formation. J. Marriage Fam. 2014; 76:247-60.

Mansour D, Korver T, Marintcheva-Petrova M, Fraser IS. The effects of Implanon on menstrual bleeding patterns. Eur J Contracept Reprod Health Care. 2008;13(Suppl 1):13-28. DOI:10.1080/13625180801959931.

Martin A. La Anticonceptión de Emergencia en América Latina y el Caribe. Rev Panam Salud Publica. 2004;16(6):424-31.

Martins-Melo FR, Lima $\mathrm{M}$ da $\mathrm{S}$, Alencar $\mathrm{CH}$, et al. Temporal trends and spatial distribution of unsafe abortion in Brazil, 1996-2012. Rev Saude Publica. 2014; 48(3):508-520. DOI:10.1590/S0034-8910.2014048004878.

Mayer JP. Unintended childbearing, maternal beliefs, and delay of prenatal care. Birth. 1997;24(4):247-52.

Mehra D, Agardh A, Petterson KO, Östergren PO. Non-use of contraception: determinants among Ugandan university students. Glob Health Action. 2012; 5:18599. DOI: 10.3402/gha.v5i0.18599.

Mehra D, Östergren PO, Ekman B, Agardh A. Inconsistent condom use among Ugandan university students from a gender perspective: a cross-sectional study. Glob Health Action. 2014;10;7:229-42. DOI:10.3402/gha.v7.22942.

Meier AM. Adolescents' transition to first intercourse, religiosity, and attitudes about sex. Soc Forces. 2003;81(3):1031-52. DOI 10.1353/sof.2003.0039.

Menezes GMS, Aquino EML. Mortalidade materna na Bahia, 1998: relatório de pesquisa. Salvador: Instituto de Saúde Coletiva/Secretaria de Saúde do Estado da Bahia; 2001.

Meng CX, Gemzell-Danielsson K, Stephansson O, Kang JZ, Chen QF, Cheng LN. Emergency contraceptive use among 5677 women seeking abortion in Shanghai, China. Hum Reprod. 2009;24(7):1612-8. 
Michie L, Cameron ST, Glasier A, Larke N, Muir A, Lorimer A. Pharmacy-based interventions for initiating effective contraception following the use of emergency contraception: a pilot study. Contraception. 2014;90(4):447-53. DOI: 10.1016/ j.contraception.2014.05.004.

Moreau C, Bouyer J, Goulard H, Bajos N. The remaining barriers to the use of emergency contraception: perception of pregnancy risk by women undergoing induced abortions. Contraception. 2005;71(3):202-7.

Moreau C, Trussell J, Bajos N. The determinants and circumstances of use of emergency contraceptive pills in France in the context of direct pharmacy access. Contraception. 2006;74(6):476-82. Epub 2006 Sep 7.

Moreau C, Cleland K, Trussell J. Contraceptive discontinuation attributed to method dissatisfaction in the United States. Contraception. 2007;76(4):267-72.

Moreau C, Bouyer J, Bajos N, Rodríguez G, Trussell J. Frequency of discontinuation of contraceptive use: results from a French population-based cohort. Hum Reprod. 2009a;24(6):1387-92. DOI: 10.1093/humrep/dep027.

Moreau C, Trussell J, Michelot F, Bajos N. The effect of access to emergency contraceptive pills on women's use of highly effective contraceptives: results from a French national cohort study. Am J Public Health. 2009b;99(3):441-2. DOI: 10.2105/AJPH.2007.118935.

Moreau C, Trussell J, Desfreres J, Bajos N. Patterns of contraceptive use before and after an abortion: results from a nationally representative survey of women undergoing an abortion in France. Contraception. 2010;82:337-44. DOI: $10.1016 /$ j.contraception.2010.03.011.

Moreau C, Trussell J, Bajos N. Contraceptive paths of adolescent women undergoing an abortion in France. J Adolesc Health. 2012;50(4):389-94. DOI: 10.1016/ j.jadohealth.2011.07.013.

Moreau C, Hall K, Trussell J, Barber J. Effect of prospectively measured pregnancy intentions on the consistency of contraceptive use among young women in Michigan. Hum Reprod. 2013a;28(3):642-50. DOI: 10.1093/humrep/des421. 
Moreau C, Bohet A, Trussell J, Bajos N; FECOND group. Estimates of unintended pregnancy rates over the last decade in France as a function of contraceptive behaviors. Contraception. 2014;89(4):314-21. DOI: 10.1016/j.contraception.2013. 11.004 .

Moreau C, Bohet A. Frequency and correlates of unintended pregnancy risk perceptions. Contraception. 2016;94(2):152-9. DOI: 10.1016/j.contraception.2016. 02.029. Epub 2016 Mar 18.

Moreira-Almeida A, Pinsky I, Zaleski M, Laranjeira R. Envolvimento religioso e fatores sociodemográficos: resultados de um levantamento nacional no Brasil. Rev Psiquiatr Clín. 2010;37(1):12-15. DOI: 10.1590/S0101-60832010000100003.

Mosher WD, Jones J. Use of Contraception in the United States: 1982-2008. National Center for Health Statistics. Vital Health Stat. 2010; 23(29). Available at: http://www.cdc.gov/NCHS/data/series/sr 23/sr23 029.pdf.

Mosher WD, Jones J, Abma JC. Intended and unintended births in the United States: 1982-2010. National health statistics reports; no. 55. Hyattsville, MD: National Center for Health Statistics. 2012. Available at: https://www.cdc.gov/nchs/data/nhsr/nhsr055.pdf.

Moura ERF, Silva RM, Galvão RT. Dinâmica do atendimento em planejamento familiar no Programa de Saúde da Família no Brasil. Cad Saúde Pública. 2007; 23(4):961-70.

Nappi RE, Lobo Abascal P, Mansour D, Rabe T, Shojai R; Emergency Contraception Study Group. Use of and attitudes towards emergency contraception: a survey of women in five European countries. Eur J Contracept Reprod Health Care. 2014; 19(2):93-101. doi: 10.3109/13625187.2013.865164.

Nascimento CB. Conhecimento e uso da anticoncepção de emergência entre adolescentes estudantes do ensino médio. [Dissertação de Mestrado]. São Paulo: Escola de Enfermagem da Universidade de São Paulo; 2012.

National Institute for Health and Care Excellence. CG30: Long-acting reversible contraception [webpage on the Internet]. London, UK: NICE; 2014. Available from: http://publications.nice.org.uk/long-actingreversible-contraception-cg30. Accessed May 16, 2016. 
Nelson AL. Recent use of condoms and emergency contraception by women who selected condoms as their contraceptive method. Am J Obstet Gynecol. 2006; 194(6):1710-5.

NHS Contraceptive Services: England, 2011/12. Community Contraceptive Clinics Health and Social Care Information Centre ( $\mathrm{HSClC})$, Lifestyles statistics. October 2012.

Nguyen BT, Zaller N. Male access to over-the-counter emergency contraception: a survey of acceptability and barriers in Providence, Rhode Island. Womens Health Issues. 2009; 19(6):365-72.

Nsubuga H, Sekandi JN, Sempeera H, Makumbi FE. Contraceptive use, knowledge, attitude, perceptions and sexual behavior among female University students in Uganda: a cross-sectional survey. BMC Womens Health. 2016 Jan 27;16:6. doi: 10.1186/s12905-016-0286-6.

Osei IF, Mayhew SH, Biekro L, Collumbien M; ECAF Team. Fertility decisions and contraceptive use at different stages of relationships: windows of risk among men and women in accra. Int Perspect Sex Reprod Health. 2014; 40(3):135-43. doi: $10.1363 / 4013514$.

Paiva SP, Brandão ER. Contracepção de emergência no contexto das farmácias: revisão crítica de literatura. Physis. 2012; 22(1): 17-34. doi: 10.1590/S010373312012000100002.

Palermo T, Bleck J, Westley E. Knowledge and Use of Emergency Contraception: A Multicountry Analysis. Int Perspect Sex Reprod Health. 2014; 40(2):79-86.

Patton EW, Hall KS, Dalton VK. How does religious affiliation affect women's attitudes toward reproductive health policy? Implications for the affordable care act. Contraception. 2015; 91(6):513-9. doi: 10.1016/j.contraception.2015.02.012.

Pazol K, Whiteman MK, Folger SG, Kourtis AP, Marchbanks PA, Jamieson DJ. Sporadic contraceptive use and nonuse: age-specific prevalence and associated factors. Am J Obstet Gynecol. 2015; 212(3):324.e1-8. doi: 10.1016/j.ajog.2014.10.004. 
Peterson LS, Oakley D, Potter LS, Darroch JE. Women's efforts to prevent pregnancy: consistency of oral contraceptive use. Fam Plann Perspect. 1998; 30(1): 19-23.

Pike, GR. Using college students' self-reported learning outcomes in scholarly research. New Directions for Institutional Research. 2011; (150): 41-58. doi:10.1002/ir.388.

Pirotta KCM, Schor N. Intenções reprodutivas e práticas de regulação da fecundidade entre universitários. Rev Saúde Pública. 2004; 38:495-502.

Polis CB, Schaffer K, Blanchard K, et al. Advance provision of emergency contraception for pregnancy prevention (full review) Cochrane Db Syst Rev. 2010; 3. Available at: http://www.clacaidigital.info:8080/xmlui/bitstream/handle/123456789/194/Advance_pr ovision_of_EC_for_pregnancy_prevention.pdf?sequence=1\&isAllowed=y

Prietsch SOM, González-Chica DA, Cesar JA., Mendoza-Sassi RA. Gravidez não planejada no extremo Sul do Brasil: prevalência e fatores associados. Cad. Saúde Pública. 2011; 27(10): 1906-1916. doi: 10.1590/S0102-311X2011001000004.

Pulerwitz J, Amaro H, De Jong W, Gortmaker SL, Rudd R. Relationship power, condom use and HIV risk among women in the USA. AIDS Care. 2002; 14:789-800.

Raine T, Harper C, Leon K, Darney P. Emergency contraception: advance provision in a young, high-risk clinic population. Obstet Gynecol. 2000; 96(1):1-7.

Raine TR, Harper CC, Rocca CH, Fischer R, Padian N, Klausner JD, Darney PD. Direct access to emergengy contraception through pharmacies and effect on unintended pregnancy and STIs: a randomized controlled trial. JAMA. 2005; 293(1):54-62.

Raine TR, Gard JC, Boyer CB, Haider S, Brown BA, Ramirez Hernandez FA, Harper CC. Contraceptive decision-making in sexual relationships: young men's experiences, attitudes and values. Cult Health Sex. 2010; 12(4):373-86. doi: 10.1080/13691050903524769. 
Ranjit N, Bankole A, Darroch J, Singh S. Contraceptive failure in the first two years of use: differences across socioeconomic subgroups. Fam Plann Perspect. 2001; 33(1): 19-27.

Rash V, Knudsen LB, Gammeltoft T, et al. Contraceptive attitudes and contraceptive failure among women requesting induced abortion in Denmark. Hum Reprod. 2007; 22:1320-6.

Reed J, England P, Littlejohn K, Bass BC, Caudillo ML. Consistent and inconsistent contraception among young women: insights from qualitative interviews. Family Relations. 2014; 63(2): 244-58. doi:10.1111/fare.12058.

Richters J, Fitzadam S, Yeung A, Caruana T, Rissel C, Simpson JM, de Visser RO. Contraceptive practices among women: the second Australian study of health and relationships. Contraception. 2016; 94(5):548-555. DOI: 10.1016/j.contraception. 2016.06.016.

Ricketts S, Klingler G, Schwalberg R. Game change in Colorado: widespread use of long- acting reversible contraceptives and rapid decline in births among young, lowincome women. Perspect Sex Reprod Health. 2014;46:125-32.

Rocca CH, Schwarz EB, Stewart FH, Darney PD, Raine TR, Harper CC. Beyond access: acceptability, use and nonuse of emergency contraception among young women. Am J Obstet Gynecol. 2007;196(29):1-6.

Rocca CH, Harper CC, Raine-Bennett TR. Young women's perceptions of the benefits of childbearing: associations with contraceptive use and pregnancy. Perspect Sex Reprod Health. 2013;45(1):23-32. DOI:10.1363/4502313.

Ross J, Hardee K. Use of male methods of contraception worldwide. J Biosoc Sci. 2016;28:1-16.

Sant'Anna MJC, Carvalho KAM, Passarelli MLB, Coates V. Comportamento sexual entre jovens universitários. Adolesc Saude. 2008;5(2):52-6.

Santelli JS, Warren CW, Lowry R, Sogolow E, Collins J, Kann L, Kaufmann RB, Celentano DD. The use of condoms with other contraceptive methods among young men and women. Fam Plann Perspect. 1997;29(6):261-7. DOI: 10.1363/2926197. 
Santelli J, Rochat R, Hatfield-Timajchy K, Gilbert BC, Curtis K, Cabral R, Hirsch JS, Schieve L; Unintended Pregnancy Working Group. The measurement and meaning of unintended pregnancy. Perspect Sex Reprod Health. 2003;35(2):94-101.

Santos OA, Borges, Borges ALV, Chofakian CBN, Pirotta KCM. Determinants of emergency contraception non-use among women in unplanned or ambivalent pregnancies. Rev. esc. enferm. USP [online]. 2014;48(spe):16-22. DOI: $10.1590 /$ S0080-623420140000600003.

Sassler S, Miller A, Favinger SM. Planned parenthood: Fertility intentions and experiences among cohabiting couples. J Fam Issues. 2009;30:206-232.

Schünmann C, Glasier A. Measuring pregnancy intention and its relationship with contraceptive use among women undergoing therapeutic abortion. Contraception. 2006;73(5):520-4.

Secura GM, Madden T, McNicholas C, Mullersman J, Buckel CM, Zhao Q, Peipert $\mathrm{JF}$. Provision of no-cost, long-acting contraception and teenage pregnancy. N Engl J Med. 2014;371(14):1316-23.

Sedgh G, Bankole A, Singh S, Eilers M. Legal abortion levels and trends by woman's age at termination. Int Perspect Sex Reprod Health. 2012;38(3):143-53.

Sereshti M, Delaram M, Rafieian M. Prevalence and causes of unwanted pregnancy from the perspective of pregnant women (Persian). JRHS. 2005;13(24)8-15.

Shih SL, Kebodeaux CA, Secura GM, Allsworth JE, Madden T, Peipert JF. Baseline correlates of inconsistent and incorrect condom use among sexually active women in the contraceptive CHOICE Project. Sex Transm Dis. 2011;38(11):1012-9. DOI: $10.1097 / O L Q .0 b 013 e 318225 f 8 c 3$.

Sidebottom A, Harrison PA, Donna A, Finnegan K. The varied circumstances prompting requests for emergency contraception at school-based clinics. J Sch Health. 2008;78(5):258-63.

Silva FC, Vitalle MSS, Maranhão HS, Canuto MHA, Pires MS, Fisberg M. Diferenças regionais de conhecimento, opinião e uso de contraceptivo de emergência entre universitários brasileiros de cursos da área de saúde. Cad Saúde Pública. 2010;26(9):1821-31. 
Silva LP, Camargo FC, Iwamoto HH. Comportamento sexual dos acadêmicos ingressantes em cursos da área da saúde de uma universidade pública. REAS. 2014;3(1):39-52.

Somba MJ, Mbonile M, Obure J, Mahande MJ. Sexual behaviour, contraceptive knowledge and use among female undergraduates' students of Muhimbili and Dar es Salaam Universities, Tanzania: a cross-sectional study. BMC Womens Health. 2014; 14:94. DOI: 10.1186/1472-6874-14-94.

Sorhaindo A, Beckera D, Fletcherb H, Garciaa SG. Emergency contraception among university students in Kingston, Jamaica: a survey of knowledge, attitudes, and practices. Contraception. 2002;66:261-8.

Sørensen MB, Pedersen BL, Nyrnberg LE. Differences between users and non-users of emergency contraception after a recognized unprotected intercourse. Contraception. 2000;62(1):1-3.

Souza RA, Brandão RE. Marcos normativos da anticoncepção de emergência e as di culdades de sua institucionalização nos serviços de saúde. Physis. 2009; 19(4):1067-1086. DOI: 10.1590/S0103-73312009000400009.

Steele F, Curtis S. Appropriate methods for analyzing the effect of method choice on contraceptive discontinuation. Demography. 2003;40(1):1-22.

Tafuri S, Martinelli D, Germinario C, Prato R.A survey of opinions on emergency contraception in young women in Southern Italy. Eur $\mathrm{J}$ Contracept Reprod Health Care 2012;17:164-9.

Tavares MP, Foster AM. Emergency contraception in a public health emergency: exploring pharmacy availability in Brazil. Contraception. 2016; 94(2):109-14. DOI: 10.1016/j.contraception.2016.04.006.

Theme-Filha MM, Baldisserotto ML, Fraga AC, Ayers S, da Gama SG, Leal MD. Factors associated with unintended pregnancy in Brazil: cross-sectional results from the Birth in Brazil National Survey, 2011/2012. Reprod Health. 2016;13(Suppl 3):118.

Trieu SL, Shenoy DP, Bratton S, Marshak HH. Provision of emergency contraception at student health centers in California community colleges. Womens Health Issues. 2011;21(6):431-7. DOI: 10.1016/j.whi.2011.04.011. 
Trussell J, Rodriguez G, Ellertson C Updated estimates of the effectiveness of the Yuzpe regimen of emergency contraception. Contraception. 1999;59(3):147-51.

Trussell J. Contraceptive failure in the United States. Contraception. 2004;70(2):8996.

Trussell J. Contraceptive efficacy. In: Hatcher RA, Trussell J, Nelson AL, Cates W, Stewart FH, Kowal D, editors. Contraceptive Technology: Nineteenth revised edition. Ardent Media; New York NY: 2007.

Trussell J. Contraceptive failure in the United States. Contraception. 2011;83(5):397404. doi: 10.1016/j.contraception.2011.01.021.

Trussell J, Raymond E, Cleland K. Emergency contraception: A Last Chance to Prevent Unintended Pregnancy. Contemporary Readings in Law and Social Justice. 2014;6(2):7-38.

Vaughan B, Trussell J, Kost K, Singh S, Jones R. Discontinuation and resumption of contraceptive use: results from the 2002 National Survey of Family Growth. Contraception. 2008;78(4):271-83. DOI: 10.1016/j.contraception.2008.05.007.

Veloso, DLC, Peres VC, Lopes JSOC, Salge AKM, Guimarães JV. Anticoncepção de emergência: conhecimento e atitude de acadêmicos de enfermagem. Rev Gaucha Enferm. 2014;35(2):33-9.

Vieira EM, Souza L. A satisfação com o serviço de esterilização cirúrgica entre os usuários do Sistema Único de Saúde em um município paulista. Rev Bras Epidemiol. 2011;14(4):556-64.

Zembe YZ, Townsend L, Thorson A, Ekström AM. Predictors of inconsistent condom use among a hard to reach population of young women with multiple sexual partners in peri-urban South Africa. PLoS One. 2012;7(12):e51998. DOI: 10.1371/ journal.pone.0051998.

Walsh TL, Frezieres RG, Peacock K, Nelson AL, Clark VA, Bernstein L. Evaluation of the efficacy of a nonlatex condom: results from a randomized, controlled clinical trial. Perspect Sex Reprod Health. 2003;35(2):79-86. 
Wang H, Long L, Cai H, Wu Y, Xu J, Shu C, Wang P, Li B, Wei Q, Shang X, Wang X, Zhang $\mathrm{M}$, Xiong $\mathrm{C}$, Yin $\mathrm{P}$. Contraception and Unintended Pregnancy among Unmarried Female University Students: A Cross-sectional Study from China. PLoS One. 2015;10(6):e0130212. DOI: 10.1371/journal.pone.0130212.

Wellings K, Brima N, Sadler K, Copas AJ, McDaid L, Mercer CH, McManus S, Stephenson J, Glasier A. Stopping and switching contraceptive methods: findings from Contessa, a prospective longitudinal study of women of reproductive age in England. Contraception. 2015;91(1):57-66. DOI: 10.1016/j.contraception.2014. 09.008 .

Westley E, Schwarz EB. Emergency contraception: global challenges, new opportunities. Contraception. 2012;85(5):429-31. DOI: 10.1016/j.contraception.2012. 01.012. Epub 2012 Mar 2.

Westley E, Kapp N, Palermo T, Bleck J. A review of global access to emergency contraception. Int J Gynaecol Obstet. 2013;123(1):4-6. DOI: 10.1016/j.ijgo.2013. 04.019. Epub 2013 Jul 13.

Westley E, Bass J, Puig C. A global assessment of emergency ontraception acessibility. In: Figueiredo R, Borges ALV, Paula SHB, organizadores. 1 ed. São Paulo: Instituto de Saúde; 2016. p.24-38.

Wildsmith E, Manlove J, Steward-Streng N. Relationship characteristics and contraceptive use among dating and cohabiting young adult couples. Perspect Sex Reprod Health. 2015;47(1):27-36. DOI: 10.1363/47e2515.

Williamson LM, Buston K, Sweeting $\mathrm{H}$. Young women's perceptions of pregnancy risk and use of emergency contraception: findings from a qualitative study. Contraception. 2009;79(4):310-5. DOI: 10.1016/j.contraception.2008.10.014.

World Health Organization (WHO). Global Strategy for STI Prevention and Control Meeting. Geneva: WHO; 2004.

World Health Organization (WHO). Emergency contraception. Report. Geneva: WHO; 2012. Available at: http://www.who.int/mediacentre/factsheets/fs244/en. 
APPENDICES 



\title{
APPENDIX A - CONSENT FORM
}

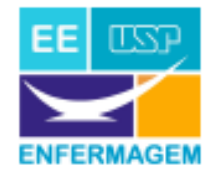

\author{
UNIVERSITY OF SÃO PAULO \\ SCHOOL OF NURSING \\ DEPARTMENT OF PUBLIC HEALTH NURSING
}

(Obrigatório para Pesquisas Científicas em Seres Humanos- Resolução no 196 de 10/10/96- CNS)

Estamos realizando uma pesquisa com as graduandas da Universidade de São Paulo (USP) com o objetivo de avaliar as descontinuidades no uso de métodos contraceptivos, bem como a dinâmica contraceptiva antes e após o uso da anticoncepção de emergência. Na verdade, gostaríamos de conhecer sua história contraceptiva no último ano, ou seja, quais os métodos contraceptivos que você usou neste período e, caso tenha usado a anticoncepção de emergência, quais métodos foram utilizados antes e após o uso deste método. Mesmo que faça sexo apenas com mulheres e não tenha preocupação em evitar uma gravidez, é importante que responda todo o questionário. Queremos conhecer aspectos da saúde sexual e reprodutiva de todas as universitárias da USP. Esta pesquisa é coordenada pela Profa. Dra. Ana Luiza Vilela Borges da Escola de Enfermagem da Universidade de São Paulo.

O questionário é anônimo, ou seja, o nome da entrevistada não aparece em nenhum momento. Todas as informações são sigilosas e as pessoas não serão identificadas. O questionário deverá ser respondidoonline e, durará em média 30 minutos. Caso tenha qualquer dúvida sobre a pesquisa, esteja à vontade para entrar em contato com a Coordenação do Projeto. Você pode se recusar a participar da pesquisa inteira ou de qualquer parte dela e isto será bem compreendido pela entrevistadora. Este formulário online serve para comprovar que você está de acordo em participar desta pesquisa. Você deveráclicar em "aceite", caso queira participar da pesquisa. Em seguida, será redirecionada para um link contendo o questionário online.

Em caso de dúvidas sobre a pesquisa, entre em contato com:

\begin{tabular}{|lr}
\hline Coordenadora do Projeto: & Comitê de Ética em Pesquisa: \\
Ana Luiza Vilela Borges & Escola de Enfermagem da USP \\
Av. Dr. Enéas de Carvalho Aguiar, 419 & Av. Dr. Enéas de Carvalho Aguiar, 419 \\
CEP 05401-001 São Paulo/SP & CEP 05401-001 São Paulo/SP \\
Tel: (11) 3061-7652 & Tel: (11) 3061 748/8858 \\
E-mail: alvilela@usp.br & E-mail: edipesq@usp.br \\
\hline
\end{tabular}

Caso, ACEITE participar da pesquisa clique no botão ao lado $O$

Caso, NÃO ACEITE participar da pesquisa clique no botão ao lado $O$ 



\section{APPENDIX B - QUESTIONNAIRE (ENGLISH VERSION)}

\section{SCHOOL DATA}

What is the area of knowledge of your undergraduate degree?

1 ( ) Health Sciences

2 ( ) Exact Sciences

3 ( ) Human Sciences

Your undergraduate degree belongs to which campus?

1 ( ) São Paulo

2 ( ) Countryside

What is the study period of your undergraduate degree?

1 ( ) Full-time

2 ( ) Part-time (morning)

3 ( ) Part-time (afternoon)

4 ( ) Part-time (evening)

Do you have a scholarship?

1 ( ) No

2 ( ) Yes

SOCIODEMOGRAPHIC INFORMATION

How old are you? years

How do you rate your race?

1 ( ) White (caucasian)

2 ( ) Black (african american)

3 ( ) Yellow (asian)

4 ( ) Indian

What's your religion?

1 ( ) No religion

2 ( ) Roman Catholic

3 ( ) Spiritism

4 ( ) Evangelical

5 ( ) Other

Do you work (wage labor)?

0 ( ) No

1 ( ) Yes

Do you have a formal contract?

0 ( ) No

1 ( ) Yes 
Which of the items below do you have in your home, and how many do you own?

\begin{tabular}{|l|c|c|c|c|c|}
\hline \multicolumn{1}{|c|}{ Items } & \multicolumn{5}{c}{ Quantity } \\
& 0 & 1 & 2 & 3 & 4 ou + \\
\hline Television & 0 & 0 & 0 & 0 & 0 \\
\hline Bathroom & 0 & 0 & 0 & 0 & 0 \\
\hline Automobile & 0 & 0 & 0 & 0 & 0 \\
\hline Housekeeper & 0 & 0 & 0 & 0 & 0 \\
\hline Washing machine & 0 & 0 & 0 & 0 & 0 \\
\hline DVD & 0 & 0 & 0 & 0 & 0 \\
\hline Refrigerator & 0 & 0 & 0 & 0 & 0 \\
\hline Freezer & 0 & 0 & 0 & 0 & 0 \\
\hline
\end{tabular}

Who is the householder in your home?

1 ( ) Father

2 ( ) Mother

3 ( ) Uncle/aunt

4 ( ) Grandfather/grandmother

5 ( ) Brother/sister

6 ( ) You

7 ( ) Outher:

Which school degree did the head of the family study or complete with approval?

Does your house have piped water?

0 ( ) No

1 ( ) Yes

Does your house have piped water?

0 ( ) No

1 ( ) Yes

SEXUAL BEHAVIOR

What's your marital status?

1 ( ) Married or living with a partner

2 ( ) Single

3 ( ) Divorced

5 ( ) Widow

What type of relationship do you have?

0 ( ) None

1 ( ) Steady, as with boyfriend

2 ( ) Casual relationship (have a fling) 


\begin{tabular}{|l|}
\hline Have you ever had sexual intercourse? \\
0 ( ) No (Questionnaire ends here) \\
1 ( ) Yes \\
\hline How old were you when you first had sexual intercourse? \\
\hline How many sexual partners have you had in your life? \\
\hline $\begin{array}{l}\text { Have you ever become pregnant? } \\
\text { ( ) No ( ) Yes }\end{array}$ \\
\hline How old were you at your first pregnancy? \\
\hline How many times have you become pregnant? \\
\hline \begin{tabular}{l} 
How many abortions have you had? \\
How ( ) Yes \\
\hline Have you ever had an abortion?
\end{tabular} \\
\hline
\end{tabular}


Which was the reason for not using contraception in the past year?

0 ( ) I didn't have sexual intercourse

1 ( ) Infrequent sexual intercourse

2 ( ) I became pregnant

3 ( ) l'd like to become pregnant

4 ( ) I did not want to use any contraceptive method

5 ( ) Partner opposition

6 ( ) Religious reasons

7 ( ) I did not know anything about contraception

8 ( ) I did not know where to get contraception

9 ( ) Health problems

10( ) Fear of side effects

11( ) Access difficulties

12( ) Cost of contraception

13( ) Inconvenient to use

14( ) Interfere with normal body functions

15( ) Husband / partner infertile

16( ) You or your partner has any condition that prevents pregnancy (hysterectomy, azoospermia)

17 ( ) I have sexual intercourse only with women

18( ) Other:

(The questionnaire ends for women who answered this question)

Currently, do you use some contraceptive method?

1 ( ) No

2 ( ) Yes

Which contraceptive method are you using?

1 ( ) Oral pill

2 ( ) Male condom

3 ( ) Injectable

4 ( ) Withdrawal/Fertility-awareness

5 ( ) IUD

6 ( ) Other

Did you use a contraceptive method in your last sexual intercourse?

1 ( ) No

2 ( ) Yes

Which contraceptive method did you use in your last sexual intercourse?

1 ( ) Oral pill

2 ( ) Male condom

3 ( ) Injectable

4 ( ) Withdrawal/Fertility-awareness

5 ( ) IUD

6 ( ) Other 


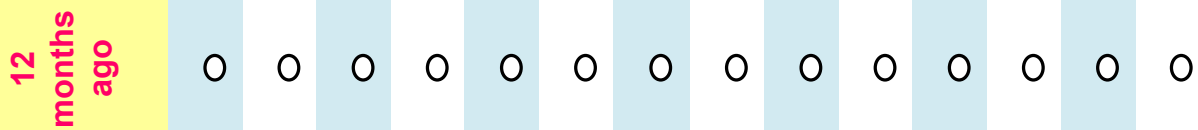

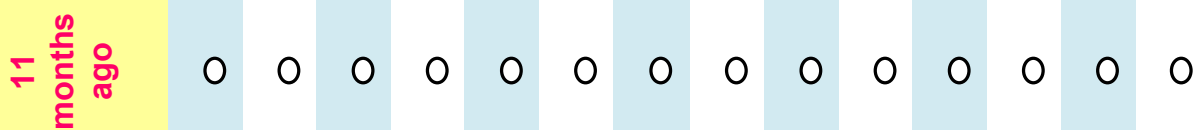

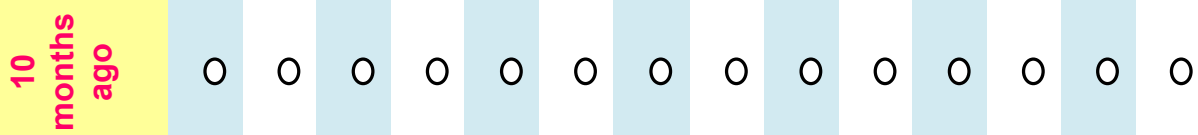

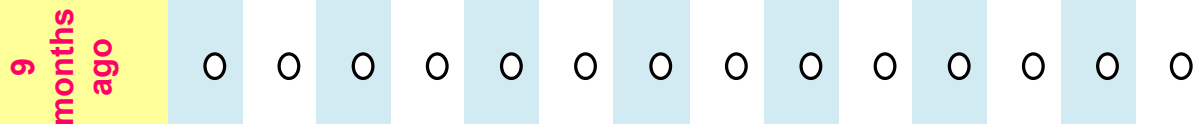

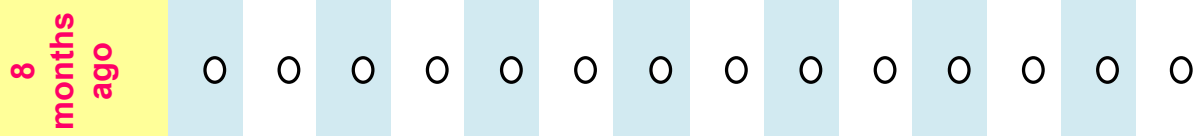

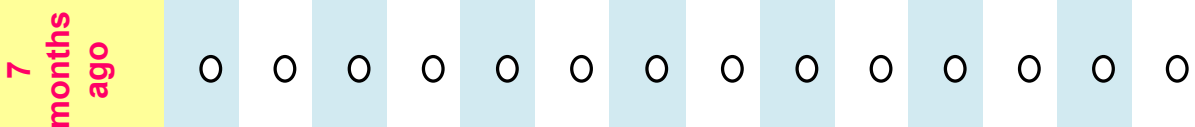
绖哭 几

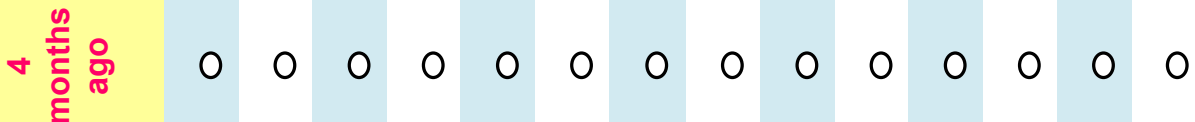

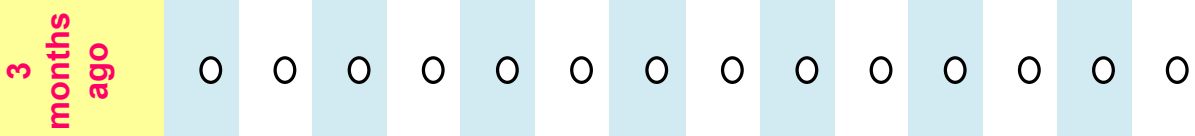

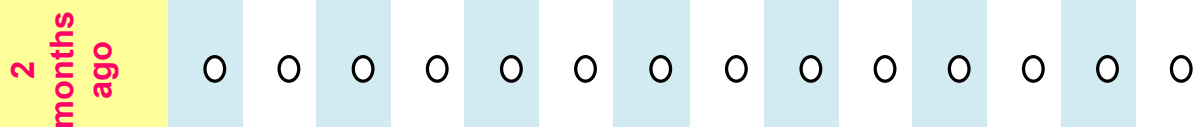

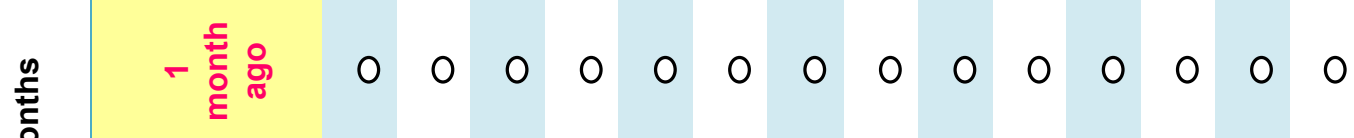

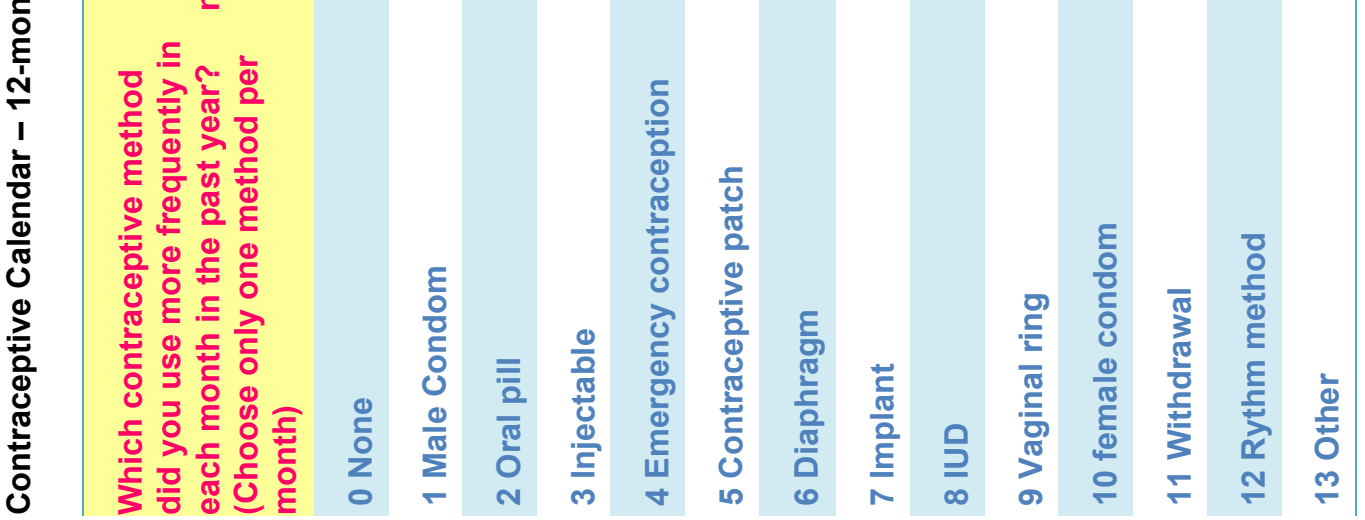




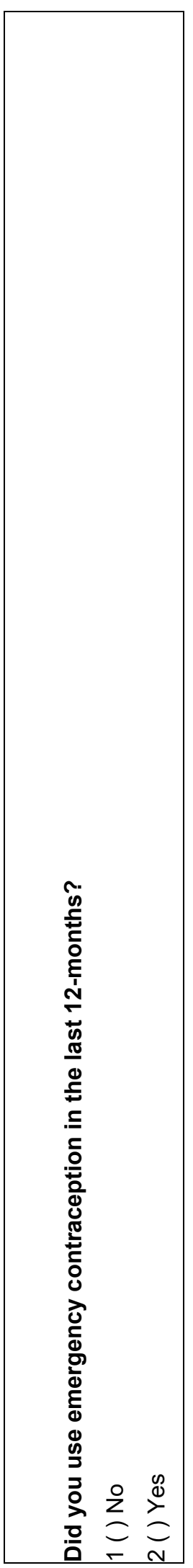

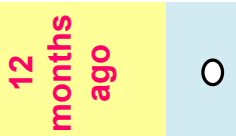

$$
\begin{aligned}
& \text { F产 욜 }
\end{aligned}
$$

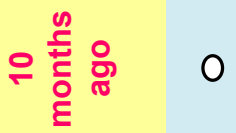

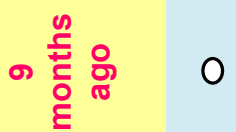

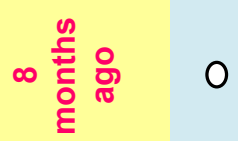

$$
\begin{aligned}
& \wedge \text { ^ } \\
& \checkmark \text { 돌 }
\end{aligned}
$$

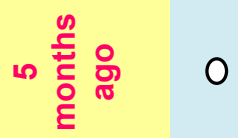

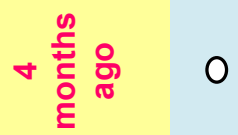

$$
\begin{aligned}
& \text { ๓ }
\end{aligned}
$$

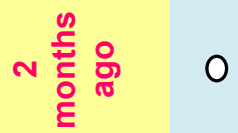

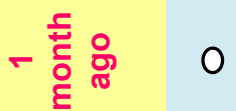

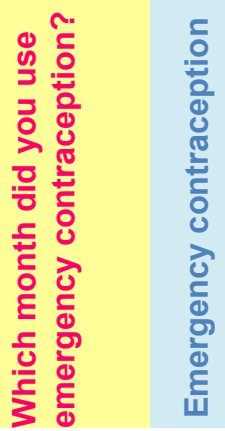



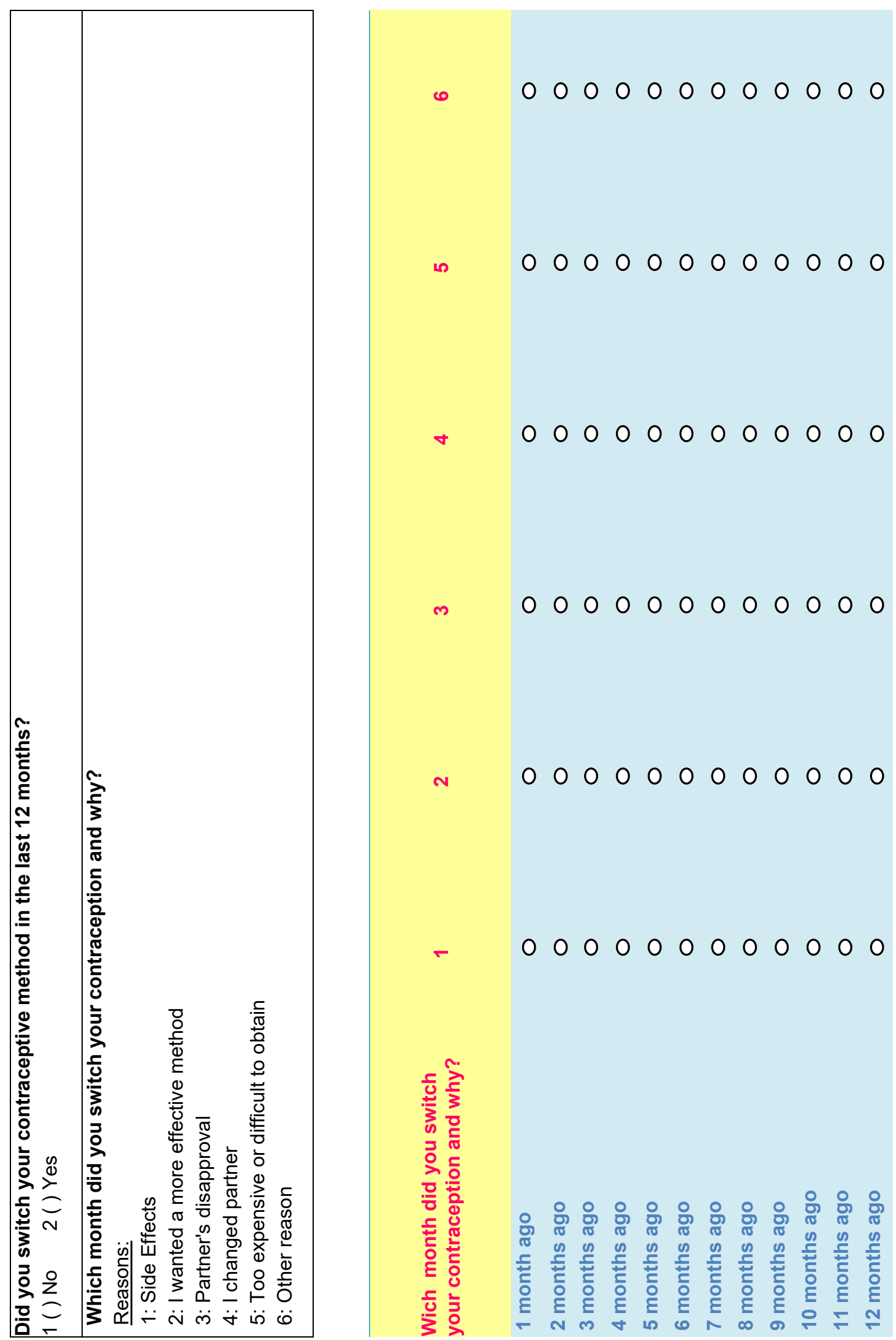


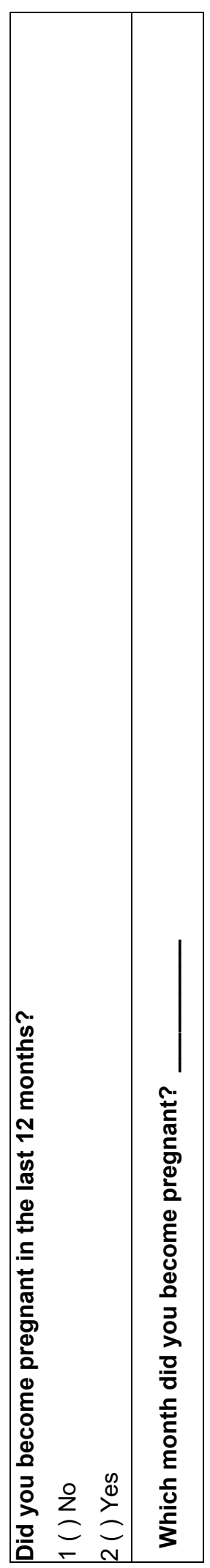

$\stackrel{0}{2} 000000000000$
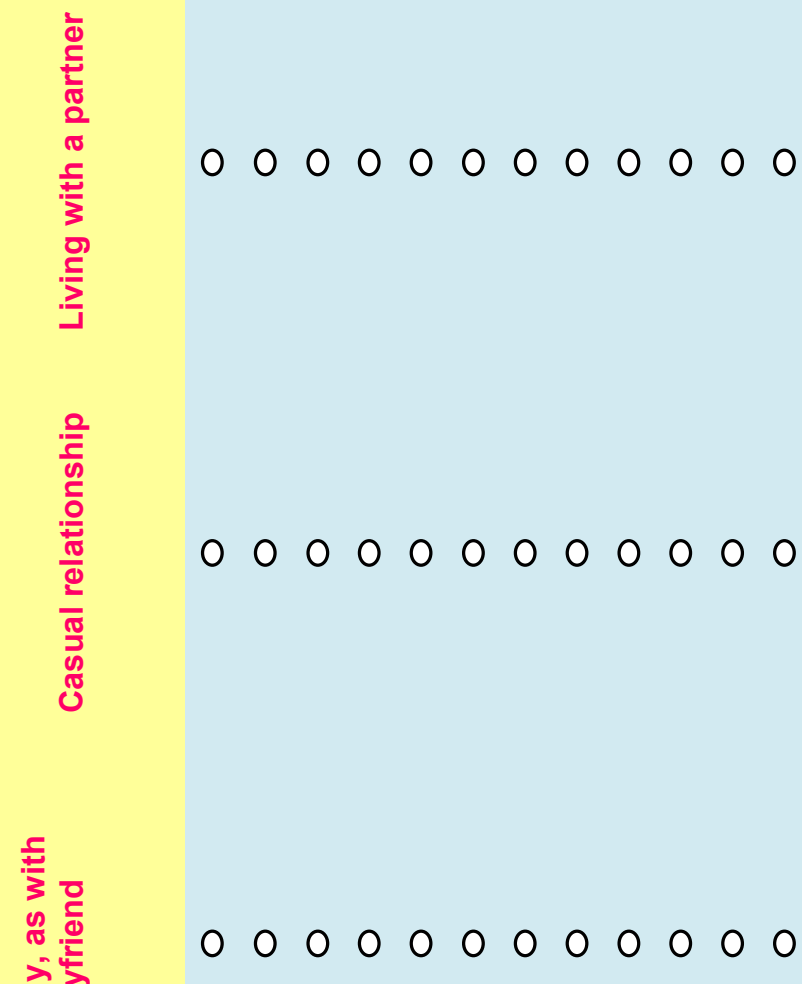

츙

क

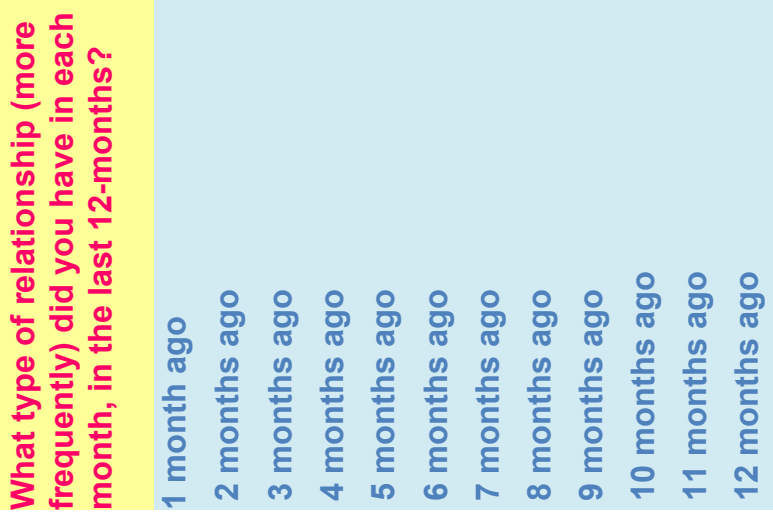




\section{EMERGENCY CONTRACEPTION}

Do you know anyone who has used the emergency contraception?

0 ( ) No

1 ( ) Yes

Have you ever used emergency contraception?

0 ( ) No (The questionnaire ends here)

1 ( ) Yes

Have you used the emergency contraception in the last 12 months?

0 ( ) No

1 ( ) Yes

IF YES - What was the reason that led you to use the emergency contraception in the last time?

1 ( ) The contraceptive method used failed

2 ( ) I forgot to use a contraceptive method

3 ( ) I did not want to use any contraceptive method

4 ( ) I was a victim of sexual violence

5 ( ) By sheer insecurity

6 ( ) Other

IF YES - In last time that you used the emergency contraception, the relationship was:

1 ( ) Steady, as with boyfriend

2 ( ) Casual relationship (have fling)

IF YES - Who took the initiative in the emergency contraception use?

1 ( ) You

2 ( ) Partner

3 ( ) Both

IF YES - The emergency contraception was acquired with doctor's prescription?

0 ( ) No

1 ( ) Yes

IF YES - Where did you get the emeregency contraception?

1 ( ) Drugstore

2 ( ) Health Center

3 ( ) In particular doctor or medical insurance

4 ( ) With friends or acquaintances

5 ( ) Boyfriend who brought the contraception of emergency

6 ( ) Relatives

7 () Other

How long after an unprotected sexual intercourse did you take the emergency contraception (in the last time)?

1 ( ) Least one day 


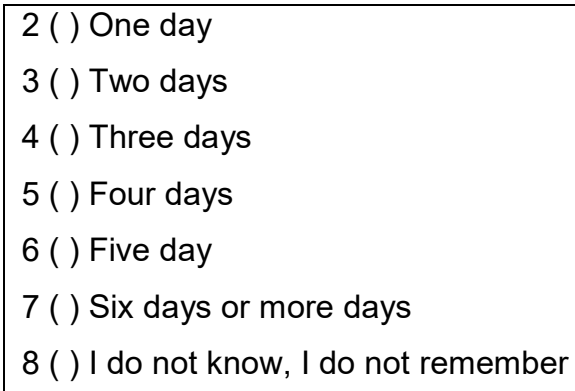

0 ( ) No

1 ( ) Yes

Which contraceptive method were you using?

1 ( ) Oral pill

2 ( ) Male condom

3 ( ) Injectable

4 ( ) Withdrawal/Fertility-awareness

5 ( ) IUD

6 ( ) Other

$\rightarrow 30$ DAYS BEFORE THE USE OF EMERGENCY CONTRACEPTION

Did you use some contraceptive method 30 days BEFORE emergency contraception use?

0 ( ) No

1 ( ) Yes

Which contraceptive method did you use on most days?

1 ( ) Oral pill

2 ( ) Male condom

3 ( ) Male condom and oral pill 
4 ( ) Injectable

5 ( ) Withdrawal/Fertility-awareness

6 ( ) IUD

7 ( ) Other

In these 30 days BEFORE emergency contraception use, did you use this method continuously (every day without exception)?

0 ( ) No 1 ( ) Yes

In these 30 days BEFORE emergency contraception use, which days you used a contraceptive method?

\begin{tabular}{|c|c|c|c|}
\hline & Day & $\begin{array}{l}\text { I did not use } \\
\text { contraception }\end{array}$ & $\begin{array}{c}\text { I used } \\
\text { contraception }\end{array}$ \\
\hline & 30 & & \\
\hline & 29 & & \\
\hline & 28 & & \\
\hline & 27 & & \\
\hline & 26 & & \\
\hline & 25 & & \\
\hline & 24 & & \\
\hline & 23 & & \\
\hline & 22 & & \\
\hline & 21 & & \\
\hline & 20 & & \\
\hline & 19 & & \\
\hline \multirow{18}{*}{$\begin{array}{c}30 \\
\text { DAYS } \\
\text { BEFORE }\end{array}$} & 18 & & \\
\hline & 17 & & \\
\hline & 16 & & \\
\hline & 15 & & \\
\hline & 14 & & \\
\hline & 13 & & \\
\hline & 12 & & \\
\hline & 11 & & \\
\hline & 10 & & \\
\hline & 9 & & \\
\hline & 8 & & \\
\hline & 7 & & \\
\hline & 6 & & \\
\hline & 5 & & \\
\hline & 4 & & \\
\hline & 3 & & \\
\hline & 2 & & \\
\hline & 1 & & \\
\hline El & EGE & CONTRAC & TIVE USE \\
\hline
\end{tabular}


$\rightarrow 30$ DAYS AFTER THE USE OF EMERGENCY CONTRACEPTION

Did you use some contraceptive method during 30 days AFTER emergency contraception use?

0 ( ) No

1 ( ) Yes

Which contraceptive method did you use on most days?

1 ( ) Oral pill

2 ( ) Male condom

3 ( ) Male condom and oral pill

4 ( ) Injectable

5 ( ) Withdrawal/Fertility-awareness

6 ( ) IUD

7 ( ) Other

Did you adopt a contraceptive method immediately after the use of emergency contraception? 0 ( ) No

1 ( ) Yes

How many days after using emergency contraception did you start contraceptive methods use?

1()$<10$ days

2 ( ) $10-15$ days

3()$\geq 15$ days

How long did you use this method continuously?

1 ( ) $<1$ month

2 ( ) 1 month

3 ( ) 1 - 6 months

4 ( ) 6 - 12 months

5 ( ) 1 - $\mid 2$ years

6()$\geq 2$ years 


\section{APPENDIX C - QUESTIONÁRIO (VERSÃO EM PORTUGUÊS)}

\section{DADOS ESCOLARES}

Qual é a área de conhecimento do seu curso de graduação?

1 ( ) Biológicas/Saúde

2 ( ) Exatas

3 ( ) Humanas

Seu curso de graduação pertence a qual campus?

1 ( ) São Paulo

2 ( ) São Carlos

3 ( ) Ribeirão Preto

4 ( ) Pirassununga

5 ( ) Bauru

6 ( ) Piracicaba

7 ( ) Santos

8 ( ) Lorena

Qual é o período de estudo de seu curso de graduação?

1 ( ) Integral

2 ( ) Matutino

3 ( ) Vespertino

4 ( ) Noturno

INFORMAÇÕES SOCIODEMOGRÁFICAS

Quantos anos você tem? anos

Como você classifica sua cor ou raça?

1 ( ) Branca

2 ( ) Preta

3 ( ) Parda

4 ( ) Amarela (de origem asiática)

5 ( ) Indígena

Qual é a sua religião?

1 ( ) Católica

2 ( ) Evangélica

3 ( ) Espírita

4 ( ) Pentecostal

5 ( ) Judaica 
6 ( ) Umbanda, candomblé, batuque

7 ( ) Budista

8 ( ) Nenhuma

8 ( ) Outra:

Você trabalha (trabalho assalariado)?

0 ( ) Não

1 ( ) Sim

Tem carteira assinada?

0 ( ) Não

1 ( ) Sim

Dos itens abaixo, quais você possui em sua casa e quantos você possui de cada?

\begin{tabular}{|c|c|c|c|c|c|}
\hline \multirow{2}{*}{ Variáveis } & \multicolumn{5}{|c|}{ Quantidade } \\
\hline & 0 & 1 & 2 & 3 & 4 ou + \\
\hline Televisão em cores & 0 & 0 & 0 & 0 & $\mathrm{O}$ \\
\hline Banheiro & $\mathrm{O}$ & $\mathrm{O}$ & $\mathrm{O}$ & $\mathrm{O}$ & $\mathrm{O}$ \\
\hline Automóvel & 0 & 0 & 0 & 0 & 0 \\
\hline Empregada mensalista & 0 & $\mathrm{O}$ & $\mathrm{O}$ & $\mathrm{O}$ & $\mathrm{O}$ \\
\hline Máquina de lavar & $\mathrm{O}$ & $\mathrm{O}$ & $\mathrm{O}$ & $\mathrm{O}$ & $\mathrm{O}$ \\
\hline Videocassete e/ou DVD & 0 & 0 & 0 & 0 & 0 \\
\hline Geladeira & 0 & 0 & $\mathrm{O}$ & 0 & $\mathrm{O}$ \\
\hline $\begin{array}{l}\text { Freezer (aparelho } \\
\text { independente ou parte } \\
\text { da geladeira duplex) }\end{array}$ & 0 & 0 & $\mathrm{O}$ & 0 & $\mathrm{O}$ \\
\hline
\end{tabular}

\section{Quem é o chefe da sua família?}

1 ( ) Pai

2 ( ) Mãe

3 ( ) Tio(a)

4 ( ) Avô(á)

5 ( ) Irmão(a)

6 ( ) Você

7 ( ) Outro:

Até que série na escola o chefe da família estudou ou completou com aprovação?

1 ( ) Analfabeto

2 ( ) Ensino fundamental 1 incompleto

3 ( ) Ensino fundamental 1 completo

4 ( ) Ensino fundamental 2 incompleto

5 ( ) Ensino fundamental 2 completo

6 ( ) Ensino médio incompleto 


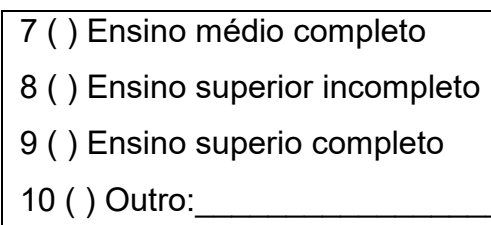

Com quantos anos teve a sua $1^{\mathrm{a}}$ relação sexual? anos

Quantos parceiros (as) sexuais já teve na vida? parceiros

Você já engravidou anteriormente?

0 ( ) Não(Pule as próximas perguntas sobre gravidez)

1 ( ) Sim

Que idade tinha quando engravidou pela primeira vez? anos

Quantas vezes você ficou grávida? vezes 


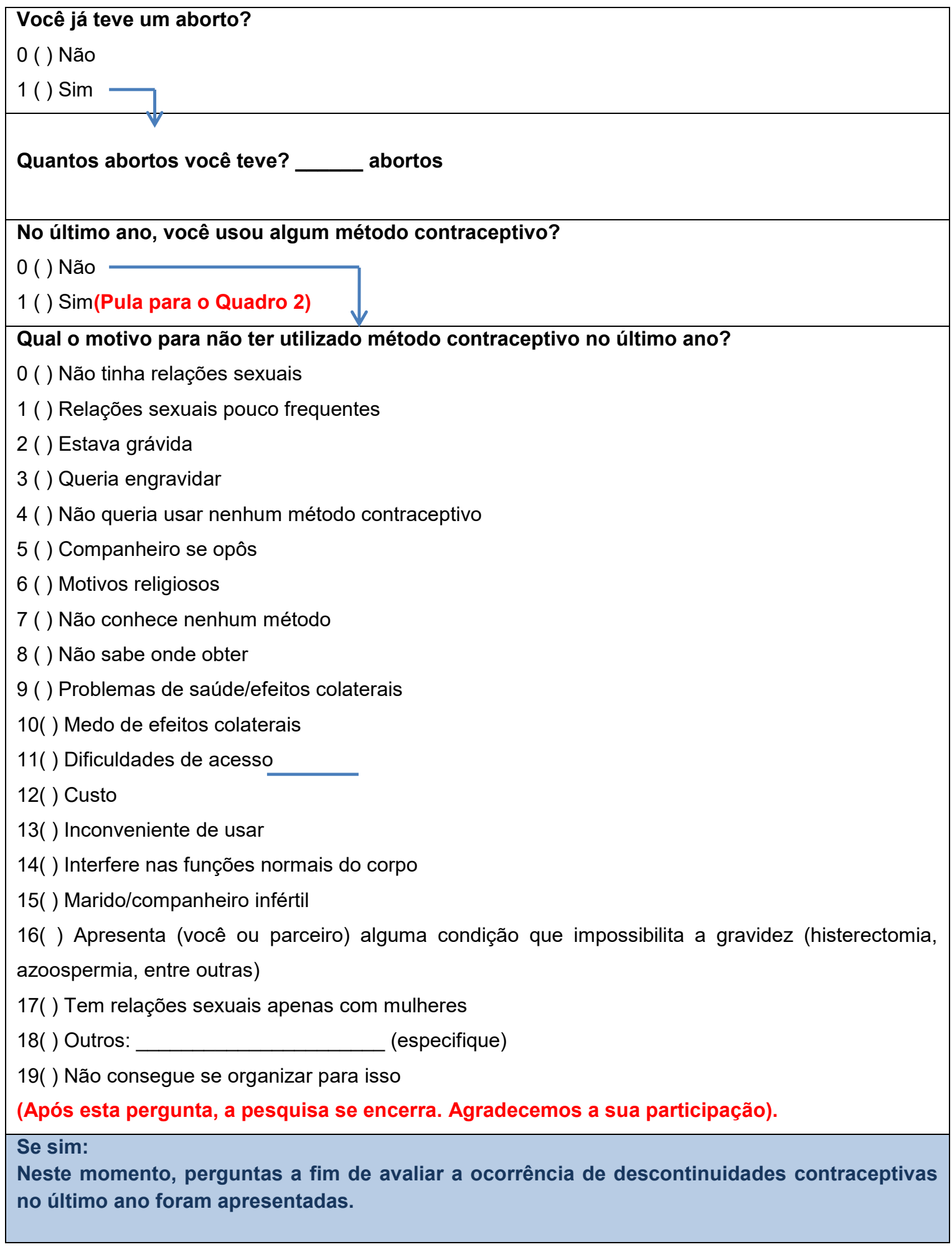


253

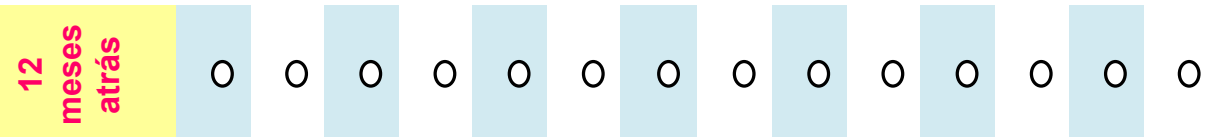

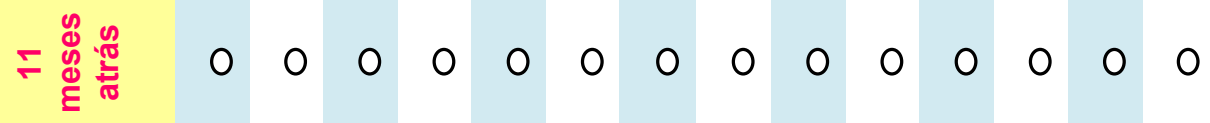

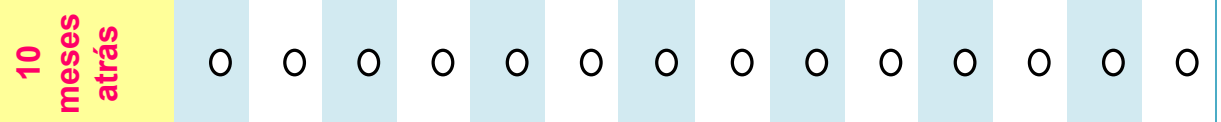

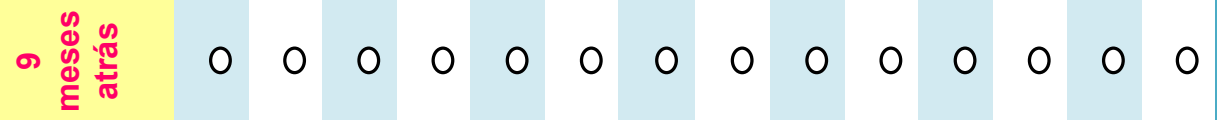

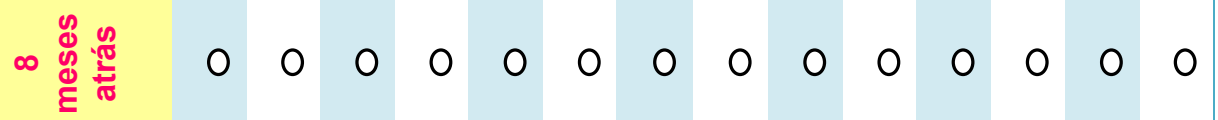

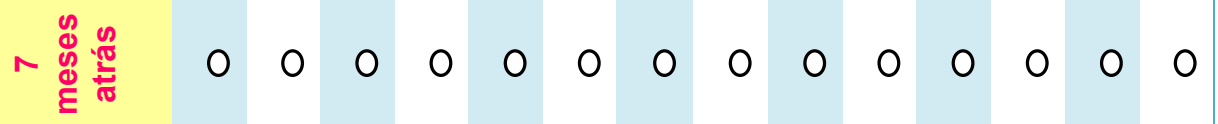

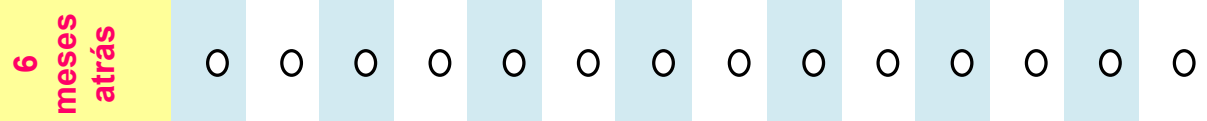

以几

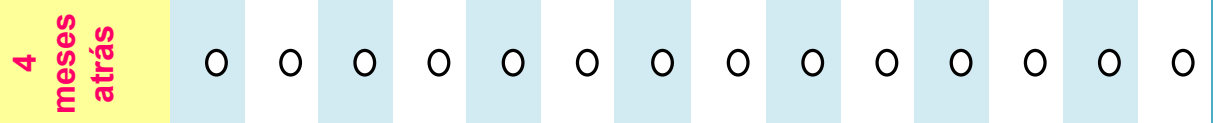

m

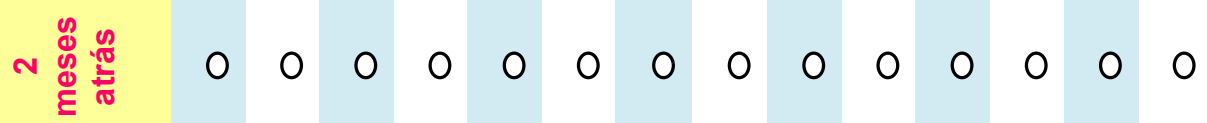

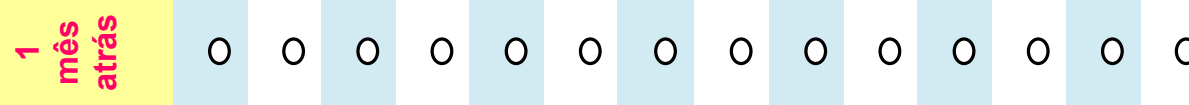

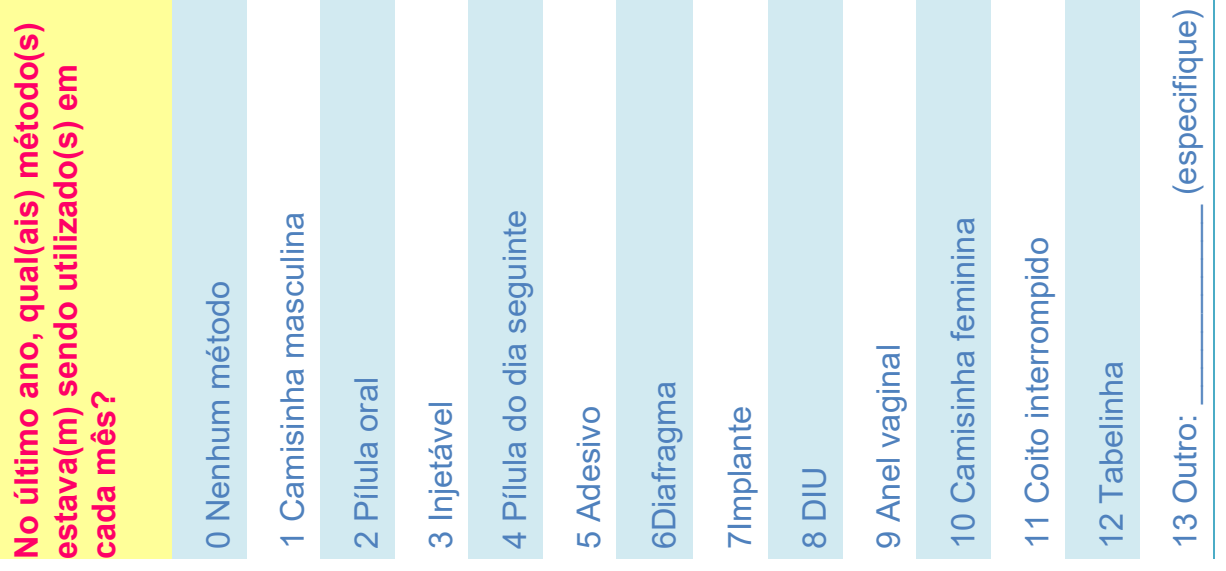



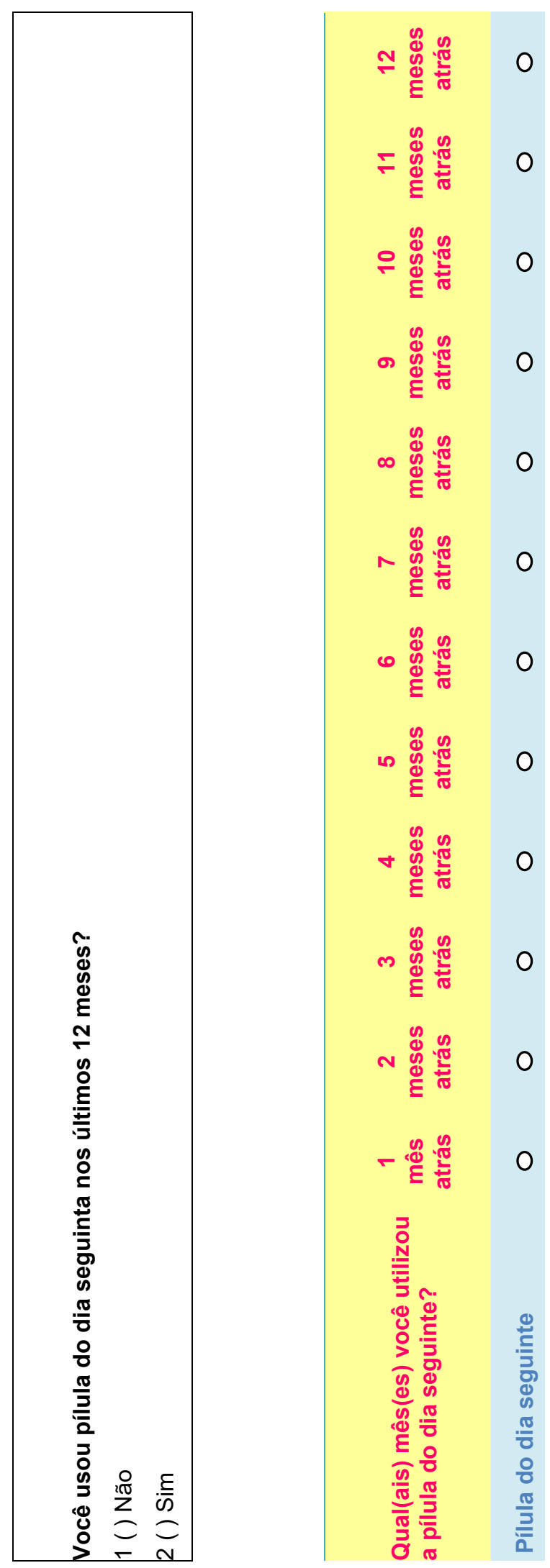

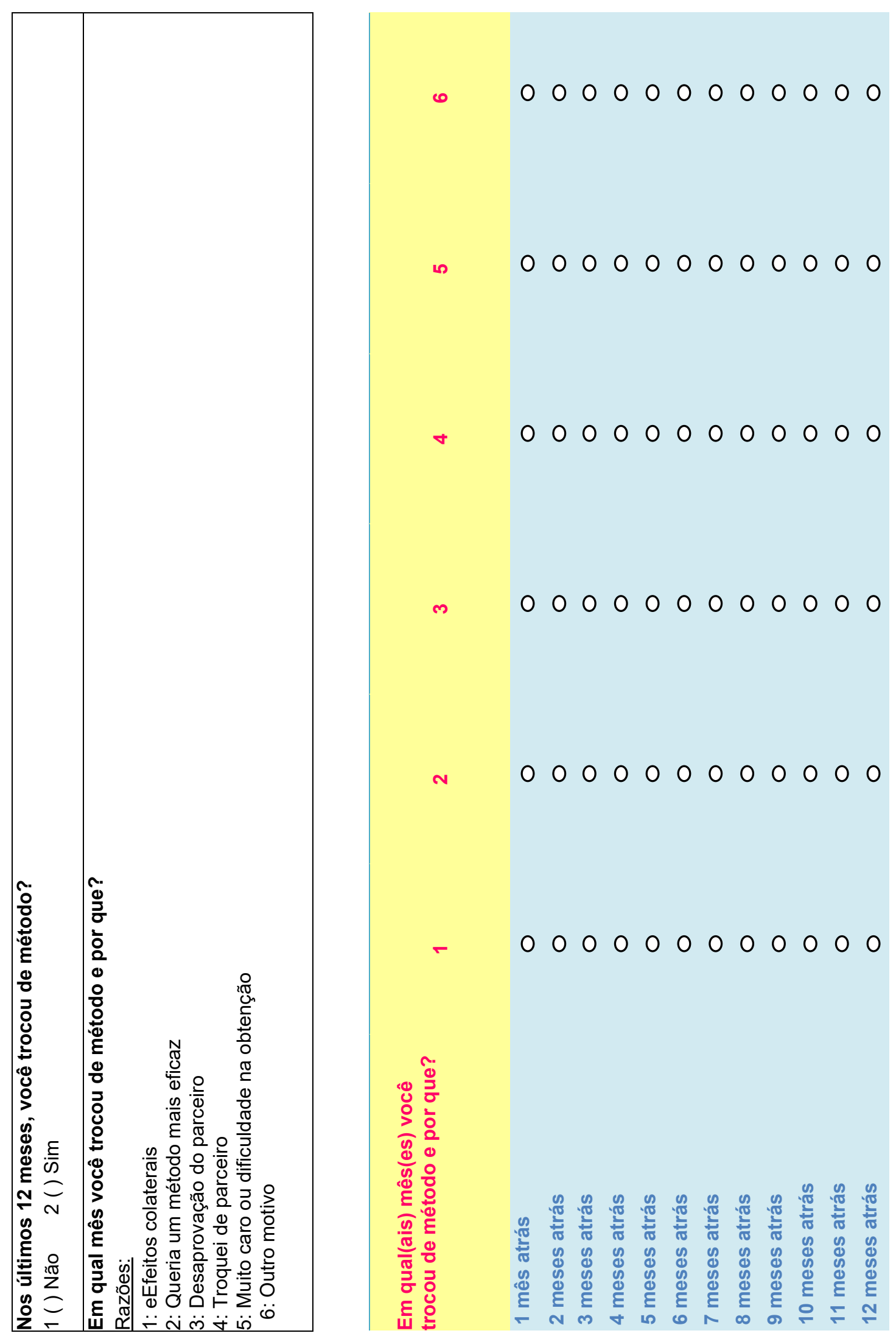

m 000000000000

n 000000000000

$-000000000000$ 


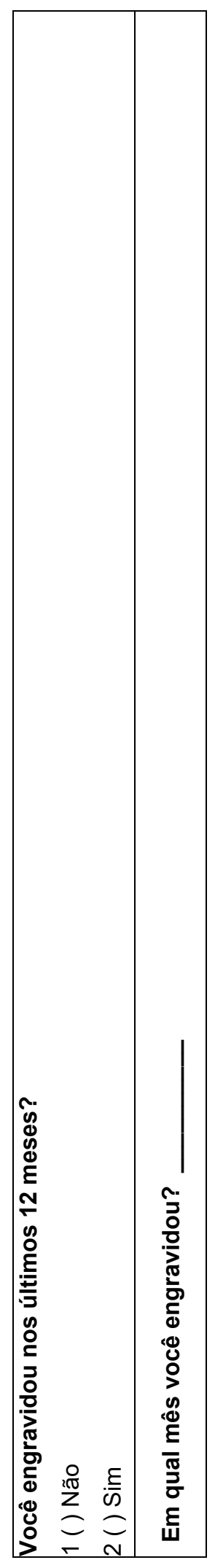

产

$\stackrel{\circ}{\mathrm{\delta}}$

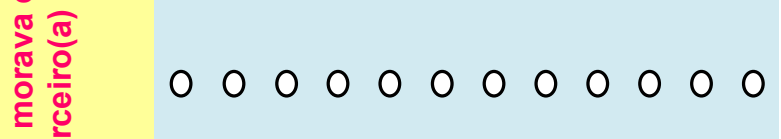

ว ํํำ

$\frac{\pi}{5}$

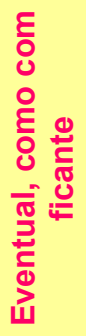

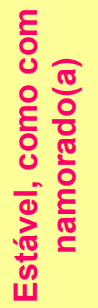

000000000000

$\begin{array}{llllllllllllll}\frac{0}{0} & 0 & 0 & 0 & 0 & 0 & 0 & 0 & 0 & 0 & 0 & 0 & 0\end{array}$

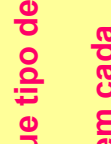

ㅇํㅇ

\&ै

\&

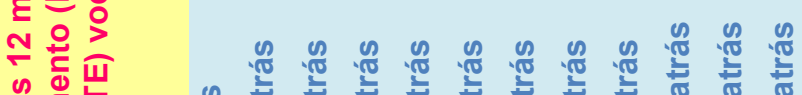

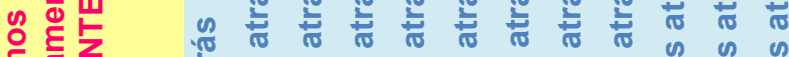

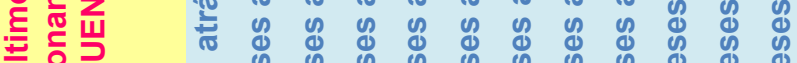

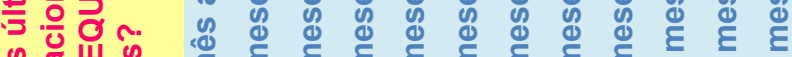

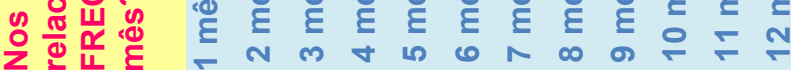


AGORA IREMOS FAZER ALGUMAS PERGUNTAS SOBRE O USO DA PÍLULA DO DIA SEGUINTE!!!

Você conhece alguém que já usou a pílula do dia seguinte?

0 ( ) Não

1 ( ) Sim

Você já usou alguma vez a anticoncepção de emergência (pílula do dia seguinte)?

0 ( ) Não (Se você respondeu não, a pesquisa se encerra. Agradecemos a sua participação)

1 ( ) Sim

SE SIM - Qual foi a razão que levou você ao uso da pílula do dia seguinte da última vez?

1 ( ) O método que usava falhou

2 ( ) Houve esquecimento de usar algum método

3 ( ) Não quis usar nenhum método

4 ( ) Foi vítima de violência sexual

5 ( ) Por pura insegurança

6 ( )Outros:

SE SIM - Nessa última vez que usou a pílula do dia seguinte, o relacionamento era:

1 ( ) fixo(a)/regular, como com namorado(a)

2 ( ) eventual, como com ficante

SE SIM - Quem tomou a iniciativa do uso da pílula do dia seguinte?

1 ( ) Você

2 ( ) Parceiro

3 ( ) Ambos

SE SIM - A pílula do dia seguinte foi adquirida com receita médica?

0 ( ) Não

1 ( ) Sim

SE SIM - Onde você adquiriu a pílula do dia seguinte?

1 ( ) Farmácia

2 ( ) No posto de saúde

3 ( ) No médico particular ou do convênio

4 ( ) Com amigos ou conhecidos

5 ( ) Namorado que trouxe

6 ( ) Com parente

7 ( ) Outros?

Na última vez, a pílula do dia seguinte foi tomada quanto tempo após a relação sexual desprotegida?

1 __ horas ou ___ dias

2 ( ) Não sei, não me lembro 
Quantas vezes você usou a pílula do dia seguinte no último ano?

1 vezes

2 ( ) Não sei, não me lembro

Você estava usando algum método contraceptivo quando você usou a pílula do dia seguinte na última vez?

0 ( ) Não

1 ( ) Sim

Qual método contraceptivo você estava usado?

1 ( ) Pílula oral

2 ( ) Camisinha masculina

3 ( ) Pílula oral e camisinha masculina

4 ( ) Injetável

5 ( ) Coito interrompido/Tabelinha

6 ( ) DIU

7 ( ) Other

AGORA IREMOS PERGUNTARSOBRE O USO DE MÉTODOS CONTRACEPTIVOS UM MÊS

ANTES E UM MÊS APÓS O USO DA PÍLULA DO DIA SEGUINTE!!! 
$\rightarrow 30$ DAYS BEFORE THE USE OF EMERGENCY CONTRACEPTION

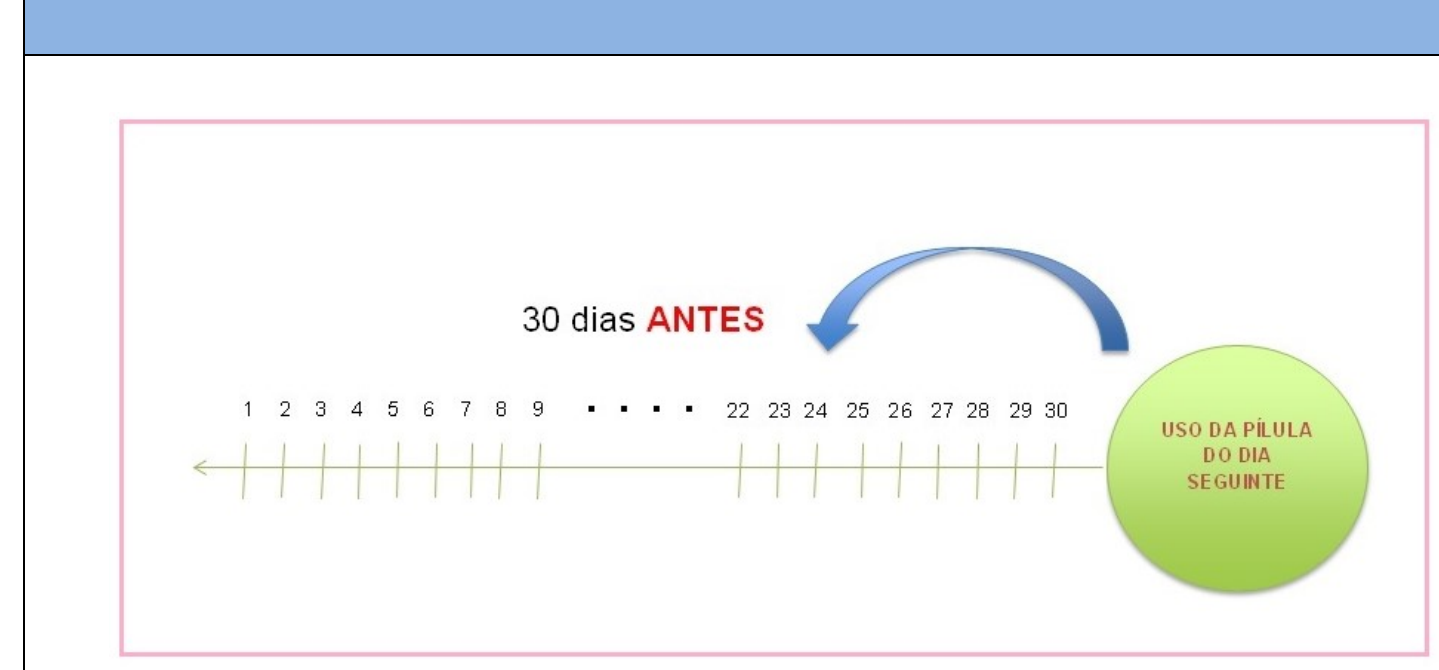

Você usou algum método anticoncepcional 30 dias ANTES do us da pílula do dia seguinte? 0 ( ) Não

1 ( ) Sim

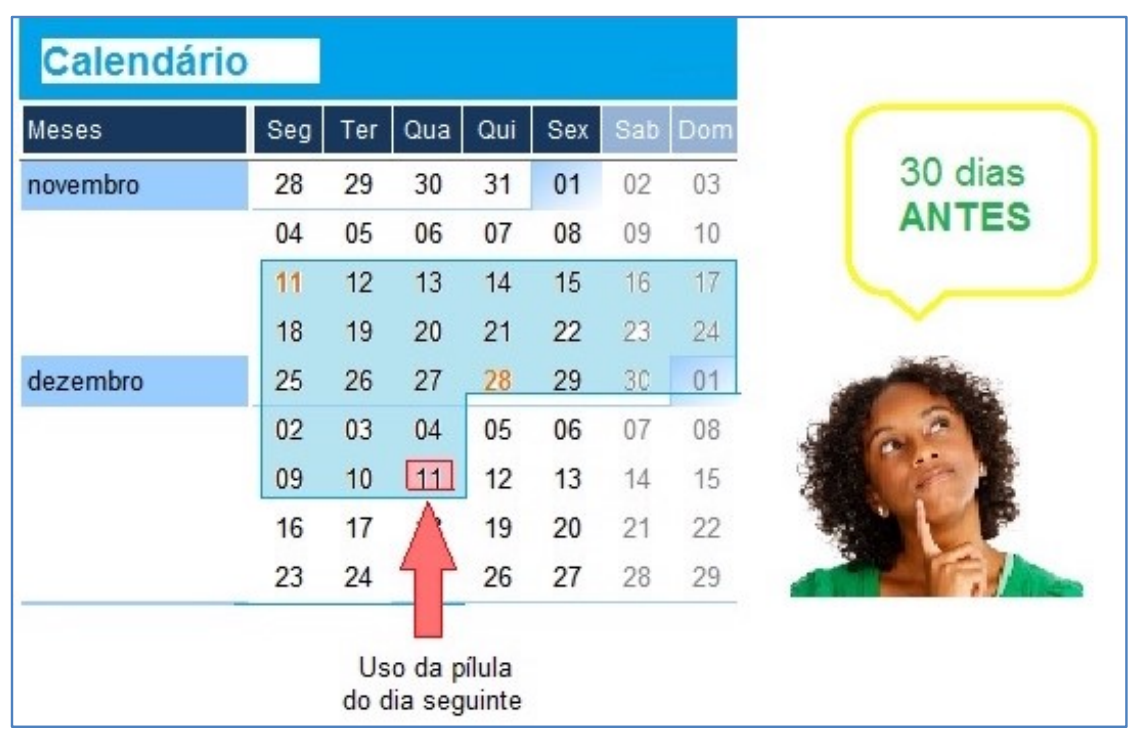

\section{Qual método contraceptivo você mais usou na maioria dos dias?}

1 ( ) Pílula oral

2 ( ) Camisinha masculina

3 ( ) Pílula oral e camisinha masculina

4 ( ) Injetável

5 ( ) Coito interrompido/Tabelinha

6 ( ) DIU

7 ( ) Other 
Nesses 30 dias ANTES de você usar a pílula do dia seguinte, você usou esse método continuamente (todos os dias sem exceção)?

0 ( ) Não 1 ( ) Sim

Nesses 30 dias ANTES de você usar a pílula do dia seguinte, quais dias você usou o método contraceptivo?

\begin{tabular}{|c|c|c|c|}
\hline & Day & $\begin{array}{c}\text { Não usou } \\
\text { contracepção }\end{array}$ & $\begin{array}{c}\text { Usou } \\
\text { contracepção }\end{array}$ \\
\hline & 30 & & \\
\hline & 29 & & \\
\hline & 28 & & \\
\hline & 27 & & \\
\hline & 26 & & \\
\hline & 25 & & \\
\hline & 24 & & \\
\hline & 23 & & \\
\hline & 22 & & \\
\hline & 21 & & \\
\hline & 20 & & \\
\hline & 19 & & \\
\hline 30 & 18 & & \\
\hline DIAS & 17 & & \\
\hline ANTES & 16 & & \\
\hline & 15 & & \\
\hline & 14 & & \\
\hline & 13 & & \\
\hline & 12 & & \\
\hline & 11 & & \\
\hline & 10 & & \\
\hline & 9 & & \\
\hline & 8 & & \\
\hline & 7 & & \\
\hline & 6 & & \\
\hline & 5 & & \\
\hline & 4 & & \\
\hline & 3 & & \\
\hline & 2 & & \\
\hline & 1 & & \\
\hline & $\overline{A B}$ & ULA DO DIA S & UINTE \\
\hline
\end{tabular}


$\rightarrow 30$ DIAS APÓS O USO DA PÍLULA DO DIA SEGUINTE

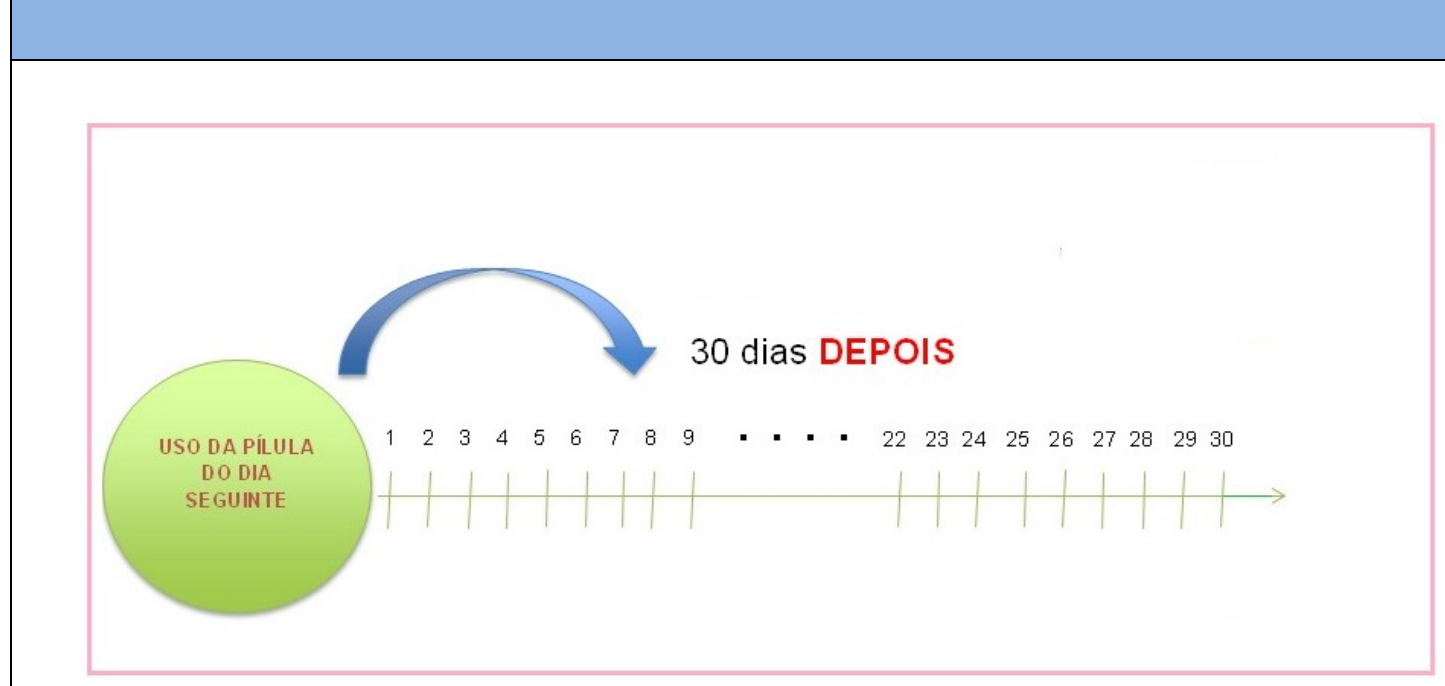

Você usou algum método contraceptivo $\mathbf{3 0}$ dias APÓS você usar a pílula do dia seguinte? 0 ( ) Não

1 ( ) Sim

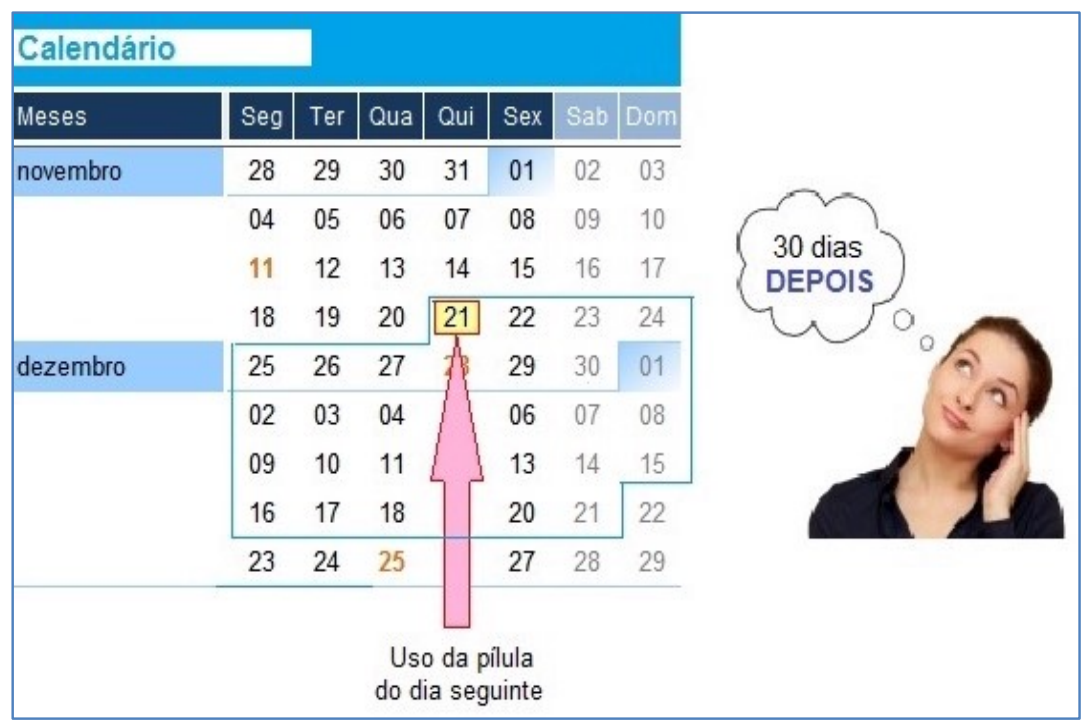

Qual método contraceptivo você mais usou na maioria dos dias?

1 ( ) Pílula oral

2 ( ) Camisinha masculina

3 ( ) Pílula oral e camisinha masculina

4 ( ) Injetável

5 ( ) Coito interrompido/Tabelinha

6 ( ) DIU

7 ( ) Other 
Você iniciou imediatamente o uso deste método, APÓS usar a pílula do dia seguinte?

0 ( ) Não

1 ( ) Sim

Quantos dias DEPOIS de usar a pílula do dia seguinte, você iniciou o uso do método?

1()$<10$ dias

2 ( ) $10-15$ dias

3()$\geq 15$ dias

Você usou este método continuamente por quanto tempo?

1()$<1$ mês

2 ( ) 1 mês

3 ( ) 1 - 6 meses

4 ( ) 6 - 12 meses

5 ( ) 1 - 2 anos

6()$\geq 2$ anos 


\section{APPENDIX D - INDEPENDENCE MODEL CRITERION (QIC)}

\section{a) Discontinuation for any reason}

\section{- Oral pill}

\begin{tabular}{|c|c|c|c|c|c|c|c|c|c|c|c|}
\hline \multirow{13}{*}{ 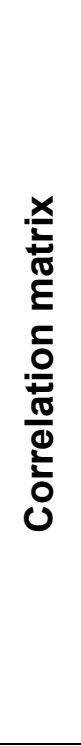 } & \multicolumn{11}{|c|}{ Working correlation structure } \\
\hline & \multicolumn{11}{|c|}{ Exchangeable } \\
\hline & 1.00 & & & & & & & & & & \\
\hline & 0.22 & 1.00 & & & & & & & & & \\
\hline & 0.22 & 0.22 & 1.00 & & & & & & & & \\
\hline & 0.22 & 0.22 & 0.22 & 1.00 & & & & & & & \\
\hline & 0.22 & 0.22 & 0.22 & 0.22 & 1.00 & & & & & & \\
\hline & 0.22 & 0.22 & 0.22 & 0.22 & 0.22 & 1.00 & & & & & \\
\hline & 0.22 & 0.22 & 0.22 & 0.22 & 0.22 & 0.22 & 1.00 & & & & \\
\hline & 0.22 & 0.22 & 0.22 & 0.22 & 0.22 & 0.22 & 0.22 & 1.00 & & & \\
\hline & 0.22 & 0.22 & 0.22 & 0.22 & 0.22 & 0.22 & 0.22 & 0.22 & 1.00 & & \\
\hline & 0.22 & 0.22 & 0.22 & 0.22 & 0.22 & 0.22 & 0.22 & 0.22 & 0.22 & 1.00 & \\
\hline & 0.22 & 0.22 & 0.22 & 0.22 & 0.22 & 0.22 & 0.22 & 0.22 & 0.22 & 0.22 & 0.22 \\
\hline QIC & \multicolumn{11}{|c|}{7645.70} \\
\hline
\end{tabular}

\begin{tabular}{|c|c|c|c|c|c|c|c|c|c|c|c|}
\hline \multirow{13}{*}{ 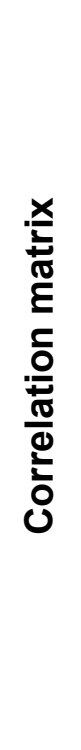 } & \multicolumn{11}{|c|}{ Working correlation structure } \\
\hline & \multicolumn{11}{|c|}{ Unstructured } \\
\hline & 1.00 & & & & & & & & & & \\
\hline & 0.02 & 1.00 & & & & & & & & & \\
\hline & 0.01 & 0.01 & 1.00 & & & & & & & & \\
\hline & 0.01 & 0.06 & 0.02 & 1.00 & & & & & & & \\
\hline & 0.06 & 0.03 & 0.03 & 0.01 & 1.00 & & & & & & \\
\hline & 0.00 & 0.05 & 0.00 & 0.05 & 0.00 & 1.00 & & & & & \\
\hline & 0.00 & 0.02 & 0.01 & 0.00 & 0.00 & 0.00 & 1.00 & & & & \\
\hline & 0.02 & -0.01 & -0.01 & 0.04 & 0.02 & -0.01 & -0.01 & 1.00 & & & \\
\hline & 0.00 & 0.11 & 0.00 & 0.00 & 0.01 & 0.01 & 0.04 & 0.00 & 1.00 & & \\
\hline & 0.02 & 0.05 & -0.01 & 0.05 & 0.02 & 0.07 & 0.00 & -0.01 & -0.01 & 1.00 & \\
\hline & 0.06 & 0.04 & -0.02 & 0.05 & 0.01 & 0.05 & 0.05 & 0.11 & 0.08 & -0.02 & 1.00 \\
\hline QIC & \multicolumn{11}{|c|}{7655.56} \\
\hline
\end{tabular}




\begin{tabular}{|c|c|c|c|c|c|c|c|c|c|c|c|}
\hline \multirow{13}{*}{ 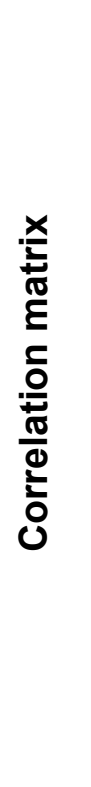 } & \multicolumn{11}{|c|}{ Working correlation structure } \\
\hline & \multicolumn{11}{|c|}{ Autoregressive } \\
\hline & 1.00 & & & & & & & & & & \\
\hline & 0.00 & 1.00 & & & & & & & & & \\
\hline & 0.00 & 0.00 & 1.00 & & & & & & & & \\
\hline & 0.00 & 0.00 & 0.00 & 1.00 & & & & & & & \\
\hline & 0.00 & 0.00 & 0.00 & 0.00 & 1.00 & & & & & & \\
\hline & 0.00 & 0.00 & 0.00 & 0.00 & 0.00 & 1.00 & & & & & \\
\hline & 0.00 & 0.00 & 0.00 & 0.00 & 0.00 & 0.00 & 1.00 & & & & \\
\hline & 0.00 & 0.00 & 0.00 & 0.00 & 0.00 & 0.00 & 0.00 & 1.00 & & & \\
\hline & 0.00 & 0.00 & 0.00 & 0.00 & 0.00 & 0.00 & 0.00 & 0.00 & 1.00 & & \\
\hline & 0.00 & 0.00 & 0.00 & 0.00 & 0.00 & 0.00 & 0.00 & 0.00 & 0.00 & 1.00 & \\
\hline & 0.00 & 0.00 & 0.00 & 0.00 & 0.00 & 0.00 & 0.00 & 0.00 & 0.00 & 0.00 & 1.00 \\
\hline QIC & \multicolumn{11}{|c|}{8053.35} \\
\hline
\end{tabular}

\section{- Male Condom}

\begin{tabular}{|c|c|c|c|c|c|c|c|c|c|c|c|}
\hline \multirow{13}{*}{ 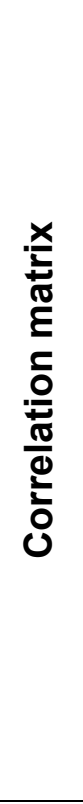 } & \multicolumn{11}{|c|}{ Working correlation structure } \\
\hline & \multicolumn{11}{|c|}{ Exchangeable } \\
\hline & & & & & & & & & & & \\
\hline & 0.11 & 1.00 & & & & & & & & & \\
\hline & 0.11 & 0.11 & 1.00 & & & & & & & & \\
\hline & 0.11 & 0.11 & 0.11 & 1.00 & & & & & & & \\
\hline & 0.11 & 0.11 & 0.11 & 0.11 & 1.00 & & & & & & \\
\hline & 0.11 & 0.11 & 0.11 & 0.11 & 0.11 & 1.00 & & & & & \\
\hline & 0.11 & 0.11 & 0.11 & 0.11 & 0.11 & 0.11 & 1.00 & & & & \\
\hline & 0.11 & 0.11 & 0.11 & 0.11 & 0.11 & 0.11 & 0.11 & 1.00 & & & \\
\hline & 0.11 & 0.11 & 0.11 & 0.11 & 0.11 & 0.11 & 0.11 & 0.11 & 1.00 & & \\
\hline & 0.11 & 0.11 & 0.11 & 0.11 & 0.11 & 0.11 & 0.11 & 0.11 & 0.11 & 1.00 & \\
\hline & 0.11 & 0.11 & 0.11 & 0.11 & 0.11 & 0.11 & 0.11 & 0.11 & 0.11 & 0.11 & 1.00 \\
\hline QIC & \multicolumn{11}{|c|}{9099.91} \\
\hline
\end{tabular}




\begin{tabular}{|c|c|c|c|c|c|c|c|c|c|c|c|}
\hline \multirow{13}{*}{ 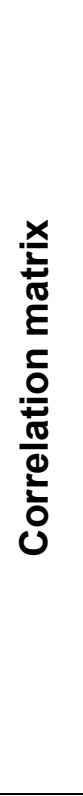 } & \multicolumn{11}{|c|}{ Working correlation structure } \\
\hline & \multicolumn{11}{|c|}{ Unstructured } \\
\hline & 1.00 & & & & & & & & & & \\
\hline & 0.11 & 1.00 & & & & & & & & & \\
\hline & 0.10 & 0.05 & 1.00 & & & & & & & & \\
\hline & 0.12 & 0.11 & 0.11 & 1.00 & & & & & & & \\
\hline & 0.23 & 0.13 & 0.13 & 0.08 & 1.00 & & & & & & \\
\hline & 0.06 & 0.16 & 0.10 & 0.07 & 0.07 & 1.00 & & & & & \\
\hline & 0.15 & 0.22 & 0.16 & 0.11 & 0.16 & 0.09 & 1.00 & & & & \\
\hline & 0.07 & 0.08 & 0.07 & 0.21 & 0.06 & 0.11 & 0.07 & 1.00 & & & \\
\hline & 0.15 & 0.11 & 0.15 & 0.02 & 0.17 & 0.03 & 0.08 & 0.03 & 1.00 & & \\
\hline & 0.00 & 0.13 & 0.12 & 0.03 & 0.13 & 0.13 & 0.10 & 0.07 & 0.03 & 1.00 & \\
\hline & 0.10 & 0.11 & 0.16 & 0.01 & 0.14 & 0.22 & 0.09 & 0.18 & 0.13 & 0.07 & 1.00 \\
\hline QIC & \multicolumn{11}{|c|}{9094.83} \\
\hline
\end{tabular}

\begin{tabular}{|c|c|c|c|c|c|c|c|c|c|c|c|}
\hline \multirow{12}{*}{ 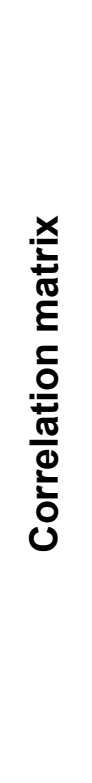 } & \multicolumn{11}{|c|}{ Working correlation structure } \\
\hline & \multicolumn{11}{|c|}{ Autoregressive } \\
\hline & & & & & & & & & & & \\
\hline & & & & & & & & & & & \\
\hline & & & & & & & & & & & \\
\hline & 0.00 & 0.00 & -0.01 & 1.00 & & & & & & & \\
\hline & 0.00 & 0.00 & 0.00 & -0.01 & 1.00 & & & & & & \\
\hline & 0.00 & 0.00 & 0.00 & 0.00 & -0.01 & 1.00 & & & & & \\
\hline & 0.00 & 0.00 & 0.00 & 0.00 & 0.00 & -0.01 & 1.00 & & & & \\
\hline & 0.00 & 0.00 & 0.00 & 0.00 & 0.00 & 0.00 & -0.01 & 1.00 & & & \\
\hline & 0.00 & 0.00 & 0.00 & 0.00 & 0.00 & 0.00 & 0.00 & -0.01 & 1.00 & & \\
\hline & 0.00 & 0.00 & 0.00 & 0.00 & م0 & 0.00 & م0 & مחم & 0.00 & 01 & 100 \\
\hline QIC & \multicolumn{11}{|c|}{9690.39} \\
\hline
\end{tabular}


b) Discontinuation for method-reason reasons

- Oral pill

\begin{tabular}{|c|c|c|c|c|c|c|c|c|c|c|c|}
\hline \multirow{13}{*}{ 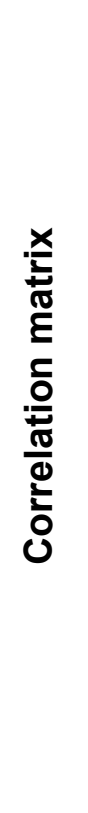 } & \multicolumn{11}{|c|}{ Working correlation structure } \\
\hline & \multicolumn{11}{|c|}{ Exchangeable } \\
\hline & 1.00 & & & & & & & & & & \\
\hline & 0.02 & 1.00 & & & & & & & & & \\
\hline & 0.02 & 0.02 & 1.00 & & & & & & & & \\
\hline & 0.02 & 0.02 & 0.02 & 1.00 & & & & & & & \\
\hline & 0.02 & 0.02 & 0.02 & 0.02 & 1.00 & & & & & & \\
\hline & 0.02 & 0.02 & 0.02 & 0.02 & 0.02 & 1.00 & & & & & \\
\hline & 0.02 & 0.02 & 0.02 & 0.02 & 0.02 & 0.02 & 1.00 & & & & \\
\hline & 0.02 & 0.02 & 0.02 & 0.02 & 0.02 & 0.02 & 0.02 & 1.00 & & & \\
\hline & 0.02 & 0.02 & 0.02 & 0.02 & 0.02 & 0.02 & 0.02 & 0.02 & 1.00 & & \\
\hline & 0.02 & 0.02 & 0.02 & 0.02 & 0.02 & 0.02 & 0.02 & 0.02 & 0.02 & 1.00 & \\
\hline & 0.02 & 0.02 & 0.02 & 0.02 & 0.02 & 0.02 & 0.02 & 0.02 & 0.02 & 0.02 & 1.00 \\
\hline QIC & & & & & & 44.1 & & & & & \\
\hline
\end{tabular}

\begin{tabular}{|c|c|c|c|c|c|c|c|c|c|c|c|}
\hline \multirow{13}{*}{ 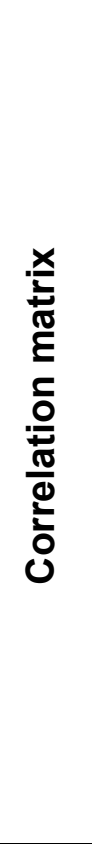 } & \multicolumn{11}{|c|}{ Working correlation structure } \\
\hline & \multicolumn{11}{|c|}{ Unstructured } \\
\hline & & & & & & & & & & & \\
\hline & 0.02 & 1.00 & & & & & & & & & \\
\hline & 0.01 & 0.01 & 1.00 & & & & & & & & \\
\hline & 0.01 & 0.06 & 0.01 & 1.00 & & & & & & & \\
\hline & 0.04 & 0.03 & 0.04 & 0.01 & 1.00 & & & & & & \\
\hline & 0.01 & 0.05 & 0.00 & 0.05 & 0.01 & 1.00 & & & & & \\
\hline & 0.00 & 0.00 & 0.00 & 0.00 & 0.00 & 0.01 & 1.00 & & & & \\
\hline & 0.03 & -0.01 & -0.02 & 0.05 & 0.02 & -0.01 & -0.01 & 1.00 & & & \\
\hline & -0.01 & 0.12 & 0.00 & 0.00 & 0.02 & -0.01 & 0.04 & 0.00 & 1.00 & & \\
\hline & 0.00 & 0.05 & 0.00 & 0.05 & 0.00 & 0.07 & 0.00 & 0.00 & 0.00 & 1.00 & \\
\hline & 0.06 & 0.02 & -0.02 & 0.07 & 0.02 & 0.07 & 0.06 & 0.13 & 0.08 & -0.01 & 1.00 \\
\hline QIC & & & & & & 957.77 & & & & & \\
\hline
\end{tabular}




\begin{tabular}{|c|c|c|c|c|c|c|c|c|c|c|c|}
\hline \multirow{13}{*}{ 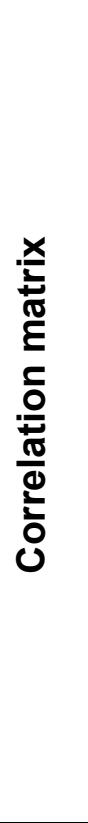 } & \multicolumn{11}{|c|}{ Working correlation structure } \\
\hline & \multicolumn{11}{|c|}{ Autoregressive } \\
\hline & & & & & & & & & & & \\
\hline & 0.00 & 1.00 & & & & & & & & & \\
\hline & 0.00 & 0.00 & 1.00 & & & & & & & & \\
\hline & 0.00 & 0.00 & 0.00 & 1.00 & & & & & & & \\
\hline & 0.00 & 0.00 & 0.00 & 0.00 & 1.00 & & & & & & \\
\hline & 0.00 & 0.00 & 0.00 & 0.00 & 0.00 & 1.00 & & & & & \\
\hline & 0.00 & 0.00 & 0.00 & 0.00 & 0.00 & 0.00 & 1.00 & & & & \\
\hline & 0.00 & 0.00 & 0.00 & 0.00 & 0.00 & 0.00 & 0.00 & 1.00 & & & \\
\hline & 0.00 & 0.00 & 0.00 & 0.00 & 0.00 & 0.00 & 0.00 & 0.00 & 1.00 & & \\
\hline & 0.00 & 0.00 & 0.00 & 0.00 & 0.00 & 0.00 & 0.00 & 0.00 & 0.00 & 1.00 & \\
\hline & 0.00 & 0.00 & 0.00 & 0.00 & 0.00 & 0.00 & 0.00 & 0.00 & 0.00 & 0.00 & 1.00 \\
\hline QIC & \multicolumn{11}{|c|}{7327.24} \\
\hline
\end{tabular}

\section{- Male Condom}

\begin{tabular}{|c|c|c|c|c|c|c|c|c|c|c|c|}
\hline \multirow{13}{*}{ 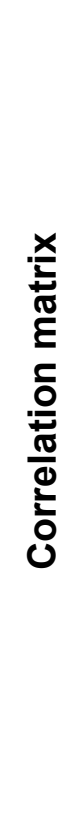 } & \multicolumn{11}{|c|}{ Working correlation structure } \\
\hline & \multicolumn{11}{|c|}{ Exchangeable } \\
\hline & 1.00 & & & & & & & & & & \\
\hline & 0.09 & 1.00 & & & & & & & & & \\
\hline & 0.09 & 0.09 & 1.00 & & & & & & & & \\
\hline & 0.09 & 0.09 & 0.09 & 1.00 & & & & & & & \\
\hline & 0.09 & 0.09 & 0.09 & 0.09 & 1.00 & & & & & & \\
\hline & 0.09 & 0.09 & 0.09 & 0.09 & 0.09 & 1.00 & & & & & \\
\hline & 0.09 & 0.09 & 0.09 & 0.09 & 0.09 & 0.09 & 1.00 & & & & \\
\hline & 0.09 & 0.09 & 0.09 & 0.09 & 0.09 & 0.09 & 0.09 & 1.00 & & & \\
\hline & 0.09 & 0.09 & 0.09 & 0.09 & 0.09 & 0.09 & 0.09 & 0.09 & 1.00 & & \\
\hline & 0.09 & 0.09 & 0.09 & 0.09 & 0.09 & 0.09 & 0.09 & 0.09 & 0.09 & 1.00 & \\
\hline & 0.09 & 0.09 & 0.09 & 0.09 & 0.09 & 0.09 & 0.09 & 0.09 & 0.09 & 0.09 & 1.00 \\
\hline QIC & \multicolumn{11}{|c|}{8185.12} \\
\hline
\end{tabular}




\begin{tabular}{|c|c|c|c|c|c|c|c|c|c|c|c|}
\hline \multirow{13}{*}{ 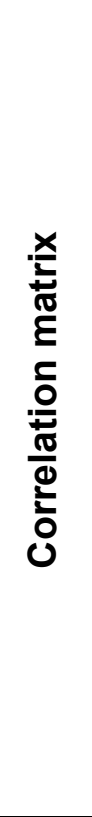 } & \multicolumn{11}{|c|}{ Working correlation structure } \\
\hline & \multicolumn{11}{|c|}{ Unstructured } \\
\hline & & & & & & & & & & & \\
\hline & & 1.00 & & & & & & & & & \\
\hline & 0.09 & 0.04 & 1.00 & & & & & & & & \\
\hline & 0.09 & 0.08 & 0.09 & 1.00 & & & & & & & \\
\hline & 0.21 & 0.10 & 0.11 & 0.06 & 1.00 & & & & & & \\
\hline & 0.03 & 0.16 & 0.08 & 0.06 & 0.05 & 1.00 & & & & & \\
\hline & 0.14 & 0.19 & 0.14 & 0.10 & 0.14 & 0.07 & 1.00 & & & & \\
\hline & 0.04 & 0.05 & 0.05 & 0.19 & 0.04 & 0.08 & 0.05 & 1.00 & & & \\
\hline & 0.13 & 0.07 & 0.12 & 0.01 & 0.17 & 0.02 & 0.08 & 0.02 & 1.00 & & \\
\hline & 0.00 & 0.15 & 0.04 & 0.05 & 0.14 & 0.13 & 0.07 & 0.03 & 0.02 & 1.00 & \\
\hline & 0.09 & 0.12 & 0.16 & 0.02 & 0.10 & 0.18 & 0.08 & 0.11 & 0.12 & 0.05 & 1.00 \\
\hline QIC & \multicolumn{11}{|c|}{8191.82} \\
\hline
\end{tabular}

\begin{tabular}{|c|c|c|c|c|c|c|c|c|c|c|c|}
\hline \multirow{13}{*}{ 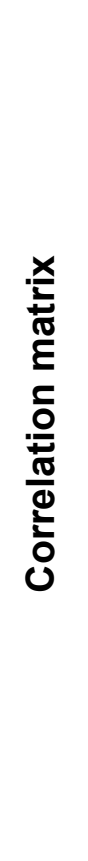 } & \multicolumn{11}{|c|}{ Working correlation structure } \\
\hline & \multicolumn{11}{|c|}{ Autoregressive } \\
\hline & 1.00 & & & & & & & & & & \\
\hline & -0.01 & 1.00 & & & & & & & & & \\
\hline & 0.00 & -0.01 & 1.00 & & & & & & & & \\
\hline & 0.00 & 0.00 & -0.01 & 1.00 & & & & & & & \\
\hline & 0.00 & 0.00 & 0.00 & -0.01 & 1.00 & & & & & & \\
\hline & 0.00 & 0.00 & 0.00 & 0.00 & -0.01 & 1.00 & & & & & \\
\hline & 0.00 & 0.00 & 0.00 & 0.00 & 0.00 & -0.01 & 1.00 & & & & \\
\hline & 0.00 & 0.00 & 0.00 & 0.00 & 0.00 & 0.00 & -0.01 & 1.00 & & & \\
\hline & 0.00 & 0.00 & 0.00 & 0.00 & 0.00 & 0.00 & 0.00 & -0.01 & 1.00 & & \\
\hline & 0.00 & 0.00 & 0.00 & 0.00 & 0.00 & 0.00 & 0.00 & 0.00 & -0.01 & 1.00 & \\
\hline & 0.00 & 0.00 & 0.00 & 0.00 & 0.00 & 0.00 & 0.00 & 0.00 & 0.00 & -0.01 & 1.00 \\
\hline QIC & \multicolumn{11}{|c|}{9113.63} \\
\hline
\end{tabular}


c) Abandonment or switching to less effective method

- Oral pill

\begin{tabular}{|c|c|c|c|c|c|c|c|c|c|c|c|}
\hline \multirow{13}{*}{ 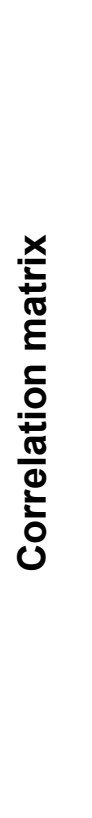 } & \multicolumn{11}{|c|}{ Working correlation structure } \\
\hline & \multicolumn{11}{|c|}{ Exchangeable } \\
\hline & 1.00 & & & & & & & & & & \\
\hline & 0.00 & 1.00 & & & & & & & & & \\
\hline & 0.00 & 0.00 & 1.00 & & & & & & & & \\
\hline & 0.00 & 0.00 & 0.00 & 1.00 & & & & & & & \\
\hline & 0.00 & 0.00 & 0.00 & 0.00 & 1.00 & & & & & & \\
\hline & 0.00 & 0.00 & 0.00 & 0.00 & 0.00 & 1.00 & & & & & \\
\hline & 0.00 & 0.00 & 0.00 & 0.00 & 0.00 & 0.00 & 1.00 & & & & \\
\hline & 0.00 & 0.00 & 0.00 & 0.00 & 0.00 & 0.00 & 0.00 & 1.00 & & & \\
\hline & 0.00 & 0.00 & 0.00 & 0.00 & 0.00 & 0.00 & 0.00 & 0.00 & 1.00 & & \\
\hline & 0.00 & 0.00 & 0.00 & 0.00 & 0.00 & 0.00 & 0.00 & 0.00 & 0.00 & 1.00 & \\
\hline & 0.00 & 0.00 & 0.00 & 0.00 & 0.00 & 0.00 & 0.00 & 0.00 & 0.00 & 0.00 & 1.00 \\
\hline QIC & & & & & & $504.5 c$ & & & & & \\
\hline
\end{tabular}

\begin{tabular}{|c|c|c|c|c|c|c|c|c|c|c|c|}
\hline \multirow{13}{*}{ 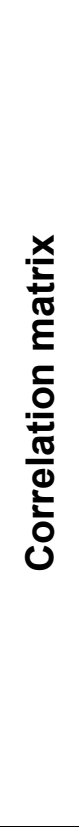 } & \multicolumn{11}{|c|}{ Working correlation structure } \\
\hline & \multicolumn{11}{|c|}{ Unstructured } \\
\hline & 1.00 & & & & & & & & & & \\
\hline & -0.01 & 1.00 & & & & & & & & & \\
\hline & -0.02 & -0.03 & 1.00 & & & & & & & & \\
\hline & 0.02 & 0.04 & -0.02 & 1.00 & & & & & & & \\
\hline & 0.05 & 0.05 & 0.01 & -0.01 & 1.00 & & & & & & \\
\hline & 0.00 & 0.02 & -0.03 & 0.03 & -0.02 & 1.00 & & & & & \\
\hline & -0.02 & -0.02 & -0.03 & 0.00 & -0.02 & -0.03 & 1.00 & & & & \\
\hline & 0.01 & 0.02 & 0.00 & 0.09 & 0.01 & 0.03 & -0.04 & 1.00 & & & \\
\hline & -0.03 & 0.02 & -0.04 & -0.03 & 0.00 & -0.03 & 0.02 & -0.03 & 1.00 & & \\
\hline & 0.00 & 0.02 & -0.04 & 0.03 & 0.00 & 0.09 & 0.04 & 0.02 & -0.03 & 1.00 & \\
\hline & 0.02 & 0.01 & 0.00 & 0.01 & 0.02 & 0.02 & 0.01 & 0.01 & 0.01 & 0.01 & 1.00 \\
\hline QIC & \multicolumn{11}{|c|}{5505.24} \\
\hline
\end{tabular}




\begin{tabular}{|c|c|c|c|c|c|c|c|c|c|c|c|}
\hline \multirow{12}{*}{ 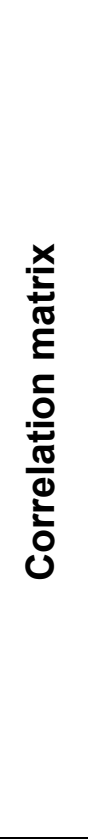 } & \multicolumn{11}{|c|}{ Working correlation structure } \\
\hline & \multicolumn{11}{|c|}{ Autoregressive } \\
\hline & -0.02 & 1.00 & & & & & & & & & \\
\hline & 0.00 & -0.02 & 1.00 & & & & & & & & \\
\hline & 0.00 & 0.00 & -0.02 & 1.00 & & & & & & & \\
\hline & 0.00 & 0.00 & 0.00 & -0.02 & 1.00 & & & & & & \\
\hline & 0.00 & 0.00 & 0.00 & 0.00 & -0.02 & 1.00 & & & & & \\
\hline & 0.00 & 0.00 & 0.00 & 0.00 & 0.00 & -0.02 & 1.00 & & & & \\
\hline & 0.00 & 0.00 & 0.00 & 0.00 & 0.00 & 0.00 & -0.02 & 1.00 & & & \\
\hline & 0.00 & 0.00 & 0.00 & 0.00 & 0.00 & 0.00 & 0.00 & -0.02 & 1.00 & & \\
\hline & 0.00 & 0.00 & 0.00 & 0.00 & 0.00 & 0.00 & 0.00 & 0.00 & -0.02 & 1.00 & \\
\hline & 0.00 & 0.00 & 0.00 & 0.00 & 0.00 & 0.00 & 0.00 & 0.00 & 0.00 & -0.02 & 1.00 \\
\hline QIC & \multicolumn{11}{|c|}{5529.75} \\
\hline
\end{tabular}

- Male Condom

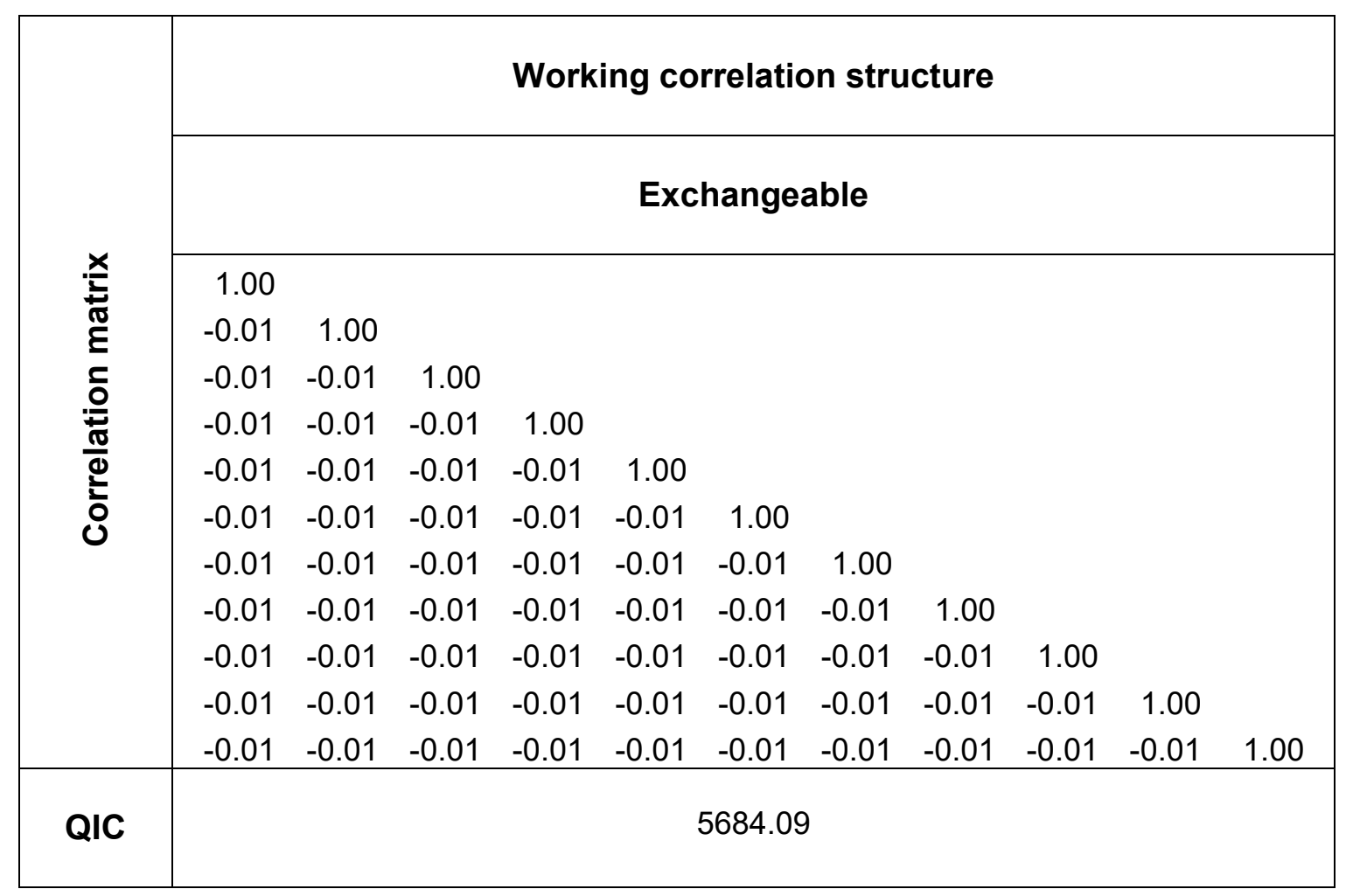




\begin{tabular}{|c|c|c|c|c|c|c|c|c|c|c|c|}
\hline \multirow{13}{*}{ 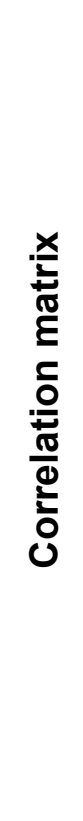 } & \multicolumn{11}{|c|}{ Working correlation structure } \\
\hline & \multicolumn{11}{|c|}{ Unstructured } \\
\hline & 1.00 & & & & & & & & & & \\
\hline & -0.06 & 1.00 & & & & & & & & & \\
\hline & -0.01 & -0.07 & 1.00 & & & & & & & & \\
\hline & -0.03 & -0.02 & -0.02 & 1.00 & & & & & & & \\
\hline & 0.03 & -0.02 & 0.00 & -0.04 & 1.00 & & & & & & \\
\hline & 0.04 & 0.02 & 0.11 & -0.01 & -0.03 & 1.00 & & & & & \\
\hline & 0.04 & 0.02 & -0.04 & -0.03 & -0.01 & -0.04 & 1.00 & & & & \\
\hline & 0.07 & -0.04 & 0.00 & 0.07 & -0.01 & -0.03 & -0.05 & 1.00 & & & \\
\hline & -0.03 & -0.11 & -0.01 & 0.00 & -0.06 & 0.00 & -0.06 & -0.09 & 1.00 & & \\
\hline & -0.11 & -0.09 & -0.10 & 0.02 & 0.05 & 0.08 & 0.00 & 0.00 & -0.11 & 1.00 & \\
\hline & 0.00 & 0.01 & 0.00 & 0.03 & 0.05 & 0.02 & 0.03 & 0.03 & 0.01 & -0.01 & 1.00 \\
\hline QIC & \multicolumn{11}{|c|}{5725.83} \\
\hline
\end{tabular}

\begin{tabular}{|c|c|c|c|c|c|c|c|c|c|c|c|}
\hline \multirow{13}{*}{ 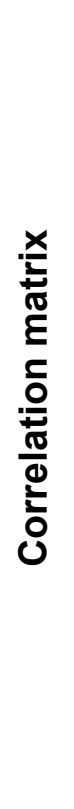 } & \multicolumn{11}{|c|}{ Working correlation structure } \\
\hline & \multicolumn{11}{|c|}{ Autoregressive } \\
\hline & 1.00 & & & & & & & & & & \\
\hline & -0.05 & 1.00 & & & & & & & & & \\
\hline & 0.00 & -0.05 & 1.00 & & & & & & & & \\
\hline & 0.00 & 0.00 & -0.05 & 1.00 & & & & & & & \\
\hline & 0.00 & 0.00 & 0.00 & -0.05 & 1.00 & & & & & & \\
\hline & 0.00 & 0.00 & 0.00 & 0.00 & -0.05 & 1.00 & & & & & \\
\hline & 0.00 & 0.00 & 0.00 & 0.00 & 0.00 & -0.05 & 1.00 & & & & \\
\hline & 0.00 & 0.00 & 0.00 & 0.00 & 0.00 & 0.00 & -0.05 & 1.00 & & & \\
\hline & 0.00 & 0.00 & 0.00 & 0.00 & 0.00 & 0.00 & 0.00 & -0.05 & 1.00 & & \\
\hline & 0.00 & 0.00 & 0.00 & 0.00 & 0.00 & 0.00 & 0.00 & 0.00 & -0.05 & 1.00 & \\
\hline & 0.00 & 0.00 & 0.00 & 0.00 & 0.00 & 0.00 & 0.00 & 0.00 & 0.00 & -0.05 & 1.00 \\
\hline QIC & & & & & & 5750.0 & & & & & \\
\hline
\end{tabular}





\section{APPENDIX E - REASONS FOR CONTRACEPTIVE DISCONTINUATION}

Table 19 - Reasons for discontinuation the contraceptive method by method type. São Paulo, Brazil - 2015

\begin{tabular}{lcccccc}
\hline Variables & $\begin{array}{c}\text { Oral pill } \\
\text { users }\end{array}$ & & $\begin{array}{c}\text { Male } \\
\text { condom } \\
\text { users }\end{array}$ & $\begin{array}{c}\text { Other } \\
\text { methods } \\
\text { users }\end{array}$
\end{tabular} $\mathbf{p}^{*}$

Reasons for Discontinuation for any reasons $(n=567)$

0.011

$\begin{array}{lcccccc}\text { Side effects } & 196 & 68.8 & 02 & 0.9 & 35 & 62.5 \\ \quad \text { Wanted a more effective } & 18 & 6.3 & 146 & 64.6 & 07 & 12.5 \\ \text { method } & 04 & 1.4 & 39 & 17.3 & 02 & 3.6 \\ \quad \text { Criticism of the partner } & 04 & 1.4 & 01 & 0.4 & 02 & 3.6 \\ \quad \begin{array}{l}\text { Too expensive or difficult to } \\ \text { obtain }\end{array} & 63 & 22.1 & 38 & 16.8 & 10 & 17.9 \\ \text { Another reason } & & & & & \end{array}$

Discontinuation for method-related reasons $(n=464)$

0.123

Side effects

Wanted a more effective

method

$\begin{array}{cccccc}151 & 65.9 & 02 & 1.1 & 28 & 60.9 \\ 17 & 7.4 & 117 & 61.9 & 07 & 15.2 \\ 03 & 1.3 & 34 & 18.0 & 01 & 2.2 \\ 02 & 0.9 & 01 & 0.5 & 01 & 2.2 \\ 56 & 24.5 & 35 & 18.5 & 09 & 19.6\end{array}$

Criticism of the partner

Too expensive or difficult to obtain

Another reason

Abandoned or switched to less effective method $(n=305)$ 0.829

\begin{tabular}{lcccccc} 
Side effects & 146 & 67.6 & 01 & 1.7 & 21 & 67.7 \\
$\quad$ Wanted a more effective & 14 & 6.5 & 03 & 5.2 & 02 & 6.5 \\
method & 03 & 1.4 & 43 & 74.1 & 01 & 3.2 \\
$\quad$ Criticism of the partner & 02 & 0.9 & 0 & 0 & 01 & 3.2 \\
$\quad \begin{array}{l}\text { Too expensive or difficult to } \\
\text { obtain }\end{array}$ & 51 & 23.6 & 11 & 19.0 & 06 & 19.4 \\
$\quad$ Another reason & & & & & & \\
\hline
\end{tabular}



ANNEX 



\section{ANNEX - APPROVAL OF THE RESEARCH ETHICS COMMITTEE}

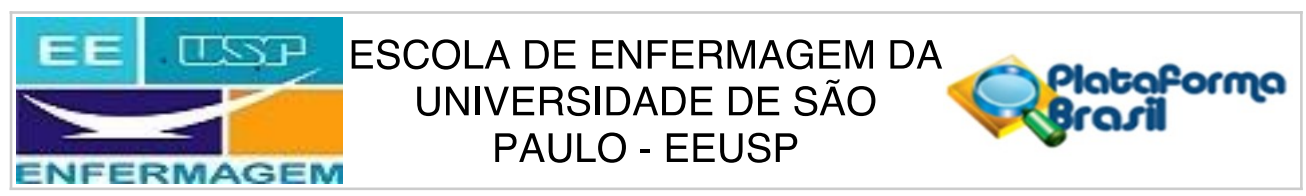

\section{PARECER CONSUBSTANCIADO DO CEP}

\section{DADOS DO PROJETO DE PESQUISA}

Título da Pesquisa: DESCONTINUIDADES CONTRACEPTIVAS E SUA RELAÇÃO COM O USO DA ANTICONCEPÇÃO DE EMERGÊNCIA ENTRE UNIVERSITÁRIAS

Pesquisador: Christiane Borges do Nascimento Chofakian

Área Temática:

Versão: 1

CAAE: 39142514.4 .0000 .5392

Instituição Proponente: Escola de Enfermagem da Universidade de São Paulo - EEUSP

Patrocinador Principal: Financiamento Próprio

\section{DADOS DO PARECER}

Número do Parecer: 912.504

Data da Relatoria: 08/12/2014

\section{Apresentação do Projeto:}

As práticas contraceptivas de jovens universitárias apresentam dinâmica própria, na qual o alto uso de métodos contraceptivos coexiste com as descontinuidades e as irregularidades de seu uso; situações que constituem uma das indicações de uso da anticoncepção de emergência. No Brasil, há escassez de estudos que abordem as descontinuidades contraceptivas e sua relação com o uso da anticoncepção de emergência. Com a finalidade de compreender melhor a dinâmica contraceptiva, para além da prevalência e dos tipos de métodos utilizados, a proposta deste estudo é estimar a probabilidade de ocorrência de descontinuidades contraceptivas e analisar as práticas contraceptivas antes e após o uso da anticoncepção de emergência entre jovens universitárias. Para isto, será conduzido um estudo quantitativo, do tipo longitudinal, com jovens universitárias de todos os campi da Universidade de São Paulo. Por se tratar de questões de cunho íntimo, será usado um questionário de autopreenchimento respondido online. $O$ questionário é composto por questões sociodemográficas; questões sobre o uso de métodos contraceptivos - para analisar as descontinuidades contraceptivas - nos 12 meses anteriores à pesquisa; e questões que versam sobre o uso de métodos contraceptivos um mês antes e um mês após o uso da anticoncepção de emergência, no caso de relato de uso anterior. A análise da probabilidade de ocorrência de descontinuidades contraceptivas por tipo de método e da prática contraceptiva antes

Endereço: Av. Dr Enéas de Carvalho Aguiar, 419 Bairro: Cerqueira Cesar

UF: SP Município: SAO PAULO

Telefone: (11)3061-7548 Fax: (11) $3061-7548$

CEP: $\quad 05.403-000$

E-mail: edipesq@usp.br 